\title{
Articulated Hub Model for 3D Aeromechanical Simulation of Helicopter Rotors
}

\author{
by \\ Michael G. Martin, B. Eng. \\ Carleton University \\ A thesis submitted to \\ the Faculty of Graduate Studies and Research \\ in partial fulfillment of \\ the requirements for the degree of
}

\section{Master of Applied Science}

Ottawa-Carleton Institute for

Mechanical and Aerospace Engineering

Department of

Mechanical and Aerospace Engineering

Carleton University

Ottawa, Ontario

September 2011

(C) Copyright

2011 - Michael G. Martin 
Library and Archives

Canada

\section{Published Heritage} Branch

395 Wellington Street Ottawa ON K1A ON4 Canada
Bibliothèque et

Archives Canada

Direction du

Patrimoine de l'édition

395 , rue Wellington

Ottawa ON K1A ON4

Canada
Your file Votre référence

ISBN: 978-0-494-83038-3

Our file Notre référence

ISBN: 978-0-494-83038-3

\section{NOTICE:}

The author has granted a nonexclusive license allowing Library and Archives Canada to reproduce, publish, archive, preserve, conserve, communicate to the public by telecommunication or on the Internet, loan, distribute and sell theses worldwide, for commercial or noncommercial purposes, in microform, paper, electronic and/or any other formats.

The author retains copyright ownership and moral rights in this thesis. Neither the thesis nor substantial extracts from it may be printed or otherwise reproduced without the author's permission.
AVIS:

L'auteur a accordé une licence non exclusive permettant à la Bibliothèque et Archives Canada de reproduire, publier, archiver, sauvegarder, conserver, transmettre au public par télécommunication ou par l'internet, prêter, distribuer et vendre des thèses partout dans le monde, à des fins commerciales ou autres, sur support microforme, papier, électronique et/ou autres formats.

L'auteur conserve la propriété du droit d'auteur et des droits moraux qui protège cette thèse. $\mathrm{Ni}$ la thèse ni des extraits substantiels de celle-ci ne doivent être imprimés ou autrement reproduits sans son autorisation.
In compliance with the Canadian Privacy Act some supporting forms may have been removed from this thesis.

While these forms may be included in the document page count, their removal does not represent any loss of content from the thesis.
Conformément à la loi canadienne sur la protection de la vie privée, quelques formulaires secondaires ont été enlevés de cette thèse.

Bien que ces formulaires aient inclus dans la pagination, il n'y aura aucun contenu manquant.

\section{Canadä}


The undersigned recommend to

the Faculty of Graduate Studies and Research

acceptance of the thesis

Articulated Hub Model for 3D Aeromechanical Simulation of Helicopter Rotors

submitted by

Michael G. Martin, B. Eng.

in partial fulfillment of the requirements for

the degree of

Master of Applied Science

F. Nitzsche, Thesis Supervisor

D. Feszty, Thesis Supervisor

M. I. Yaras, Chair, Department of Mechanical and Aerospace Engineering

Carleton University

September 2011 


\begin{abstract}
The SMARTROTOR code is a 3D aeroelastic computational tool for the simulation of helicopter rotor aeromechanics. This code has been created through collaborated work of interfacing aerodynamic, structural, and dynamic models. The aerodynamic model was adapted from the GENUVP discrete vortex method which was originally developed for studying wind turbine blades and its surrounding wake environment. Therefore, the current version of the SMARTROTOR code allows modeling of a hingeless blades based on the Hodges non-linear deformation equations. However, since helicopter blades are hinged, i.e. articulated at their root, the code only allowed modeling of hingeless rotors in the past. The objective of the work presented herein was to add hinges to the dynamic model of SMARTROTOR, while assuming rigid blades. The rigid blade hinged model is based on the equations of motion presented in J.G. Leishman's Principles of Helicopter Aerodynamics. The new model is validated by comparing simulations to F.D. Harris' experiment on a scaled articulated rotor at various advance ratios, shaft tilts and collective pitch settings. Comparison of blade angle, amplitudes and paths for the flapping and lead-lag motions indicate that the articulated rotor hub model captures key blade dynamics accurately.
\end{abstract}




\section{Acknowledgements}

I would like to thank my supervisors Professor Fred Nitzsche and Professor Daniel Feszty for granting me the opportunity to join Carleton Rotorcraft Research Group and allow me to make a contribution to the SMARTROTOR program. I would like to acknowledge the help of Gregory Oxley, Sean McTavish, and Derek Gransden for introducing me to the basic workings of the SMARTROTOR program. I would like to acknowledge the assistance of Neil McFayden and Bruce Johnston for allowing me access to the Department's Linux servers and their associated services in keeping me connected when I worked off site.

I would like to thank the Canada-EU Student Exchange Program in Aerospace Engineering and Prof. Eric Gillies at the University of Glasgow for their support in permitting me to study this program in Glasgow, Scotland.

I would like thank my parents David and Ann Martin for encouragement and help at times of challenge, to value this education and apply it to one's current and future vocational activities.

I would like to thank Voyageur Airways Ltd. in North Bay, Ontario, my current employer for allowing me to enter the ever interesting and exciting aerospace industry while completing my graduate studies. In particular I would like to thank my supervisors Georges Dubytz, Jeff MacFarlane, Jeff Cooke, and company President, Max Shapiro for their continued support and patience as I worked on this project. On this subject I would like to thank again Fred and Daniel, the Department of Mechanical and Aerospace Engineering, and the Graduate Studies Department for permitting me to begin my Engineering career while working on these studies part time and several hundred kilometers away from the University. 


\section{List of Symbols}

a Global frame, Chapter 2

$a_{1} \quad$ Lateral flapping angle, Chapter 4

$A_{1 c} \quad$ Lateral cyclic, Chapter 4

$b_{1} \quad$ Harris flap coefficient, Chapter 4

$\overline{\delta A} \quad$ Change in the spatial domain, Chapter 2

$b \quad$ Local undeformed frame, Chapter 2

$B \quad$ Local deformed frame, Chapter 2

$B_{1 c} \quad$ Longitudinal cyclic, Chapter 4

$C^{a b}, C^{B a}, C^{B b}$ Transformational matricies, Chapter 2

$C_{D} \quad$ Drag coefficient, Chapter 2

$C_{L} \quad$ Lift coefficient, Chapter 2

$C_{L_{\alpha}} \quad$ Lift slope coefficient, Chapter 4

$C_{M} \quad$ Pitching moment coefficient, Chapter 2

$C_{T} \quad$ Thrust coefficient, Chapter 4

D Drag, Chapter 1

DELTAX Node displacements used in TWIST123 subroutine, Chapter 3

DISP Spanwise aero node displacements used in MAP_DEFORM subroutine, Chapter 3

Disp_1D Spanwise structural node displacements used in TRAN subroutine, Chapter 3

Disp_2D

Disp_3D

$e$

Hinge offset faction of blade radius, Chapter 3

F Internal force vector, Chapter 2

F $\quad$ Force segment, Chapter 3 


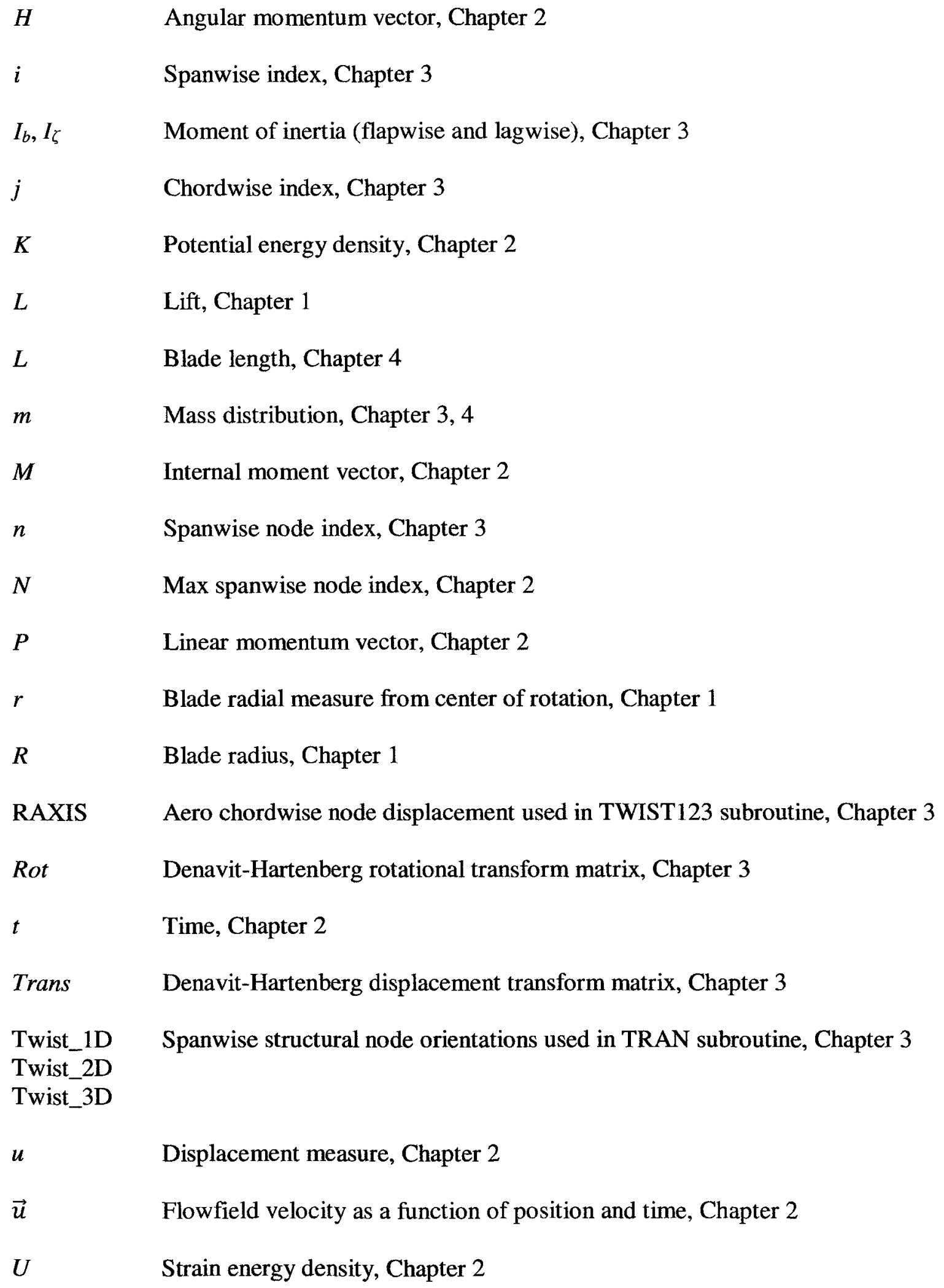




\begin{tabular}{|c|c|}
\hline$V$ & Velocity, Chapter 1 \\
\hline$V_{l}$ & Incident velocity, Chapter 1 \\
\hline$V_{R}$ & Resultant velocity, Chapter 1 \\
\hline$V_{T i p}$ & Tip velocity, Chapter 1 \\
\hline$V_{\infty}$ & Incoming velocity, Chapter 1 \\
\hline$\overline{\delta W}$ & Change in the virtual work, Chapter 2 \\
\hline$x$ & Chordwise displacement (local frame of reference), Chapter 3 \\
\hline$\vec{x}$ & Position vector, Chapter 2 \\
\hline $\mathrm{X}$ & Vector that described the structural state of the rotor blade, Chapter 2 \\
\hline XFINAL & Final aero node positions in TWIST123 subroutine, Chapter 3 \\
\hline XINIT & Undeformed aero node positions in TWIST123 subroutine, Chapter 3 \\
\hline XROTATE & Aero node positions in TWIST123 subroutine, Chapter 3 \\
\hline$y$ & Spanwise displacement (local frame of reference), Chapter 3 \\
\hline$Y_{a}, Y_{b}, Y_{a}$ & Beam node vectors, Chapter 2 \\
\hline$z$ & Vertical displacement (local frame of reference), Chapter 3 \\
\hline$\alpha$ & Angle of attack, Chapter 1 \\
\hline$\alpha_{T P P}$ & Tip path plane angle, Chapter 2 \\
\hline$\beta$ & Flap angle, Chapters 1 \\
\hline$\beta_{0}$ & Mean flap angle, Chapter 2 \\
\hline$\zeta$ & Lag angle, Chapter 1 \\
\hline$\theta$ & Angular orientation measure, Chapter 2 \\
\hline$\theta$ & Pitch angle, Chapter 3 \\
\hline$\theta_{0}$ & Root pitch angle, Chapter 4 \\
\hline
\end{tabular}




\begin{tabular}{|c|c|}
\hline$\theta_{75}$ & Pitch angle at the $75 \%$ radius station, Chapter 4 \\
\hline$\theta_{t w}$ & Blade twist per unit length of blade, Chapter 4 \\
\hline$\lambda$ & Inflow ratio, Chapter 4 \\
\hline$\mu$ & Advance ratio, Chapter 4 \\
\hline$\rho$ & Air density, Chapter 4 \\
\hline$v_{b}, v_{\zeta}$ & Frequency (flapping and lagging), Chapter 3 \\
\hline$\sigma$ & Solidity, Chapter 4 \\
\hline$\psi$ & Azimuth angle, Chapter 4 \\
\hline$\Omega$ & Rotor rotational velocity, Chapter 1 \\
\hline & Vector, Chapter 2 \\
\hline ) & Beam boundary value, Chapter 2 \\
\hline$\left({ }^{\circ}\right)$ & Velocity, Chapter 3 \\
\hline “) & Acceleration, Chapter 3 \\
\hline
\end{tabular}




\section{Contents}

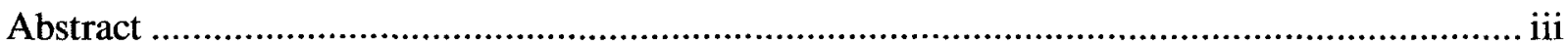

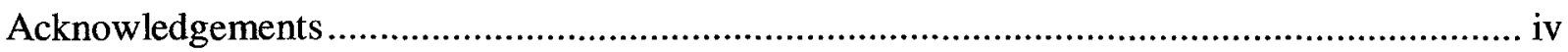

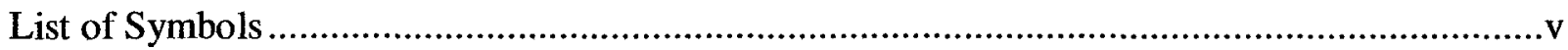

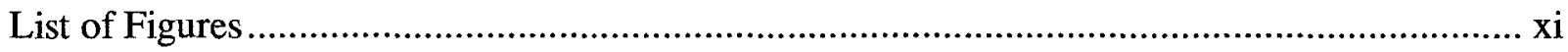

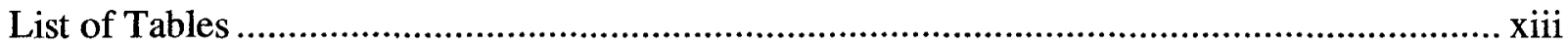

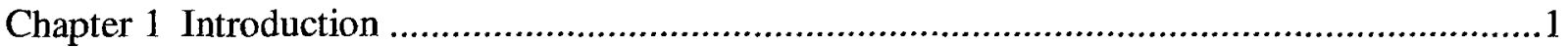

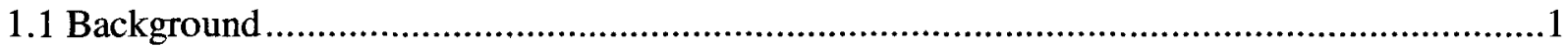

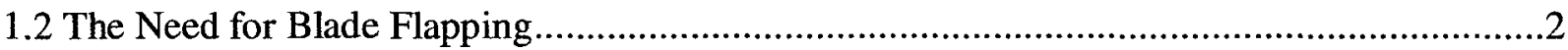

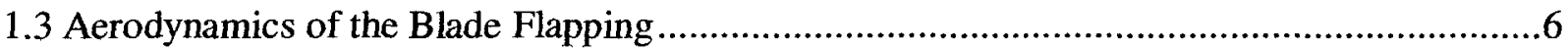

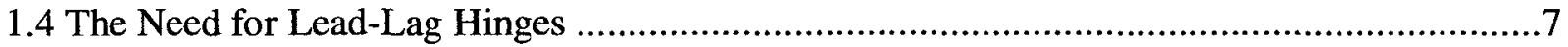

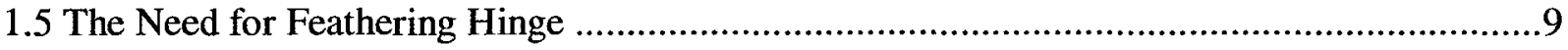

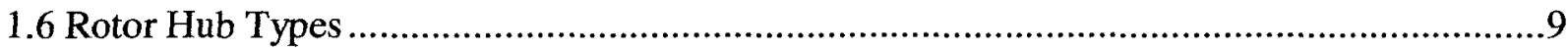

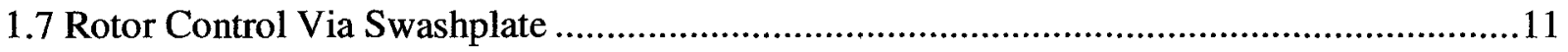

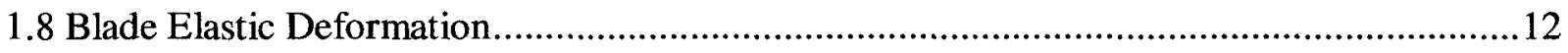

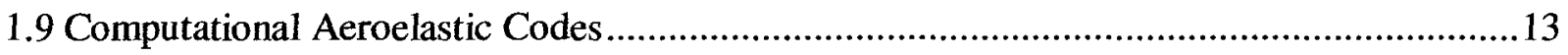

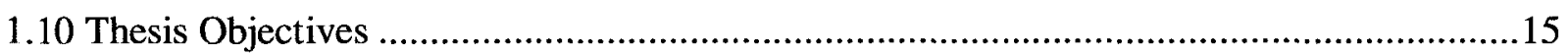

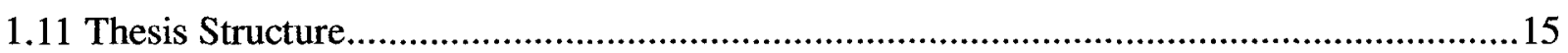

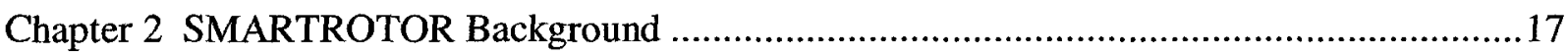

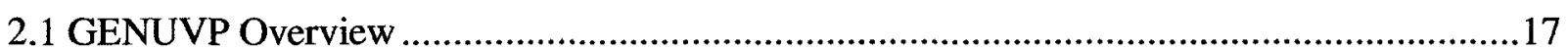

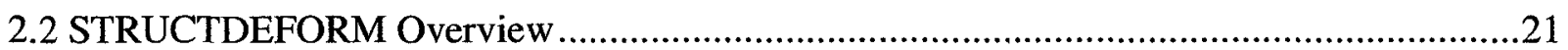

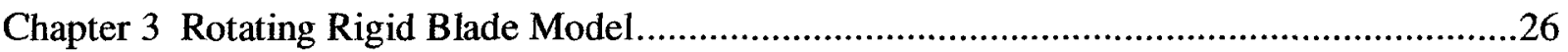

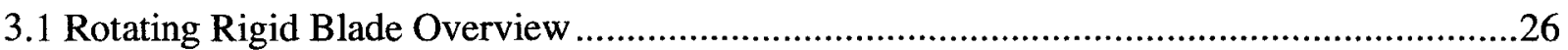

3.2 Coupling Rigid Motion with Aerodynamics ..................................................................

3.3 Interpolation from Aerodynamic Model to Rigid Blade Model .............................................34

3.4 Interpolation from Rigid Blade Model to Aerodynamic Model .............................................34

Chapter 4 CH-47C Rotor Blade Flapping Motion Analysis ......................................................43

4.1 Harris Articulated Blade Flapping Motion Overview ........................................................44

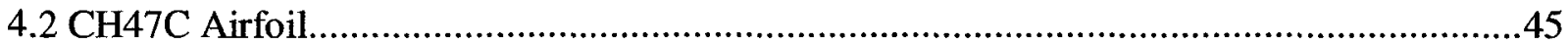

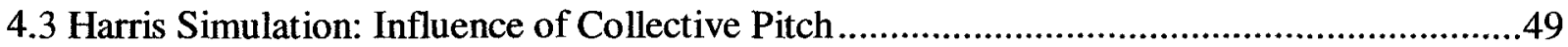

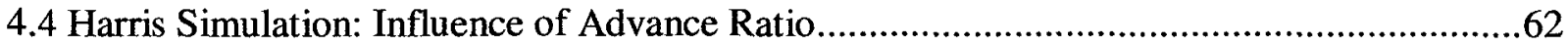

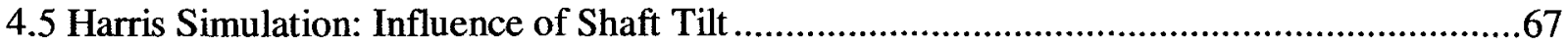

Chapter 5 Summary, Conclusions and Recommendations...................................................72

5.1 Summary 


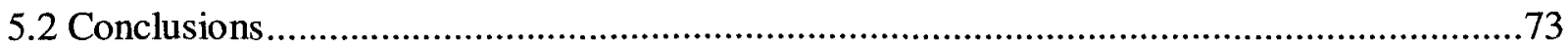

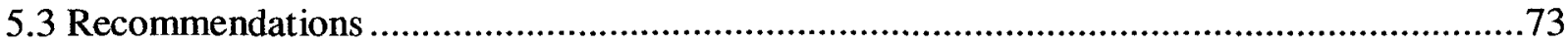

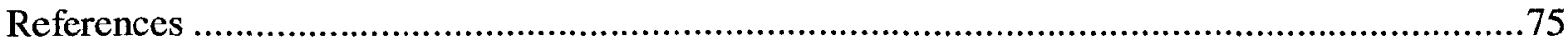

Appendix A SMARTROTOR User's Guide and Input Files .........................................78

A.1 SMARTROTOR Operators Guide ..................................................................... 78

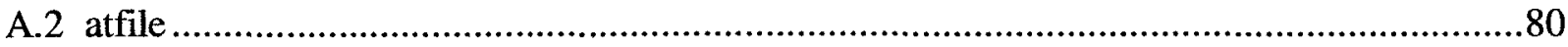

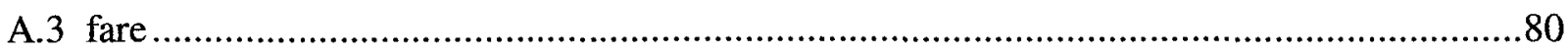

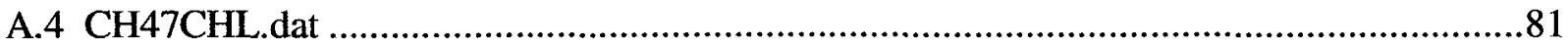

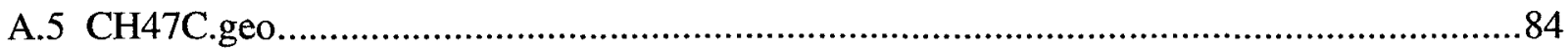

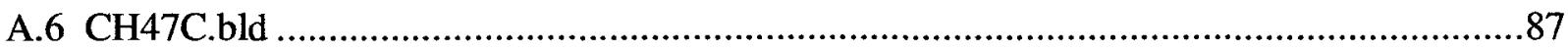

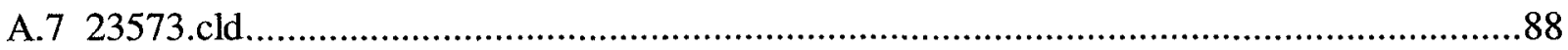

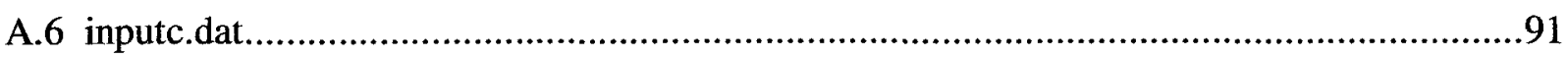

Appendix B SMARTROTOR Amended Source Code ..................................................94

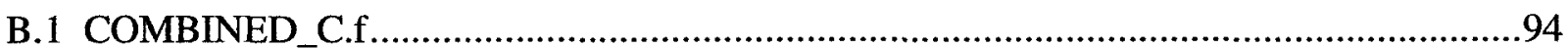

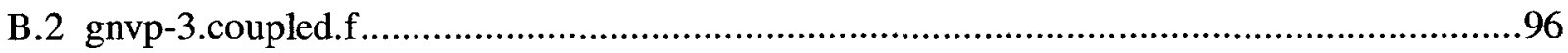

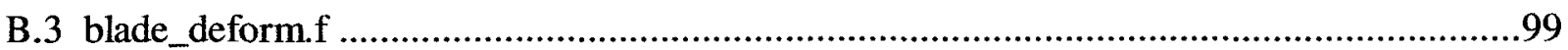

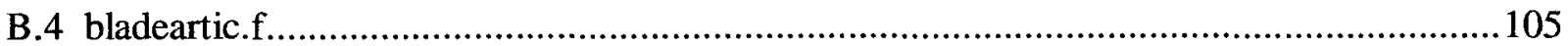

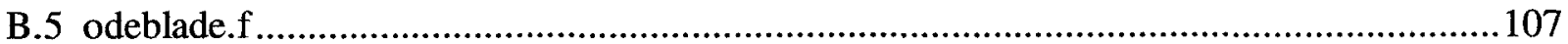

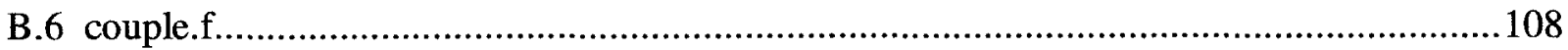

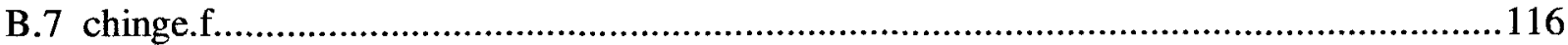




\section{List of Figures}

Figure 1.1 - Comparison of fixed-wing and rotary-wing lift and incident velocity distributions...3 Figure 1.2 - Comparison of incident velocity distribution on rotor blades between (a) hovering

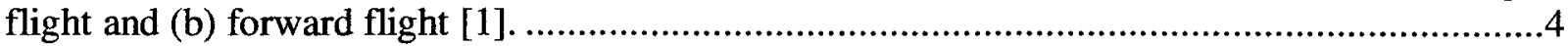

Figure 1.3 - Imbalance of rotor disk in forward flight.......................................................5

Figure 1.4 - Blade flapping on Juan de la Cierva's C.8 Autogiro [3]. ...............................6

Figure 1.5 - Reduction or increase in lift due to blade flapping. . ...................................

Figure 1.6 - Figure skating spinning speed as a function of arm displacement.........................8

Figure 1.7 - "Lead-lag" hinge allows for in-plane rotation. ........................................

Figure 1.8 - Rotor types [4] .......................................................................... 10

Figure 1.9 - Swashplate on a UH-1M Iroquois (Bell Model 204) [4].............................11

Figure 2.1 - 3D Visualization of the wake model. ........................................................19

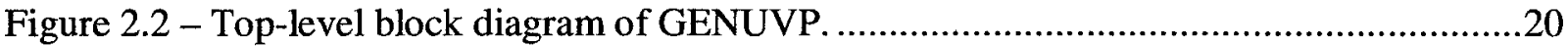

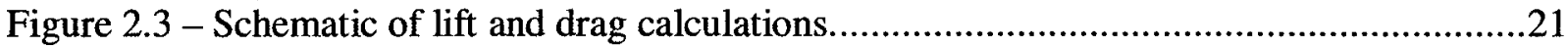

Figure 2.4 - Illustrated comparison of hingeless and hinged rotors [15] .............................22

Figure 2.5 - A schematic Diagram of the coordinate frames used by the structural component in

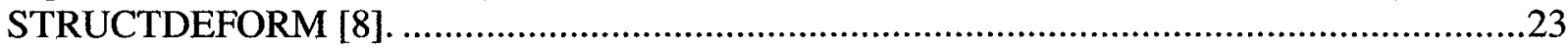

Figure 3.1 -Flapping lead-lag and feathering motion of a rotor blade [1] .........................27

Figure 3.2 -Equilibrium of blade forces about the flapping hinge [1] ...............................28

Figure 3.3 -Equilibrium of blade forces about the lead-lagging hinge [1] ............................28

Figure 3.4 - Blade discretized lift and drag profiles.................................................30

Figure 3.5 - Original SMARTROTOR main subroutine flow chart. .....................................32

Figure 3.6 - Modified SMARTROTOR main subroutine flow chart......................................33

Figure 3.7 - Rigid blade model coordinate system.................................................... 35

Figure 3.8 - Temporary aerodynamic node linear grid..................................................38

Figure 3.9 - Displacing aerodynamic nodes from undeformed position. ..............................41

Figure 3.10 - Aerodynamic blade model coordinate system. ............................................42

Figure 4.1 - Vertol division helicopter model [9]. .....................................................43

Figure 4.2 - V23010-1.58 airfoil lift curves as shown in [21] . ....................................46

Figure 4.3 - V23010-1.58 airfoil drag curves as shown in [21].........................................46

Figure 4.4 - V23010-1.58 airfoil pitching moment curves as shown in [21] ..........................47

Figure 4.5 - V23010-1.58 airfoil lift curves as set up in SMARTROTOR. ...........................48

Figure 4.6 - V23010-1.58 airfoil drag curves as set up in SMARTROTOR...........................48

Figure 4.7 - V23010-1.58 airfoil pitching moment curves as set up in SMARTROTOR...........49

Figure 4.8 - Flap Angle Vs. Azimuth Position - Collective Pitch $\theta_{75}=8.83^{\circ} \ldots \ldots \ldots \ldots \ldots \ldots \ldots \ldots . . .50$

Figure 4.9 - Helicopter azimuth reference positions. .................................................51

Figure 4.10 - 3D Visualization of rotor path (4 blades, pitch $13.05^{\circ}$, last $36^{\circ}$ sweep) ..............53

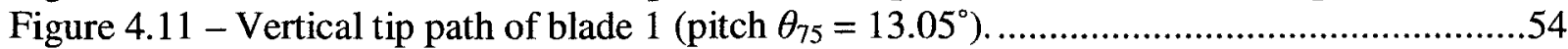

Figure 4.12 - Flap and lead-lag angles of blade 1 (pitch $\left.\theta_{75}=13.05^{\circ}\right)$. .............................54

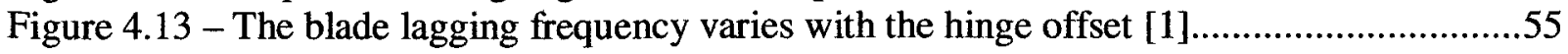

Figure 4.14 - Blade lift histories (pitch $\theta_{75}=13.05^{\circ}$ ) ...............................................56

Figure 4.15 - Flap angle comparison between twisted and untwisted blades...........................57 


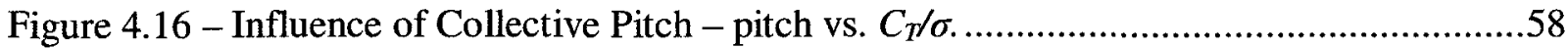

Figure 4.17 - Influence of Collective Pitch - pitch vs. flap amplitude. ..................................58

Figure 4.18 - Comparison of Harris \& SMARTROTOR flap angles. ....................................59

Figure 4.19 - Out-of-phase azimuth lag between simulation \& Harris test.............................60

Figure 4.20 - Influence of Collective Pitch - Harris experiment flap path. ...........................61

Figure 4.21 - Influence of Collective Pitch - SMARTROTOR flap path. ..............................62

Figure 4.22 - Influence of Advance Ratio - comparison of thrust coefficients.......................64

Figure 4.23 - Influence of Advance Ratio - comparison of flap amplitude...........................65

Figure 4.24 - Influence of Advance Ratio - Harris flap angles. ........................................66

Figure 4.25 - Influence of Advance Ratio - SMARTROTOR flap angles ............................67

Figure 4.26 - Influence of Shaft Tilt - comparison of thrust coefficients. .............................69

Figure 4.27 - Influence of Shaft Tilt - comparison of flap amplitude. ................................69

Figure 4.28 - Influence of Shaft Tilt - Harris flap angles. ..............................................70

Figure 4.29 - Influence of Shaft Tilt - SMARTROTOR flap angles................................. 70 


\section{List of Tables}

Table 4.1 - CH47C scaled rotor geometry.............................................................44

Table 4.2 - Harris collective pitch experiment results.................................................49

Table 4.3 - Harris simulation parameters. ...............................................................52

Table 4.4 - SMARTROTOR results for CH47C rotor blade model. .....................................57

Table 4.5 - Influence of Collective Pitch - SMARTROTOR results flap angle coefficients. ......61

Table 4.6 - Harris' Influence of Advance Ratio experiment results. .................................63

Table 4.7 - Harris' Influence of Advance Ratio flap angle coefficients...............................63

Table 4.8 - SMARTROTOR results for CH47C rotor blade model .....................................64

Table 4.9 - Influence of Advance Ratio - SMARTROTOR results flap angle coefficient ..........66

Table 4.10 - Harris' Influence of Shaft Tilt experiment results...........................................66

Table 4.11 - SMARTROTOR results for CH47C rotor blade model. ...................................68

Table 4.12 - Influence of Shaft Tilt - SMARTROTOR results flap angle coefficient ...............70 


\section{Chapter 1 Introduction}

\subsection{Background}

The helicopter is a transport vehicle, which has become indispensible in the modern world. While the airplane contributes greatly to international commerce, transport, and military applications, the helicopter has special niches. The ability of vertical take-off and slow flight maneuverability has found its place in such roles as transportation, geological surveying, forest fire fighting, search and rescue operations, and personal recreation, among others. The need for continuing technological advancement in this field presents opportunities to study and develop methods to improve helicopter research and designs.

One particular area of interest of the helicopter community is the study of rotor wing aeroelasticity. The challenge in modeling elastic rotating wings is that one must take into account the blade's rotational dynamics, elastic dynamics, and aerodynamics. There is an interest to model this complicated system of motion, so that various research activities related to studying helicopter vibration, rotor blade design, and helicopter noise can be accomplished.

The Rotorcraft Research Group at Carleton University, in collaboration with the National Technical University of Athens (Greece) and the Massachusetts Institute of Technology (U.S.A.), has developed a rotorcraft aeroelastic code called SMARTROTOR. This can simulate the motions and deformations of elastic helicopter and wind turbine blades. However, the present version of SMARTROTOR allows the modeling of hingeless rotors only. This is because the origins of SMARTROTOR began as a wind turbine rigid blade simulation tool, used to predict the aerodynamic performance of wind turbine blades, including the downstream wake 
environment. However, while wind turbine blades are rigidly attached at their root (i.e. cantilevered), helicopter blades must be articulated (i.e. hinged) at their root to allow two degrees of freedom during rotation to provide a balance of aerodynamic forces on the rotor. Unfortunately, the present version of SMARTROTOR does not allow to model articulated rotors, hence the main objective of this thesis is to address this issue.

The next sections will describe in detail the need for blade articulation for helicopters, the state-of-the-art in employing such models, and the need for this model in the SMARTROTOR code.

\subsection{The Need for Blade Flapping}

Why is the hinge configuration important to rotorcraft systems? In short, hinges allow the helicopter's rotor blades to resolve an imbalance created by the lifting forces generated on the blades in forward flight. A general explanation of the aerodynamics of rotor blade hinges is as follows.

Helicopters generate thrust (or commonly referred to as lift) by rotating the lifting surfaces, known as blades. Helicopter blades are essentially rotating wings, which create lift by generating pressure difference between the upper and lower surfaces. Unlike fixed wings on aircraft, rotory wings generate a linear lift distribution across the blade as illustrated in Figure 1.1 . 


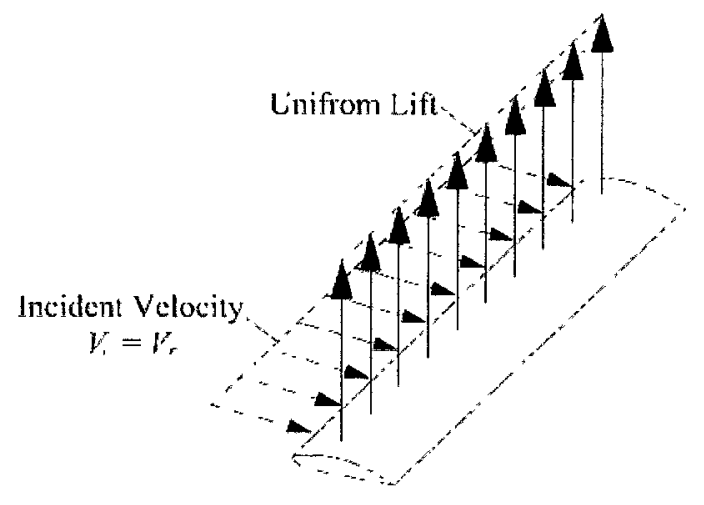

(Fixed-Wing)

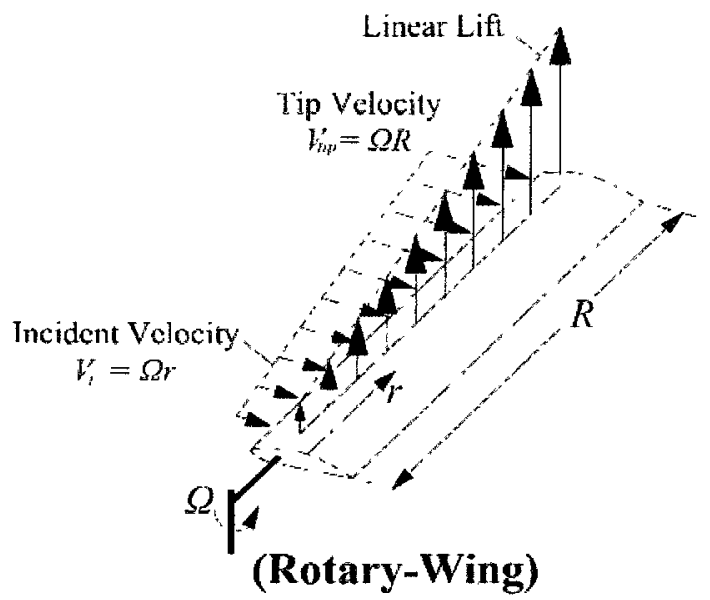

(Rotary-Wing)

Figure 1.1 - Comparison of fixed-wing and rotary-wing lift and incident velocity distributions.

It is noticed that for a simple fixed-wing there is a uniform incident velocity which produces a uniform lift distribution across the wing. On the rotary-wing lifting surface, the magnitude of lift varies across the span of the blade as a function of the incident velocity, which increases from the blade root to the tip. However, this affects the stability of the helicopter for different flight regimes. For example, for hovering flight configuration, there is an equal distribution of velocity and lift along the azimuth $(\Psi)$, as illustrated in Figure 1.2 (a). This produces symmetric lift distribution on the rotor disk which is the circular path of the rotor blades. 


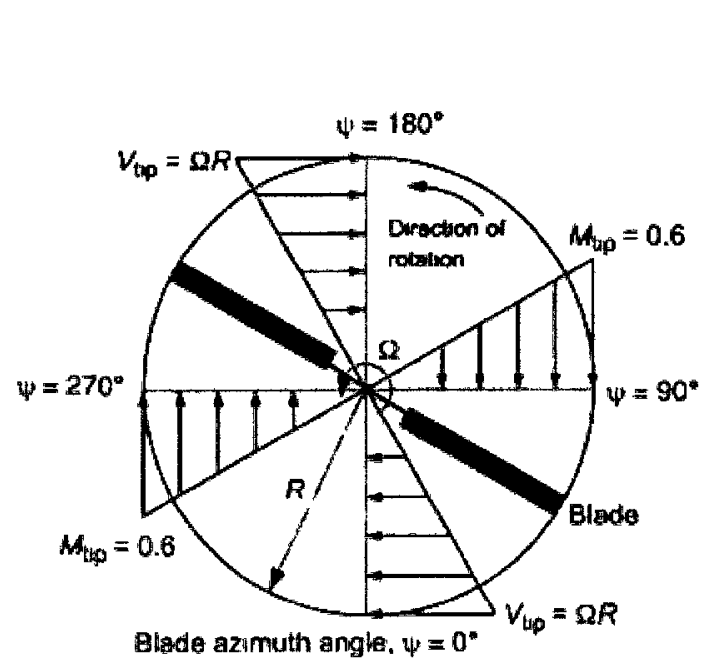

(a) Hovering flight

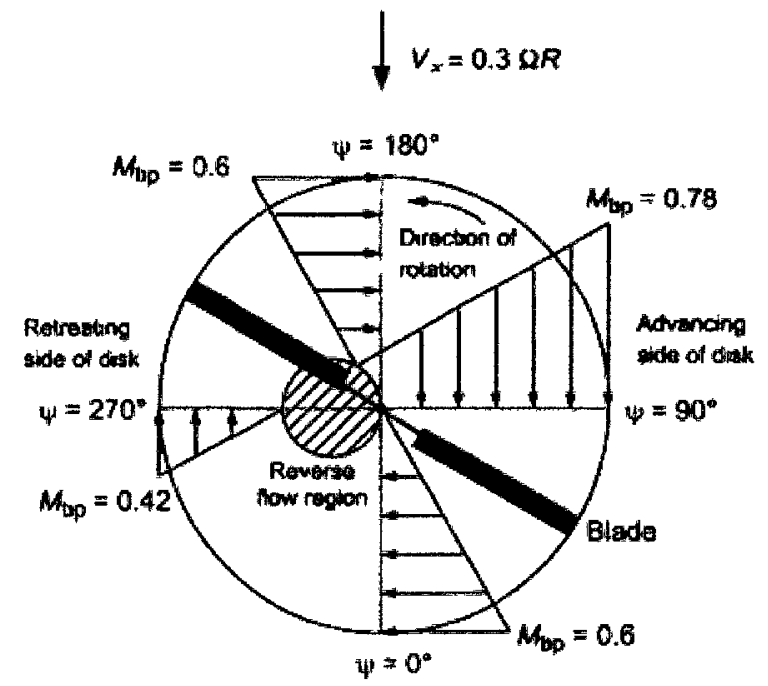

(b) Forwand flght, $\mu=0.3$

Figure 1.2 - Comparison of incident velocity distribution on rotor blades between (a) hovering flight and (b) forward flight [1].

However, in forward flight an asymmetric lift distribution is produced on the rotor disk, as illustrated in Figure 1.2 (b). In this configuration the incident velocity increases on the advancing side, but decreases on the retreating side of the disk. For example at the azimuth position of $\Psi=90^{\circ}$, the incident velocity at the blade tip is the sum of the tip speed $(\Omega R)$ and the oncoming velocity $\left(V_{\infty}\right)$, while at azimuth $\Psi=270^{\circ}$, the incident velocity at the blade tip will decrease to the difference of the tip speed $(\Omega R)$ and the oncoming velocity $\left(V_{\infty}\right)$, such that:

$$
\begin{aligned}
& V_{i}\left(\Psi=90^{\circ}\right)=\Omega R+V_{\infty} \\
& V_{i}\left(\Psi=270^{\circ}\right)=\Omega R-V_{\infty}
\end{aligned}
$$

If the blade pitch angle (an analogy to angle of attack) is constant at all radial positions, more lift is generated on the advancing (right) side of the disk than on the retreating (left) side, causing an imbalance of lift on the rotor disk. This would lead to undesired rolling moment to the left, as illustrated in Figure 1.3. 


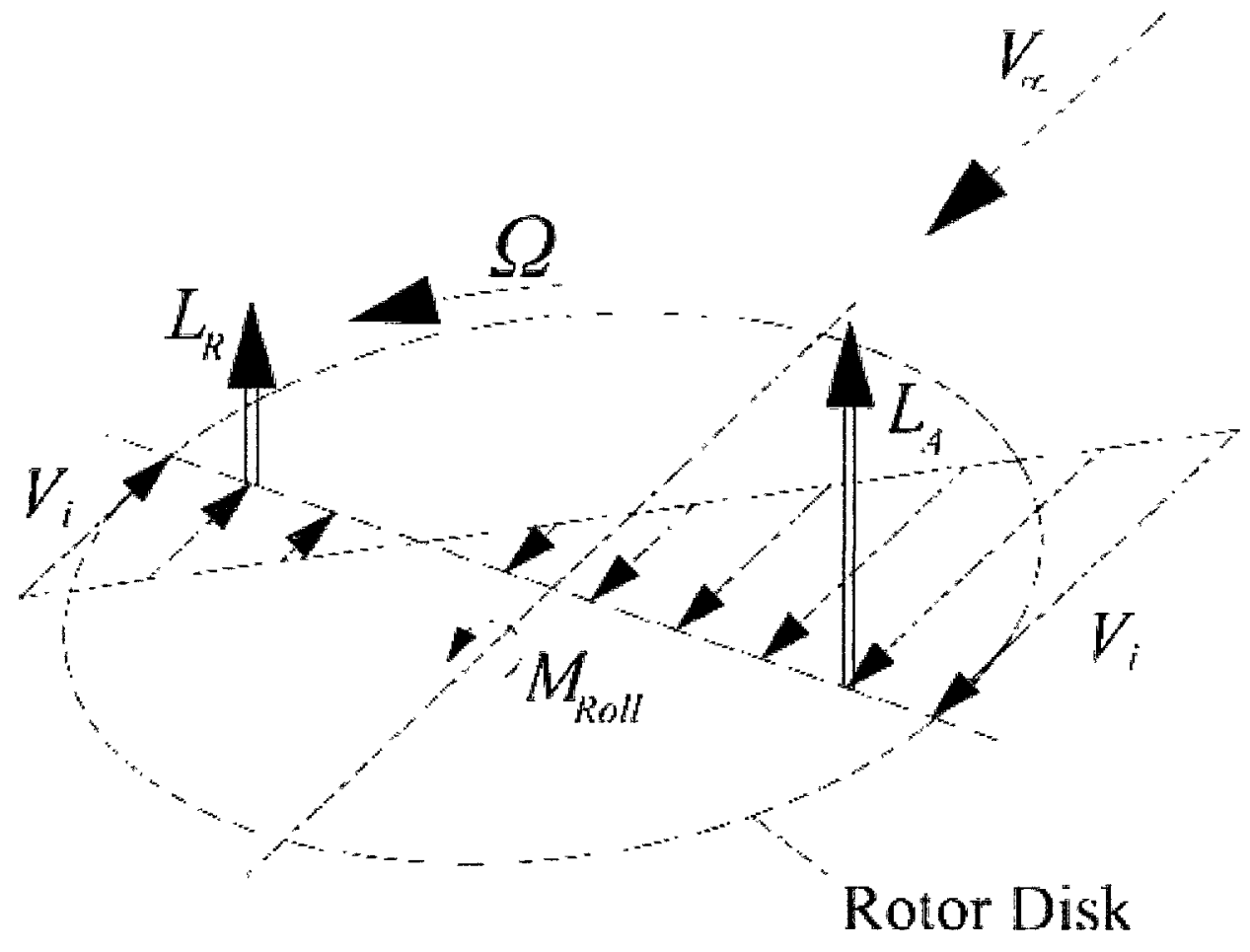

Figure 1.3 - Imbalance of rotor disk in forward flight.

The problem of this imbalance was recognized early in rotorcraft development. The first flapping hinge was patented by Bartha \& Madzer in 1913 [2]. The first successful incorporation of the flapping hinge was then installed by Spanish inventor Juan de la Cierva, during his work on autogiros in the 1920s, as illustrated in Figure 1.4. The problem with his early rigid blade autogiros was that as the autogiro flew forward, the lift generated on the advancing side was much greater than the lift generated on the retreating side causing the autogiro to roll over. However, noticing the effect of hinge movements on windmill blades, Cierva installed hinges to his rotors [3]. When the blades were allowed to flap, it was found that on the advancing side, the blade could flap upward and lose some of its lift, while on the retreating side the blade could flap downward and produce extra lift. Remarkably, this lift fluctuation over the azimuth leads to 
perfect balance of the aerodynamic forces, and hence this blade-flapping solution remains the key to all rotor systems today.

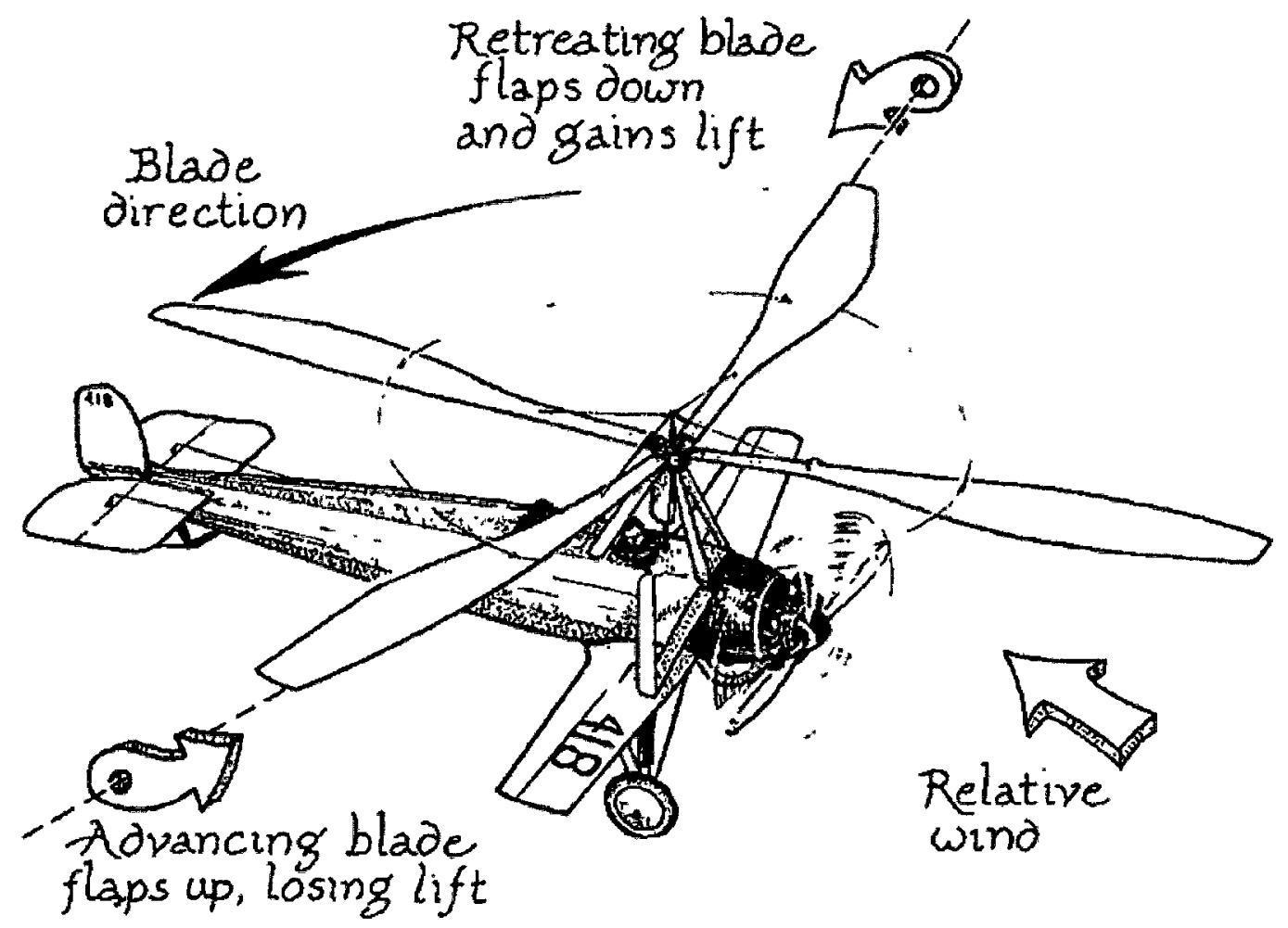

Figure 1.4 - Blade flapping on Juan de la Cierva's C.8 Autogiro [3].

\subsection{Aerodynamics of the Blade Flapping}

It is instructive to examine blade aerodynamics to explain how the imbalance described in Figure 1.3 is resolved when the blades are allowed to flap up and down. On a fixed airfoil, the cross-section of a blade produces lift by its pitch (angle of attack) relative to the direction of the air stream, as illustrated in Figure 1.5 (a). However, when a blade is allowed to flap upward, the effective angle of attack is reduced, as the addition of the upward velocity of the blade reduces the angle of the blade relative to the oncoming air stream, as illustrated in Figure 1.5 (b). Similarly, when the blade flaps down, the angle of attack increases, and correspondingly this increases the blade's lift, as illustrated in Figure 1.5 (c) [1]. 


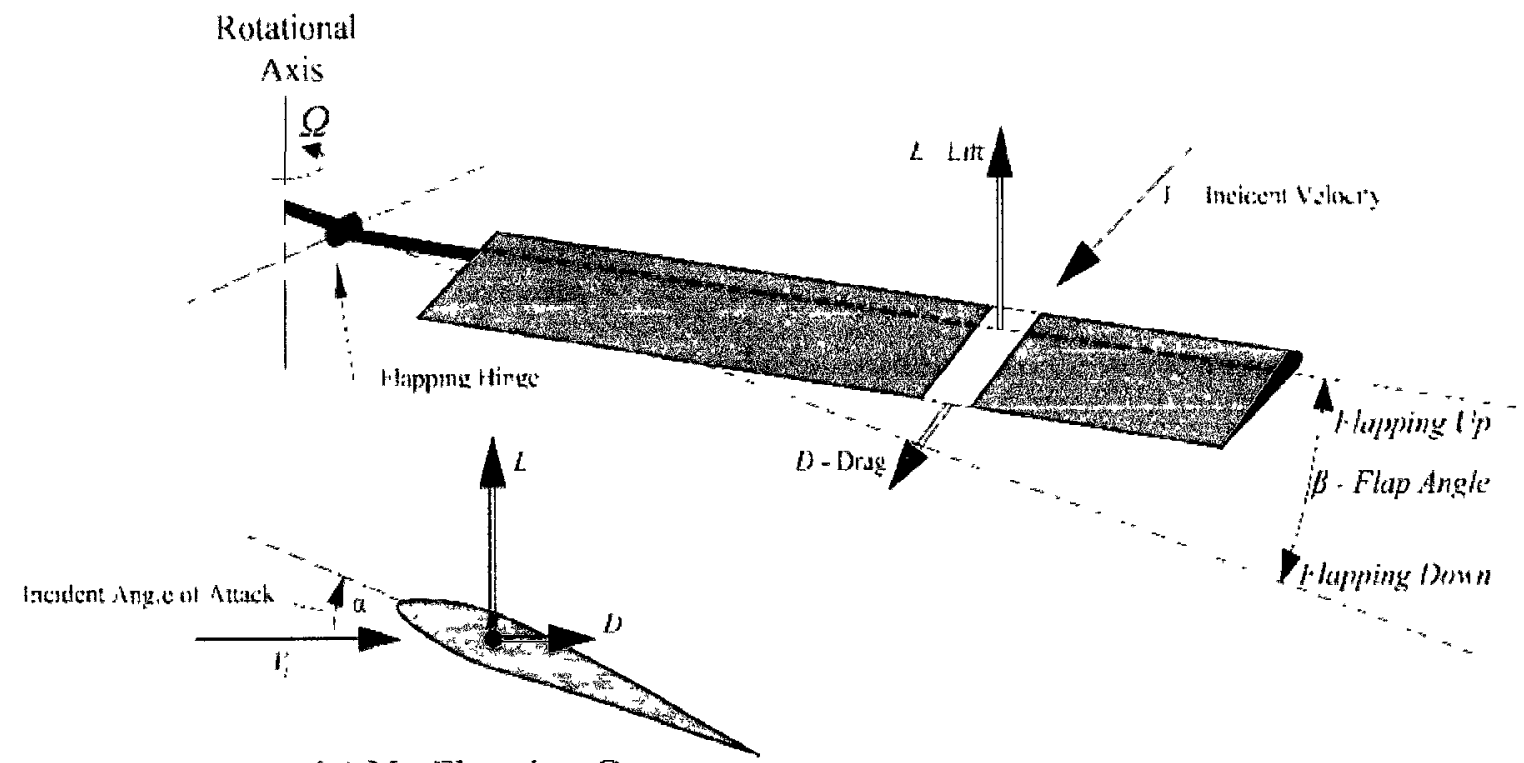

(a) No Flapping Casc

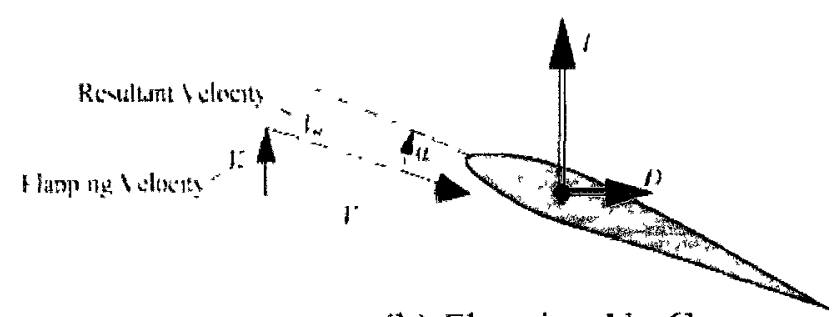

(b) Flapping Up Casc

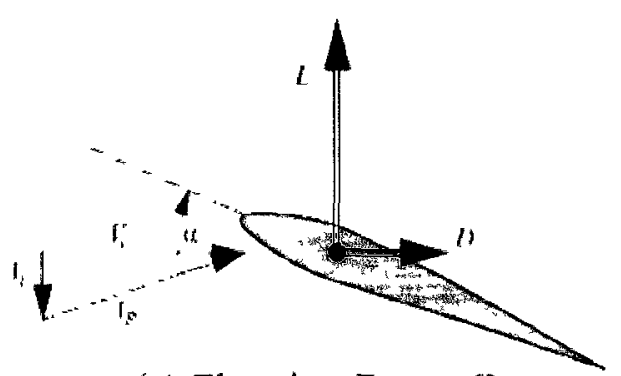

(c) Flapping Down Casc

Figure 1.5 - Reduction or increase in lift due to blade flapping.

Interestingly, this effect can fully compensate for the lift asymmetry in most flight regimes.

\subsection{The Need for Lead-Lag Hinges}

A side effect was noticed with the allowance of blade flapping. When the blade flaps up or down, it also moves the blade's centre of gravity closer to the center of rotation. This means that the blade will want to accelerate in the plane of rotation. This is analogous to a spinning figure skater, where the skater's speed of rotation increases when the arms are brought inward, whereas it slows down when the arms are brought outward, as illustrated in Figure 1.6. 


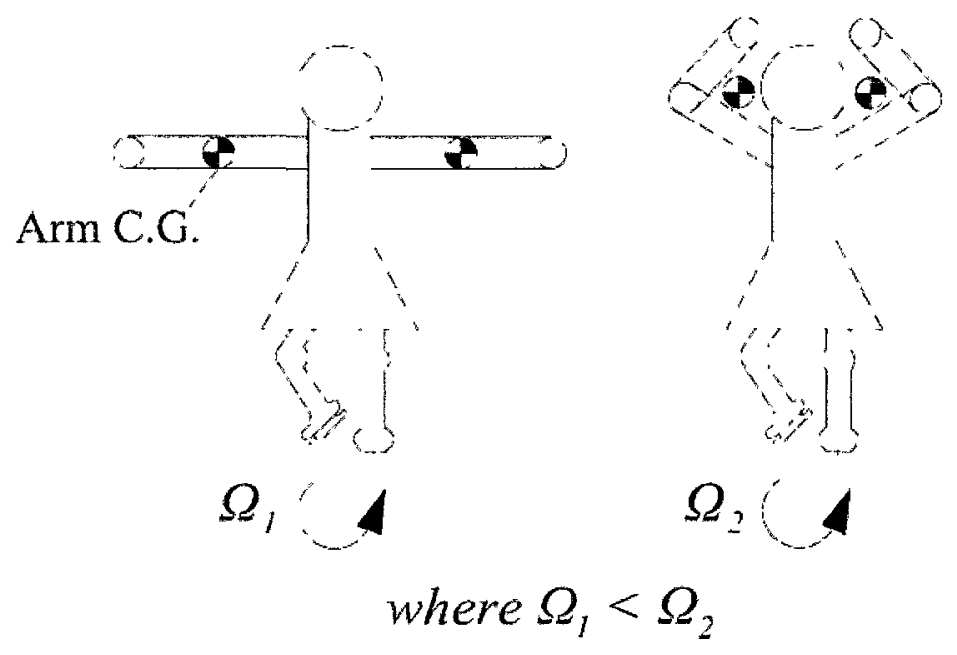

Figure 1.6 - Figure skating spinning speed as a function of arm displacement.

If this motion is restrained, then to equalize the inertial forces applying to the blade, the in-plane stresses can become excessive. As, a result a second hinge called the "lead-lag" hinge was introduced to compensate for the side effects of flapping motion. This allows for the blade to rotate in the plane of rotation, as illustrated in Figure 1.7. In other words, if one allows the blade to flap, then it must be allowed to lead and lag as well.

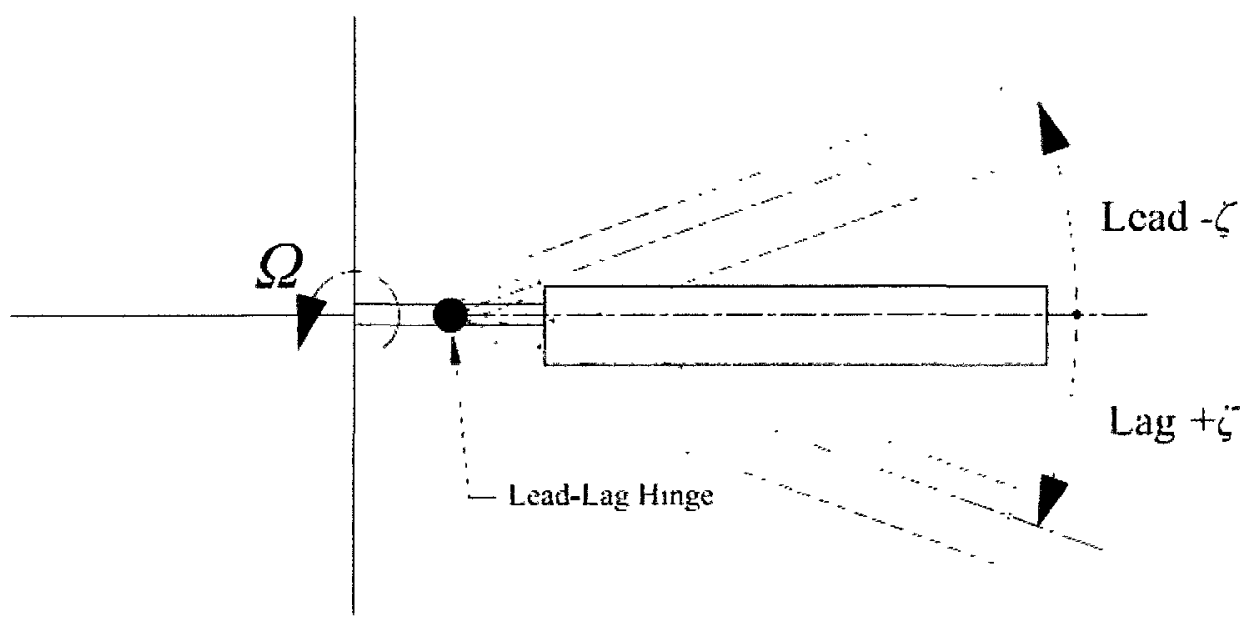

View: Looking Down on Rotation Plane

Figure 1.7 - "Lead-lag" hinge allows for in-plane rotation. 
Chapter 1 - Introduction

\subsection{The Need for Feathering Hinge}

There is a third hinge that allows the pilot to change the blade's pitch angle. It is called the feathering hinge (see Figure 1.8 (b)). This controls the amount of thrust generated by the rotor by controlling the pitch angle (i.e. angle of attack) of the blade. Unlike aircraft propellers which are mostly controlled by adjusting the speed (RPM) of the blade (and yes, some propellers do have pitch control which is similar to the helicopter's feathering hinge control), on helicopters the RPM is fixed. Helicopters are designed to run at a constant RPM so that vibration resonance with other parts of the hub and fuselage can be avoided. Therefore, to control the thrust, only the blade's pitch angle is changed, and not the RPM.

\subsection{Rotor Hub Types}

There are four fundamental types of helicopter rotor hubs in use: the teetering rotor hub, the articulated rotor hub, the hingeless rotor hub, and the bearingless rotor hub. The teetering rotor hub is the simplest, and consists of a single structure that is hinged at the rotational axis as illustrated in Figure 1.8 (a). There are no independent flap hinges, and as such when the blade flaps up, the other blade correspondingly flaps down like a seesaw. To allow for this motion each blade has its own lead-lag hinge. The second rotor type is the articulated rotor hub, as illustrated in Figure 1.8 (b). The articulated rotor hub consists of flapping and lead-lag hinges which are free to rotate, while the feathering hinge is controlled by the collective and cyclic pitch input by the pilot. This design is discussed in more detail in later chapters, and a module was created and added to the SMARTROTOR program to simulate flight regimes with this rotor hub model. The third rotor type is the hingeless rotor hub, as illustrated in Figure 1.8 (c), where the hinges of the articulated design are replaced with flexures. The flexures allow for the blade to rotate in the flap 
and lead-lag directions, while the feathering hinge is kept to allow pitching motion. The fourth rotor type is the advanced bearingless rotor hub, as illustrated in Figure 1.8 (d). This design is similar to the hingeless rotor hub, except the feathering bearings are replaced with a pitch case. The flap and lead-lag motion is allowed via a flexbeam.

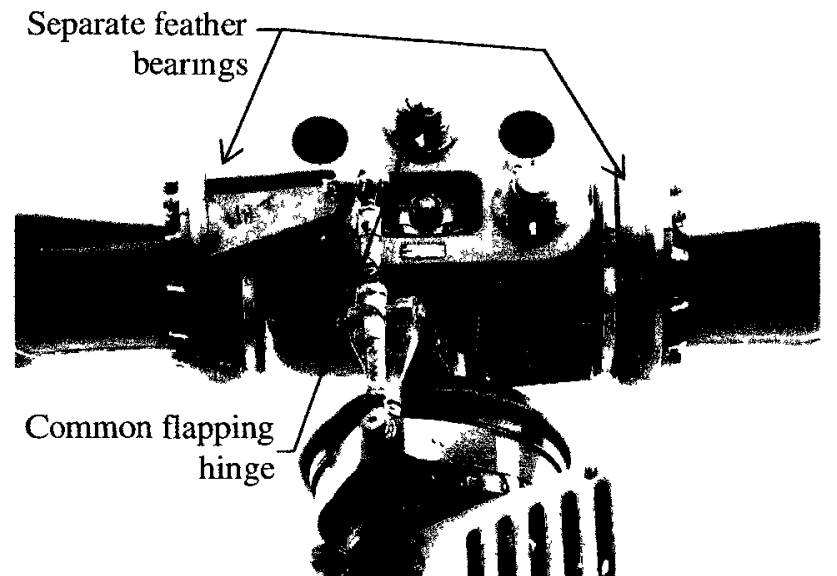

(a) Teetering hinge Example: Robinson R44

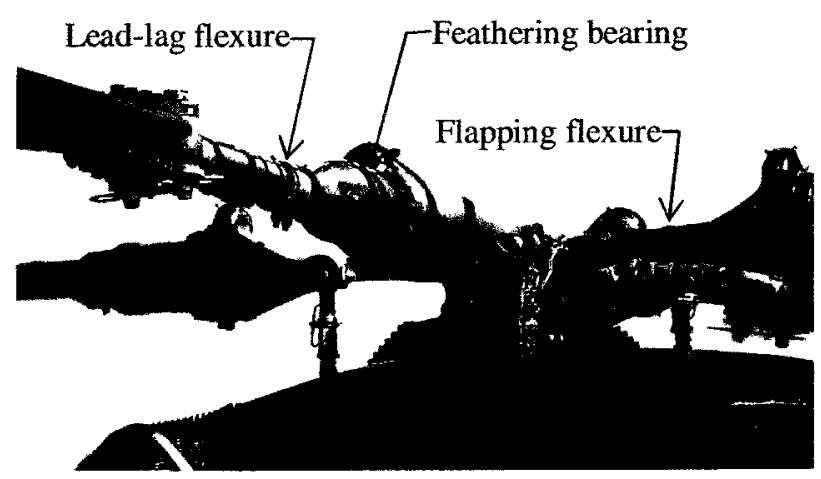

(c) Hingeless rotor Example: Westland Lynx

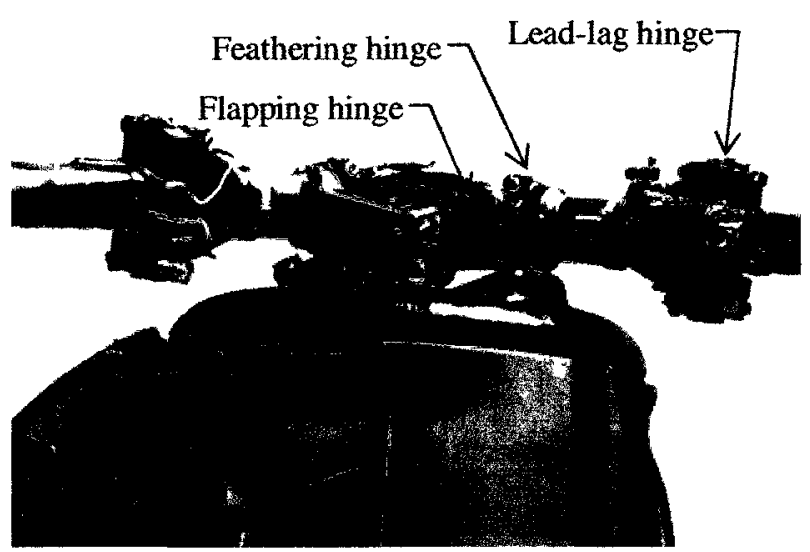

(b) Articulated rotor Example: Boeing CH-47D Chinook

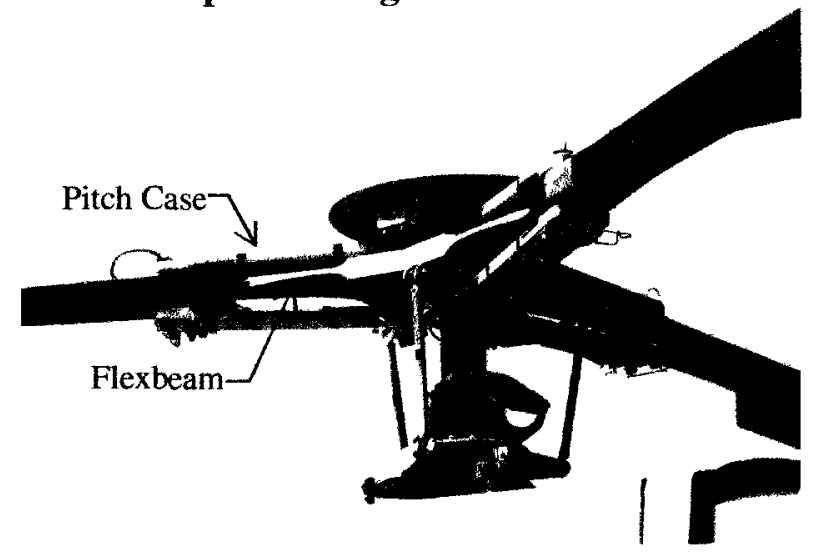

(d) Bearingless hub

Figure 1.8 - Rotor types [4].

It should be noted that in all four designs the blades are allowed 3 degrees of freedom via different methods, which include the flap, lead-lag, and pitch motions. 


\subsection{Rotor Control Via Swashplate}

In addition to the flap and lead-lag motion, pitch control is important to control the thrust and motion of the helicopter. Unlike a fixed wing aircraft where typically directional control is delivered via the flight control surfaces (ailerons, elevators and rudders), helicopters are controlled via cycle variations in the pitch of the rotor blades. Rotor pitch changes are delivered via the swashplate, as illustrated in Figure 1.9.

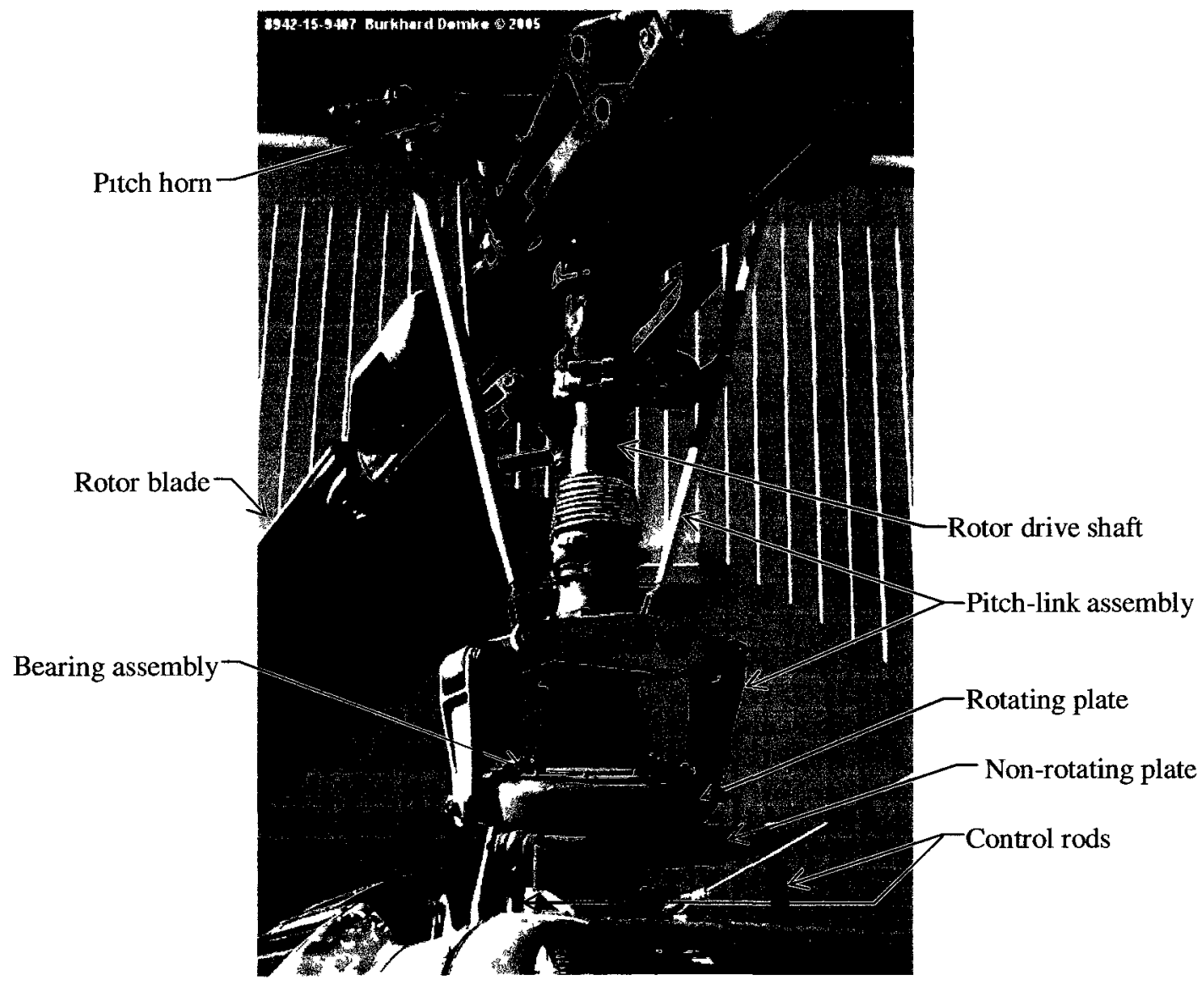

Figure 1.9 - Swashplate on a UH-1M Iroquois (Bell Model 204) [4].

The swashplate consists of a bearing assembly which transfers directional control from a nonrotating disk to the rotating disk. Directional input is transferred by the pilot's collective and cyclic control through control rods in the non-rotating frame. Through the bearing assembly, the direction is maintained through the rotating plate. The pitch link is attached to the rotating plate, 
and delivers the change in pitch input to the pitch horn, which defines the final pitch of the blade. For example as the pilot inputs an increase in collective pitch, the swashplate is pushed up, and consequently tilts the blades upward, increasing the blades' angle of attack and lift, enabling the helicopter to climb up. Likewise, if the swashplate responds to the cyclic control, cyclical changes to the pitch angle along the azimuth, enables the helicopter directional control in the forward, aft, and left/right rolling directions. For a hinged rotor as in Figure 1.8 (b), the swashplate influences the feathering hinge, which then controls the pitch of the blades.

With the many design options and configurations, it presents the opportunity for research in $3 \mathrm{D}$ aeroelastic codes, the challenge for rotorcraft code developers is to create models that provide a good representation of the dynamics that occur in the many helicopter systems.

\subsection{Blade Elastic Deformation}

It was shown that in forward flight, a helicopter blade experiences 3-degrees of freedom (flap, lead-lag, pitch). Since the blade is a slender body, the blade itself elastically deforms mostly in the flap and torsion directions. When designing the blade, one has to evaluate how the blade will perform in the various helicopter flight regimes (forward flight, hover, ascent, descent, etc.) and whether the blade will perform safely, efficiently and within the control of the pilot. This requires rotorcraft code developers to model not only the aerodynamic environment but also the blades' structural dynamics, their kinematics and their effects on the helicopter and surrounding environment. Accounting for these additional effects may include calculating the vibration loads occurring on the helicopter, the downstream rotor wake patterns, and aeroacoustics. It is clear that developing such a simulation is a complex task, requiring 
sophisticated models from aerodynamics, structural dynamics, and blade kinematics points of view.

At this point, there is no one single code which has the adequate sophistication in all these areas. However, it is the work presented in this thesis that presents the expansion to the SMARTROTOR rotorcraft model, by adding blade articulation and validating this model by comparing simulation results to a series of wind tunnel test results.

\subsection{Computational Aeroelastic Codes}

Computational modeling of rotorcraft is used for evaluating new developments. However, while rotorcraft testing, blade fabrication, etc., can be quite expensive, running computational feasibility studies can provide a cost effective and timely solution to illustrate the parameters and limits for new designs and testing. The challenge of these computational models is their validation to how well they replicate the aerodynamic, dynamic and structural parameters that effect the rotorcraft and its surrounding environment.

There are three comprehensive rotorcraft computational codes commercially available at present. They are the DYMORE, CAMRAD II, and CHARM codes. DYMORE is a comprehensive code that models multi-body structures through non-linear finite element methods (FEM) of both hingeless and hinged blades [5]. The aerodynamic component consists of two options. The first option is a built-in simple lifting-line and vortex method. The other option allows for the user to couple a sophisticated computational fluid dynamics (CFD) module to model the aerodynamics environment around the rotor at each time step. The second model, CAMRAD II is a comprehensive aeromechanical model that can model geometrically complex rotorcraft systems through a selection of several structural dynamic models [6]. The aerodynamic 
component consists of a $2^{\text {nd }}$-order lifting line theory and a sophisticated free wake geometry model. CAMRAD II can model single, dual and tilt-rotor configurations, with articulated, teetering, hingeless and bearingless hubs. The third model, CHARM is another comprehensive model available, which can model the full complex fuselage body geometry of a helicopter [7]. The structural model consists of a simple finite element method to model the blade deformations, for hinged and hingeless configurations. The aerodynamic model consists of a fast-panel and fast-vortex method, designed to reduce the time and computational resources normally required to model the complete helicopter configurations (including main rotor, tail rotor, and fuselage) and interacting wake. Unlike DYMORE and CAMRAD II, the CHARM code has an aeroacoustic model, allowing for the study of Blade Vortex Interaction (BVI) and rotor noise.

SMARTROTOR is the rotorcraft research modeling code used by the Rotorcraft Research Group at Carleton University. As detailed later in Chapter 2, it consists of an aerodynamic model, a structural model, and an aeroacoustic model. The structural model consists of hingeless blades that deform based on Hodges non-linear deformation equations [8]. The aerodynamic model uses a coupled panel method and vortex method.

SMARTROTOR has some sophisticated features superior to the ones of DYMORE, CAMRAD II or CHARM. These include the GENUVP aerodynamics module, the aeroacoustic module, and the ability to model smart structures and active noise reduction technologies [8]. A deficiency in SMARTROTOR is the absence of the articulated rotor hub model, i.e. the inability to include hinges at the blade root. At present, SMARTROTOR consists of a hingeless hub model based on Hodges' non-linear deformation equations, and a fixed rigid non-deforming blade model used for wind turbine study. The work presented in this thesis therefore aims to add 
a simple rigid hinge model, as a step towards modeling the complex dynamics and kinematics of an articulated hub with flexible blades.

\subsection{Thesis Objectives}

Based on the above review it is clear that in order to be able to design active rotor based control systems, one needs a credible 3D aeroelastic code to predict the rotor aeromechanics. The aeromechanics consists of the aerodynamics, dynamics, kinematics, and blade elasticity. The SMARTROTOR code, though has an advanced aerodynamics model and blade elasticity model, currently lacks the ability to model articulated hubs. Therefore, the objective of this thesis is to introduce hinges or blade articulation into the SMARTROTOR code.

In particular, the following objectives were identified to achieve the overall goal:

1. Add a rigid blade articulated hub model.

2. Verify this model by comparing simulation results to the data from the Harris experiment [9].

3. Complete the coupling of existing hingeless deformation code with an articulation model.

\subsection{Thesis Structure}

Chapter 2 provides a background and history of the SMARTROTOR program. A description of the aerodynamic module developed in the original wind turbine simulation program GENUVP will be presented. Following this, the existing hingeless rotorcraft features, created by Daniel Opoku and Tao Cheng are described [8] [10]. 
Chapter 1 - Introduction

Chapter 3 explains the construction of the rigid blade model, and the underlying theory according to the Leishman equations of motion for rotor blades. The additions and amendments to the SMARTROTOR code are explained.

Chapter 4 provides the results of the comparison of the rigid blade model to Franklin D Harris' experiment on blade flapping motion [9]. This section illustrates that the simulations of the rigid blade model correlate well with the wind tunnel results.

Chapter 5 contains a summary, concluding remarks, and recommendations of directions for future work. 


\section{Chapter 2 SMARTROTOR Background}

This chapter summarizes the existing functionality of the SMARTROTOR program. Due to the length and complexity of the preceding contributions, only the sections of the code that are relevant to the current modeling work are described in detail. The SMARTROTOR program consists of two distinct modules: the aerodynamic module and the structural module. From here forward the term GENUVP will generally refer to the aerodynamic module, i.e. that portion of the code that calculates the rotor blade aerodynamics and surrounding fluid environment. The term STRUCTDEFORM will refer to the later part of the code that estimates the structural deformation or displacement of the rotor blades.

\subsection{GENUVP Overview}

The aerodynamic component of SMARTROTOR was created from the GENeral Unsteady Vortex Particle (GENUVP) Fortran 77 code. It was developed by Prof. Spyros G. Voutsinas and his team at the National Technical University of Athens, Greece [11]. It consists of a panel method to calculate the blade aerodynamics loads and a discrete vortex method, which generates the aerodynamic wake environment. The wake model estimates the path and rotations of the vortex particles shedding off the blades, predicts their paths through the fluid environment, and interaction with the adjacent blades. The code is essentially grid-free, enabling easy modeling of mutually moving rigid bodies, such as that of a rotating rotor. Details of GENUVP are found in references [12] and [13], and is also summarized in Daniel Opoku's Thesis on Aeroelastic and Aeroacoustic Modelling of Rotorcraft [8]. A brief explanation of GENUVP is as follows: 
The GENUVP aerodynamic environment is based on the Helmholtz decomposition, which states that any velocity field, $\vec{u}$ can be represented by a irrotational part $\vec{u}_{\text {solid }}$ and a rotational part $\vec{u}_{\text {wake }}$ [13]. The aerodynamic flowfield is decomposed as a function of position and time where:

$$
\vec{u}(\vec{x}, t)=\vec{u}_{\text {ext }}(\vec{x}, t)+\vec{u}_{\text {solid }}(\vec{x}, t)+\vec{u}_{\text {near-wake }}(\vec{x}, t)+\vec{u}_{\text {far-wake }}(\vec{x}, t)
$$

For GENUVP in (2.1) the flowfield vector $\vec{u}$, is influenced by 4 factors: $\vec{u}_{\text {ext }}$ is the external or freestream velocity field; $\vec{u}_{\text {solid }}$ is the influence of solid bodies such as the rotor blades or fuselage; and $\vec{u}_{\text {near-wake }}$ and $\vec{u}_{f a r-w a k e}$ are the velocities influenced by the near and far wake in the flowfield domain [11]. As will be shown in Chapter 4, during the simulation of the Harris experiment, the flowfield starts as a freestream velocity field $\vec{u}_{\text {ext }}$. Then the boundary conditions from the rotor blade $\vec{u}_{\text {solid }}$ interact with the flowfield particles and generate the near wake vorticies that shed off the trailing edge of the blade $\vec{u}_{\text {near-wake. }}$ This then becomes the far-wake velocity flowfield $\vec{u}_{f a r-w a k e}$ which flows away from the rotor blade. In this new flowfield $\vec{u}$ the next oncoming blade interacts with the flowfield, and generates a new flowfield which affects the lift and drag of the rotor blade. A visualization of the wake generated from SMARTROTOR is illustrated in Figure 2.1, it was generated from one of the Harris simulations as presented in Chapter 4. 


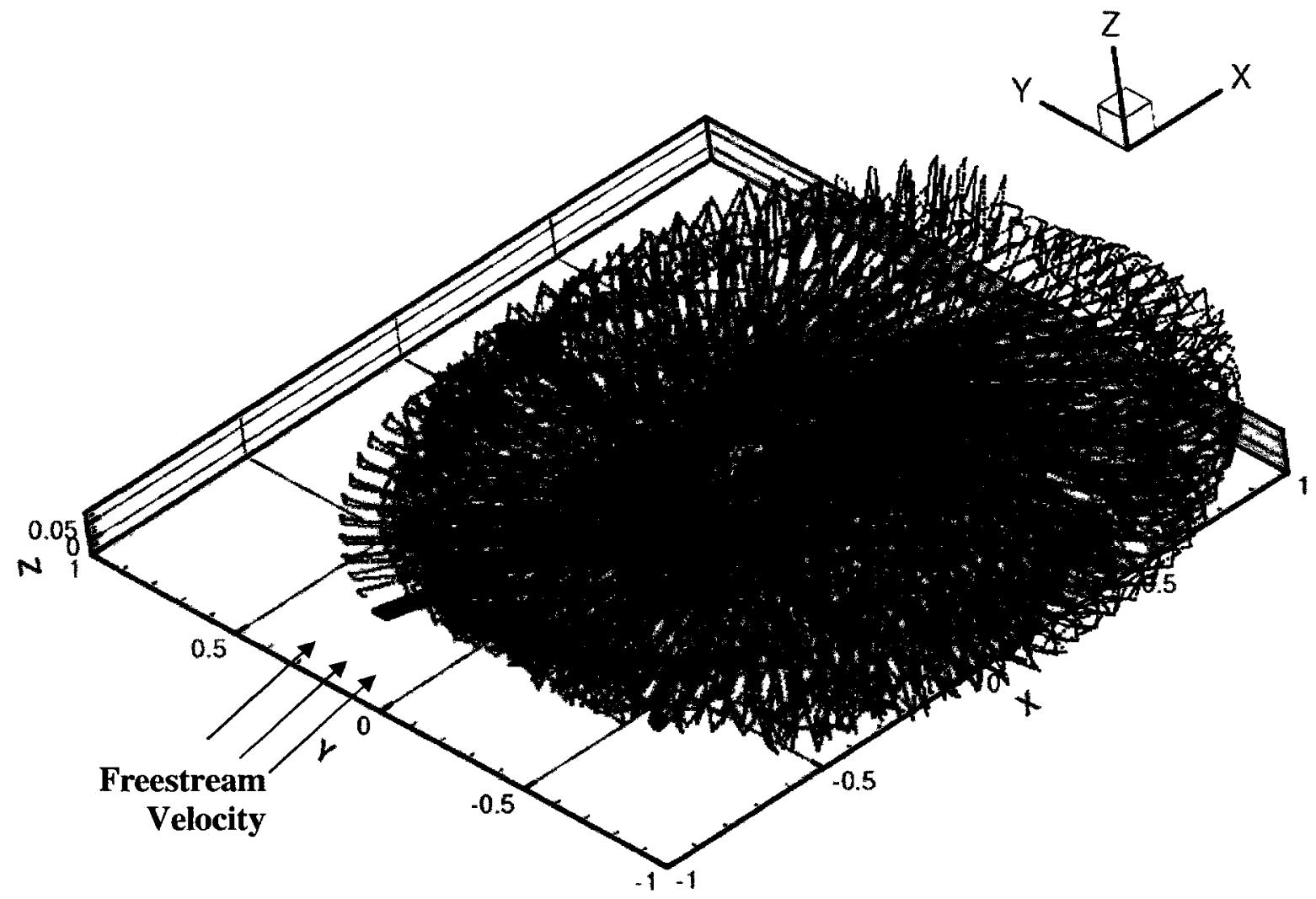

Figure 2.1 - 3D Visualization of the wake model.

There are three main of sets aerodynamic subroutines in GENUVP, which are represented in the block diagram in Figure 2.2 by the three blocks: initialization, potential calculations, and vortical calculations. The initialization block inputs the rotor geometric parameters, freestream speed and direction, environment parameters such as air density and Mach number, pitch input (collective and cyclic), and the blade discretization by panels. The potential block determines the point when the non-penetration boundary condition and the Kutta condition has been satisfied on the blade panel, and outputs data such as the lift, drag, and pitching moment distribution across the blade and the velocity fields generated from the rotating blade $\vec{u}_{\text {body }}$ and the trailing edge near-wake $\vec{u}_{\text {near-wake }}$. The vortical block calculates the wake 
shedding off the blades and generates the far-wake flowfield $\vec{u}_{f a r-w a k e}$ downstream of the rotating blade. The potential and vortical subroutines are repeated through subsequent time steps.

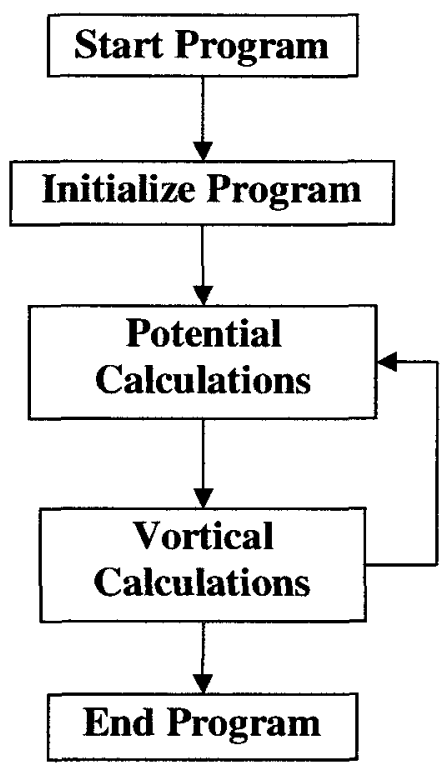

\section{Repeat loop for} each time step

\section{Figure 2.2 - Top-level block diagram of GENUVP.}

To reduce the computational cost of running GENUVP, the panel method, which is a lifting-line method, is used. Note that a grid-based CFD code would require the input and description of the shape of the airfoils, which is computationally expensive to calculate the lift, drag and pitching moments of the airfoil. Instead, the panel method used in GENUVP provides a representation of the airfoil in the aerodynamic environment, where the airfoil panel reads the pitch (angle of attack) and velocity of the oncoming flowfield and generates the lift, drag and pitching moment of the airfoil panel from interpolating the lift from a list of charts, as illustrated in Figure 2.3. In GENUVP the blade airfoil is defined in the .cld file (Appendix A.7), which lists the lift, drag, and pitching moment of the blade through a range of angles of attack and from Mach speeds of 0 to 1.0. GENUVP was found to be computationally efficient for modeling both wind turbines and rotorcraft by extensive tests by Voutsinas, based on [11]. 


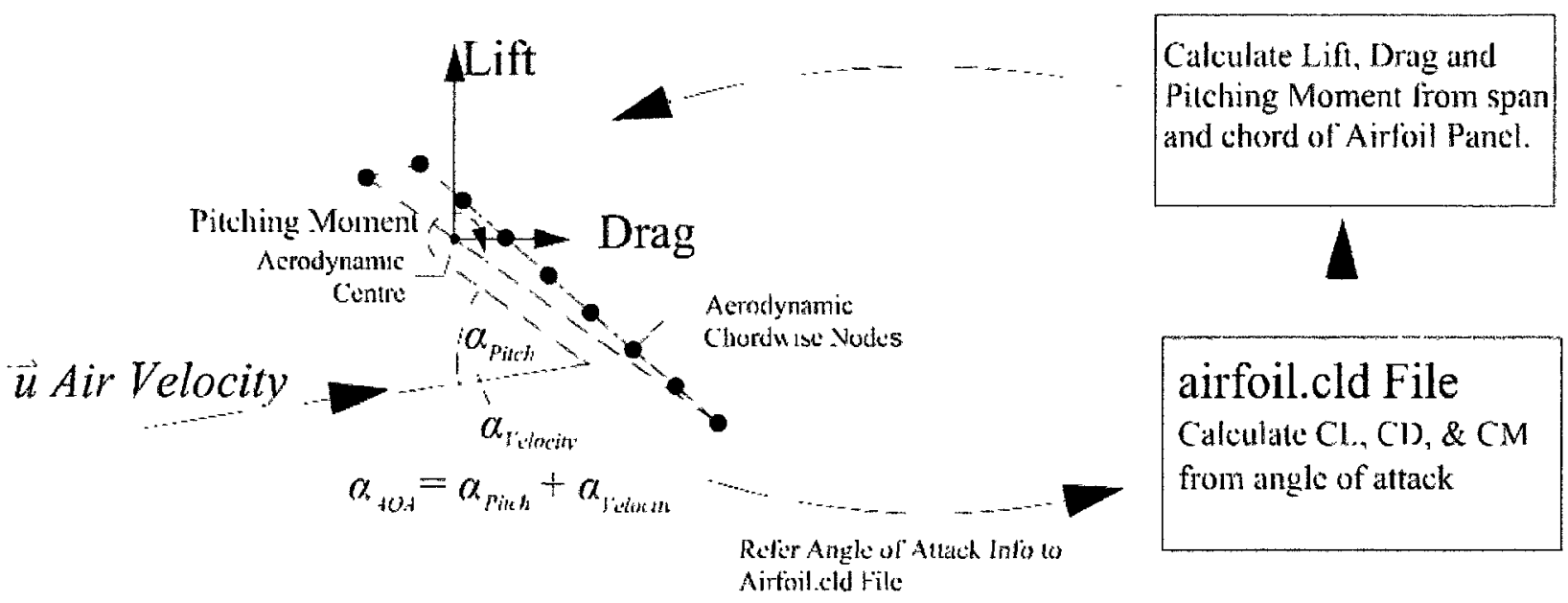

Figure 2.3 - Schematic of lift and drag calculations.

\subsection{STRUCTDEFORM Overview}

SMARTROTOR is a program that couples the aerodynamic code, GENUVP, with an elastic code for a rotating beam, hereafter referred to as STRUCTDEFORM. A former Master's student at Carleton University, Daniel Opoku, completed the coupling for a hingeless blade model based on Hodges' non-linear deformation equations using a mixed variational approach [14]. This work was done in collaboration with Tao Cheng from the Massachusetts Institute of Technology (M.I.T.) who simulated the time response of an active twist rotor. Their work is detailed in refs [8] and [10]. 
-HINGELESS ROTORS-

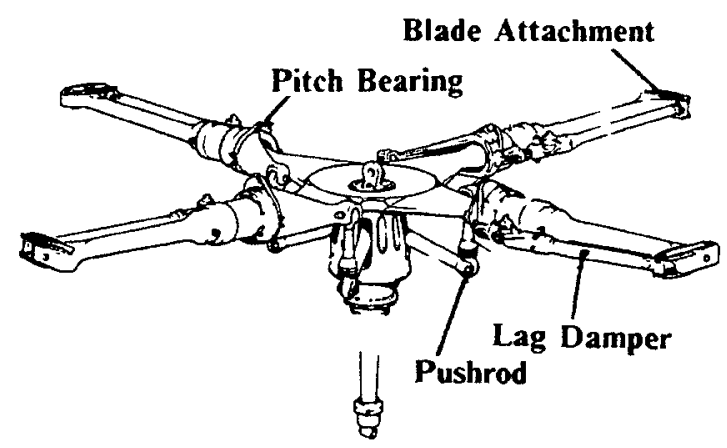

\section{HINGED ROTOR}

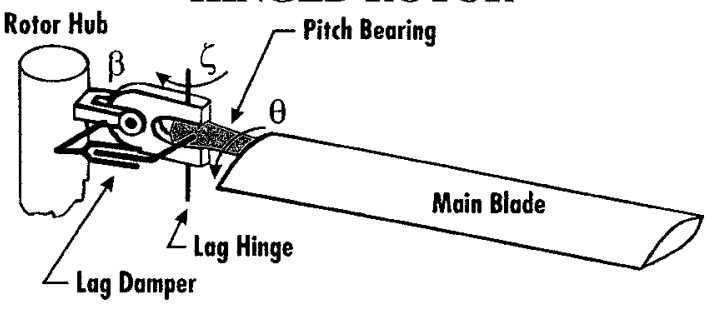

Figure 2.4 - Ilustrated comparison of hingeless and hinged rotors [15].

In a hingeless rotor, as illustrated in Figure 2.4, the flap and lag articulation joints are absent, and the rotor blade may experience large deflections due to the changes of pressures through its path. Hodges simplifies the blade flexing from a three dimensional blade to a nonlinear, one-dimensional representation along a reference line. Hodges' equations take into account the blade's local elastic and inertial properties.

The equations were discretized by Xiaoyang Shang [16], where he applied a finite element method to describe the motion of the blade in a global rotating frame. Opoku introduced these equations into STRUCTDEFORM. In Shang's formulation, three coordinate frames are used to describe the blade motion: the global frame $a$, the local undeformed beam frame $b$, and the local deformed beam frame $B$. The global frame $a$ is the frame of reference that expresses the beam's position relative to blade hub and follows the beam around the azimuth. The undeformed beam frame $b$ describes the geometry and geometric twist of the blade in the local rotating frame. The local beam frame $B$, describes the elastic deformation with respect to the undeformed local frame $b$. 


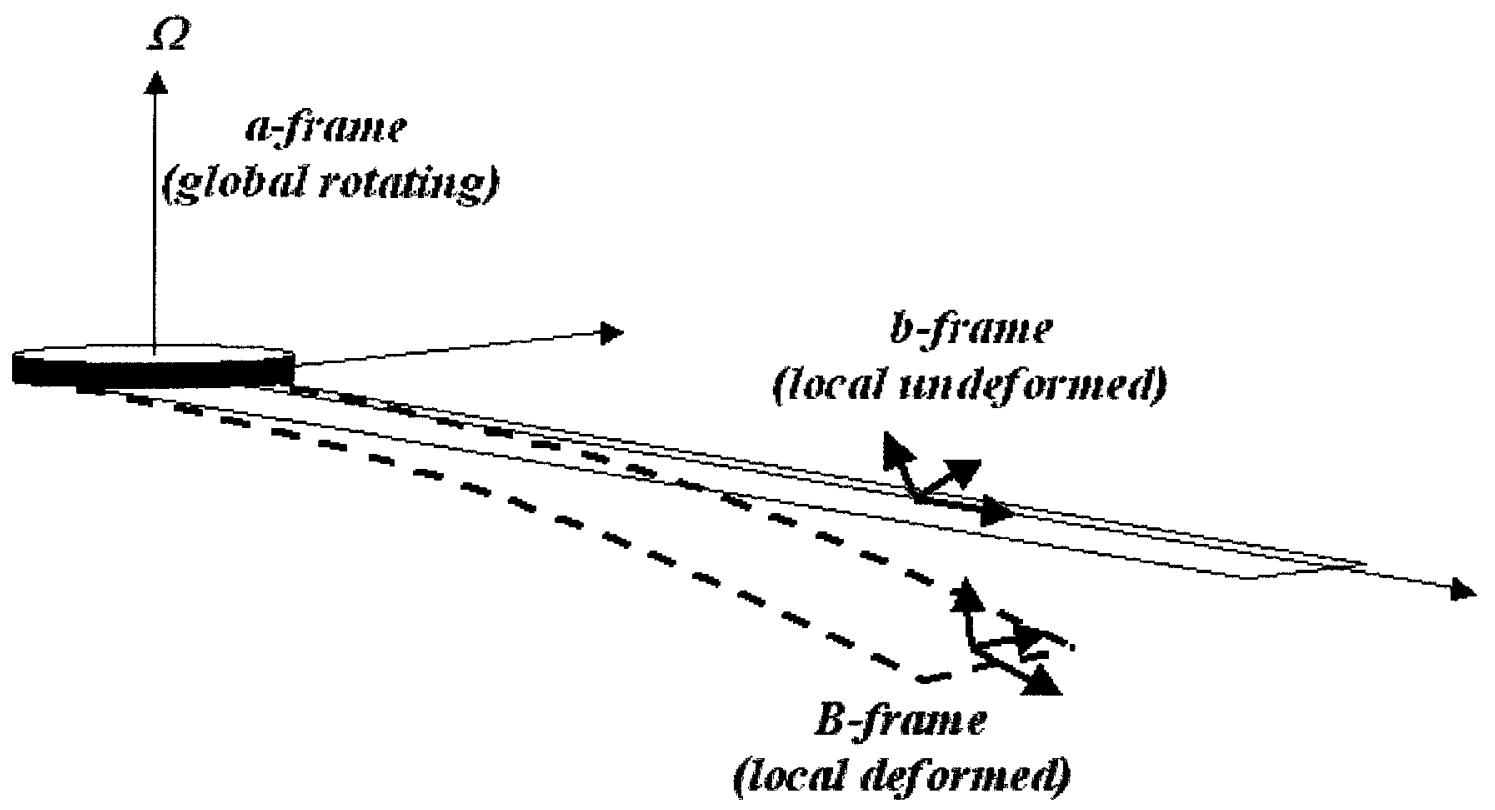

Figure 2.5 - A schematic Diagram of the coordinate frames used by the structural component in STRUCTDEFORM [8].

The conversion between these frames and the equations that describes the deformation of the blade is described in Opoku's and Cheng's theses [8] [10]. The notation used for the transformation matricies between each frame are:

$$
Y_{a}=C^{a b} Y_{b}, Y_{B}=C^{B a} Y_{a}, Y_{B}=C^{B b} Y_{b}
$$

where $Y_{a}, Y_{b}, Y_{B}$, describe the beam node vectors in each frame: while $C^{a b}, C^{B a}$, and $C^{B b}$ are the transformation matricies. It is important to recognize that the structural component is in a different frame of reference than the aerodynamic component. This will be clarified later in Chapter 3.

Hodges derived the intrinsic variational equation that describes the work and energy applied to the beam, using Hamilton's principle [14]:

$$
\int_{t_{1}}^{t_{2}} \int_{0}^{l}[\delta(K-U)+\overline{\delta W}] d x_{1} d t=0
$$

This equation states that between times steps $t_{1}$ and $t_{2}$, the change in the potential energy density $K$ and the strain energy density $U$ will balance the change in the virtual work $\overline{\delta W}$ generated from 
the applied loads. For a detailed description of mixed formulation refer again to Opoku's and Cheng's theses [8] [10].

The next section of interest is the discretized equations, which solves for the beams equations of motion:

$$
\int_{t_{1}}^{t_{2}} \delta X^{T}\left[F_{S}(X, \dot{X})\right] d t=0
$$

Here, $F_{S}$ is the matrix operator containing the beam's complete non-linear equations of motion. $X$ is the vector that contains the unknown measures of displacement, rotation, internal loads, momenta, and energies, of each spanwise node from 1 to node $N$, and includes the unknown boundary values. $\delta X^{T}$ is the change of the $X$ vector from time $t_{1}$ to time $t_{2}$, and the superscript $T$ denotes the matrix transpose. Dot denotes the time differential. The $X$ vector describes the structural state of the rotor blade, in terms of the local nodal variables. It takes the form:

$$
X=\left[\hat{F}_{1}^{T} \widehat{M}_{1}^{T} u_{1}^{T} \theta_{1}^{T} F_{1}^{T} M_{1}^{T} P_{1}^{T} H_{1}^{T} \ldots u_{N}^{T} \theta_{N}^{T} F_{N}^{T} M_{N}^{T} P_{N}^{T} H_{N}^{T} \hat{u}_{N+1}^{T} \hat{\theta}_{N+1}^{T}\right]^{T}
$$

where the nodal measures are as follows: $F$ is the internal force vector, $M$ is the internal moment vector, $u$ is the displacement measure (the nodal deformation from the undeformed frame), $\theta$ is the angular orientation measure, $P$ is the linear momentum vector, and $H$ is the angular momentum vector. The boundary conditions are also described in the $X$ vector; in this case presented for the hingeless blade condition. At the root, $\hat{F}_{1}^{T}$ and $\widehat{M}_{1}^{T}$ are the unknown internal force and moment vectors, respectively. At the blade tip, at node location $N+1, \hat{u}_{N+1}^{T}$ and $\hat{\theta}_{N+1}^{T}$ are the unknown displacement and angular orientation measures. Also note that for the hingeless rotor at the root, the root nodal displacement and angles measures are $\hat{u}_{1}=0$ and $\hat{\theta}_{1}=0$, and at the blade tip the internal forces and moments $\widehat{F}_{N+1}=0$ and $\widehat{M}_{N+1}=0$ equal zero.

The structural deformation code solves the preceding non-linear equations of motion. The solver was developed by Tao Cheng [10], and was based on the discretization of Shang's 
formulation [16]. The integration of the equations is accomplished by a second-order Euler method, and then the $\mathrm{X}$ vector of unknowns is solved iteratively by using the Newton-Raphson method.

Opoku validated his hingeless model against the HELINOISE test results. The HELINOISE (synonym for helicopter external noise) test program was a series of detailed hingeless rotor blade tests conducted at the German-Dutch Wind Tunnel (DNW) in 1990 [17]. Details of the hingeless model can be found is Opoku's thesis [8]. This thesis will not discuss much more concerning the hingless model. Instead, references to the hingeless model will be concerned with its decoupling structural subroutines from the GENUVP aerodynamics model, and its replacement with the subroutines to run the hinged rigid model. 


\section{Chapter 3 Rotating Rigid Blade Model}

As discussed in Chapter 2, the current version of SMARTROTOR originally began as a rigid aerodynamic wind turbine code called GENUVP. Then, a hingeless aeroelastic model, STRCUTDEFORM was added to create SMARTROTOR. This chapter presents the addition of new subroutines to SMARTROTOR by this author to calculate the flap and lead-lag motions of hinged rigid rotor blades, and coupling them with the aerodynamic code. The previous hingeless aeroelastic structural code, STRUCTDEFORM is turned off when the hinged rigid model is run. The verification of this model is presented in Chapter 4 , where a series of simulations are compared to the experimental results presented in Franklin D. Harris' experiment [9].

\subsection{Rotating Rigid Blade Overview}

The equations behind the rotating rigid blade model are presented in Leishman's Principles of Helicopter Aerodynamics [1]. A simple hinged rotor design allows the blade to rotate in the flap and lead-lagging directions as illustrated in Figure 3.1. As the blade rotates, it is allowed to flap up and down about the flapping hinge, and it is allowed to lead forward and lag aft about the leading hinge. This relieves the imbalance verified in early hingeless designs. 


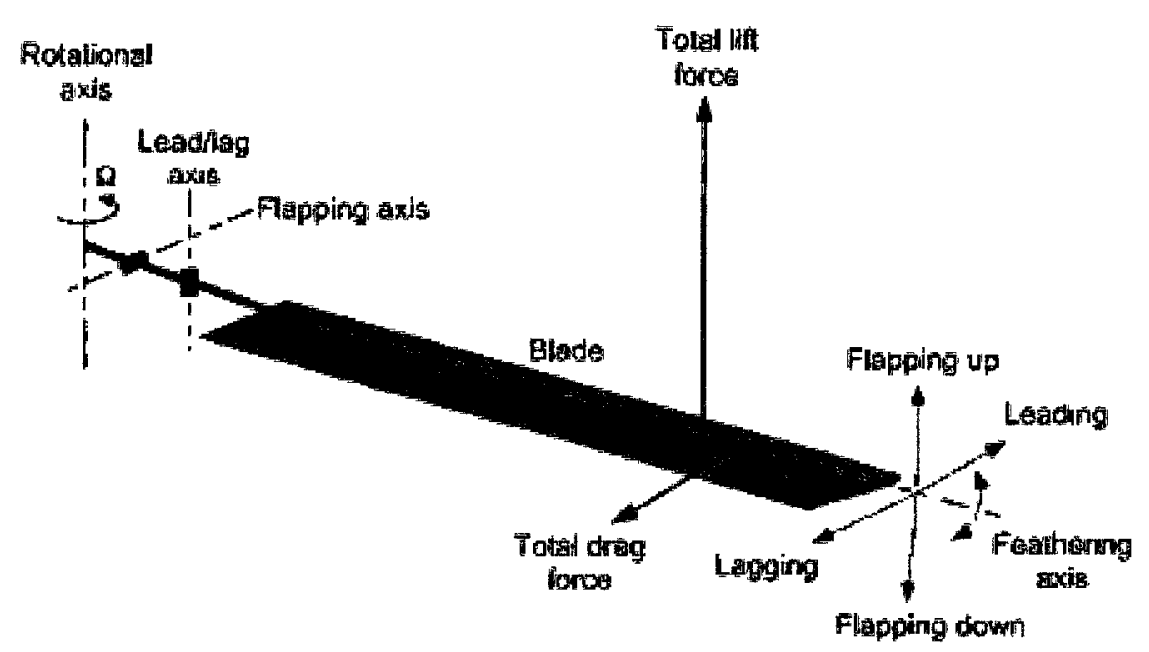

Figure 3.1 -Flapping lead-lag and feathering motion of a rotor blade [1].

In most cases, for hinged rotors, the blade can be assumed to be rigid due to the relatively small elastic deformations that occur. The flap and lag motions are a function of the inertial, centrifugal, Coriolis and aerodynamics forces that act on the blade. The equations of motions that couple the aerodynamic forces with the blade motion are derived from the equations presented in Leishman [1]. The discretization of these equations was presented in Mehrdaad Ghorashi's dissertation on "Dynamics of Elastic Nonlinear Rotating Composite Beams" [18]. Ghorashi generated a Matlab program that simulated the dynamic response of composite beams based on the Variational-Asymptotic Method of solving dynamic problems concerning thin-walled beams. Ghorashi presented a hingeless and a hinged composite model, and coupled the flap and lead-lag motion directly to his rotating beam model. However unlike GENUVP, he used a simple aerodynamic model in his studies. The discretized version of the equations of motion presented in Leishman were adapted here to create the rigid blade model that couples directly with SMARTROTOR's more sophisticated aerodynamic model. 
The forces acting on the blade for the flapping motion are shown in Figure 3.2:

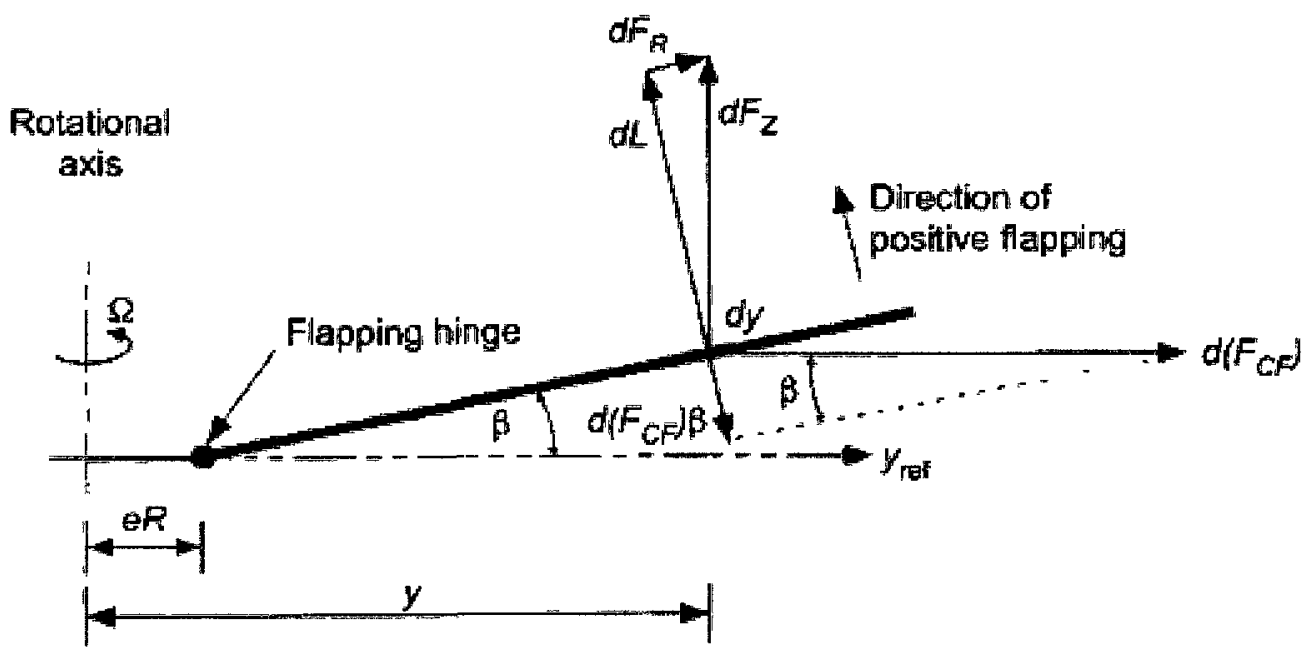

Figure 3.2 -Equilibrium of blade forces about the flapping hinge [1].

The four forces acting on the blade about the flapping hinge are:

1. Inertia force, $m(y-e R) \ddot{\beta} d y$ acting at a distance $(y-e R)$ about the flap hinge.

2. Centrifugal force, $m \Omega^{2} y d y$ acting at a distance $(y-e R) \beta$ from the flap hinge.

3. Coriolis force, $2 m(y-e R) \Omega \dot{\zeta} d y$ acting at a distance $(y-e R) \beta$ from the flap hinge.

4. Aerodynamic lift, $L d y$ acting at a distance $(y-e R)$ from the flap hinge.

The forces acting on the blade for the lead-lagging motion are as shown in Figure 3.3:

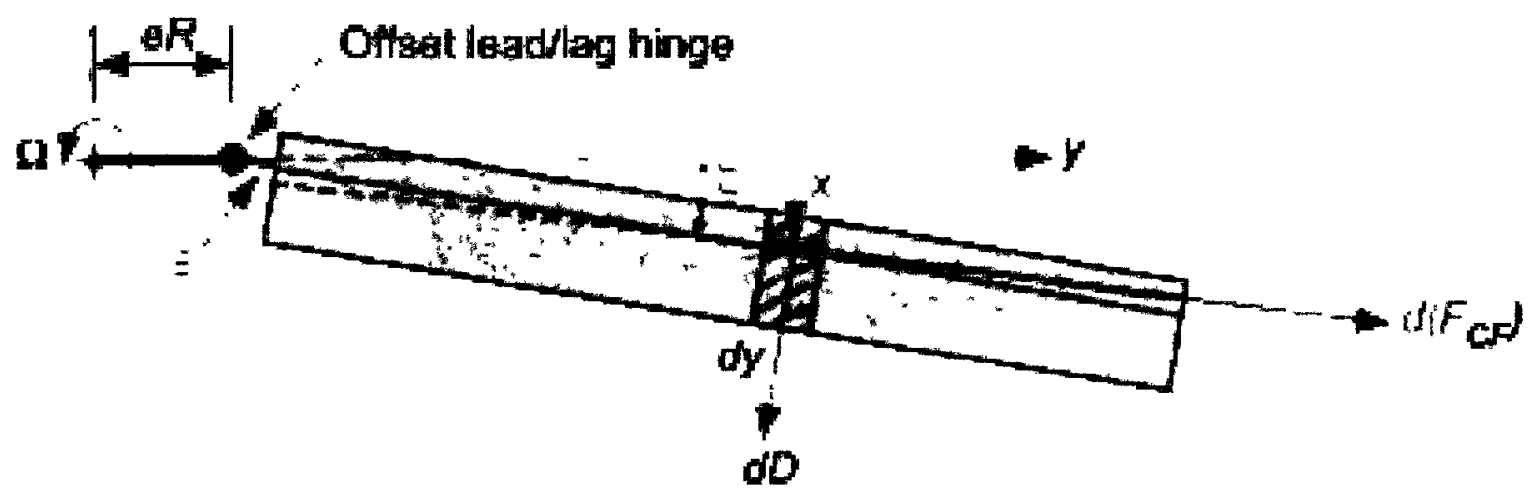

Figure 3.3 -Equilibrium of blade forces about the lead-lagging hinge [1]. 
The four forces acting on the blade about the lead-lag hinge are:

1. Inertia force, $m(y-e R) \ddot{\zeta} d y$ acting at a distance $(y-e R)$ about the lag hinge.

2. Centrifugal force, $m \Omega^{2} y d y$ acting at a distance $(y-e R) e R / y \zeta$ from the lag hinge.

3. Coriolis force, $2 m(y-e R) \beta \Omega d y$ acting at a distance $(y-e R)$ from the lag hinge.

4. Aerodynamic drag, $\mathrm{D} d y$ acting at a distance $(y-e R)$ from the lag hinge.

To simplify the nomenclature, $m$ is the weight of the blade section per unit length, and not the mass of the blade.

The summation of the forces about the flapping and lagging hinges give:

$$
\begin{gathered}
\int_{e R}^{R} m(y-e R)^{2} \ddot{\beta} d y+\int_{e R}^{R} m \Omega^{2} y(y-e R) \beta d y-\int_{e R}^{R} 2 m \Omega(y-e R)^{2} \beta \zeta^{2} d y \\
-\int_{e R}^{R} L(y-e R) d y=0 \\
\int_{e R}^{R} m(y-e R)^{2} \ddot{\zeta} d y+\int_{e R}^{R} m \Omega^{2} e R(y-e R) \zeta d y+\int_{e R}^{R} 2 m \Omega(y-e R)^{2} \beta \dot{\beta} d y \\
-\int_{e R}^{R} D(y-e R) d y=0
\end{gathered}
$$

For a blade of uniform mass and shape, these equations can be coupled into two differential equations. For the flapping hinge:

$$
I_{b}\left(\ddot{\beta}+v_{\beta}^{2} \Omega^{2} \beta-2 \Omega \dot{\zeta} \beta\right)=\int_{e R}^{R} L(y-e R) d y
$$

where the flapping frequency is

$$
v_{\beta}^{2}=1+\frac{e R \int_{e R}^{R} m(y-e R) d y}{I_{b}}
$$

For lagging hinge:

$$
l_{\zeta}\left(\ddot{\zeta}+v_{\zeta}^{2} \Omega^{2} \zeta-2 \Omega \dot{\beta} \beta\right)=\int_{e R}^{R} D(y-e R) d y
$$

where the lagging frequency is 
Chapter 3 - Rotating Rigid Blade Model

$$
v_{\zeta}^{2}=\frac{e R \int_{e R}^{R} m(y-e R) d y}{I_{\zeta}}
$$

In the present work, these equations are discretized and introduced in the subroutine BLADEARTICULATE, located in the file bladeartic.f (Appendix B.4).

The lift and drag moments $\left(\int_{e R}^{R} L(y-e R) d y\right.$ and $\left.\int_{e R}^{R} D(y-e R) d y\right)$ were discretized for separate lift and drag values at each node across the rotor blade. For example, as illustrated in Figure 3.4, if the blade has 16 structural nodes, then there are 16 lift and drag elements acting at each position from the blade cut off, such that:

$$
\int_{e R}^{R} L(y-e R) d y=\sum_{n=1}^{16} L_{i}\left(y_{i}-e R\right) \text { and } \int_{e R}^{R} D(y-e R) d y=\sum_{n=1}^{16} D_{i}\left(y_{i}-e R\right)
$$

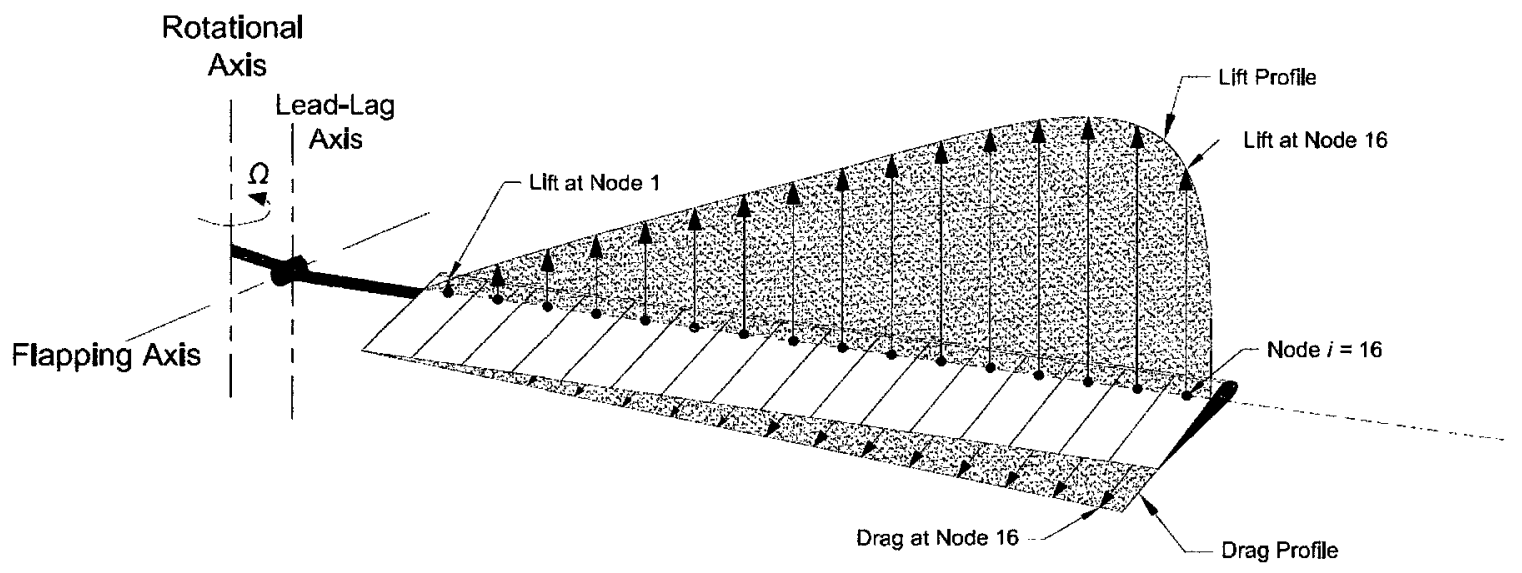

Figure 3.4 - Blade discretized lift and drag profiles.

The final discretized flap and lead-lag equations of motions equation are as follows:

$$
\begin{aligned}
& I_{b}\left(\ddot{\beta}+v_{\beta}^{2} \Omega^{2} \beta-2 \Omega \dot{\zeta} \beta\right)=\sum_{n=1}^{16} L_{i}\left(y_{i}-e R\right) \\
& I_{\zeta}\left(\ddot{\zeta}+v_{\zeta}^{2} \Omega^{2} \zeta-2 \Omega \dot{\beta} \beta\right)=\sum_{n=1}^{16} D_{i}\left(y_{i}-e R\right)
\end{aligned}
$$

To solve for the flap and lag angles, velocities and accelerations, an ordinary differential solver subroutine was implemented. As the present code is written in Fortran 77, a collection of subroutines from the library entitled ODEPACK was used to solve the differential equation. [19] 
The code for solving the flap and lead-lag angles are found in subroutine BLADEARTICULATE, located in file bladeartic.f. Refer to the code in Appendix B.5 for the method of setting up the ODEPACK subroutines.

\subsection{Coupling Rigid Motion with Aerodynamics}

With the flap and lead-lag subroutines complete, interpolation subroutines were created to rotate the aerodynamic nodes along the azimuth position. Opoku's version of SMARTROTOR calculates the structural deformation of hingeless rotor blades, as described in Chapter 2 . In this case, the rigid blade model is assumed, and the structural deformation subroutines were turned off.

The main program that runs SMARTROTOR is located in the file COMBINED_C.f. Refer to Appendix B.1 for this code. The flow chart of the main subroutine follows, in Figure 3.5 . 


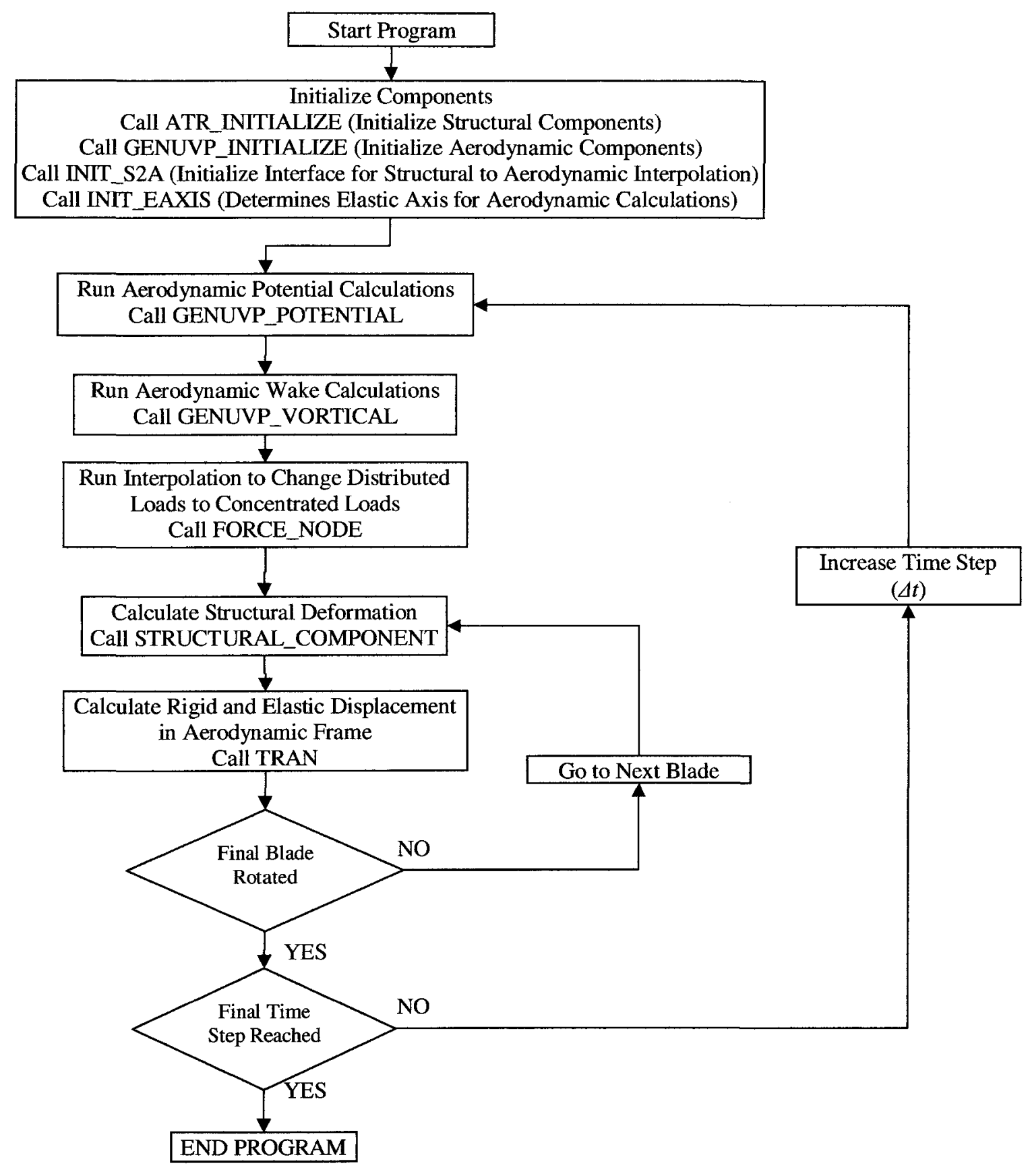

Figure 3.5 - Original SMARTROTOR main subroutine flow chart.

For the rigid blade model, the structural component subroutine is turned off and the flap/lag subroutine BLADEARTICULATE is added, as described in Section 3.1. The modified SMARTROTOR Flow chart is shown in Figure 3.6. 


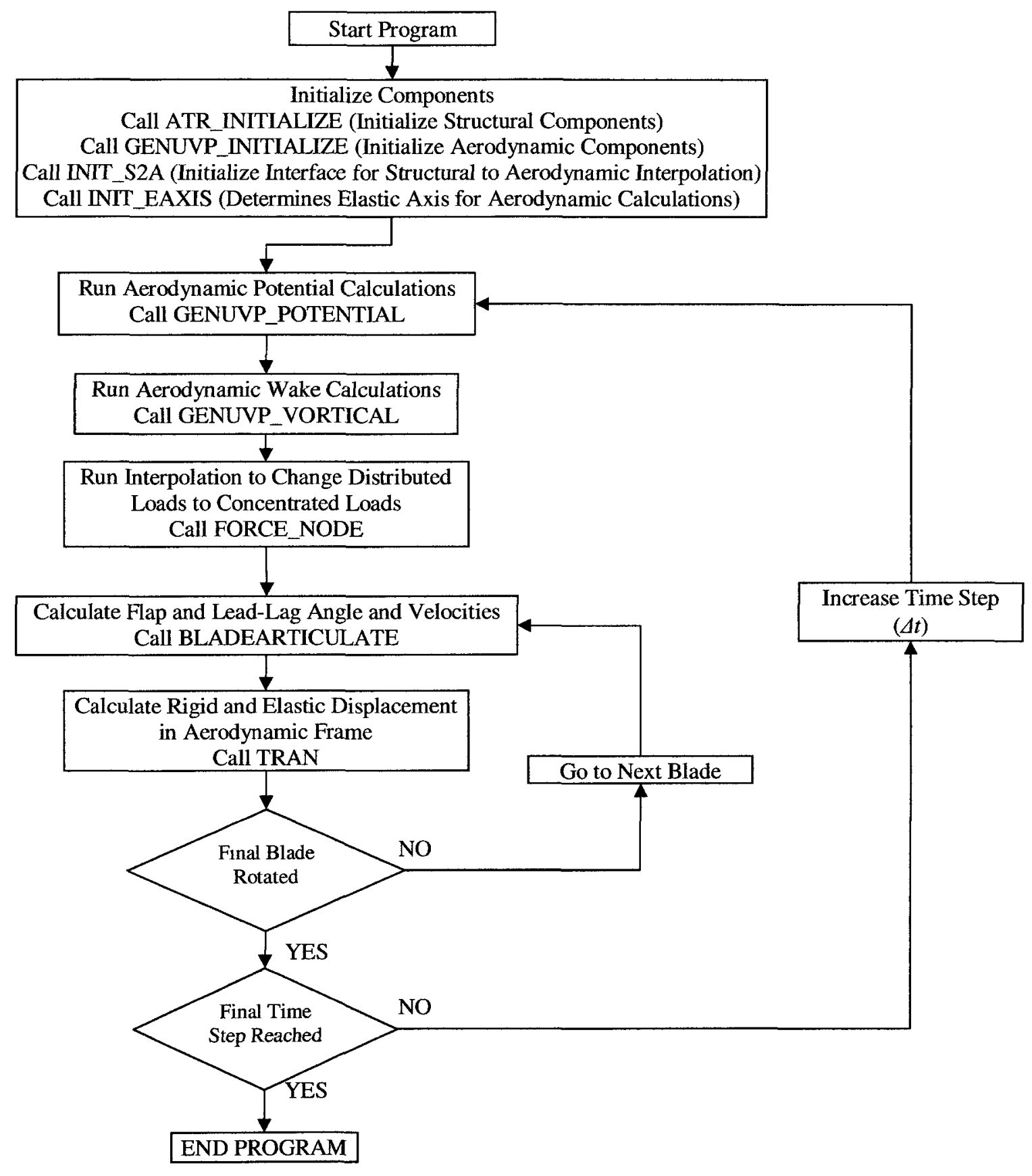

Figure 3.6 - Modified SMARTROTOR main subroutine flow chart.

To maintain the accuracy of the interpolation, some subroutines from Opoku's

SMARTROTOR were modified. These modifications are presented in the following sections. 


\subsection{Interpolation from Aerodynamic Model to Rigid Blade Model}

The lift and drag values are collected from the subroutine TNWEAOA, located in rescpv3_sp.coupled2.f. This subroutine corrects the viscous effect for thin wings based on the effective angle of attack. As the initialization requires an equal number of spanwise aerodynamic and structural nodes, it is simple to assign them, with the addition of instructions below in the TNWEAOA subroutine, located after the calculation of the lift, drag and pitching moment:

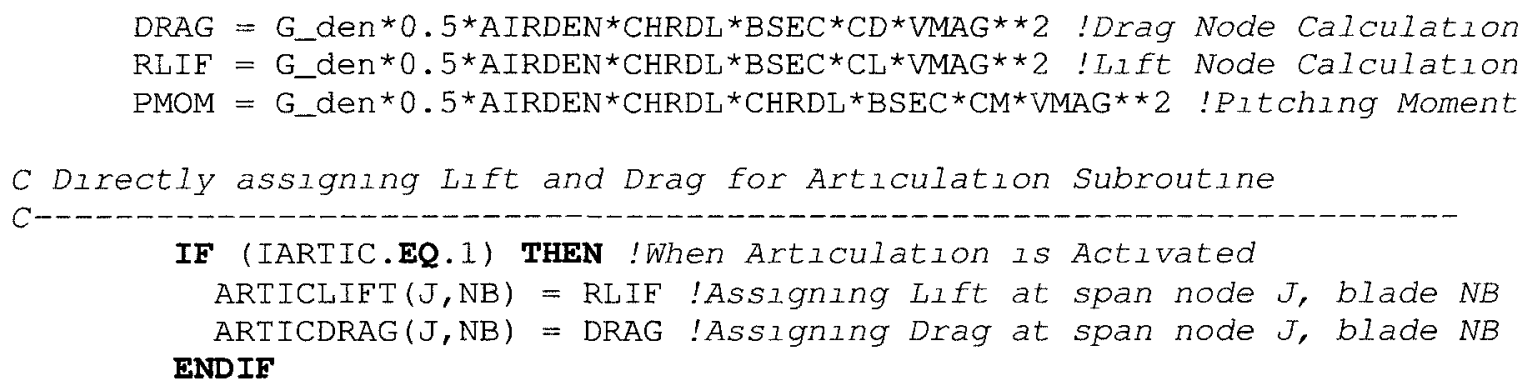

Then the lift and drag variables are recalled in the subroutine BLADEARTICULATE, as described in Section 3.1. In the above, the ARTICLIFT and ARTICDRAG are the arrays that store the nodal lift and drag magnitudes for each node index $\mathrm{J}$, and blade number NB.

\subsection{Interpolation from Rigid Blade Model to Aerodynamic Model}

From subroutine BLADEARTICULATE, the flap and lead-lag angles and velocities are sent to subroutine TRAN. Subroutine TRAN, located in file couple.f, calculates the new positions of the aerodynamic blade nodes (Appendix B.6). Normally it would have generated the displaced position of the structure nodes from subroutine STRUCTURAL_COMPONENT, located in file couple.f. However, for the rigid model, subroutine 
STRUCTURAL_COMPONENT is turned off, and the TRAN subroutine was modified to displace new positions of the structure nodes with respect to only the flap and lead-lag angles.

First, let's establish the difference between the frames of reference of the rigid blade model and the aerodynamic blade model, as illustrated in Figure 3.7.

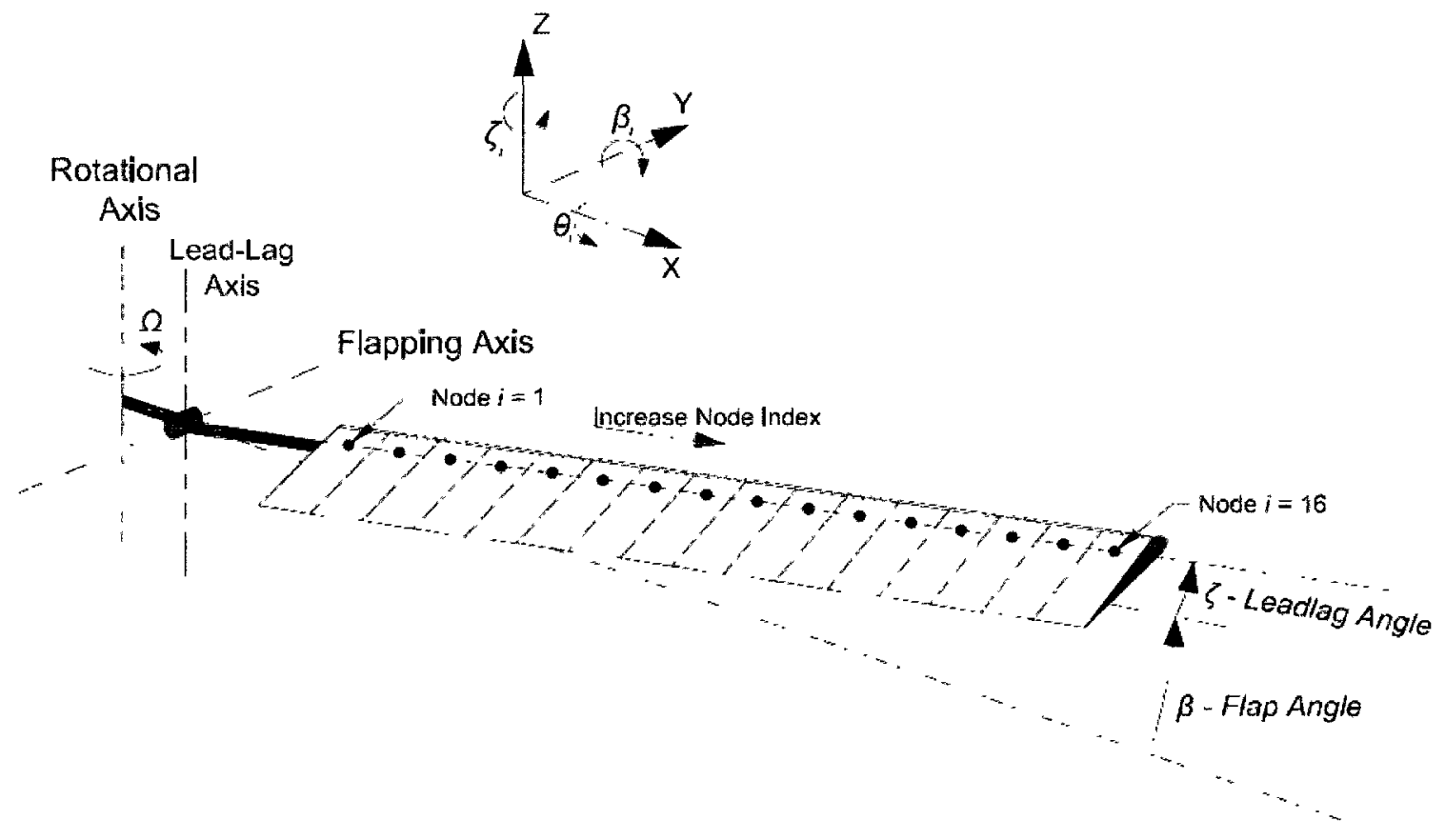

Figure 3.7 - Rigid blade model coordinate system.

In the aerodynamic frame of reference, the flap and the lead-lag angles are the negative of the rigid Leishman's angles and the collective pitch angle is the same. Hence:

Pitch: $\theta_{\mathrm{AERO}}=\theta_{\mathrm{RIGID}}$

Flap: $\beta_{\mathrm{AERO}}=-\beta_{\mathrm{RIGID}}$

Lead-lag: $\zeta_{\text {AERO }}=-\zeta_{\text {RIGI }}$

To transform the nodes from the previous position, the forward kinematics of the Denavit-Hartenberg homogeneous transformations are used [20]. The blade flaps and lags 
around the hinge. The blade nodes can only rotate in the flap and lead-lagwise directions, and twist about the pitch axis. Hence, the following basic transformations are used:

$$
A_{\imath}=\operatorname{Rot}_{x, \theta_{\imath}} \operatorname{Trans}_{x, d_{l}} \operatorname{Rot}_{y, \beta_{\imath}} \operatorname{Rot}_{z, \zeta_{l}} \operatorname{Trans}_{z, R_{\imath}-e R}
$$

where the pitch rotation is:

$$
\operatorname{Rot}_{x, \theta_{l}}=\left[\begin{array}{cccc}
1 & 0 & 0 & 0 \\
0 & \cos (\theta) & -\sin (\theta) & 0 \\
0 & \sin (\theta) & \cos (\theta) & 0 \\
0 & 0 & 0 & 1
\end{array}\right]
$$

The displacement of the nodes from the hinge, $e R$ :

$$
\operatorname{Trans}_{x, e R_{\iota}}=\left[\begin{array}{cccc}
1 & 0 & 0 & e R \\
0 & 1 & 0 & 0 \\
0 & 0 & 1 & 0 \\
0 & 0 & 0 & 1
\end{array}\right]
$$

The flap and lead-lag rotations are respectively:

$$
\begin{aligned}
\operatorname{Rot}_{y, \beta_{l}} & =\left[\begin{array}{cccc}
\cos (\beta) & 0 & \sin (\beta) & 0 \\
0 & 1 & 0 & 0 \\
-\sin (\beta) & 0 & \cos (\beta) & 0 \\
0 & 0 & 0 & 1
\end{array}\right] \\
\operatorname{Rot}_{z, \zeta_{l}} & =\left[\begin{array}{cccc}
\cos (\zeta) & -\sin (\zeta) & 0 & 0 \\
\sin (\zeta) & \cos (\zeta) & 0 & 0 \\
0 & 0 & 1 & 0 \\
0 & 0 & 0 & 1
\end{array}\right]
\end{aligned}
$$

The flap and the lead-lag of the beam nodes, situation at radius $R_{\iota}$ from the hinge $e R$ are given by:

$$
\operatorname{Trans}_{z, R_{l}-e R}=\left[\begin{array}{cccc}
1 & 0 & 0 & R_{\imath}-e R \\
0 & 1 & 0 & 0 \\
0 & 0 & 1 & 0 \\
0 & 0 & 0 & 1
\end{array}\right]
$$

Hence the full transform becomes:

$$
A_{l}=\left[\begin{array}{cc}
\cos (\theta) \cos (\zeta) & -\cos (\beta) \sin (\zeta) \\
\cos (\theta) \sin (\zeta)+\cos (\zeta) \sin (\beta) \sin (\theta) & \sin (\zeta) \cos (\theta)-\sin (\beta) \sin (\zeta) \sin (\theta) \\
\sin (\zeta) \sin (\theta)-\cos (\zeta) \cos (\theta) \sin (\beta) & \cos (\zeta) \sin (\theta)+\cos (\theta) \sin (\beta) \sin (\zeta) \\
0 & 0
\end{array}\right.
$$


Chapter 3 - Rotating Rigid Blade Model

$$
\left.\begin{array}{cc}
\sin (\beta) & e R-R_{l}+\cos (\beta) \cos (\zeta)\left(R_{\iota}-e R\right) \\
-\cos (\beta) \sin (\theta) & (\cos (\theta) \sin (\zeta)+\sin (\theta) \sin (\beta) \cos (\zeta))\left(R_{l}-e R\right) \\
\cos (\beta) \cos (\theta) & (\sin (\theta) \sin (\zeta)-\cos (\theta) \sin (\beta) \cos (\zeta))\left(R_{\iota}-e R\right) \\
0 & 1
\end{array}\right]
$$

The nodal displacements are solved and introduced in the $4^{\text {th }}$ column of the above DenavitHartenberg Transform. Hence, the nodal displacements of the rigid blade along the span are:

$$
\begin{aligned}
& \text { Disp_1D } \mathrm{D}_{1}=e R-R_{\iota}+\cos (\beta) \cos (\zeta)\left(R_{l}-e R\right) \\
& \text { Disp_2D }=(\cos (\theta) \sin (\zeta)+\sin (\theta) \sin (\beta) \cos (\zeta))\left(R_{l}-e R\right) \\
& \text { Disp_3D }_{1}=(\sin (\theta) \sin (\zeta)-\cos (\theta) \sin (\beta) \cos (\zeta))\left(R_{l}-e R\right)
\end{aligned}
$$

Next, each spanwise node is transformed into the aerodynamic frame. In the TRAN subroutine the rotation of each node is set as:

Twist_1 $\mathrm{D}_{1}=0$, as pitch rotation is taken into account in the aerodynamic subroutine.

Twist $\_2 D_{1}=-\beta$, since for the rigid model, the flap direction is the same as node direction. Twist_3 $\mathrm{D}_{1}=-\zeta$, since for the rigid model, the lead-lag direction is the same as node direction.

The program then returns to the original aerodynamic subroutines as originally written for GENUVP. The aerodynamic subroutine GENUVP_POTENTIAL, located in file gnvp3_sp.coupled.f (Appendix B.2), is called. Next, the subroutine BLADE_DEFORM (Appendix B.3), located in file blade_deform.f, is called. Subroutine BLADE_DEFORM rotates the aerodynamic nodes about the flap and lead-lag axis, from their position in the previous time step. The difference between this version of SMARTROTOR and previous version written by Opoku, is that the BLADE_DEFORM subroutine now relocates the aerodynamic grid blade nodes as 
defined by the new flap and lead-lag angles, while the previous version relocated the blade nodes as per the deformed structure of the hingeless blade.

In the BLADE_DEFORM subroutine, the structural nodes must be transformed to the aerodynamic grid. Initially, a set of 16 structural nodes per blade are defined. The structural node position is defined at the structural cell's midpoint as previously illustrated in Figure 3.8. The aerodynamic grid consists of 153 nodes (17 spanwise by 9 chordwise nodes) per blade, set in a rectangular pattern, as illustrated ahead in Figure 3.10. Initially, a linear aerodynamic node grid is created, to expand to the $17^{\text {th }}$ node position, as illustrated in Figure 3.8.

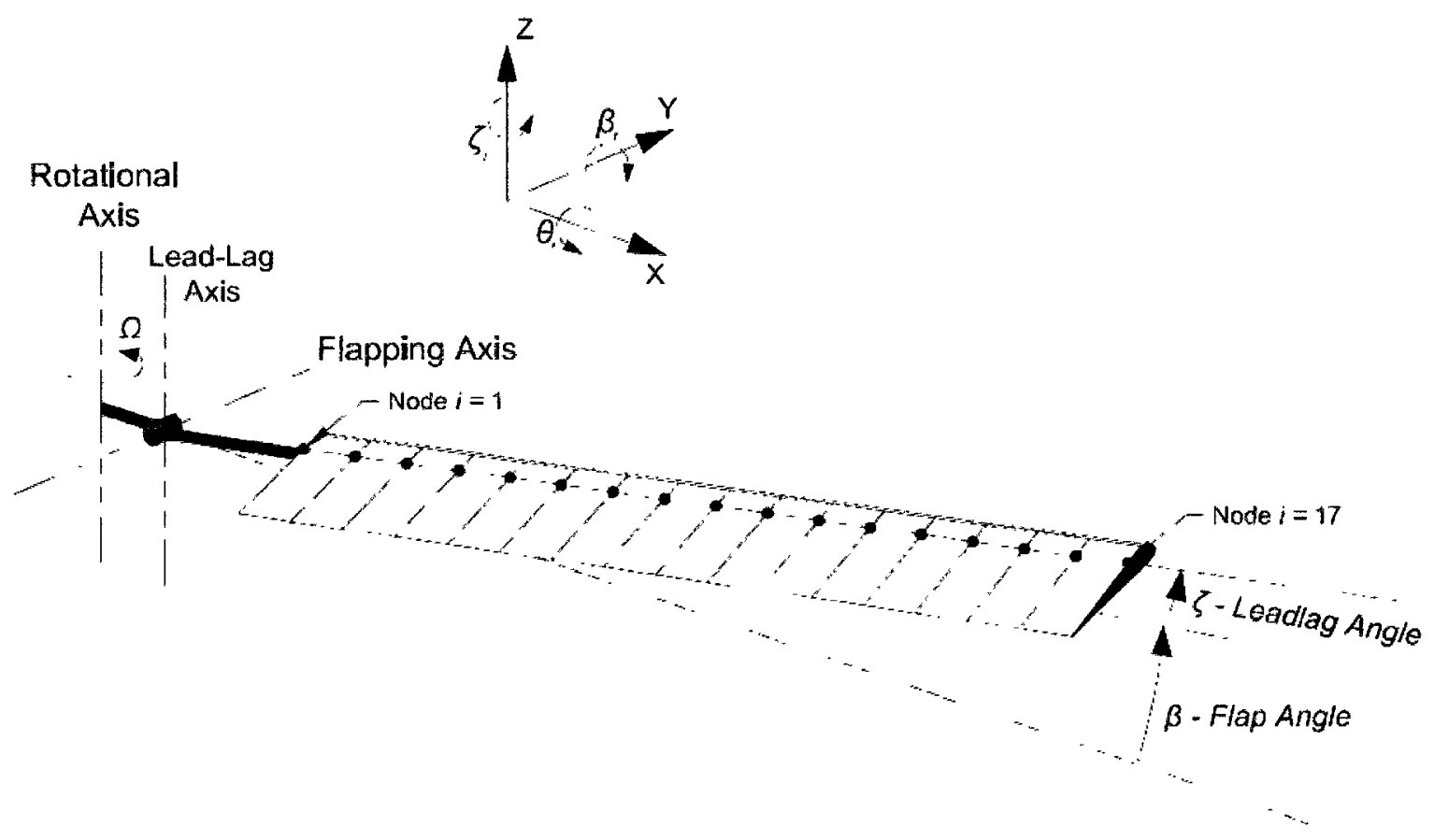

Figure 3.8 - Temporary aerodynamic node linear grid.

During this expansion to 17 spanwise aerodynamic nodes, these nodes are rotated to their new positions based on the blade's flap and lead-lag angles. Next, subroutine MAP_DEFORM is called to transform the rigid displacement and rotation positions of the nodes to calculate the final position in the aerodynamic nodal frame as illustrated in Figure 3.10. The construction of the aerodynamic node positions are as follows: 


$$
\begin{aligned}
& \operatorname{DISP}\left(\mathrm{x}_{\text {aero }}\right)_{\mathrm{i}}=-\frac{1}{2}\left(\operatorname{DISP}\left(\mathrm{y}_{\text {struct }}\right)_{\mathrm{i}}+\operatorname{DISP}\left(\mathrm{y}_{\text {struct }}\right)_{\mathrm{i}+1}\right) \\
& \operatorname{DISP}\left(\mathrm{y}_{\text {aero }}\right)_{\mathrm{i}}=\frac{1}{2}\left(\operatorname{DISP}\left(\mathrm{x}_{\text {struct }}\right)_{\mathrm{i}}+\operatorname{DISP}\left(\mathrm{x}_{\text {struct }}\right)_{\mathrm{i}+1}\right) \\
& \operatorname{DISP}\left(\mathrm{z}_{\text {aero }}\right)_{\mathrm{i}}=\frac{1}{2}\left(\operatorname{DISP}\left(\mathrm{z}_{\text {struct }}\right)_{\mathrm{i}}+\operatorname{DISP}\left(\mathrm{z}_{\text {struct }}\right)_{\mathrm{i}+1}\right)
\end{aligned}
$$

Likewise the angular orientation of the nodes changes as follows:

$$
\begin{aligned}
& \theta_{\text {aero }_{\mathrm{i}}}=\frac{1}{2}\left(\theta_{\text {struct }_{\mathrm{i}}}+\theta_{\text {struct }_{\mathrm{i}+1}}\right) \\
& \beta_{\text {aero }_{\mathrm{i}}}=-\frac{1}{2}\left(\beta_{\text {struct }_{\mathrm{i}}}+\beta_{\text {struct }_{\mathrm{i}+1}}\right) \\
& \zeta_{\text {aero }_{\mathrm{i}}}=\frac{1}{2}\left(\zeta_{\text {struct }_{\mathrm{i}}}+\zeta_{\text {struct }_{\mathrm{i}+1}}\right)
\end{aligned}
$$

At each spanwise node, a chordwise set of aerodynamic nodes must rotate about the local elastic axis. This is accomplished by another set of Denavit-Hartenberg Transformations, and is defined in the subroutine TWIST123 in file blade_deform.f (Appendix B.3). At each rigid spanwise node, there are several chordwise nodes. The chordwise location of the spanwise node is at the beam elastic axis as illustrated in Figure 3.10. Each chordwise displacement is measured from the elastic axis. The following basic transformations are used:

$$
A_{i}=\operatorname{Rot}_{x, \theta_{i}} \operatorname{Rot}_{y, \beta_{i}} \operatorname{Rot}_{z, \zeta_{i}} \operatorname{Trans}_{R A X I S x y z}
$$

where the pitch rotation about the elastic axis is:

$$
\operatorname{Rot}_{x, \theta_{i}}=\left[\begin{array}{cccc}
1 & 0 & 0 & 0 \\
0 & \cos (\theta) & -\sin (\theta) & 0 \\
0 & \sin (\theta) & \cos (\theta) & 0 \\
0 & 0 & 0 & 1
\end{array}\right]
$$

The flap and lead-lag rotations are: 


$$
\begin{aligned}
\operatorname{Rot}_{y, \beta_{\mathrm{l}}} & =\left[\begin{array}{cccc}
\cos (\beta) & 0 & \sin (\beta) & 0 \\
0 & 1 & 0 & 0 \\
-\sin (\beta) & 0 & \cos (\beta) & 0 \\
0 & 0 & 0 & 1
\end{array}\right] \\
\operatorname{Rot}_{z, \zeta_{\iota}} & =\left[\begin{array}{cccc}
\cos (\zeta) & -\sin (\zeta) & 0 & 0 \\
\sin (\zeta) & \cos (\zeta) & 0 & 0 \\
0 & 0 & 1 & 0 \\
0 & 0 & 0 & 1
\end{array}\right]
\end{aligned}
$$

The displacements of the spanwise nodes, at $(\mathrm{x}, \mathrm{y}, \mathrm{z})$ distance from the elastic axis are given by:

$$
\operatorname{Trans}_{\text {RAXISxyz }}=\left[\begin{array}{cccc}
1 & 0 & 0 & \text { RAXIS }_{\mathrm{x}} \\
0 & 1 & 0 & \text { RAXIS }_{\mathrm{y}} \\
0 & 0 & 1 & \text { RAXIS }_{\mathrm{z}} \\
0 & 0 & 0 & 1
\end{array}\right]
$$

The nodes' final positions are likewise solved and introduced in the $4^{\text {th }}$ column of the DenavitHartenberg Transform, as follows:

$$
\begin{aligned}
& \operatorname{XROTATE}(\mathrm{x})_{1, \mathrm{l}}=\cos (\beta) \cos (\zeta) \operatorname{RAXIS}(\mathrm{x})_{1} \\
& -\cos (\beta) \sin (\zeta) \operatorname{RAXIS}(y)_{1} \\
& +\sin (\beta) \operatorname{RAXIS}(\mathrm{z}) \text {, } \\
& \text { XROTATE }(y)_{1, j}=(\sin (\theta) \sin (\beta) \cos (\zeta)+\cos (\theta) \sin (\zeta)) \operatorname{RAXIS}(\mathrm{x})_{\mathrm{I}} \\
& +(-\sin (\theta) \sin (\beta) \sin (\zeta)+\cos (\theta) \cos (\zeta)) \mathrm{RAXIS}_{(\mathrm{y})} \\
& -\sin (\theta) \cos (\beta) \operatorname{RAXIS}(\mathrm{z})_{1} \\
& \text { XROTATE }(\mathrm{z})_{1, \mathrm{~J}}=(-\cos (\theta) \sin (\beta) \cos (\zeta)+\sin (\theta) \sin (\zeta)) \text { RAXIS }(\mathrm{x})_{\mathrm{I}} \\
& +(\cos (\theta) \sin (\beta) \sin (\zeta)+\sin (\theta) \cos (\zeta)) \operatorname{RAXIS}(y)_{1} \\
& +\cos (\theta) \cos (\beta) \text { RAXIS }(\mathrm{z})_{1}
\end{aligned}
$$

The linear displacements of the nodes are given by:

$$
\begin{aligned}
& \operatorname{DELTAX}(\mathrm{x})_{1, \mathrm{j}}=\operatorname{XROTATE}(\mathrm{x})_{1, \mathrm{j}}-\operatorname{RAXIS}(\mathrm{x})_{1} \\
& \operatorname{DELTAX}(\mathrm{y})_{1, \mathrm{j}}=\operatorname{XROTATE}(\mathrm{y})_{\mathrm{l}, \mathrm{j}}-\operatorname{RAXIS}(\mathrm{y})_{1}
\end{aligned}
$$




$$
\operatorname{DELTAX}(\mathrm{z})_{\mathrm{i}, \mathrm{j}}=\operatorname{XROTATE}(\mathrm{z})_{\mathrm{i}, \mathrm{j}}-\operatorname{RAXIS}(\mathrm{z})_{\mathrm{i}}
$$

Similarly, the root and tip nodal positions and orientations are extrapolated from their adjacent spanwise nodes.

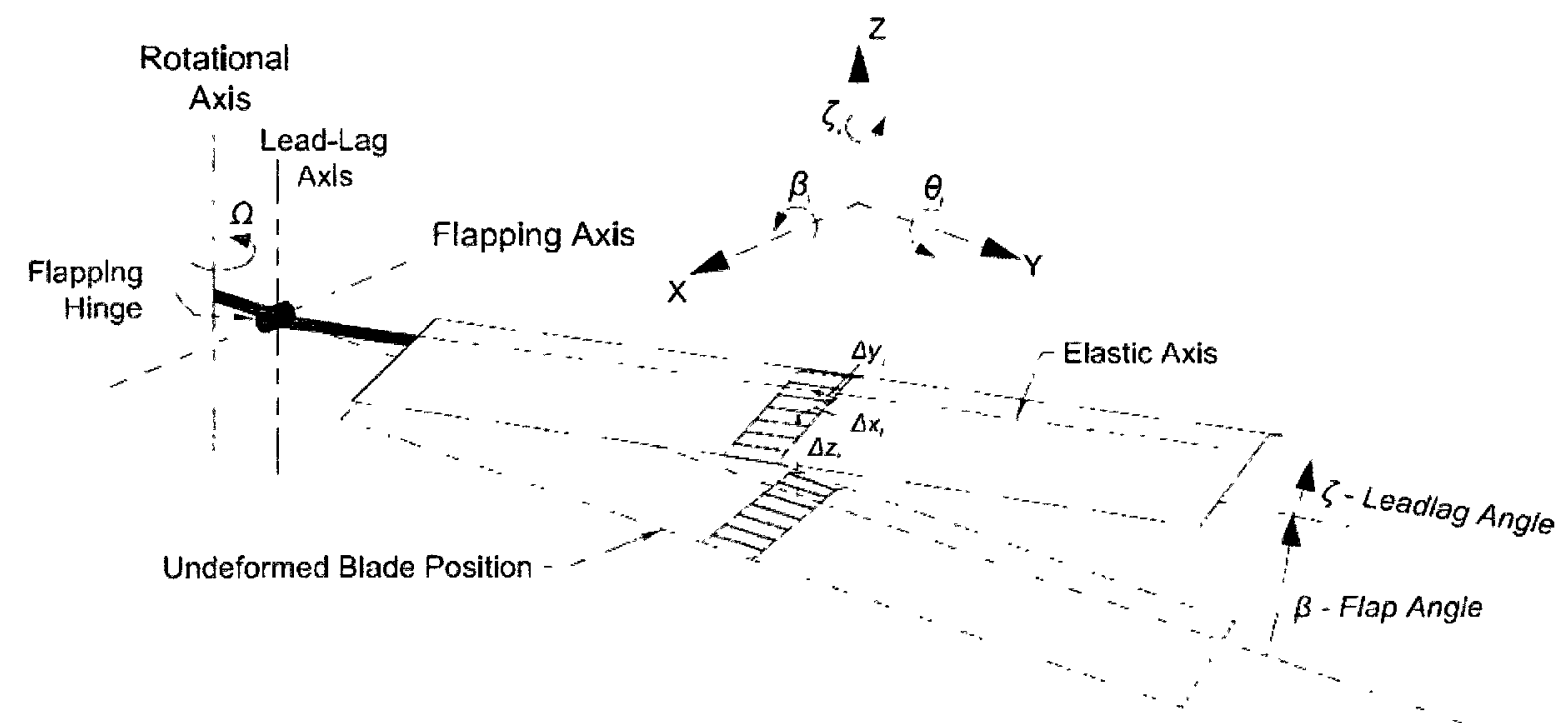

Figure 3.9 - Displacing aerodynamic nodes from undeformed position.

The final position of the twisted nodes along the chord from the undeformed blade frame are as illustrated in Figure 3.10 and given by:

$$
\begin{aligned}
& \operatorname{XFINAL}(\mathrm{x})_{\mathrm{i}, \mathrm{j}}=\operatorname{XINIT}(\mathrm{x})_{\mathrm{i}, \mathrm{j}}+\operatorname{DELTAX}(\mathrm{x})_{\mathrm{i}, \mathrm{j}} \\
& \operatorname{XFINAL}(\mathrm{y})_{\mathrm{i}, \mathrm{j}}=\operatorname{XINIT}(\mathrm{y})_{\mathrm{i}, \mathrm{j}}+\operatorname{DELTAX}(\mathrm{y})_{\mathrm{i}, \mathrm{j}} \\
& \operatorname{XFINAL}(\mathrm{z})_{\mathrm{i} . \mathrm{j}}=\operatorname{XINIT}(\mathrm{z})_{\mathrm{i}, \mathrm{j}}+\operatorname{DELTAX}(\mathrm{z})_{\mathrm{i}, \mathrm{j}}
\end{aligned}
$$

Returning to the BLADE_DEFORM subroutine, the chordwise nodes are moved by the displacements generated from the TRAN subroutine (Appendix B.6), whereby the final revised local coordinates for the aerodynamic panel, XGL becomes:

$$
\begin{aligned}
& \operatorname{XGL}(\mathrm{x})_{\mathrm{i}, \mathrm{j}}=\operatorname{XFINAL}(\mathrm{x})_{\mathrm{i}, \mathrm{j}}+\operatorname{DISP}(\mathrm{x})_{\mathrm{i}} \\
& \mathrm{XGL}(\mathrm{y})_{\mathrm{i}, \mathrm{j}}=\operatorname{XFINAL}(\mathrm{y})_{\mathrm{i}, \mathrm{j}}+\operatorname{DISP}(\mathrm{y})_{\mathrm{i}} \\
& \mathrm{XGL}(\mathrm{z})_{\mathrm{i}, \mathrm{j}}=\operatorname{XFINAL}(\mathrm{z})_{\mathrm{i}, \mathrm{j}}+\operatorname{DISP}(\mathrm{z})_{\mathrm{i}}
\end{aligned}
$$




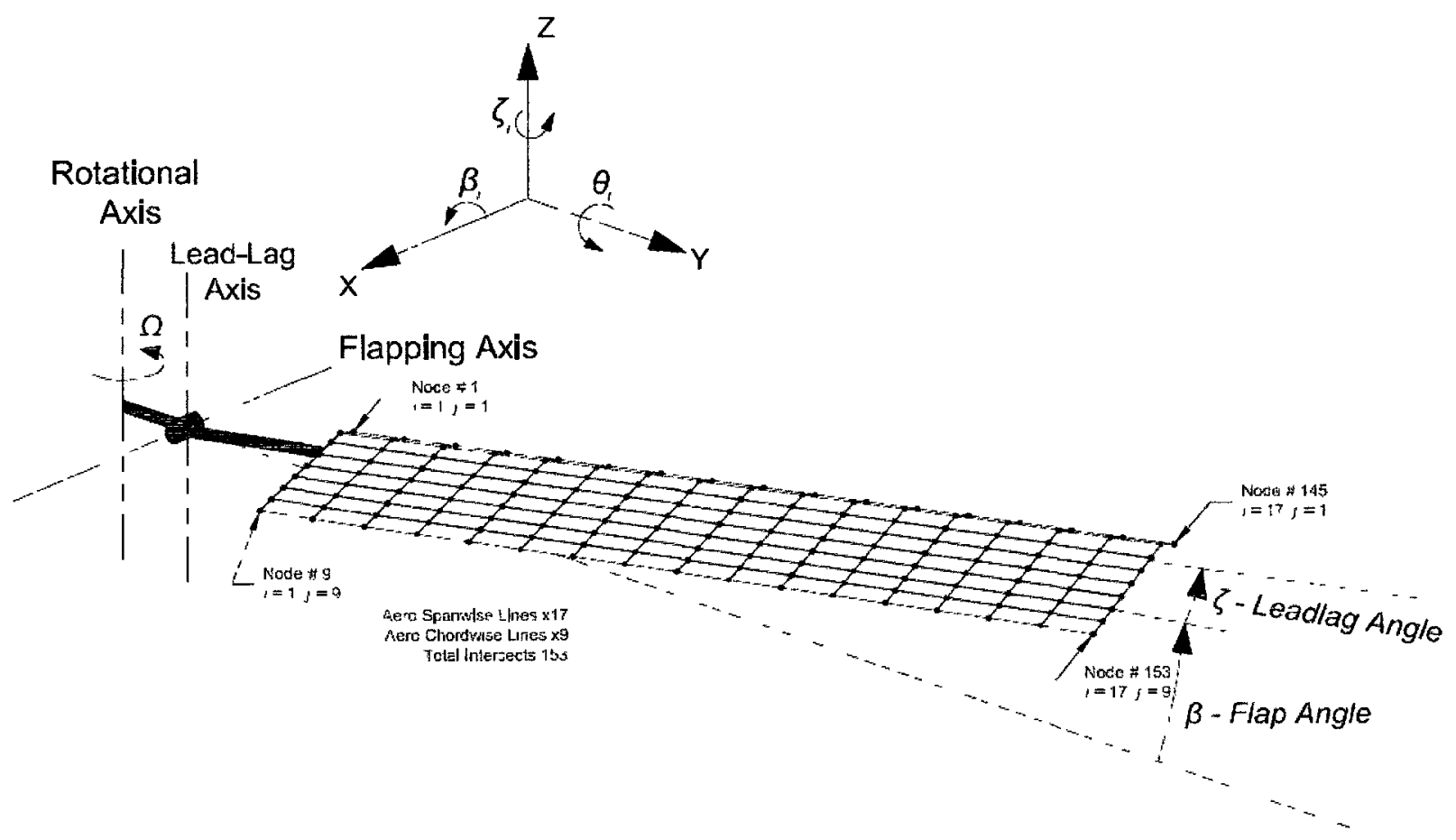

Figure 3.10 - Aerodynamic blade model coordinate system.

Figure 3.10 displays the resulting aerodynamic blade model. Now with new local aerodynamic nodal positions, the blade can now proceed through the aerodynamic domain as a blade adjusted to the calculate flap and lead-lag angle as calculated in the previous time step. These steps are repeated for each blade, and through every subsequent time step, until the simulation is terminated. 


\section{Chapter 4 CH-47C Rotor Blade Flapping Motion Analysis}

In 1972, an experiment on blade motion characteristics was conducted. The results of the experiment were presented in Harris' paper entitled “Articulated Rotor Blade Flapping Motion at Low Advance Ratios" [9]. The experiment was conducted with a $5.5 \mathrm{ft}$ diameter rotor model of a CH-47C model rotor in the $20 \times 20 \mathrm{ft}$ Boeing V/STOL Wind Tunnel, in Philadelphia, Pennsylvania, as shown in Figure 4.1. The experiment was conducted with the purpose of measuring the flap motions and downwash and to compare the measurements to momentum theory. This test showed that the wake geometry predicted from the advanced momentum theory did not correlate well with the experimental data concerning slow forward helicopter flight. It also showed that some of the blade dynamics parameters, such as the lateral flapping angles are much larger than assumed in momentum theory. This paper was selected to compare the simulation results of SMARTROTOR because of its detailed results of flap motion. This chapter presents a comparison of the rigid blade model to the Harris experiment.

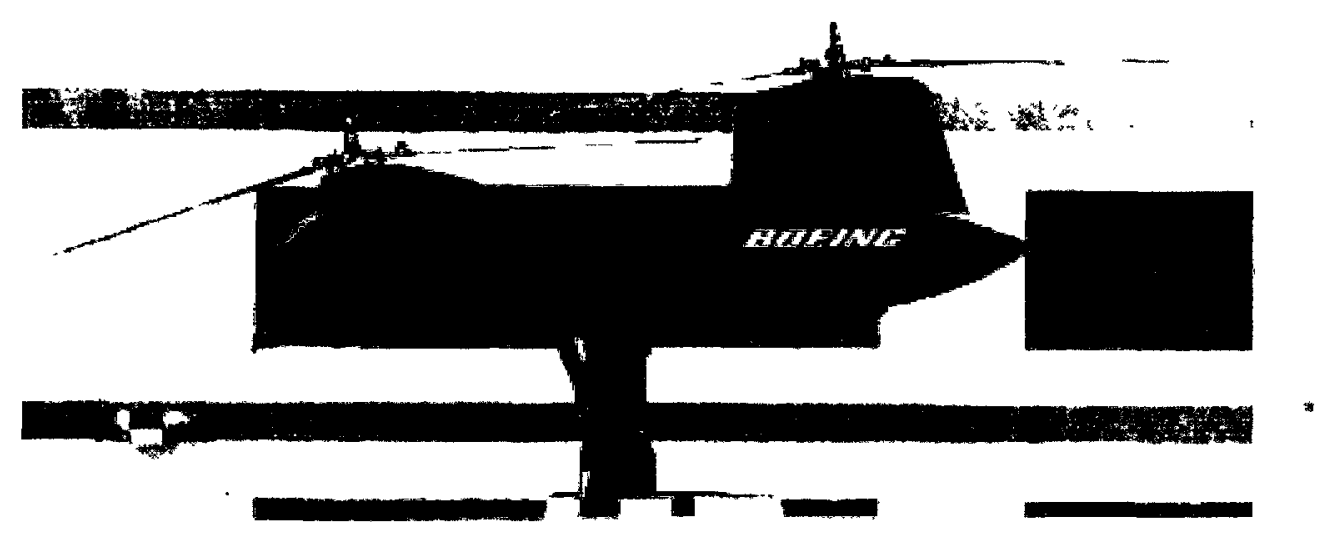

Figure 4.1 - Vertol division helicopter model [9]. 


\subsection{Harris Articulated Blade Flapping Motion Overview}

Harris [9] conducted three experiments to measure the flapping motions due to the influence of advance ratios, collective pitch, and shaft tilt. Simulations with SMARTROTOR's rigid blade model reproduced Harris' three experiments. The original experiment removed the forward rotor blades of the tandem helicopter as a means to isolate the aft rotor blades to allow for clean undisturbed oncoming air stream. The data collected was taken through increasing incoming velocities or advance ratios of 0 to 0.24 . The results showed that the maximum amplitude of flapping motion of $3.4^{\circ}$ occurred at 0.08 advance ratio. The blade motion was recorded with a Rotary Variable Displacement Transformer. The rotor rotated at a tip speed of $137.16 \mathrm{~m} / \mathrm{s}$ or a rotational speed of $164.8 \mathrm{rad} / \mathrm{s}(26.2 \mathrm{~Hz})$. The rotor geometry is described in Table 4.1 below:

Table 4.1 - CH47C scaled rotor geometry.

\begin{tabular}{|l|l|}
\hline Radius & $0.8321 \mathrm{~m}$ \\
\hline Chord & $0.0582 \mathrm{~m}$ \\
\hline Number of Blades & 4 \\
\hline Solidity & 0.0892 \\
\hline Twist & $-9.14^{\circ}$ \\
\hline Root Cut-out & $0.1600 \mathrm{~m}$ \\
\hline Airfoil & $\mathrm{V} 23010-1.58$ \\
\hline Weight Moment & $0.06789 \mathrm{~kg} \cdot \mathrm{m}$ \\
\hline Moment of Inertia & $0.03351 \mathrm{~kg} \cdot \mathrm{m}^{2}$ \\
\hline Flapping Hinge Offset & $0.0191 \mathrm{~m}$ \\
\hline
\end{tabular}

Harris' paper does not explicitly state the mass of the blade or the aeroelastic stiffness properties. The V23010-1.58 model rotor blade is geometrically simple with a constant the blade pitches downward twist of $9.14^{\circ}$ from the root cut-off to the blade tip. The mass distribution of the blade was estimated from the blade's weight moment of $0.49 \mathrm{ft} \cdot \mathrm{lbs}$. It was assumed that the 
blade has a near-uniform mass distribution form the root cut to the tip, as there is no significant variance in blade geometry. For a beam with a fixed end, the bending moment is:

$$
M=\frac{m L^{2}}{2}
$$

and the blade length $L$ from hinge point to blade tip is $0.813 \mathrm{~m}$, so the distributed mass $m$ is estimated to be $0.205 \mathrm{~kg} / \mathrm{m}$.

To comply with the equations of motion (Eqs. 3.7 and 3.8), it is assumed that the blade is rigid. In reality the blade will experience flexing, but with a hinged blade the magnitude of the flexing should be small relative to the amplitudes of the flap and lead-lag motion.

\subsection{CH47C Airfoil}

The CH47C airfoil is a V23010-1.58. SMARTROTOR requires the input of the lift, drag and moment curves for airfoil speeds from Mach 0.0 to Mach 0.95. A complete listing of experimentally derived lift, drag and moment curves for this airfoil can be found in "U.S. Army Helicopter Design Datcom Volume 1 Airfoils" [21]. The lift, drag and moment curves from the Helicopter Design Datcom are included in Figures 4.2 to 4.4. 


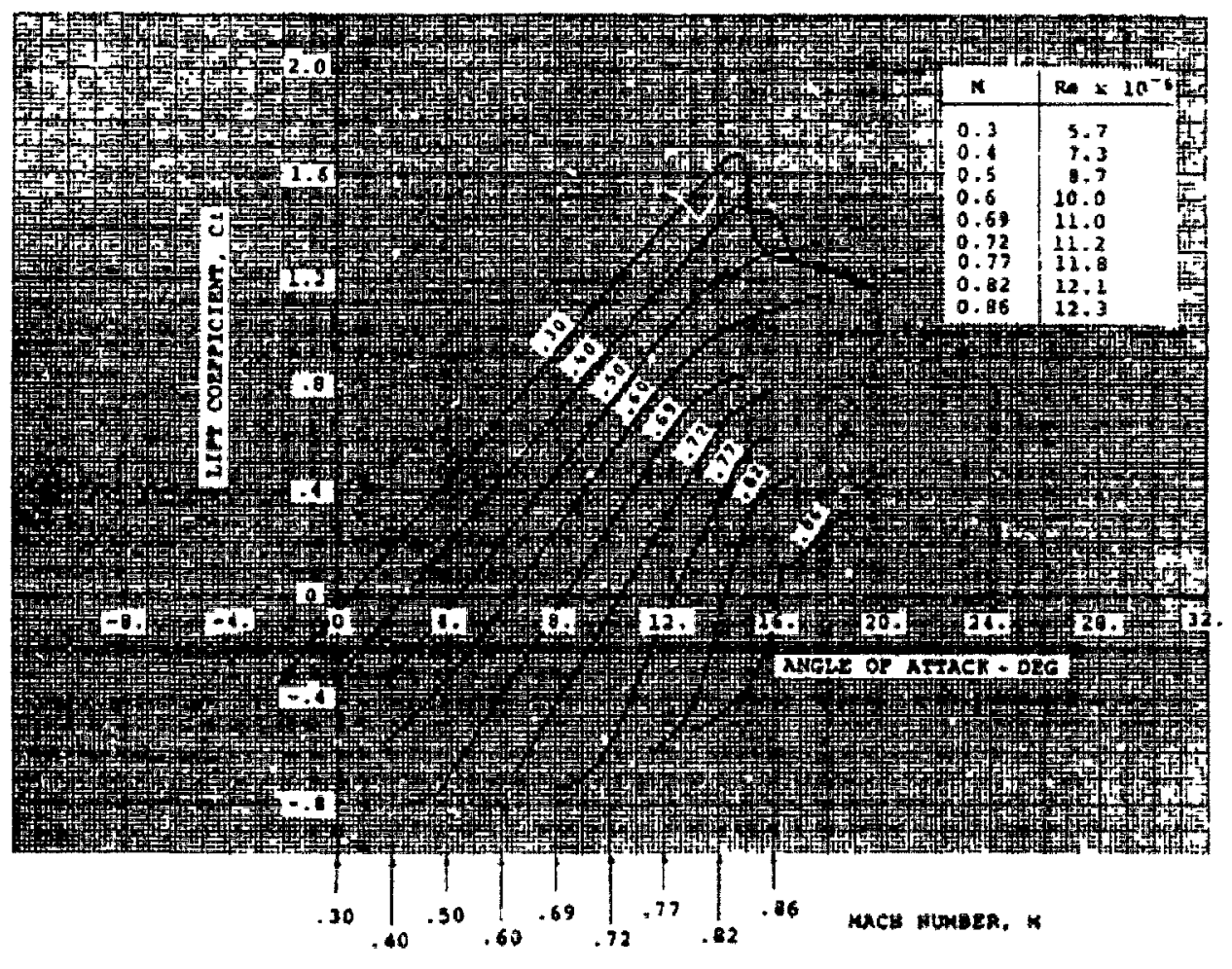

Figure 4.2 - V23010-1.58 airfoil lift curves as shown in [21].

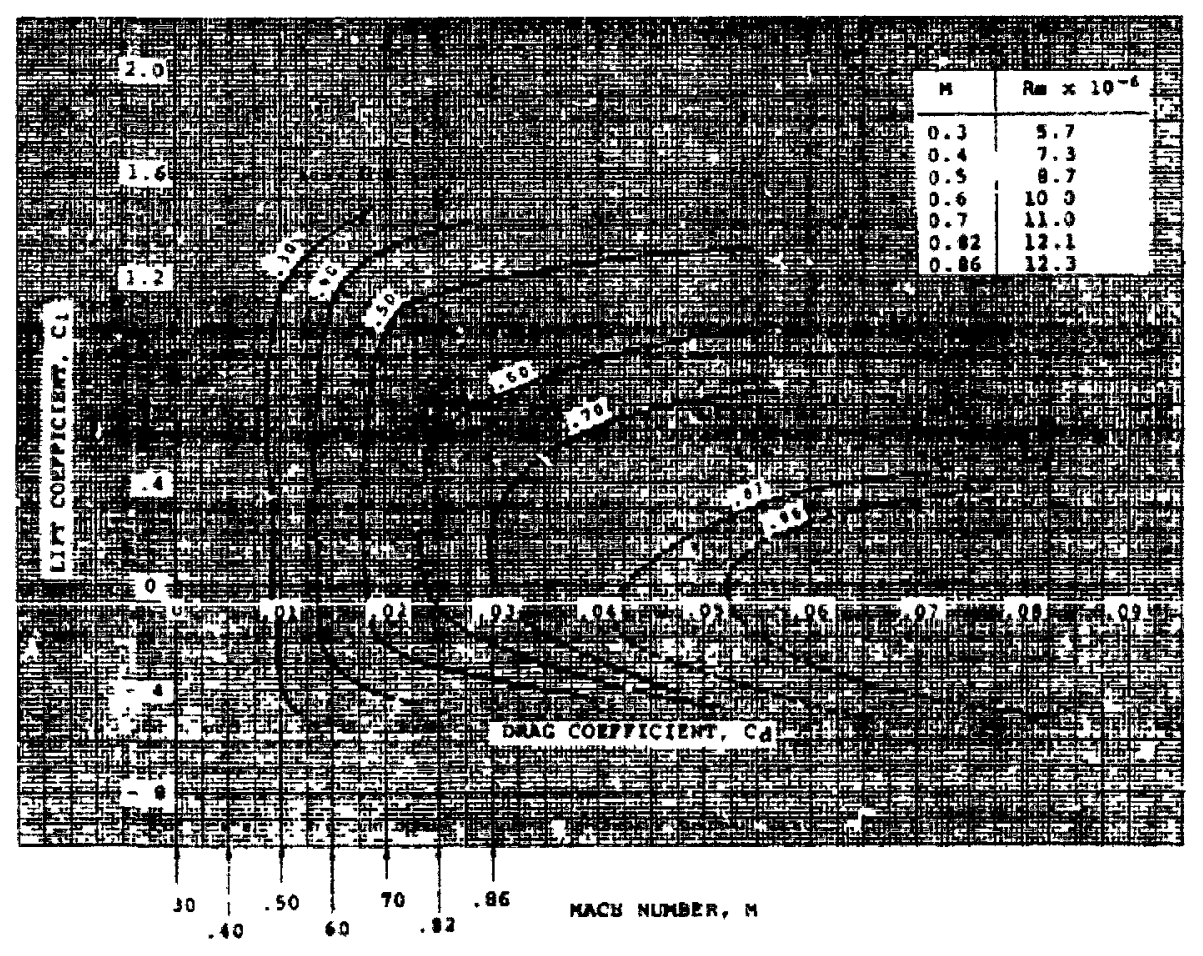

Figure 4.3 - V23010-1.58 airfoil drag curves as shown in [21]. 


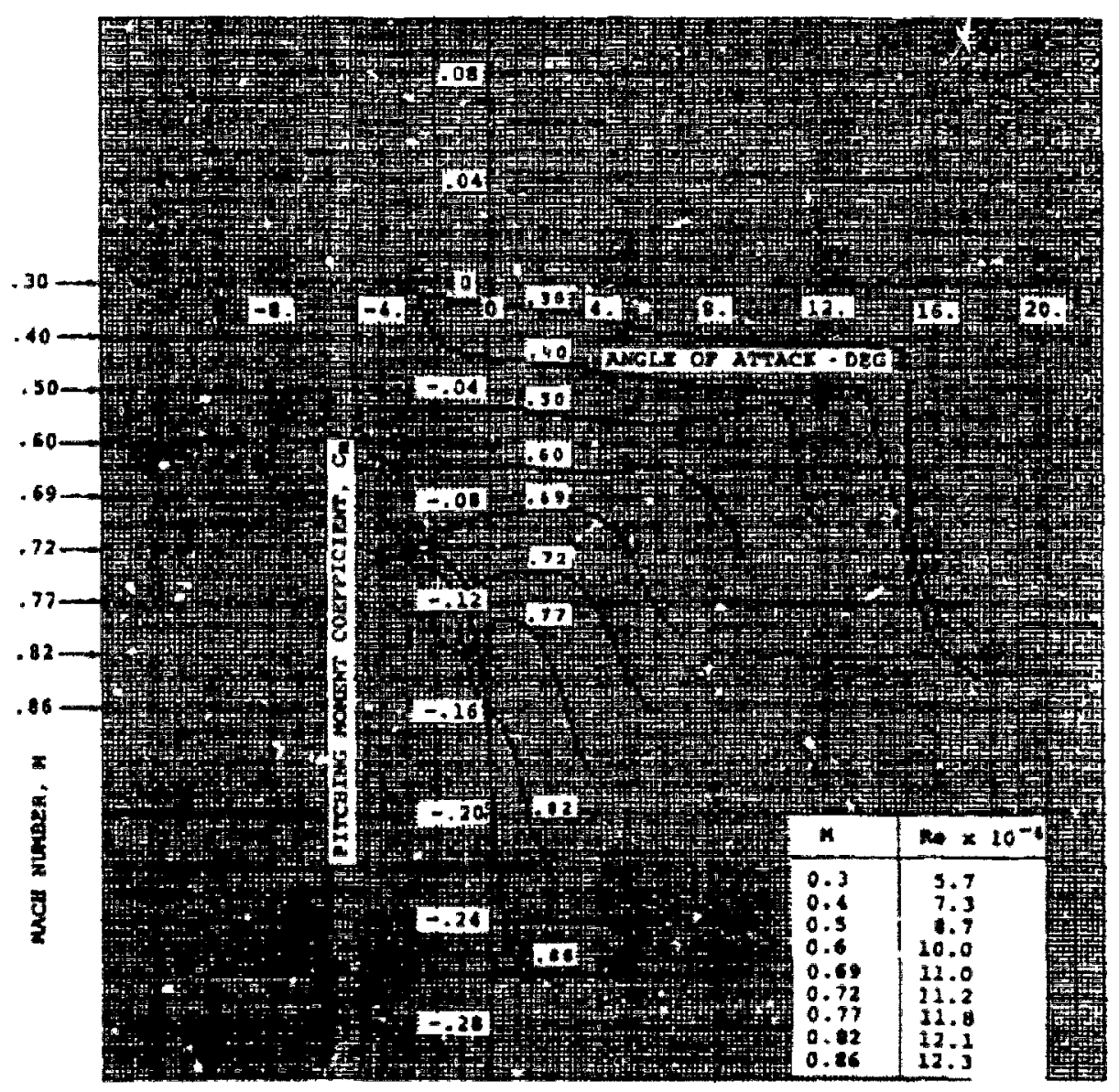

Figure 4.4 - V23010-1.58 airfoil pitching moment curves as shown in [21].

The construction of the lift, drag, and moment coefficients are recorded on the file 23573.cld (Appendix A.7). The .cld file requires the lift, drag, and moment coefficients for a sweep of increasing angle of attack form $-20^{\circ}$ to $20^{\circ}$, for Mach of $0.0,0.2,0.4,0.5,0.6,0.7,0.75$, $0.8,0.85,0.9$ and 1.0. For velocities from 0.0 to 0.85 the lift, drag and moment curves were interpolated between known curves. For values of lift in the stall regime, the lift coefficients were set to zero, to reflect zero lift being generated at that high angle of attack. For Mach greater than 0.85 the lift, drag, and moment curves were extrapolated proportionally following similar proportions of curves presented in Abbott and Von Doenhoff's Theory of Wing Sections [22]. However, Harris' experiment noted that the actual slope of airfoil is $5.73 / \mathrm{rad}$. Since the lift 
curve of the model at Mach $0.0\left(C_{L_{\alpha}}=7.03 / \mathrm{rad}\right)$ is greater than the Harris model rotor $\left(C_{L_{\alpha}}=\right.$ $5.73 / \mathrm{rad}$ ), the lift curves for the .cld input file is reduced by a factor of 0.81 to reflect the airfoil in the Harris experiment. A selection of lift, drag and moment curves is illustrated in Figures 4.5 to 4.7 :

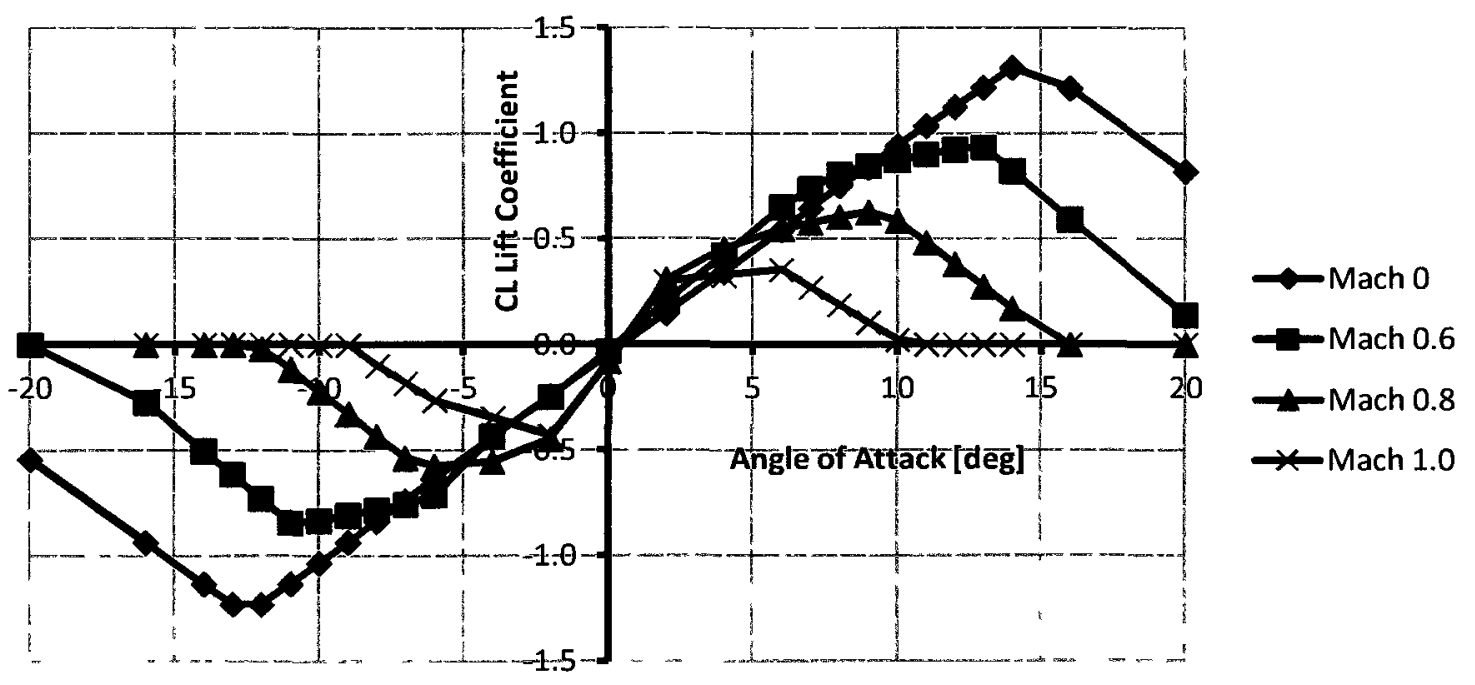

Figure 4.5 - V23010-1.58 airfoil lift curves as set up in SMARTROTOR.

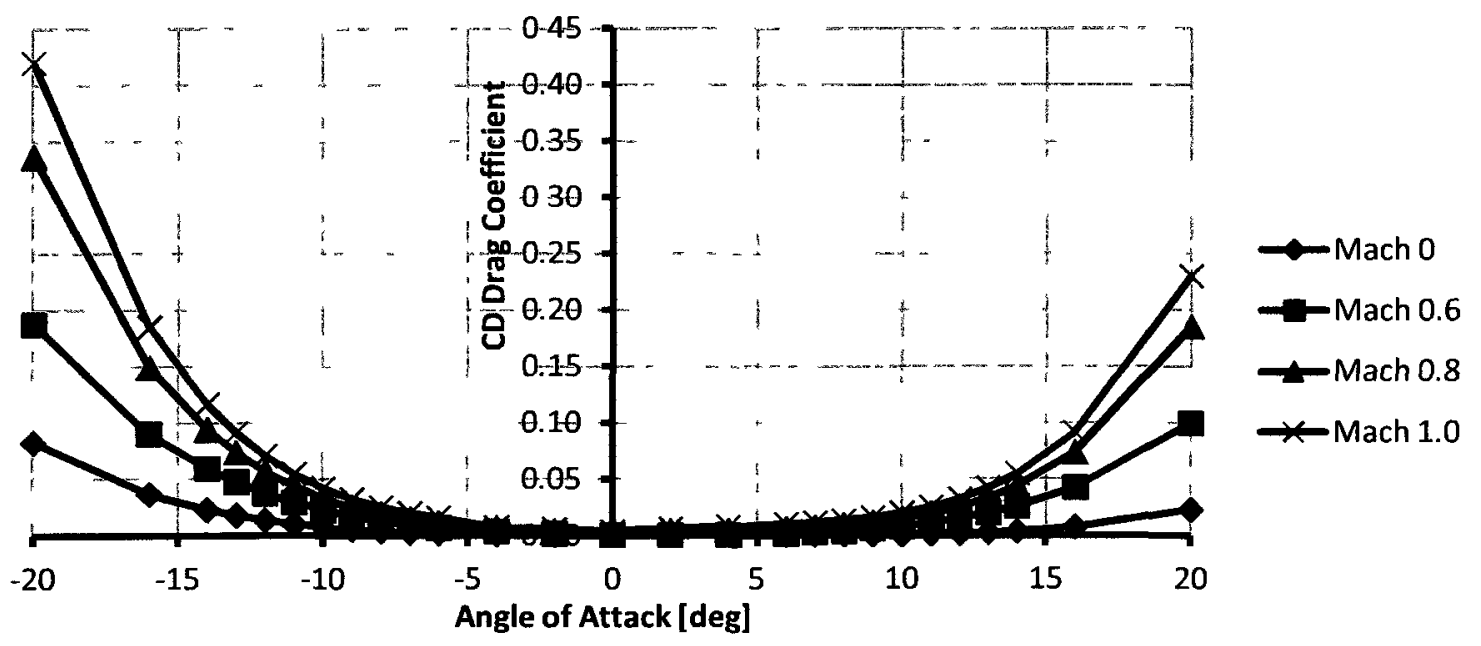

Figure 4.6 - V23010-1.58 airfoil drag curves as set up in SMARTRO'TOR. 


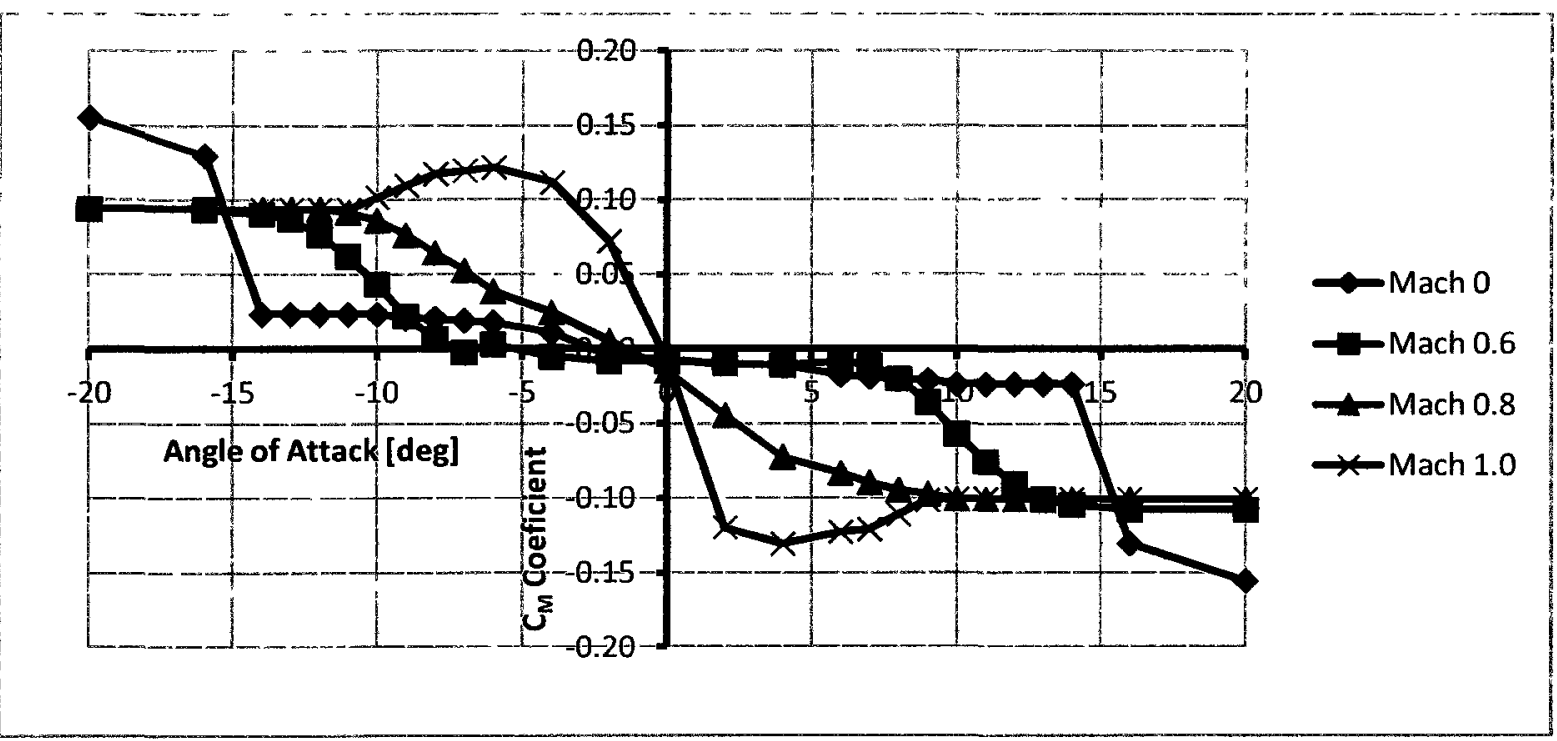

Figure 4.7 - V23010-1.58 airfoil pitching moment curves as set up in SMARTROTOR.

\subsection{Harris Simulation: Influence of Collective Pitch}

The first simulation presented is the Influence of Collective Pitch. This experiment established blade motion trends on the influence increasing collective pitch. This experiment illustrates a good comparison of the simulation to the Harris experiment. This experiment was conducted with a tip speed of $137 \mathrm{~m} / \mathrm{s}(450 \mathrm{ft} / \mathrm{s})$, with a constant shaft tilt angle of $-1.35^{\circ}$, at a constant advance ratio of 0.08 , no lateral cyclic $\left(A_{I C}=0^{\circ}\right)$, and $-0.73^{\circ}$ longitudinal cyclic $\left(B_{I C}=-\right.$ $0.73^{\circ}$ ). The results from the Harris experiment are shown in Table 4.2.

Table 4.2 - Harris collective pitch experiment results.

\begin{tabular}{|c|c|c|c|c|c|c|c|}
\hline $\begin{array}{c}\text { Coll. Pitch at } \\
\text { 75\% Radius } \\
\text { Station } \boldsymbol{\theta}_{\boldsymbol{0} .75}[\mathrm{deg}]\end{array}$ & $\begin{array}{c}\text { Root Pitch } \\
\boldsymbol{\theta}_{\boldsymbol{0}} \text { [deg] }\end{array}$ & $\begin{array}{c}\text { Advance } \\
\text { Ratio } \boldsymbol{\mu}\end{array}$ & $\begin{array}{c}\text { Thrust Coef./ } \\
\text { Solidity } \boldsymbol{C}_{\boldsymbol{T}} \boldsymbol{\sigma} \boldsymbol{\sigma}\end{array}$ & $\begin{array}{c}\text { Mean } \\
\text { Flap } \\
\text { Angle } \\
\boldsymbol{\beta}_{0} \text { [deg] }\end{array}$ & $\begin{array}{c}\text { Lateral } \\
\text { Flapping } \boldsymbol{a}_{\boldsymbol{1}} \\
\text { [deg] }\end{array}$ & $\begin{array}{c}\text { Longitudinal } \\
\text { Flapping } \\
\boldsymbol{b}_{\boldsymbol{1}} \text { [deg] }\end{array}$ & $\begin{array}{c}\text { Tip Path } \\
\text { Plane } \boldsymbol{\alpha}_{\boldsymbol{T} P} \\
\text { [deg] }\end{array}$ \\
\hline 2.20 & 8.51 & 0.0801 & 0.0005 & 0.838 & 0.974 & 0.563 & -0.356 \\
\hline 4.33 & 10.64 & 0.0799 & 0.0201 & 1.45 & 1.407 & 1.419 & 0.077 \\
\hline 6.61 & 12.92 & 0.0800 & 0.0399 & 2.08 & 1.861 & 2.242 & 0.528 \\
\hline 8.83 & 15.14 & 0.0806 & 0.0602 & 2.71 & 2.229 & 2.960 & 0.775 \\
\hline 11.04 & 17.35 & 0.0801 & 0.0815 & 3.41 & 2.662 & 3.548 & 1.284 \\
\hline 13.05 & 19.36 & 0.0797 & 0.1002 & 4.1 & 2.927 & 4.080 & 1.533 \\
\hline
\end{tabular}


The collective pitch angles listed in the Harris experiment were measured at the $75 \%$ radius station $\left(\boldsymbol{\theta}_{0.75}\right)$ of the rotor blades. The blade twists downward from root to tip by $-9.14^{\circ}$. So the pitch adjustment at the blade root is $6.31^{\circ}$. The collective root pitch angles for each Harris run are therefore also listed in Table 4.2 . The tip speed is $137.16 \mathrm{~m} / \mathrm{s}$. For a radius of $0.8321 \mathrm{~m}$, the rotational speed $\Omega$ is found $164.8 \mathrm{rad} / \mathrm{s}$.

The advance ratio equation is:

$$
\mu=\frac{V \cos \left(\alpha_{T P P}\right)}{\Omega R}
$$

from which the oncoming freestream velocity $V$ can be solved as $10.97 \mathrm{~m} / \mathrm{s}$ for all runs.

The blade flapping angle equation for a complete rotor cycle is:

$$
\beta=\beta_{0}-a_{1} \cos \psi-b_{1} \sin \psi
$$

For example, the run at collective pitch setting $\theta_{75}=8.83^{\circ}$, the flapping motion was defined by the mean flap angle of $\beta_{0}=2.71^{\circ}$, lateral flapping angle of $a_{1}=2.229^{\circ}$, and longitudinal flapping angle of $b_{1}=2.960^{\circ}$, as depicted in Figure 4.8 .

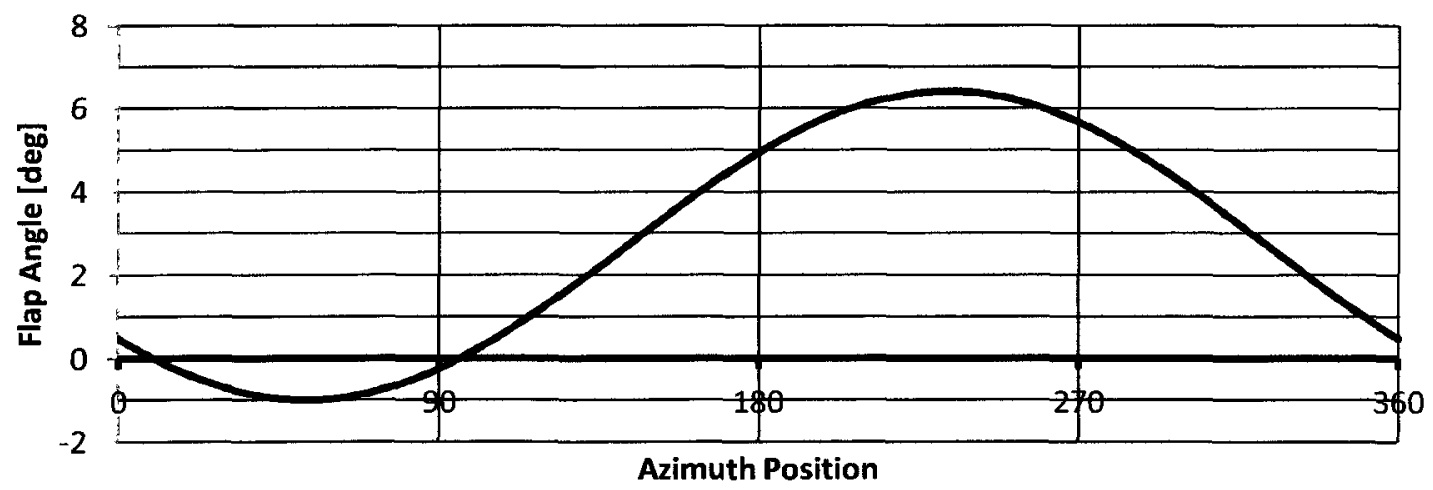

Figure 4.8 - Flap Angle Vs. Azimuth Position - Collective Pitch $\theta_{75}=\mathbf{8 . 8 3}^{\circ}$.

The rotor blades rotate counter-clockwise (looking down). The azimuth position references are illustrated in Figure 4.9, where $0^{\circ}$ starts at the aft radial, $90^{\circ}$ at the advance (right-hand side) 
radial, $180^{\circ}$ at the front radial, and $270^{\circ}$ at the retreating (left-hand side) radial, as illustrated in Figure 4.9 .

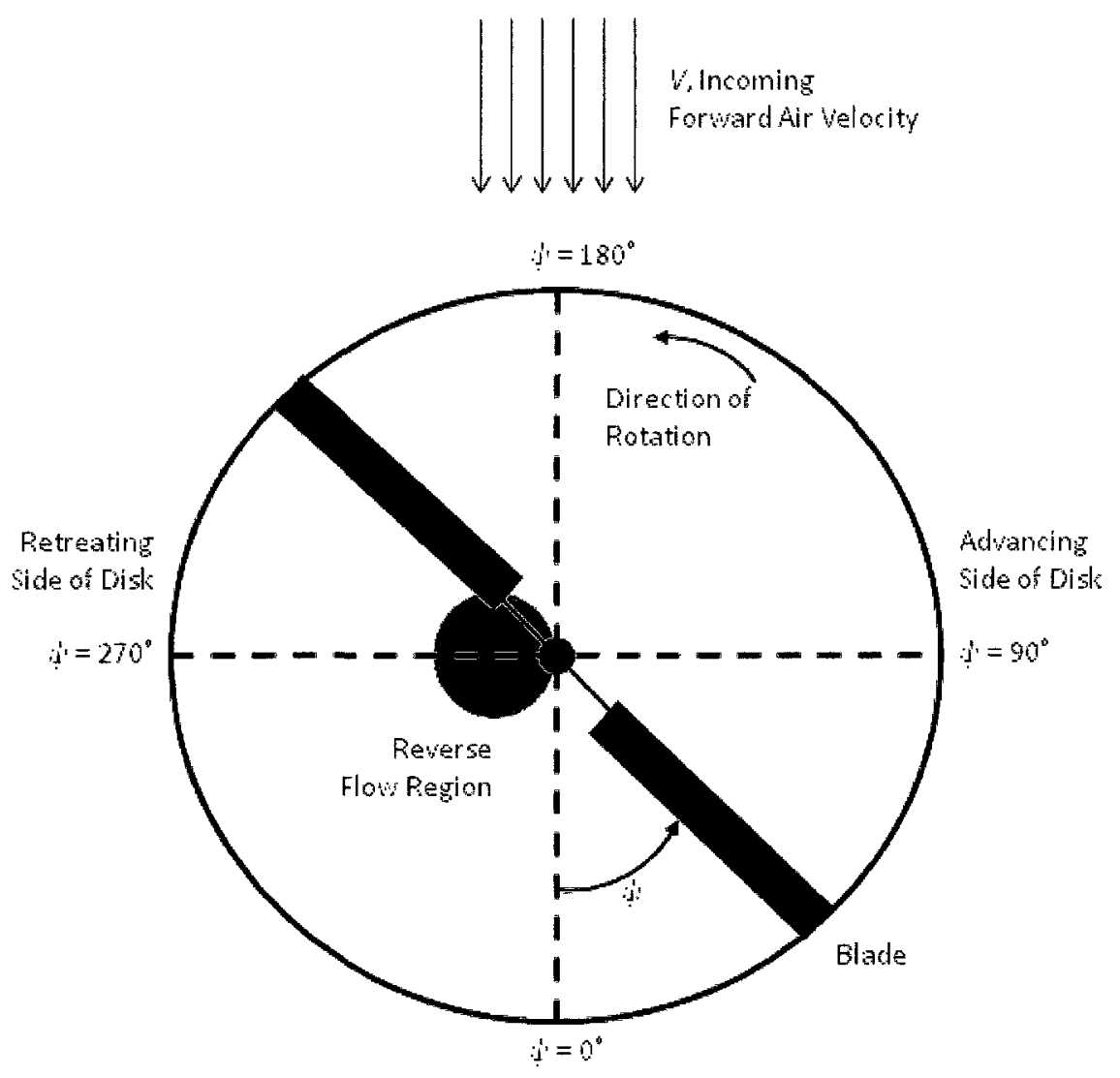

Figure 4.9 - Helicopter azimuth reference positions.

The input files CH47C.bld, CH47C.geo, CH47CHL.dat and inputc.dat are defined and can be found in the Appendix A. File $\mathrm{CH} 47 \mathrm{C}$.bld defines the geometry of the rotor blade, as described in Table 4.1. File CH47C.geo defines the rotor blades rotation and orientation, such as the collective and cyclic input. File CH47CHL.dat defines the aerodynamic environment such as the freestream and wake generation properties. Finally, file inputc.dat defines the rotor blade structural characteristics specific to the rigid blade model subroutines. 
Six simulations were conducted with the SMARTROTOR code, matching the input as described in the Harris experiment. The simulations consisted of the following constant parameters:

Table 4.3 - Harris simulation parameters.

\begin{tabular}{|l|l|}
\hline Blade Model & CH47C, see Table 4.1 for geometry details \\
\hline Number of Blades & 4 \\
\hline Aerodynamic Nodes & $\begin{array}{l}17 \times 9 \text { (spanwise } x \text { chordwise) nodes } \\
\text { Total }=153 \text { nodes per blade }\end{array}$ \\
\hline Number of Time Steps & $525(8.75 \mathrm{revolutions})$ \\
\hline Rotational Speed & $164.8 \mathrm{rad} / \mathrm{s}(26.2 \mathrm{~Hz})$ \\
\hline Time Step & $0.602 \times 10^{-3} \mathrm{~s}\left(6^{\circ}\right.$ per Step) \\
\hline Forward to Aft Air Velocity & $10.97 \mathrm{~m} / \mathrm{s}($ Advance Ratio 0.0800$)$ \\
\hline Sideways Velocity & $0 \mathrm{~m} / \mathrm{s}$ \\
\hline Vertical Velocity & $0 \mathrm{~m} / \mathrm{s}$ \\
\hline Number of Steps to Turn Wake ON & 150 \\
\hline Number of Steps to Reach Full Air Density & 250 \\
\hline Shaft Tilt Angle & $-1.35^{\circ}(\mathrm{Tilted} \mathrm{Forward)}$ \\
\hline Pitch Collective $\theta_{75}$ (at $75 \%$ Radius) & $2.2^{\circ}, 4.33^{\circ}, 6.61^{\circ}, 8.83^{\circ}, 11.04^{\circ}, 13.05^{\circ}$ \\
\hline Pitch Collective $\theta_{0}$ (Root Pitch) & $8.51^{\circ}, 10.64^{\circ}, 12.92^{\circ}, 15.14^{\circ}, 17.35^{\circ}, 19.36^{\circ}$ \\
\hline Pitch Lateral Cyclic Angle $\left(A_{I C}\right)$ & $0^{\circ}$ \\
\hline Pitch Longitudinal Cyclic Angle $\left(B_{I C}\right)$ & $-0.73^{\circ}(\mathrm{Aft})$ \\
\hline Air Density & $1.255 \mathrm{~kg} / \mathrm{m}^{3}$ \\
\hline Kinematic Viscosity & $1.56 \times 10^{-5} \mathrm{~m}^{2} / \mathrm{s}$ \\
\hline Speed of Sound & $338.6 \mathrm{~m} / \mathrm{s}$ \\
\hline Hinged Blade & Turned ON \\
\hline Structural Deformation & Turned OFF \\
\hline & \\
\hline
\end{tabular}

It takes approximately 12 hours to a complete the simulation of 525 time steps on dualcore $3.2 \mathrm{GHz} \mathrm{CPU}$. Computational resources are required for wake generation, such that the wake shedding off the blade will disrupt the flow in the disk plane, and reduce the lift accordingly. A 3D visualization of the aerodynamic nodes during the final $36^{\circ}$ sweep of the 4 blades is illustrated in Figure 4.10. 


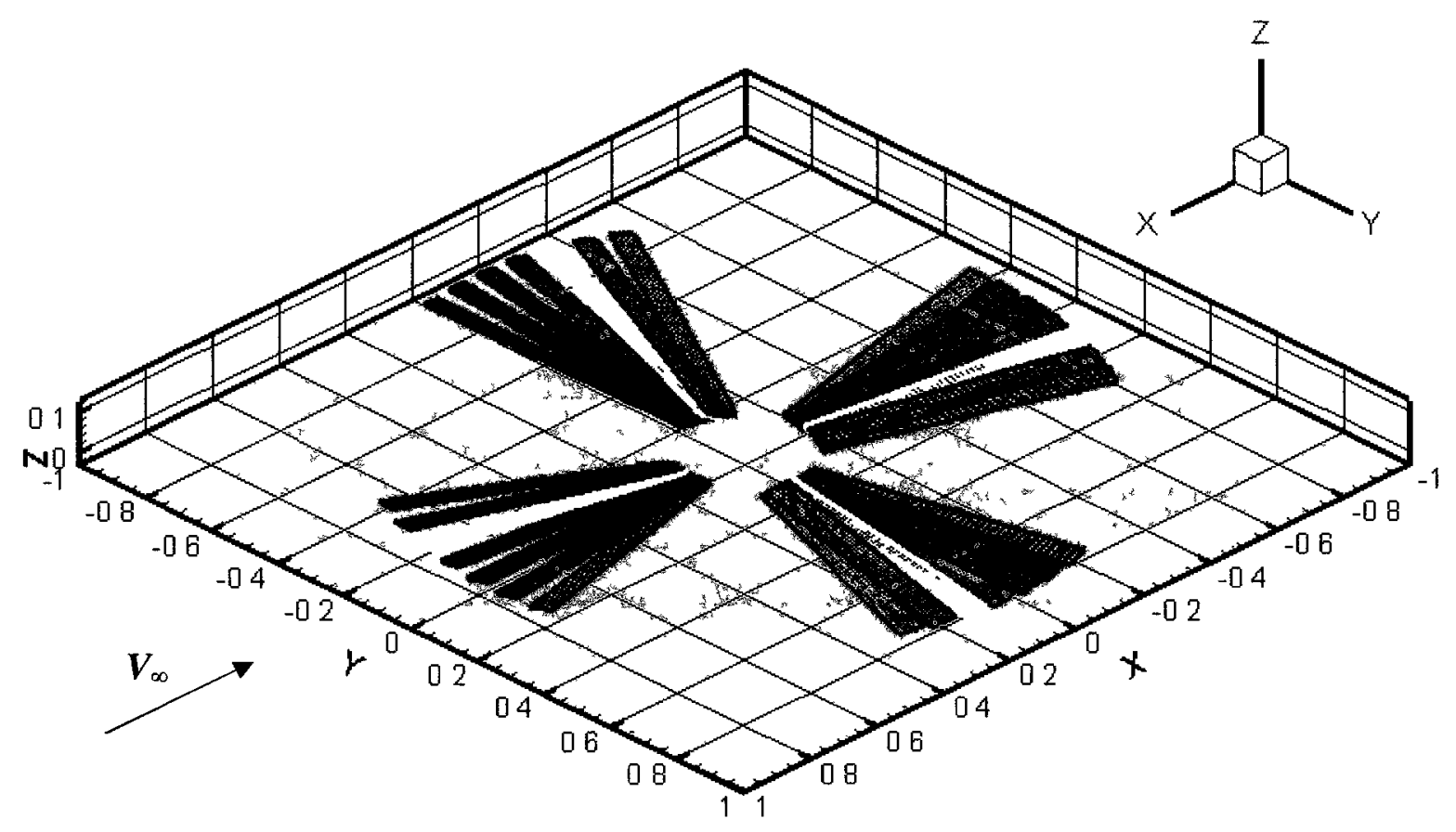

Figure 4.10 - 3D Visualization of rotor path ( 4 blades, pitch $13.05^{\circ}$, last $36^{\circ}$ sweep)

Each simulation completes 9 rotations as it runs for 525 time steps. The vertical path of the first blade is illustrated in Figure 4.11. Initially, as the blades start rotating, the air density is zero and the wake shedding is turned off. Over time the air density gradually increases, so that it allows the blades to gradually increase the lift and drag. At time step 150 the wake shedding model is turned on. This causes disruptions and reductions of the incoming velocity across the blade, and reduces the lift across the blades. At time step 250 the air reaches full density, and the simulation reaches stability over the next 4 cycles.

As illustrated in Figure 4.11 , on the retreating side of the rotor disk at azimuth $240^{\circ}$, the maximum height of the blade tip is reached at $0.104 \mathrm{~m}$, at a flap angle of $8.3^{\circ}$. On the advancing side of rotor disk at azimuth $50^{\circ}$ the minimum height of the blade tip is reached at $-0.003 \mathrm{~m}$, at a flap angle of $-1.1^{\circ}$. Should the simulation continue it is expected that the rotor blade tip will maintain this flapping profile. 


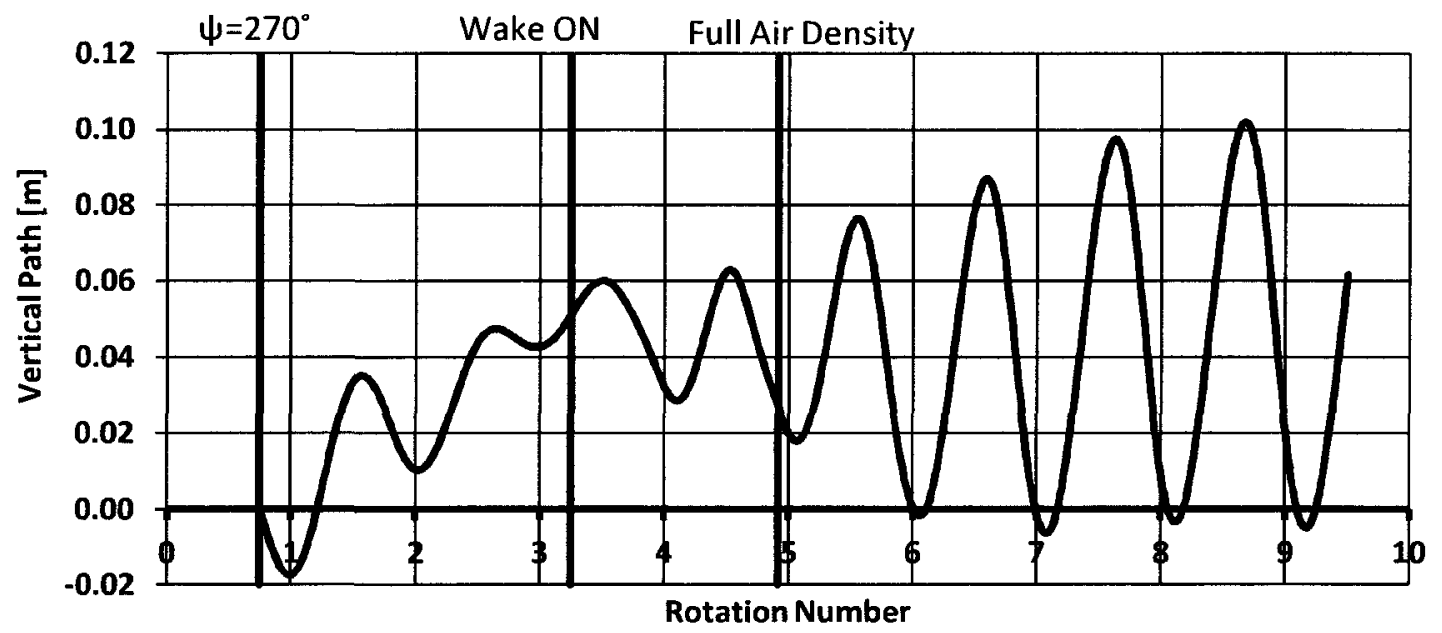

Figure 4.11 - Vertical tip path of blade $1\left(\right.$ pitch $\left.\theta_{75}=13.05^{\circ}\right)$.

Since lift is the dominant force acting on the blade, the blades' flapping motion settles and peak once per cycle as illustrated in Figure 4.12. Note that in several more cycles the blade flapping motion would repeat at constant amplitude. However, due to the computational restrictions imposed by the wake model, generating 9 cycles is sufficient for these simulations. The restriction is due to the calculation and generation of the wake aft of the rotor, the simulations slow down significantly where it becomes impractical to model beyond 10 cycles.

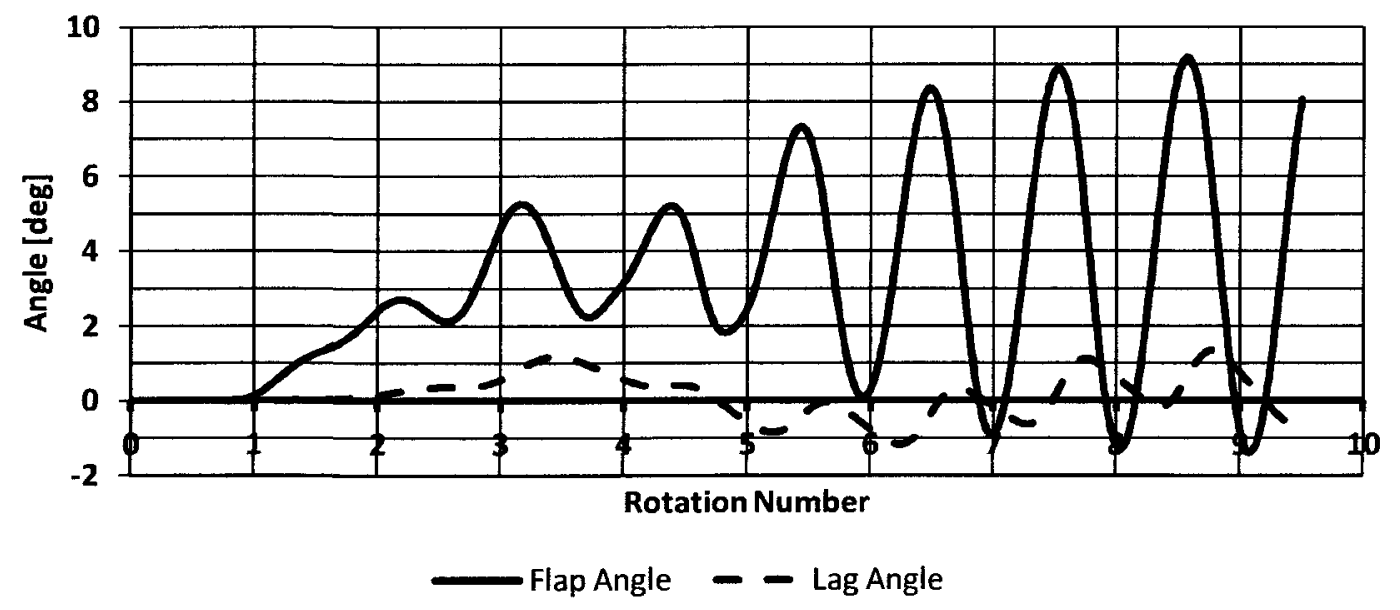

Figure 4.12 - Flap and lead-lag angles of blade $1\left(\right.$ pitch $\theta_{75}=13.05^{\circ}$ ). 
As for the lead-lag motions, the centrifugal restoring moment about the lag hinge is smaller than for flapping, and is found that the uncoupled natural frequency of lag motion is much smaller. For articulated rotors the lag frequency varies typically from 0.2 to $0.3 \Omega$. Figure 4.13 illustrates the expected lagging frequency as a function of the radius of the hinge offset. The Harris test does not state any recorded lag frequency, but from Figure 4.13 it can be expected that the lag frequency $v_{\zeta}$ would be around 0.18 . From Figure 4.12 it shows that the lag period occurs every 5 cycles, so its lag frequency is around $0.2 \Omega$, which is expected from Leishman [1].

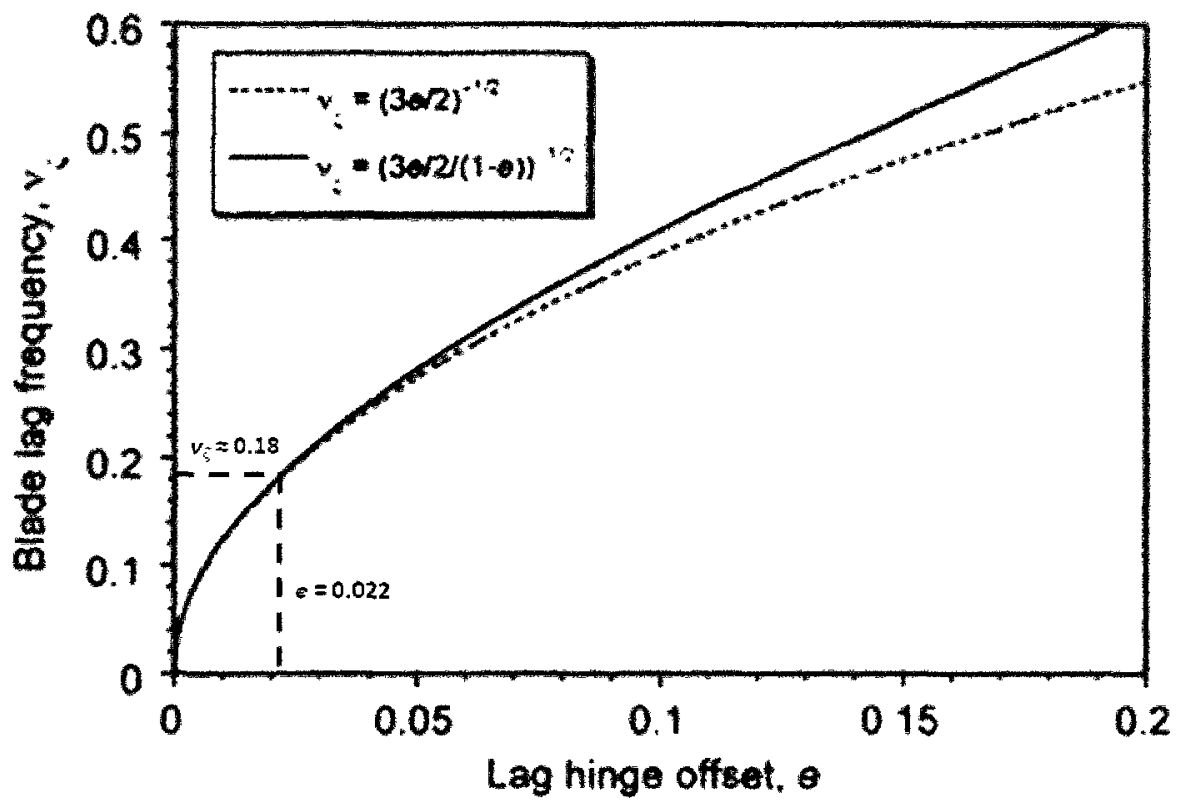

Figure 4.13 - The blade lagging frequency varies with the hinge offset [1].

The lift histories of the 4 rotor blades are illustrated in Figure 4.14, for the pitch $\theta_{75}=$ $13.05^{\circ}$ case. It shows the relative stability of the amount of the constant lift that is produced by the 4 blades, after the simulation has reached equilibrium. The thrust coefficient is calculated from the average sum of the lift in the last recorded rotation, where:

$$
C_{T}=\frac{T}{\rho \pi \Omega R^{4}}
$$




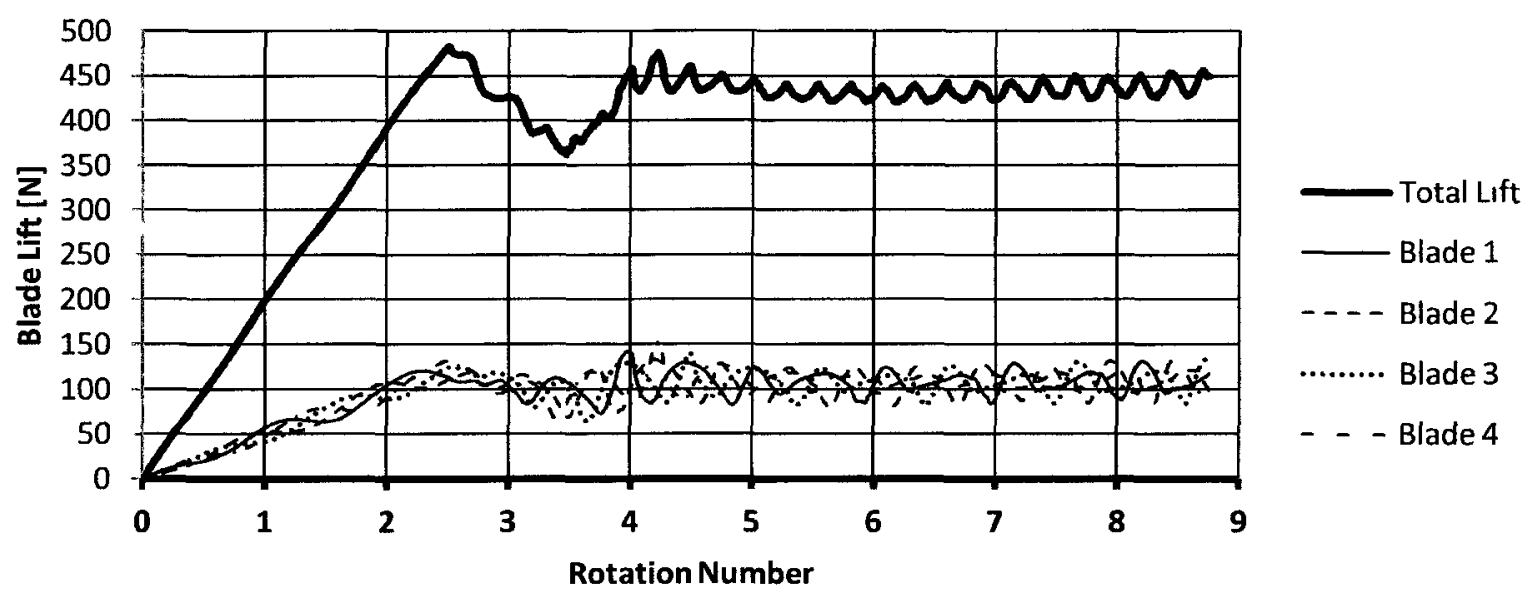

Figure 4.14 - Blade lift histories (pitch $\theta_{75}=13.05^{\circ}$ )

Interestingly, an observation can be made, concerning the use of referring to the pitch angle at the $75 \%$ radial position. An interesting result was found in a thrust coefficient equation:

$$
C_{T}=\frac{1}{2} \sigma C_{l_{\alpha}}\left[\frac{\theta_{0}}{3}+\frac{\theta_{t w}}{4}-\frac{\lambda}{2}\right]
$$

Then, if the $75 \%$ radial position blade pitch angle, $\theta_{75}$ was used instead of the root pitch angle, where:

$$
C_{T}=\frac{1}{2} \sigma C_{l_{\alpha}}\left[\frac{\theta_{75}}{3}-\frac{\lambda}{2}\right]
$$

It was noticed that the blade with a linear twist has the same thrust coefficient as the blade with constant pitch, when the blade with constant pitch has its root pitch $\theta_{0}$ set to the $\theta_{75}$ pitch of the twisted blade [1] [23]. This observation was tested by running a separate simulation with a constant pitch blade, with the root pitch $\theta_{0}$ set to $13.05^{\circ}$. As compared to the twisted blade with a pitch $\theta_{75}=13.05^{\circ}$ simulation, both simulations produced nearly the same thrust coefficients of $C_{7} / \sigma=0.96$, and both simulations produce nearly the same flap path as illustrated in Figure 4.15. 


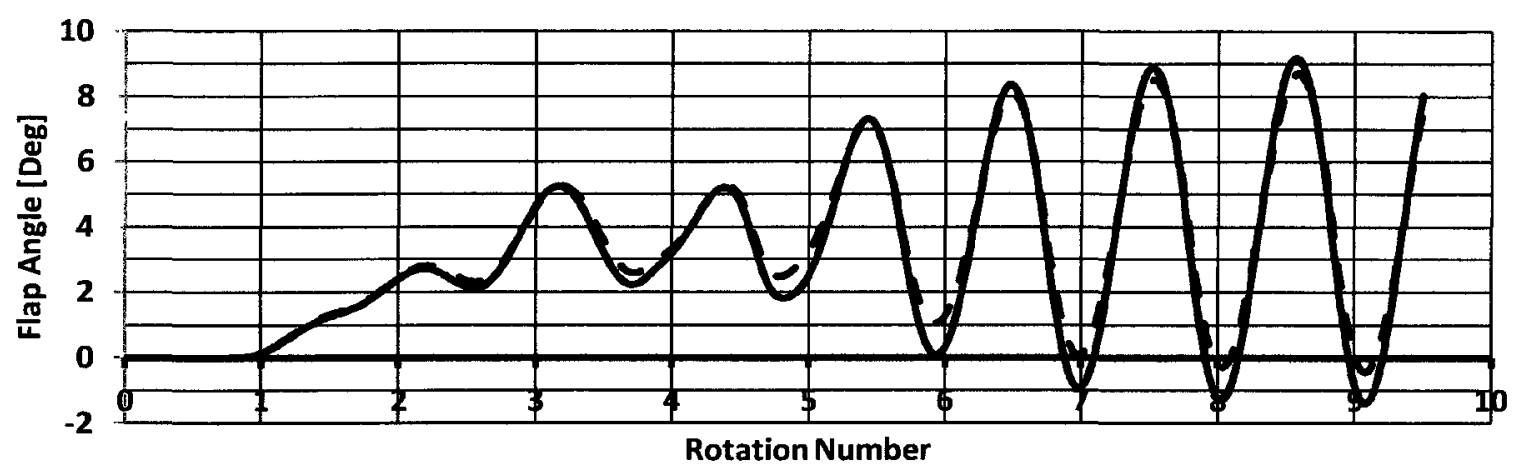

Twisted Blade, Pitch 75\% = 13.05 $\quad-$ Constant Pitch Blade, Root Pitch $=13.05^{\circ}$

Figure 4.15 - Flap angle comparison between twisted and untwisted blades.

The results for the other simulations for the Influence of Collective Pitch test were completed and were compared with the results of the Harris' experiment. Their thrust coefficients and flap amplitudes are calculated from the last cycle from each run and are presented in Table 4.4:

Table 4.4 - SMARTROTOR results for CH47C rotor blade model.

\begin{tabular}{|r|r|r|r|r|r|r|r|}
\hline $\begin{array}{c}\text { Pitch } \theta_{75} \\
{[\mathrm{Deg}]}\end{array}$ & $\begin{array}{c}\text { Total } \\
\text { Thrust } \\
{[\mathrm{N}]}\end{array}$ & $\begin{array}{c}\text { Thrust } \\
\text { Coefficient/ } \\
\text { Solidity } \boldsymbol{C}_{\boldsymbol{T}} / \boldsymbol{\sigma}\end{array}$ & $\begin{array}{c}\text { Min Flap } \\
{[\mathrm{Deg}]}\end{array}$ & $\begin{array}{c}\text { Max Flap } \\
{[\mathrm{Deg}]}\end{array}$ & $\begin{array}{c}\text { SMARTROTOR } \\
\text { Flap Amplitude } \\
{[\mathrm{Deg}]}\end{array}$ & $\begin{array}{c}\text { Harris Flap } \\
\text { Amplitude } \\
{[\mathrm{Deg}]}\end{array}$ & $\begin{array}{c}\text { Amplitude } \\
\text { Error [\%] }\end{array}$ \\
\hline 2.2 & 17.6 & 0.0038 & -1.81 & 1.89 & 1.85 & 0.97 & 89.76 \\
\hline 4.33 & 76.7 & 0.0167 & -1.72 & 2.87 & 2.29 & 2.00 & 14.82 \\
\hline 6.61 & 158.1 & 0.0345 & -1.59 & 4.31 & 2.95 & 2.87 & 2.90 \\
\hline 8.83 & 244.7 & 0.0534 & -1.45 & 5.80 & 3.62 & 3.56 & 1.75 \\
\hline 11.04 & 341.7 & 0.0746 & -1.48 & 7.48 & 4.48 & 4.26 & 5.19 \\
\hline 13.05 & 438.6 & 0.0958 & -1.28 & 9.18 & 5.23 & 4.76 & 9.94 \\
\hline
\end{tabular}

These results are plotted against the Harris data in Figures 4.16 and 4.17. Compared to Harris' experiment these simulations are comparable. When comparing the data of increasing root pitch to thrust coefficient as shown in Figure 4.16, it shows that the SMARTROTOR simulations correlate very well with the Harris experiment. The Harris' data has a slope of 0.0089 per degree and the SMARTROTOR provide a similar slope of 0.0085 per degree. 


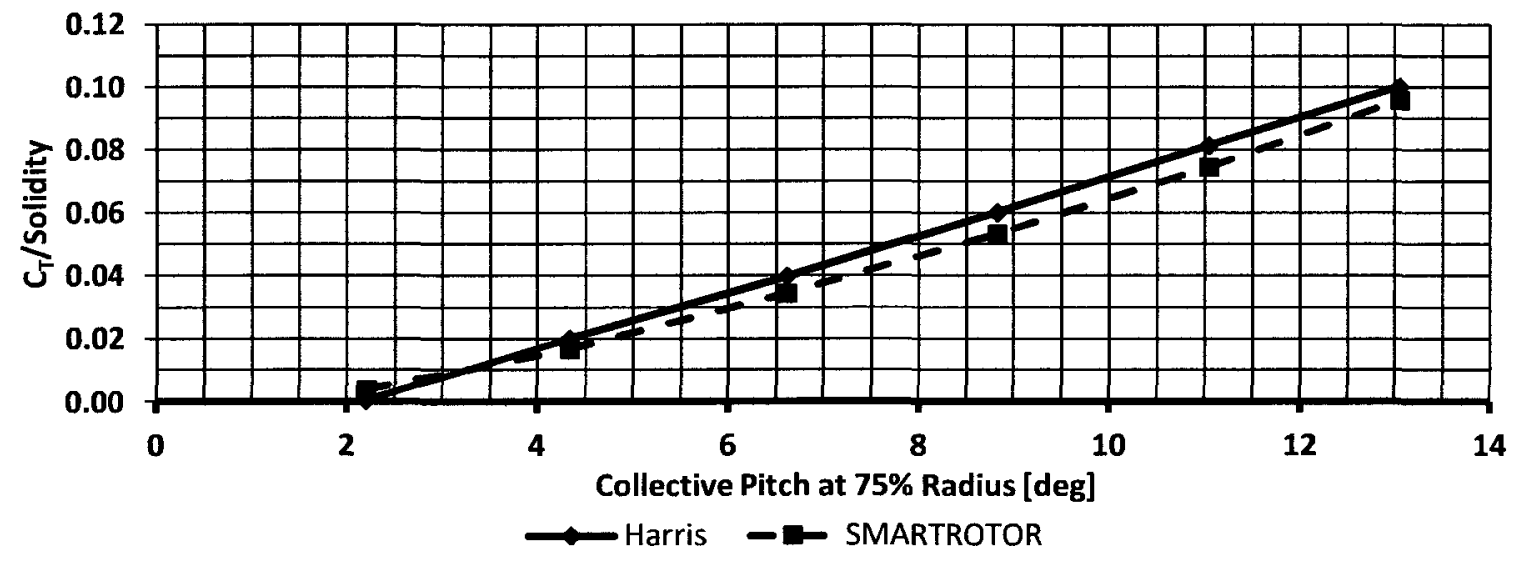

Figure 4.16 - Influence of Collective Pitch - pitch vs. $C_{\boldsymbol{T}} / \sigma$.

Looking at the flapping motion, SMARTROTOR correlates well with the Harris experiment, as shown in Figure 4.17. SMARTROTOR amplitude increases at the same rate as the Harris experiment. SMARTROTOR over predicts the flap amplitude at most by $28 \%$ at the lower collective pitch setting $2.2^{\circ}$. However, at the higher pitch settings the results show that the rigid model can predict the approximate flapping amplitude.

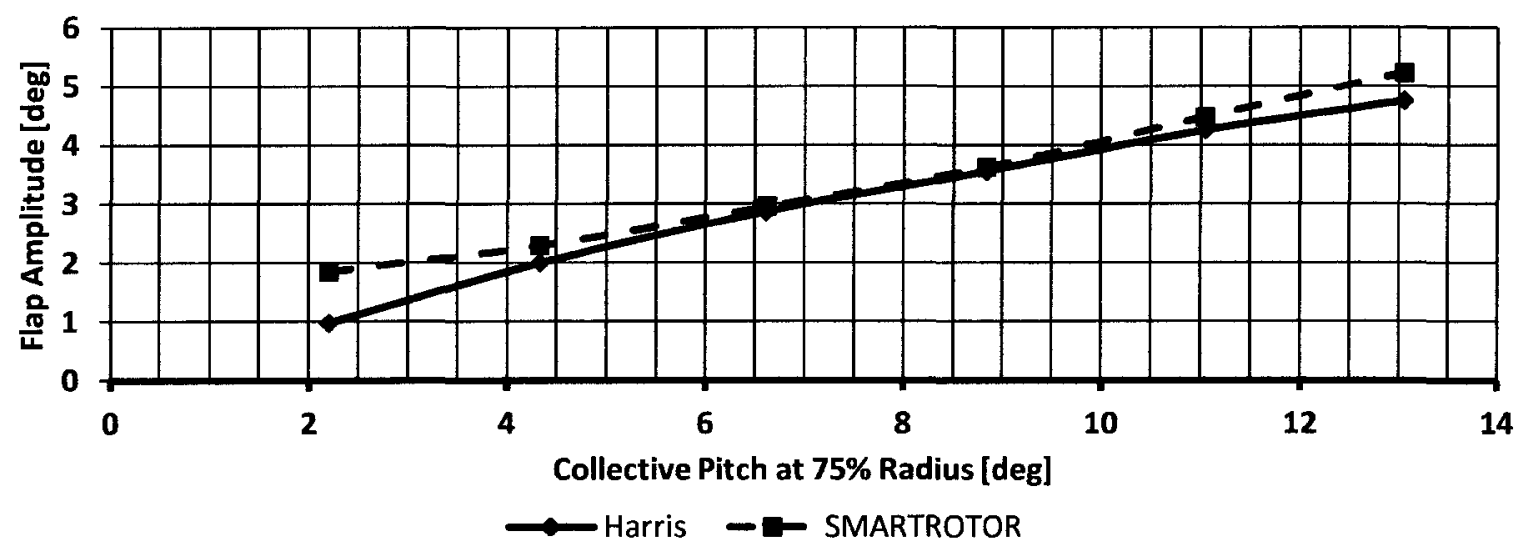

Figure 4.17 - Influence of Collective Pitch - pitch vs. flap amplitude.

The path of the blade correlates well with the Harris test. The comparison of the SMARTROTOR simulations and Harris results of the run at collective pitch $\theta_{75}=13.05^{\circ}$, is 
illustrated in Figure 4.18. The Harris curve is generated from the blade flapping motion equation

\section{Flap Angle}

(Blade 1, Pitch $\theta_{75}=13.05^{\circ}$ )

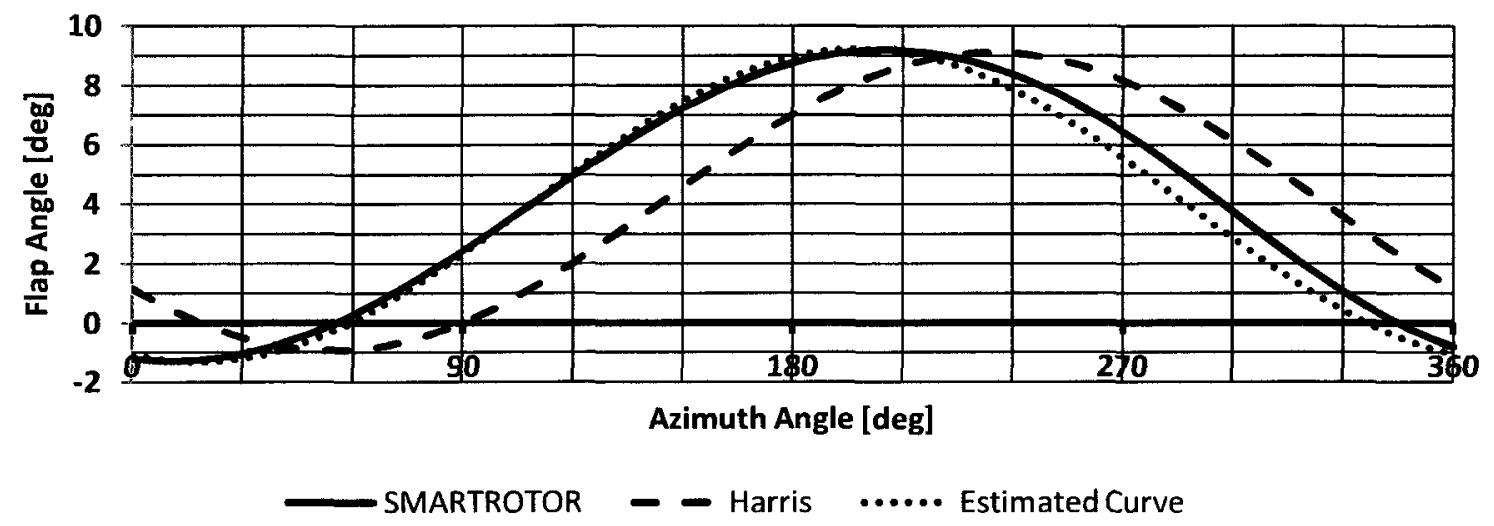

Figure 4.18 - Comparison of Harris \& SMARTROTOR flap angles.

It is shown in Figure 4.18 the flap motion correlates well, where both the simulation and the test results show that the blade peaks at around $9^{\circ}$ and troughs at $-1^{\circ}$. The SMARTROTOR simulation is present as the flap angles through its $9^{\text {th }}$ cycle. It is noticed that the SMARTROTOR path is about $30^{\circ}$ out of phase with the Harris Test. Figure 4.19 illustrates the difference between the simulation and Harris azimuth positions where the flap angle peaked. Through subsequent rotations the peak angle approaches to become more in-phase with the Harris test azimuth position at $204^{\circ}$. With subsequent rotations the flap path should match the Harris test much closer. 


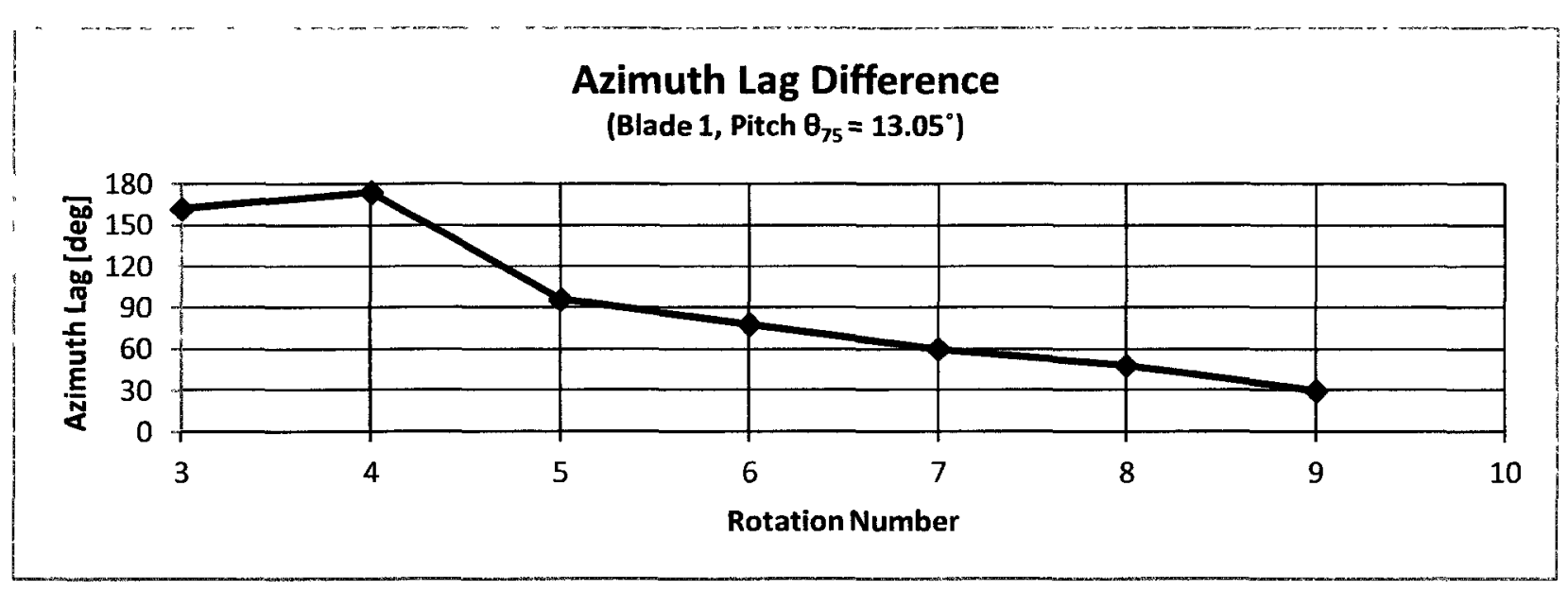

Figure 4.19 - Out-of-phase azimuth lag between simulation \& Harris test.

The dotted line in Figure 4.18, illustrates the estimated flap path using the blade flap path equation. The lateral and longitudinal angles of the flap curve are found from these equations:

the flapping angle $\beta_{0}=\left(\beta_{M A X}+\beta_{M I N}\right) / 2$

the lateral angle $a_{1}=\frac{\left(\beta_{M I N}-\beta_{0}\right) \sin \Psi_{M A X}+\left(\beta_{0}-\beta_{M A X}\right) \sin \Psi_{M A X}}{\sin \left(\Psi_{M I N}-\Psi_{M A X}\right)}$

the lateral angle $b_{1}=\frac{\beta_{0}-\beta_{M A X}-a_{1} \cos \Psi_{M A X}}{\sin \left(\Psi_{M A X}\right)}$

where $\beta_{M I N}$ and $\beta_{M A X}$ are the minimum and maximum flapping angles, and $\Psi_{M I N}$ and $\Psi_{M A X}$ are their associated azimuth positions. For the SMARTROTOR simulation at $13.05^{\circ}$ collective pitch, the mean flaping angle $\beta_{O}$ is $3.95^{\circ}$, the lateral flapping angle $a_{l}$ is $5.00^{\circ}$, and the longitudinal flaping angle $b_{1}$ is $1.62^{\circ}$. The lateral and longitudinal pitch estimates for each SMARTROTOR simulation is listed in Table 4.5. 
Table 4.5 - Influence of Collective Pitch - SMARTROTOR results flap angle coefficients.

\begin{tabular}{|r|r|r|r|r|r|r|}
\hline & \multicolumn{3}{|c|}{ Harris Flap Angle Coefficients } & \multicolumn{2}{c|}{ SMARTROTOR Flap Angle Coefficients } \\
\hline $\begin{array}{c}\text { Pitch } \boldsymbol{\theta}_{75} \\
{[\mathrm{Deg}]}\end{array}$ & $\begin{array}{c}\text { Mean Flap } \\
\text { Angle } \boldsymbol{\beta}_{\boldsymbol{0}} \\
{[\mathrm{Deg}]}\end{array}$ & $\begin{array}{c}\text { Lateral } \\
\text { Angle } \boldsymbol{a}_{\boldsymbol{1}} \\
{[\mathrm{Deg}]}\end{array}$ & $\begin{array}{c}\text { Longitudinal } \\
\text { Angle } \boldsymbol{b}_{\boldsymbol{1}} \\
{[\mathrm{Deg}]}\end{array}$ & $\begin{array}{c}\text { Mean Flap } \\
\text { Angle } \boldsymbol{\beta}_{\boldsymbol{0}} \\
{[\mathrm{Deg}]}\end{array}$ & $\begin{array}{c}\text { Lateral } \\
\text { Angle } \boldsymbol{a}_{\boldsymbol{1}} \\
{[\mathrm{Deg}]}\end{array}$ & $\begin{array}{c}\text { Longitudinal } \\
\text { Angle } \boldsymbol{b}_{\boldsymbol{1}} \\
{[\mathrm{Deg}]}\end{array}$ \\
\hline 2.2 & 0.838 & 0.974 & 0.563 & 0.04 & 0.258 & 1.833 \\
\hline 4.33 & 1.45 & 1.407 & 1.419 & 0.58 & 1.356 & 1.866 \\
\hline 6.61 & 2.08 & 1.864 & 2.242 & 1.36 & 2.204 & 1.985 \\
\hline 8.83 & 2.71 & 2.229 & 2.960 & 2.18 & 3.155 & 1.822 \\
\hline 11.04 & 3.41 & 2.662 & 3.548 & 3.06 & 4.063 & 1.809 \\
\hline 13.05 & 4.1 & 2.927 & 4.080 & 3.95 & 5.001 & 1.625 \\
\hline
\end{tabular}

Figures 4.20 and 4.21 present the flap motions at each azimuth radial for all simulations during the last rotation (no. 9). With the wake model turned on, it is shown that the SMARTROTOR rigid model makes a similar path as the Harris experiment. The difference between the SMARTROTOR and Harris' experiment is the azimuth position where the flap angles peak. The Harris flap angles peaks at azimuth $210^{\circ}$ to $235^{\circ}$ (from lowest collective pitch to highest). Meanwhile the SMARTROTOR flap angle peaks at azimuth $260^{\circ}$ to $210^{\circ}$ (from lowest collective pitch to highest).

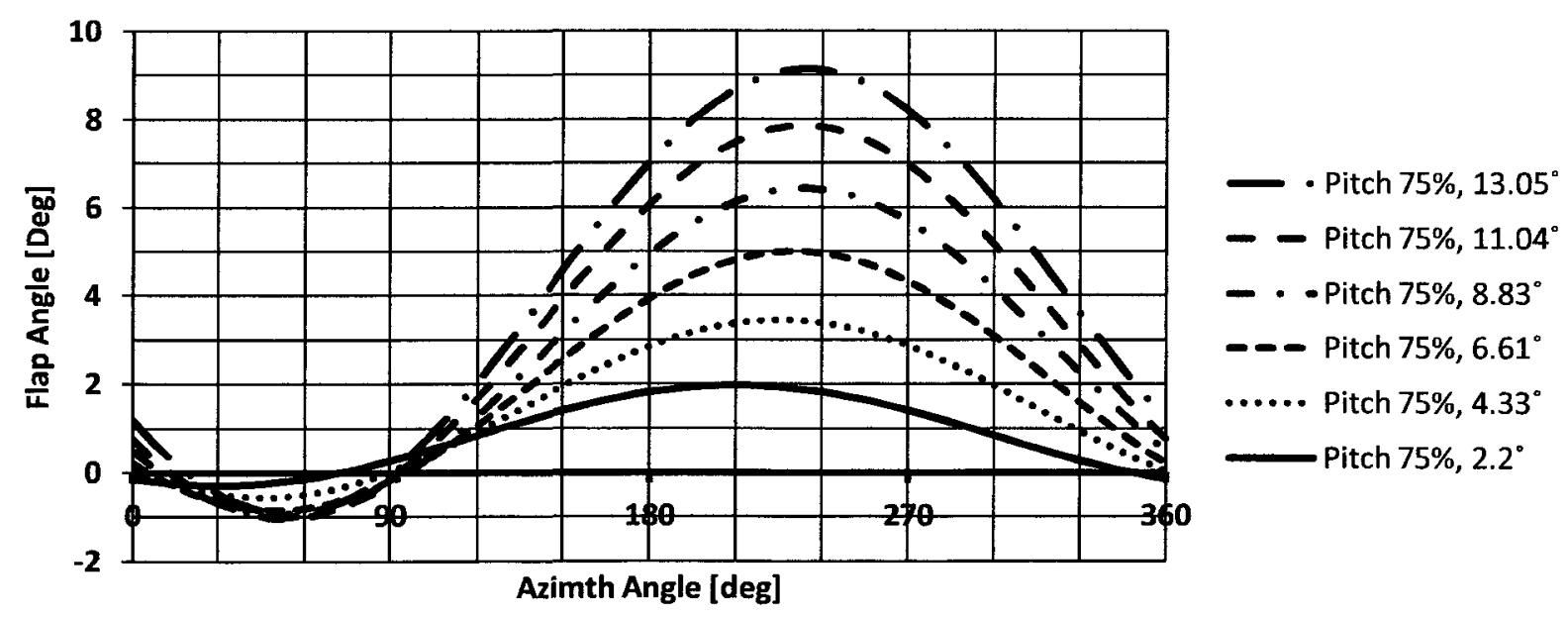

Figure 4.20 - Influence of Collective Pitch - Harris experiment flap path. 


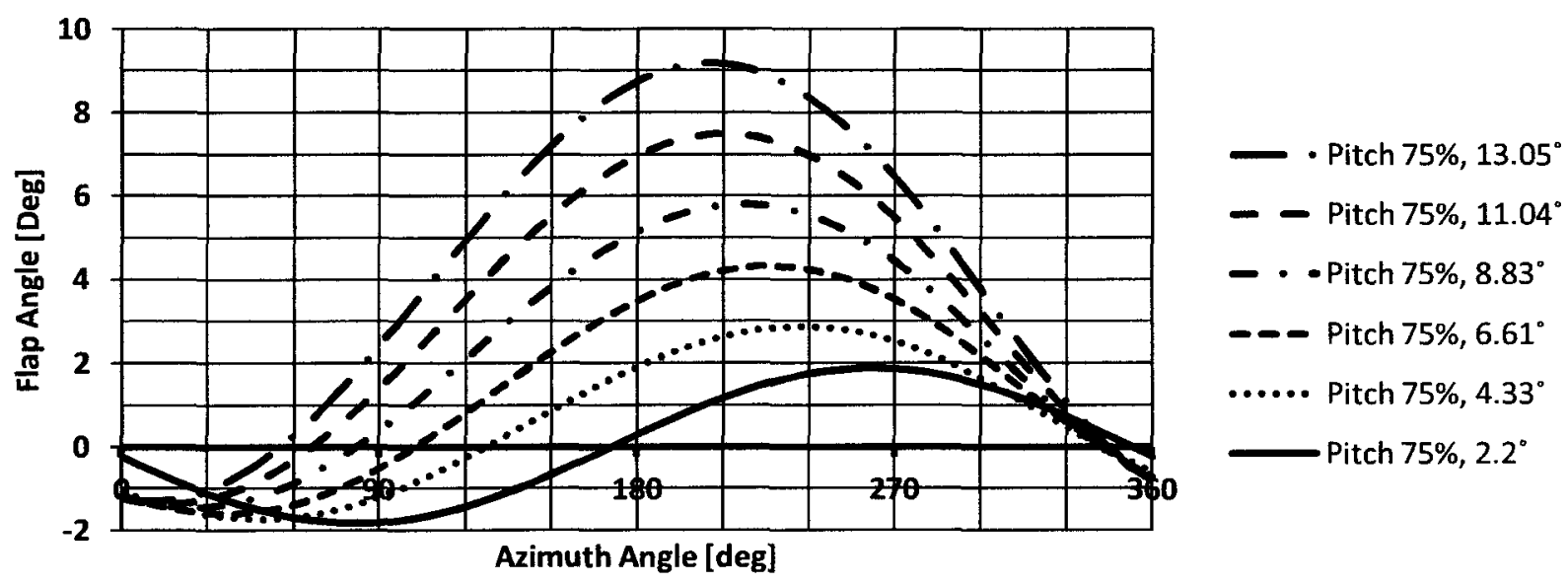

Figure 4.21 - Influence of Collective Pitch - SMARTROTOR flap path.

Since the simulations were conducted over 9 rotations and the sample rate is low at $6 \%$ step, by increasing the time step resolution and the number of rotations may generate a slightly different steady blade path may be obtained.

From running several simulations of increasing pitch in SMARTROTOR, it can be shown that for the simplified rigid model SMARTROTOR presents a good correlation compared to the experimental results from Harris' Articulate Rotor Blade Flapping Motion at Low Advance Ratio experiment [9].

\subsection{Harris Simulation: Influence of Advance Ratio}

The second simulation presented is a recreation of Harris' Influence of Collective Pitch. This experiment established blade motion trends on the influence of increasing advance ratio and illustrates another good comparison of the simulation to the Harris experiment. The simulation was conducted under conditions similar to the collective pitch experiment as presented in the previous section. Harris' experiment was conducted with a tip speed of $137.16 \mathrm{~m} / \mathrm{s}(450 \mathrm{ft} / \mathrm{s})$, with a constant shaft tilt of $1^{\circ}$ tilted aft, at varied collective pitches, no lateral cyclic $\left(A_{I C}=0^{\circ}\right)$, 
and $-0.73^{\circ}$ longitudinal cyclic $\left(B_{I C}=-0.73^{\circ}\right)$, to meet a constant thrust coefficient to solidity ratio, $C_{7} / \sigma$ of 0.08 . The results of Harris' experiment are as follows in Tables 4.6 and 4.7.

Table 4.6 - Harris' Influence of Advance Ratio experiment results.

\begin{tabular}{|r|r|r|r|r|r|r|}
\hline $\begin{array}{c}\text { Advanc } \\
\text { e Ratio } \\
\boldsymbol{\mu}\end{array}$ & $\begin{array}{c}\text { Shaft } \\
\text { Angle } \\
{[\mathrm{deg}]}\end{array}$ & $\begin{array}{c}\text { Pitch at 75\% } \\
\text { Radius Station } \\
\boldsymbol{\theta}_{\mathbf{0 . 7 5}}[\mathbf{d e g}]\end{array}$ & $\begin{array}{c}\text { Root Pitch } \boldsymbol{\theta}_{\boldsymbol{o}} \\
\text { [deg] }\end{array}$ & $\begin{array}{c}\text { Thrust Coef// } \\
\text { Solidity } \boldsymbol{C}_{\boldsymbol{T}} / \boldsymbol{\sigma}\end{array}$ & $\begin{array}{c}\text { Tip Path } \\
\text { Plane } \boldsymbol{\alpha}_{\boldsymbol{T P P}} \\
{[\mathrm{deg}]}\end{array}$ & $\begin{array}{c}\text { Incoming } \\
\text { Velocity [m/s] }\end{array}$ \\
\hline 0 & 0 & 12.27 & 18.58 & 0.0796 & 0.907 & 0.0 \\
\hline 0.0442 & -0.503 & 12.05 & 18.36 & 0.0802 & 1.463 & 6.1 \\
\hline 0.0804 & -1.247 & 10.98 & 17.29 & 0.0801 & 1.392 & 11.0 \\
\hline 0.1209 & -1.952 & 9.83 & 16.14 & 0.0793 & 1.282 & 16.6 \\
\hline 0.1601 & -2.667 & 9.31 & 15.62 & 0.0802 & 0.963 & 22.0 \\
\hline 0.2000 & -3.490 & 9.1 & 15.41 & 0.0792 & 0.764 & 27.4 \\
\hline 0.2399 & -4.385 & 9.16 & 15.47 & 0.0794 & 0.342 & 32.9 \\
\hline
\end{tabular}

Table 4.7 - Harris' Influence of Advance Ratio flap angle coefficients.

\begin{tabular}{|r|r|r|r|}
\hline Advance Ratio $\boldsymbol{\mu}$ & Mean Flap Angle $\boldsymbol{\beta}_{\boldsymbol{0}}$ [deg] & Lateral Flapping $\boldsymbol{a}_{\boldsymbol{I}}$ [deg] & Longitudinal Flapping $\boldsymbol{b}_{\boldsymbol{1}}[\mathbf{d e g}]$ \\
\hline 0 & 3.3 & 0.097 & 0.337 \\
\hline 0.0442 & 3.3 & 1.966 & 2.414 \\
\hline 0.0804 & 3.3 & 2.639 & 3.394 \\
\hline 0.1209 & 3.3 & 3.231 & 3.018 \\
\hline 0.1601 & 3.3 & 3.630 & 2.418 \\
\hline 0.2000 & 3.3 & 4.254 & 2.210 \\
\hline 0.2399 & 3.3 & 4.727 & 1.969 \\
\hline
\end{tabular}

The SMARTROTOR simulations repeat the same input as described in Harris' Influence of Advance Ratio experiment. The results of the simulations are compared with Harris' experiment. The thrust coefficient and flap amplitude is calculated from the last cycle from each run and is presented in Table 4.8. 
Table 4.8 - SMARTROTOR results for CH47C rotor blade model

\begin{tabular}{|r|r|r|r|r|r|r|r|}
\hline $\begin{array}{c}\text { Advance } \\
\text { Ratio }\end{array}$ & $\begin{array}{c}\text { Total } \\
\text { Thrust } \\
{[\mathbf{N}]}\end{array}$ & $\begin{array}{c}\text { Thrust } \\
\text { Coefficient/ } \\
\text { Solidity } \boldsymbol{C}_{T} / \boldsymbol{\sigma}\end{array}$ & $\begin{array}{c}\text { Min Flap } \\
\text { [Deg] }\end{array}$ & $\begin{array}{c}\text { Max Flap } \\
\text { [Deg] }\end{array}$ & $\begin{array}{c}\text { SMARTROTOR } \\
\text { Flap Amplitude } \\
\text { [Deg] }\end{array}$ & $\begin{array}{c}\text { Harris Flap } \\
\text { Amplitude } \\
\text { [Deg] }\end{array}$ & $\begin{array}{c}\text { Amplitude } \\
\text { Error [\%] }\end{array}$ \\
\hline 0 & 310.3 & 0.06776 & 1.81 & 4.00 & 1.09 & 0.19 & 485.64 \\
\hline 0.044 & 339.4 & 0.07411 & -0.03 & 6.41 & 3.22 & 3.05 & 5.62 \\
\hline 0.080 & 339.3 & 0.07409 & -1.00 & 7.60 & 4.30 & 4.17 & 3.13 \\
\hline 0.121 & 331.4 & 0.07237 & -1.56 & 7.32 & 4.44 & 4.41 & 0.62 \\
\hline 0.160 & 338.0 & 0.07381 & -1.37 & 7.11 & 4.24 & 4.02 & 5.40 \\
\hline 0.200 & 339.2 & 0.07408 & -1.38 & 7.11 & 4.25 & 3.92 & 8.33 \\
\hline 0.240 & 342.3 & 0.07475 & -1.77 & 7.43 & 4.60 & 3.64 & 26.48 \\
\hline
\end{tabular}

For the SMARTROTOR simulations, the thrust coefficient was slightly low at an average $C_{7} / \sigma$ of 0.073 , lower than the Harris experiment at a $C_{7} / \sigma$ of 0.080 . As seen in the previous test, influence of Collective Pitch this discrepancy can be fixed by slightly increasing the airfoil lift coefficient input. The variation in $C_{7} / \sigma$ is presented in Figure 4.22. The error between the thrust settings is about $9 \%$. Marginal changes to the lift input files, by slightly increasing the lift coefficients can correct this difference.
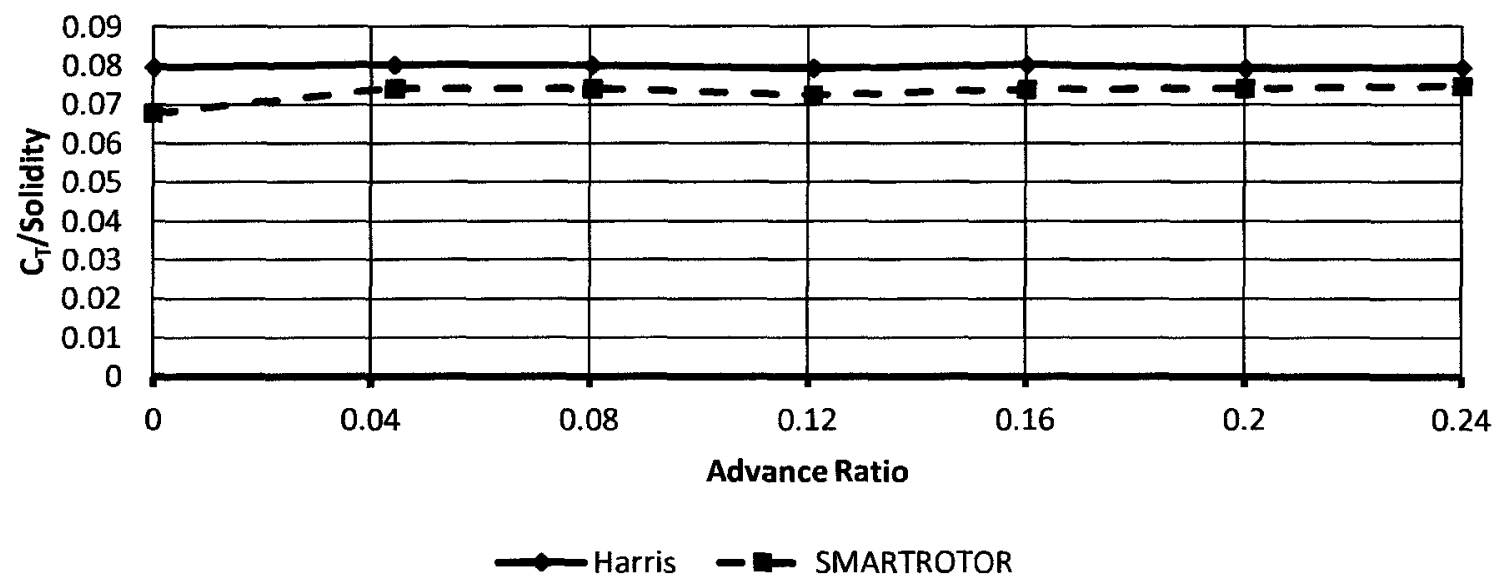

Figure 4.22 - Influence of Advance Ratio - comparison of thrust coefficients.

The resultant flap amplitudes of the SMARTROTOR simulations are presented in Figure 4.23. For most of the simulations, it is shown that the resultant flap amplitudes correlate well to 
the Harris experiment. At advance ratio of 0 , there the flap is producing some flapping motion at an amplitude of $1^{\circ}$. This small magnitude of motion may be produced, because where the simulation started the blade at rest and so far has ran as far as 9 cycles, the blade has some unsettled inertial motion which has not yet settled at a lower flap amplitude, as one may see at later flight cycles. Meanwhile at Advance Ratio of 0.24 , representing a fast flight velocity of 33 $\mathrm{m} / \mathrm{s}$, the divergence of the amplitude between $3.6^{\circ}$ and $4.6^{\circ}$, appears to be a case where also the flap amplitude has not settled yet. Only simulations of longer flight time will illustrate the final flap paths.

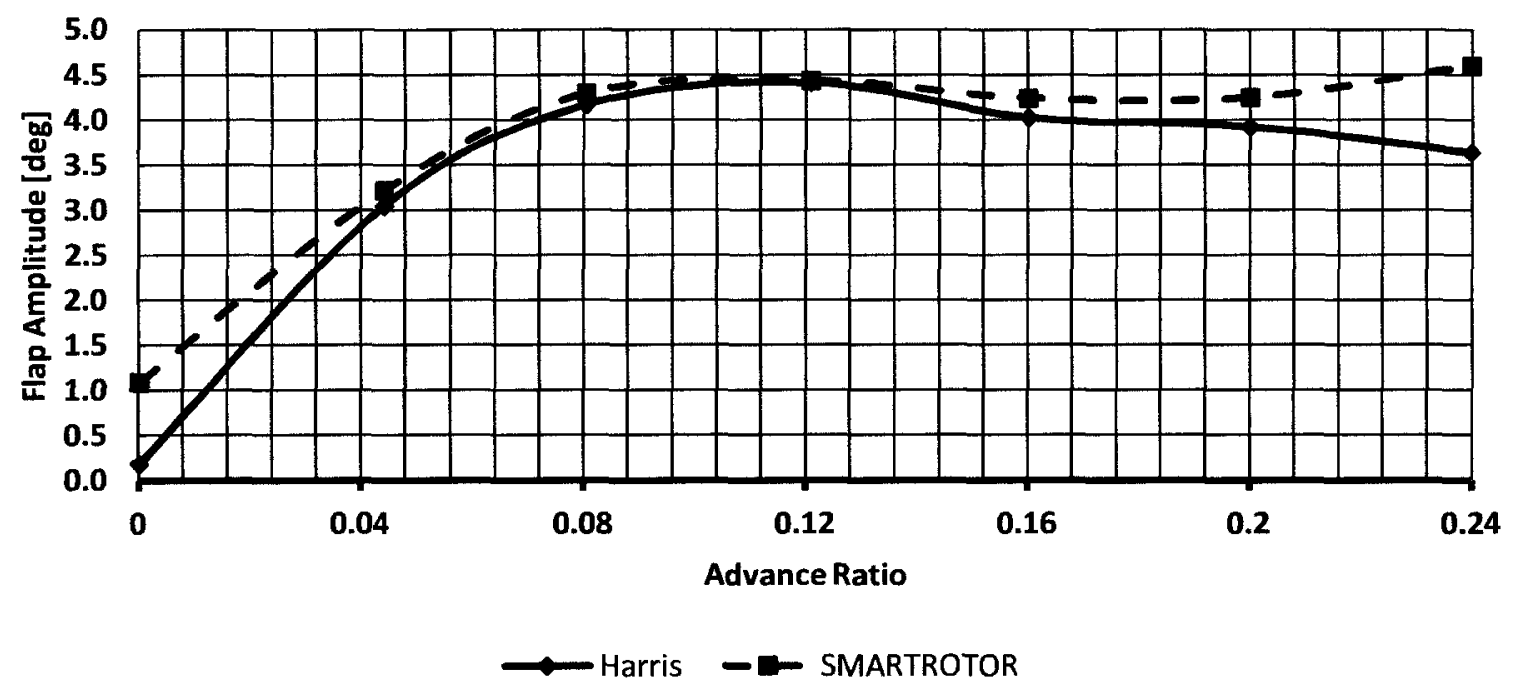

Figure 4.23 - Influence of Advance Ratio - comparison of flap amplitude.

A comparison between the Harris and SMARTROTOR flap angles for this experiment is shown in Figures 4.24 and 4.25. In this experiment the flap paths also correlate well, and as explained in the previous section with further simulations the flap angles would synchronize inphase as per the Harris experiment. The lateral and longitudinal pitch estimates for each SMARTROTOR simulation is listed in Table 4.9. 
Table 4.9 - Influence of Advance Ratio - SMARTROTOR results flap angle coefficient

\begin{tabular}{|r|r|r|r|r|r|r|}
\hline & \multicolumn{3}{|c|}{ Harris Flap Angle Coefficients } & \multicolumn{2}{c|}{ SMARTROTOR Flap Angle Coefficients } \\
\hline $\begin{array}{c}\text { Pitch } \boldsymbol{\theta}_{75} \\
{[\mathrm{Deg}]}\end{array}$ & $\begin{array}{c}\text { Mean Flap } \\
\text { Angle } \boldsymbol{\beta}_{\mathbf{0}} \\
{[\mathrm{Deg}]}\end{array}$ & $\begin{array}{c}\text { Lateral } \\
\text { Angle } \boldsymbol{a}_{\boldsymbol{1}} \\
{[\mathrm{Deg}]}\end{array}$ & $\begin{array}{c}\text { Longitudinal } \\
\text { Angle } \boldsymbol{b}_{\boldsymbol{1}} \\
{[\mathrm{Deg}]}\end{array}$ & $\begin{array}{c}\text { Mean Flap } \\
\text { Angle } \boldsymbol{\beta}_{\boldsymbol{0}} \\
{[\mathrm{Deg}]}\end{array}$ & $\begin{array}{c}\text { Lateral } \\
\text { Angle } \boldsymbol{a}_{\boldsymbol{1}} \\
{[\mathrm{Deg}]}\end{array}$ & $\begin{array}{c}\text { Longitudinal } \\
\text { Angle } \boldsymbol{b}_{\boldsymbol{1}} \\
{[\mathbf{D e g}]}\end{array}$ \\
\hline 0 & 3.3 & 0.097 & 0.337 & 2.91 & -0.602 & 0.927 \\
\hline 0.044 & 3.3 & 1.966 & 2.414 & 3.19 & 2.620 & 1.903 \\
\hline 0.080 & 3.3 & 2.639 & 3.394 & 3.30 & 3.834 & 1.953 \\
\hline 0.121 & 3.3 & 3.231 & 3.018 & 2.88 & 4.195 & 1.610 \\
\hline 0.160 & 3.3 & 3.630 & 2.418 & 2.87 & 4.126 & 1.029 \\
\hline 0.200 & 3.3 & 4.254 & 2.210 & 2.86 & 4.249 & 0.223 \\
\hline 0.240 & 3.3 & 4.727 & 1.969 & 2.83 & 4.598 & 0.000 \\
\hline
\end{tabular}

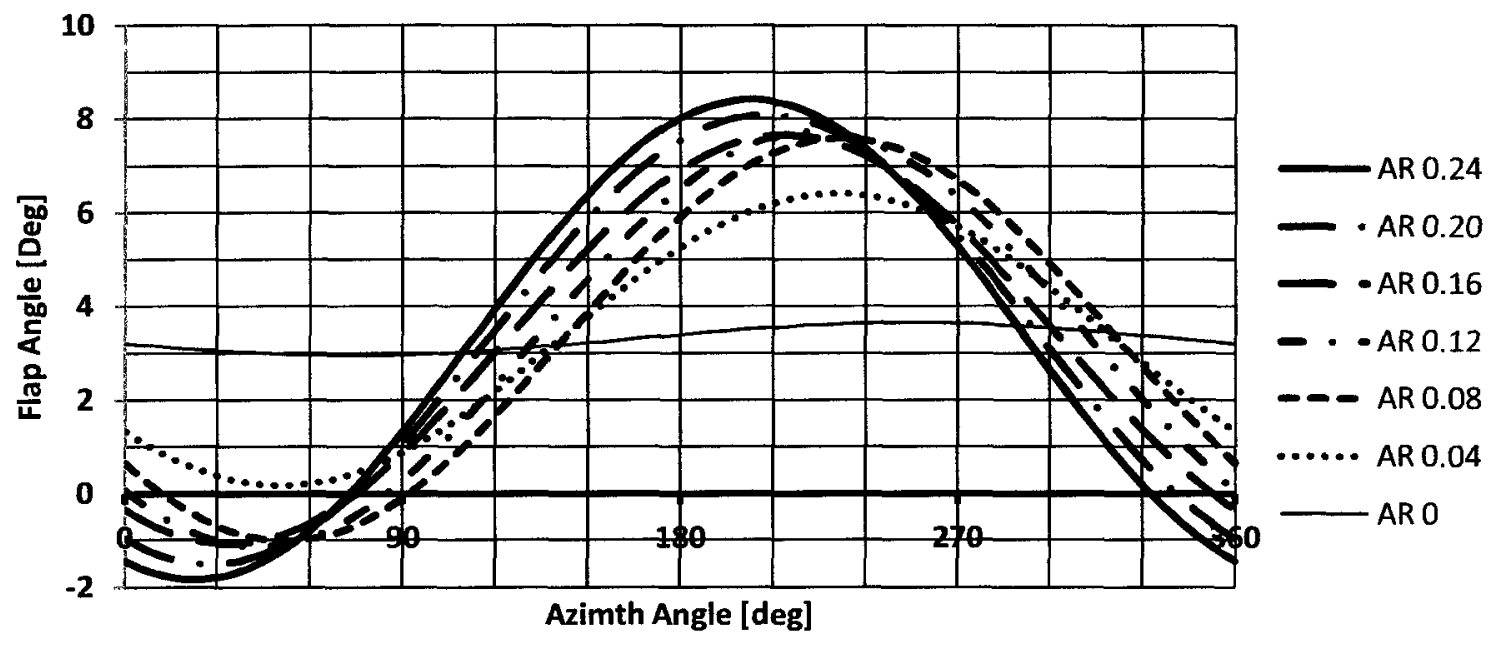

Figure 4.24 - Influence of Advance Ratio - Harris flap angles. 


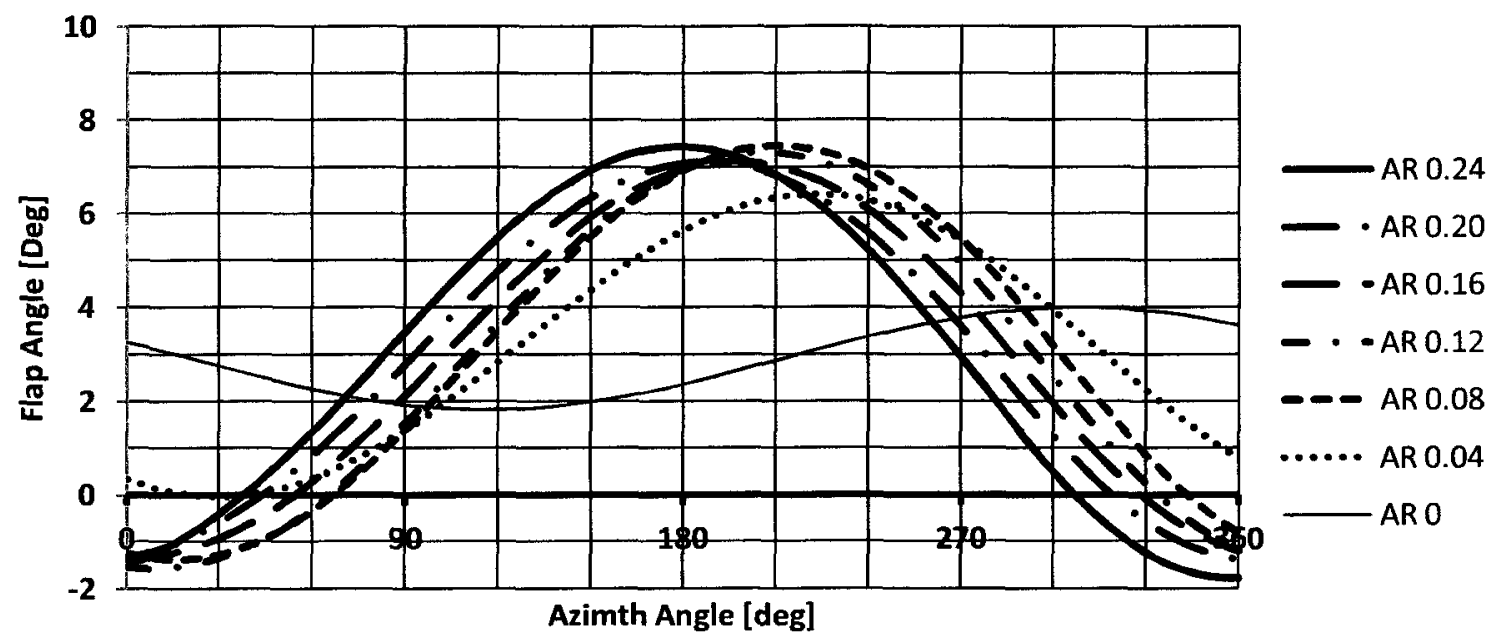

Figure 4.25 - Influence of Advance Ratio - SMARTROTOR flap angles

As shown in the previous section on the Influence of Collective Pitch, it is shown in this section that SMARTROTOR correlates well with the Influence of Advance Ratio experiment. Similarly to the Influence of Collective Pitch experiment, a lag of $30^{\circ}$ is observed between the flap paths of the SMARTROTOR simulation and the Harris experiment.

\subsection{Harris Simulation: Influence of Shaft Tilt}

The third and final simulation presented is the Influence of Shaft Tilt. This experiment established blade motion trends on the influence increasing shaft tilt. This experiment illustrates another good comparison of the simulation to the Harris experiment. This experiment was conducted under conditions similar to the collective pitch and advance ratio experiments as presented in the previous sections. This experiment was conducted with a tip speed of 137.16 $\mathrm{m} / \mathrm{s}(450 \mathrm{ft} / \mathrm{s})$, with a constant advance ratio 0.08 , at $10.97^{\circ}$ collective pitch (as measured at $75 \%$ radius station), no lateral cyclic $\left(A_{I C}=0^{\circ}\right)$, and $-0.73^{\circ}$ longitudinal cyclic $\left(B_{I C}=-0.73\right)$. The results of the Harris experiment are as follows in Tables 4.10. 
Table 4.10 - Harris' Influence of Shaft Tilt experiment results.

\begin{tabular}{|c|r|r|r|r|r|}
\hline $\begin{array}{c}\text { Shaft Angle } \\
\text { [deg] }\end{array}$ & $\begin{array}{c}\text { Thrust Coef./ } \\
\text { Solidity } \boldsymbol{C}_{\boldsymbol{T}} / \boldsymbol{\sigma}\end{array}$ & $\begin{array}{c}\text { Tip Path Plane } \\
\boldsymbol{a}_{\boldsymbol{r P P}}[\mathbf{d e g}]\end{array}$ & $\begin{array}{c}\text { Mean Flap } \\
\text { Angle } \boldsymbol{\beta}_{\boldsymbol{0}}[\mathbf{d e g}]\end{array}$ & $\begin{array}{c}\text { Lateral Flapping } \\
\boldsymbol{a}_{\boldsymbol{1}}[\mathbf{d e g}]\end{array}$ & $\begin{array}{c}\text { Longitudinal } \\
\text { Flapping } \boldsymbol{b}_{\boldsymbol{1}}[\mathrm{deg}]\end{array}$ \\
\hline-5.293 & 0.0761 & $\mathbf{3 . 5 0 2}$ & 3.23 & 2.427 & 3.123 \\
\hline-3.902 & 0.0781 & -1.451 & 3.28 & 2.451 & 3.198 \\
\hline-1.256 & 0.0805 & 1.312 & 3.32 & 2.568 & 3.477 \\
\hline 2.083 & 0.0821 & 4.843 & 3.34 & 2.760 & 3.494 \\
\hline
\end{tabular}

The SMARTROTOR simulations repeat the same input as described in Harris' Influence of Advance Ratio experiment. The results of the simulations are compared with Harris' experiment. The thrust coefficient and flap amplitude is calculated from the last cycle from each run and is presented in Table 4.11 .

Table 4.11 - SMARTROTOR results for CH47C rotor blade model.

\begin{tabular}{|c|c|r|r|r|r|r|r|}
\hline $\begin{array}{c}\text { Shaft } \\
\text { Angle } \\
\text { [deg] }\end{array}$ & $\begin{array}{c}\text { Total } \\
\text { Thrust } \\
{[\mathbf{N}]}\end{array}$ & $\begin{array}{c}\text { Thrust } \\
\text { Coefficient/ } \\
\text { Solidity } \boldsymbol{C}_{\boldsymbol{r}} / \boldsymbol{\sigma}\end{array}$ & $\begin{array}{c}\text { Min Flap } \\
{[\mathrm{Deg}]}\end{array}$ & $\begin{array}{c}\text { Max Flap } \\
{[\mathrm{Deg}]}\end{array}$ & $\begin{array}{c}\text { SMARTROTOR } \\
\text { Flap Amplitude } \\
{[\mathrm{Deg}]}\end{array}$ & $\begin{array}{c}\text { Harris Flap } \\
\text { Amplitude } \\
{[\mathrm{Deg}]}\end{array}$ & $\begin{array}{c}\text { Amplitude } \\
\text { Error [\%] }\end{array}$ \\
\hline-5.293 & 322.1 & 0.07035 & -1.09 & 6.88 & 3.98 & 3.83 & 3.87 \\
\hline-3.902 & 327.8 & 0.07158 & -1.19 & 7.07 & 4.13 & 3.89 & 6.07 \\
\hline-1.256 & 338.9 & 0.07400 & -1.39 & 7.44 & 4.42 & 4.13 & 6.94 \\
\hline 2.083 & 351.8 & 0.07682 & -1.61 & 7.93 & 4.77 & 4.33 & 10.04 \\
\hline
\end{tabular}

For the SMARTROTOR simulations the thrust coefficient was slightly low at an average $C_{T} / \sigma$ of 0.072 , lower than the Harris experiment at a $C_{T} / \sigma$ of 0.080 . As seen in the previous sections this discrepancy can be fixed by slightly increasing the airfoil lift coefficient input. The variation in $C_{T} / \sigma$ is presented in Figure 4.26. 


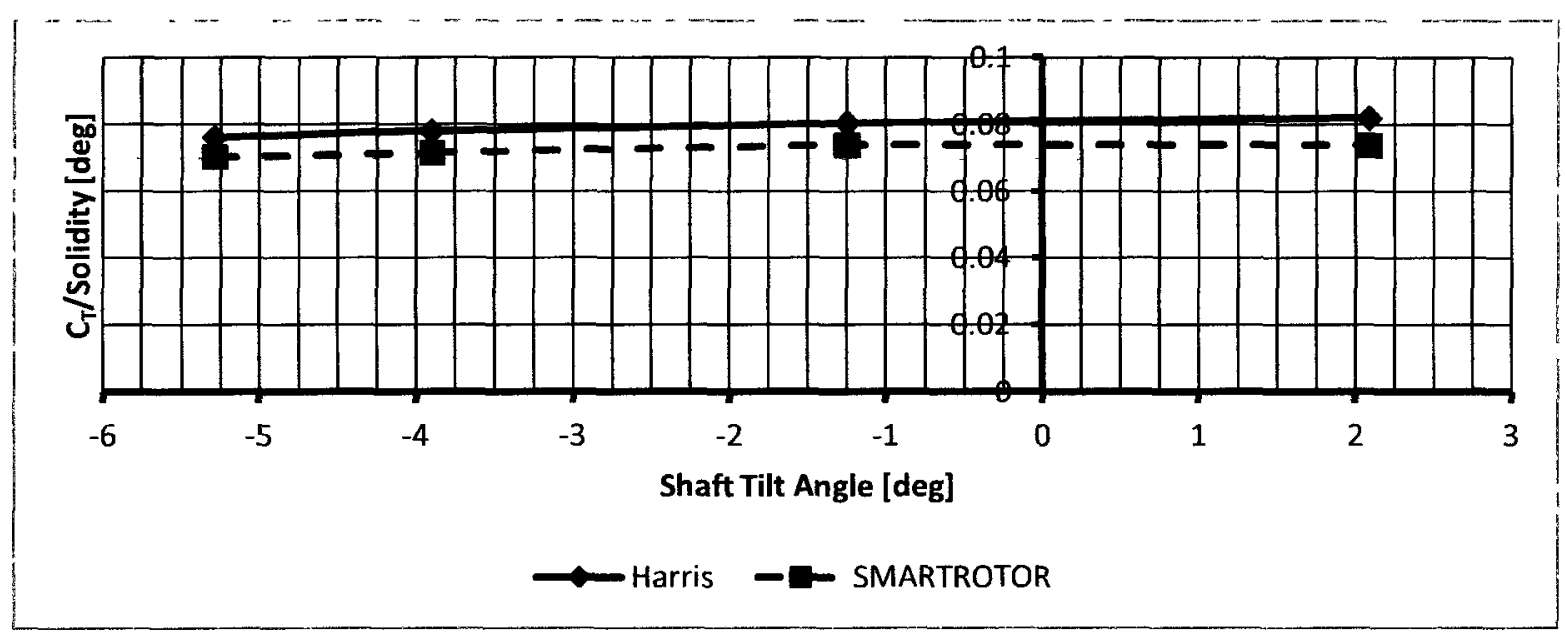

Figure 4.26 - Influence of Shaft Tilt - comparison of thrust coefficients.

The resultant flap amplitudes of the SMARTROTOR simulations are presented in Figure 4.26. It is shown that the resultant flap amplitudes correlate well together.

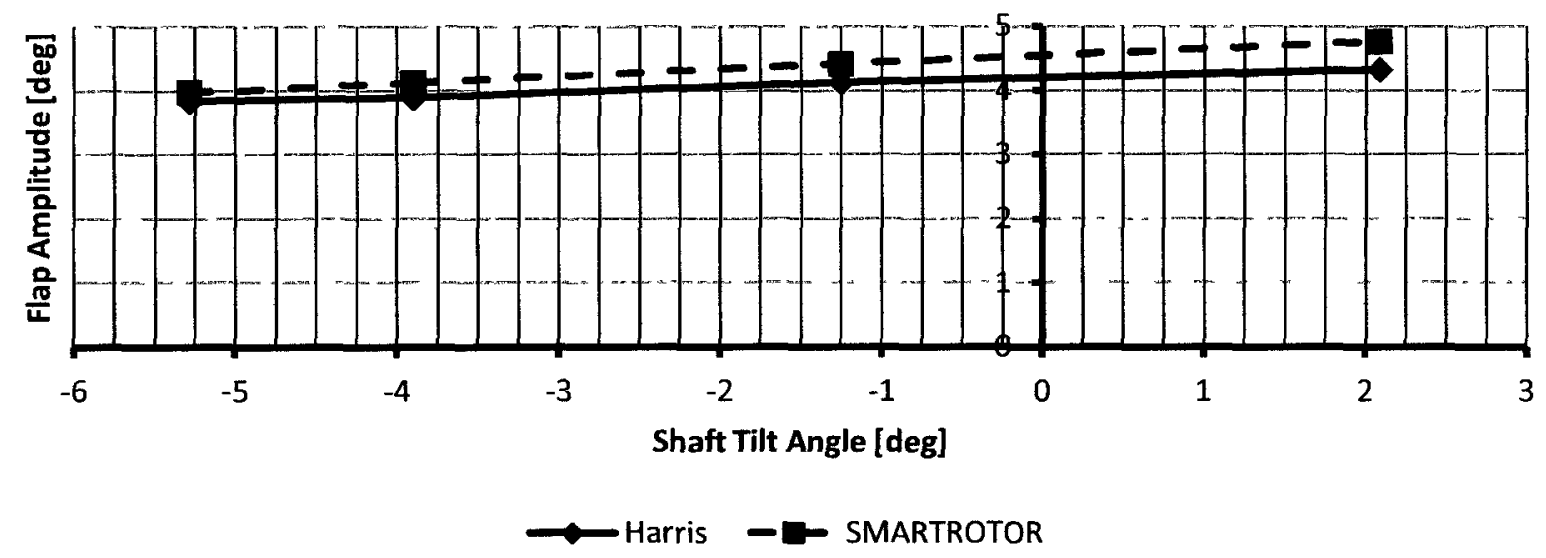

Figure 4.27 - Influence of Shaft Tilt - comparison of flap amplitude.

A comparison between the Harris and SMARTROTOR flap angles for this experiment is shown in Figures 4.28 and 4.29. In this experiment, the flap paths also correlate well, and as explained in the previous section with further simulations the flap angles would synchronize inphase as per the Harris experiment. The lateral and longitudinal pitch estimates for each SMARTROTOR simulation is listed in Table 4.12. 
Chapter 4 - CH-47C Rotor Blade Flapping Motion Analysis

Table 4.12 - Influence of Shaft Tilt - SMARTROTOR results flap angle coefficient

\begin{tabular}{|c|c|c|c|c|c|c|}
\hline \multirow[b]{2}{*}{$\begin{array}{l}\text { Shaft } \\
\text { Angle } \\
\text { [deg] }\end{array}$} & \multicolumn{3}{|c|}{ Harris Flap Angle Coefficients } & \multicolumn{3}{|c|}{ SMARTROTOR Flap Angle Coefficients } \\
\hline & $\begin{array}{c}\text { Mean Flap } \\
\text { Angle } \beta_{0} \\
\text { [Deg] }\end{array}$ & $\begin{array}{c}\text { Lateral } \\
\text { Angle } a_{1} \\
\text { [Deg] }\end{array}$ & $\begin{array}{c}\text { Longitudinal } \\
\text { Angle } b_{1} \\
\text { [Deg] }\end{array}$ & $\begin{array}{c}\text { Mean Flap } \\
\text { Angle } \boldsymbol{\beta}_{0} \\
{[\text { Deg] }}\end{array}$ & $\begin{array}{l}\text { Lateral Angle } \\
\qquad a_{1}[\mathrm{Deg}]\end{array}$ & $\begin{array}{c}\text { Longitudinal } \\
\text { Angle } \boldsymbol{b}_{\boldsymbol{I}} \\
\text { [Deg] }\end{array}$ \\
\hline-5.2929 & 3.23 & 2.427 & 3.123 & 2.90 & 3.657 & 1.628 \\
\hline-3.902 & 3.28 & 2.451 & 3.198 & 2.94 & 3.791 & 1.688 \\
\hline-1.256 & 3.32 & 2.568 & 3.477 & 3.02 & 4.058 & 1.807 \\
\hline 2.083 & 3.34 & 2.76 & 3.494 & 3.16 & 4.379 & 1.949 \\
\hline
\end{tabular}

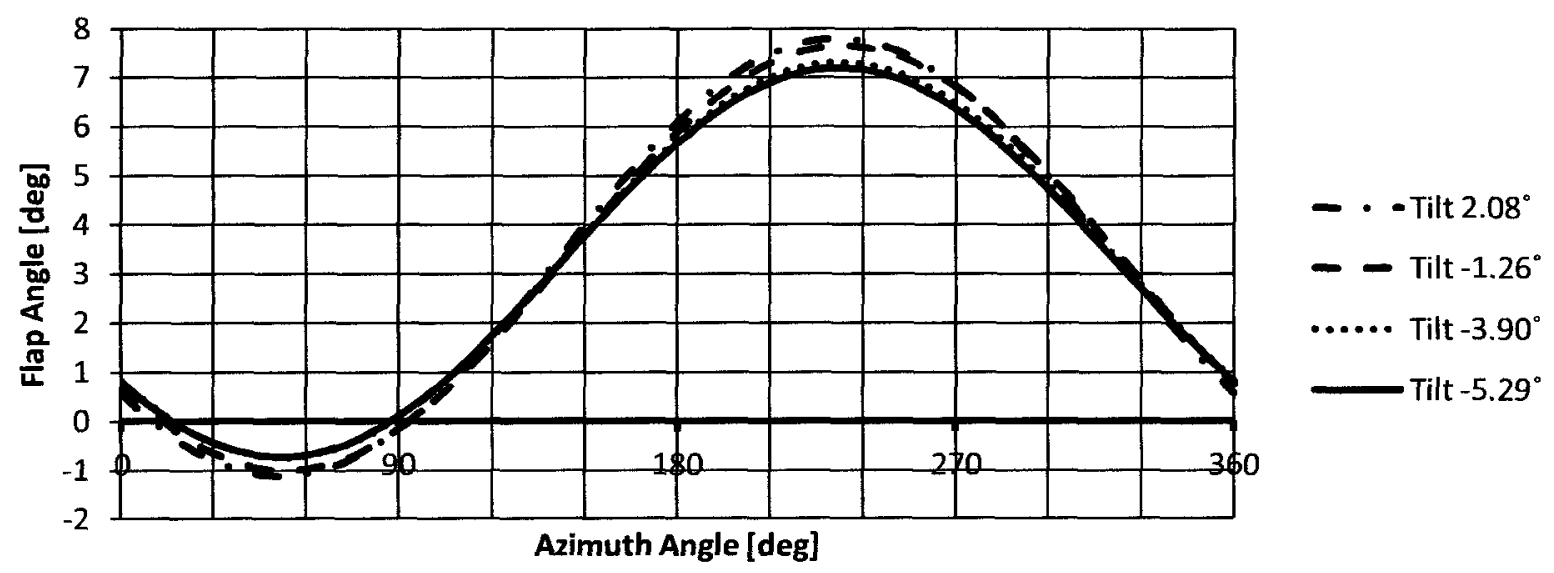

Figure 4.28 - Influence of Shaft Tilt - Harris flap angles.

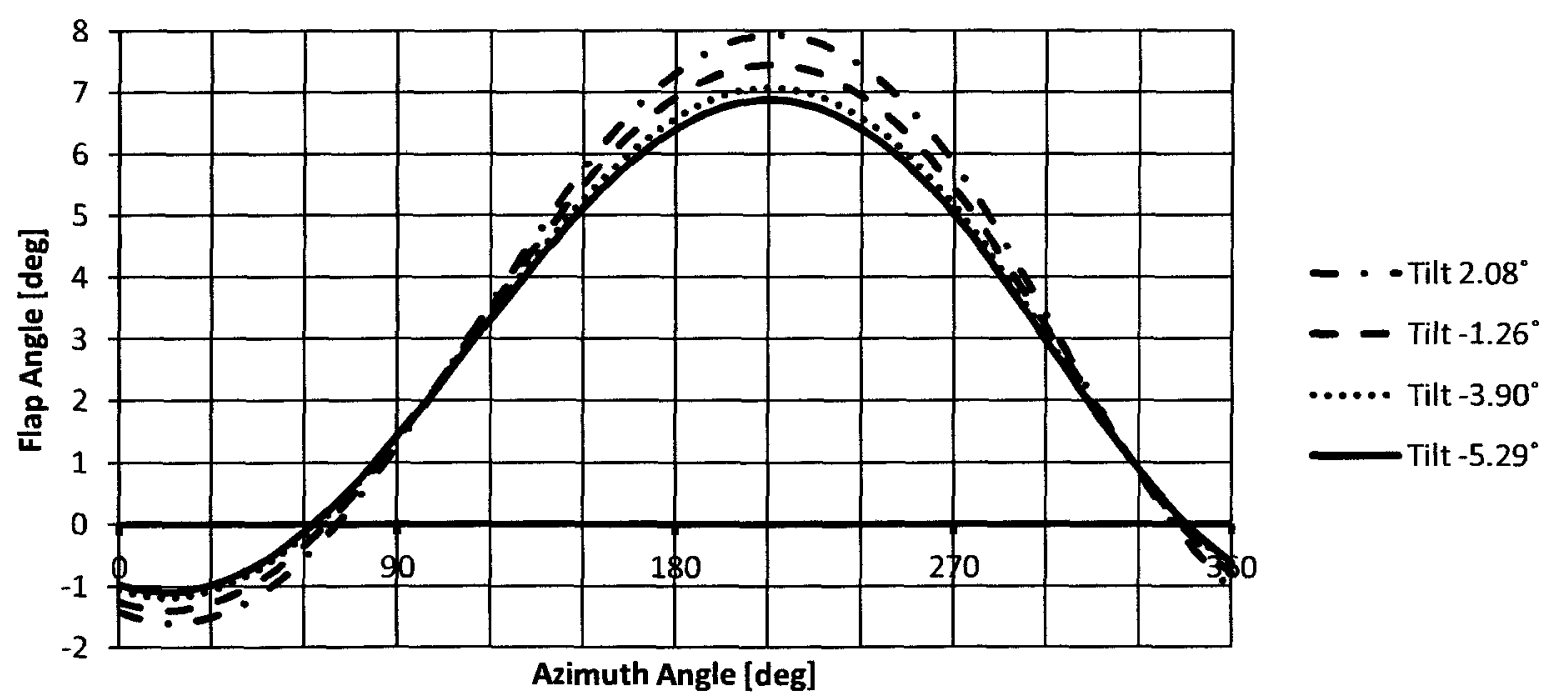

Figure 4.29 - Influence of Shaft Tilt - SMARTROTOR flap angles. 
As shown in the previous sections, it is shown in this section that SMARTROTOR correlates well with the Influence of Shaft Tilt experiment. Similarly to the Influence of Collective Pitch and Influence of Advance Ratio experiments, a lag of $30^{\circ}$ is observed between the flap paths of the SMARTROTOR simulation and the Harris experiment. 


\section{Chapter 5 Summary, Conclusions and Recommendations}

\subsection{Summary}

Computational studies of rotorcraft motion and the surrounding environment is an expanding area of study. As computational resources expand and computational methods become more sophisticated, the simulation of blade motion, blade elasticity, and the prediction of the downstream aerodynamic environment becomes more comparable to empirical data.

This thesis has presented the current expansion of the SMARTROTOR program of the Rotorcraft Research Group at Carleton University. Previous versions of SMARTROTOR were developed from the GENUVP unsteady panel method and vortex particle method, originally modeling rigid wind turbine blade. A previous research student, Daniel Opoku, collaborated with Tao Cheng in creating the present version of SMARTROTOR that simulated hingeless helicopter rotors with blade flexing based on the Hodges non-linear deformation equations, and validated their work with the Helinoise aeroacoustic rotor tests. This thesis presents the expansion of the code with the addition of the hinged rigid rotor blade model.

The hinged rigid rotor blade model was based on the equations of motion presented in J.G. Leishman's Principles of Helicopter Aerodynamics. This method was compared to the F.D. Harris experiment on blade flapping at low advance ratio. The comparison to the Harris experiment show that the SMARTROTOR simulations with the rigid blade model correlate well with the three Harris experiments presented. 


\subsection{Conclusions}

The hinged rigid blade model appears to work well as tested for forward flight helicopter configurations. The comparison of the simulations to the three Harris experiments illustrated a fair correlation between of flapping motions in forward flight at low advance ratios. The comparison of the thrust data compared well, as did the flapping motion. The lead-lag frequency was found to be at $20 \%$ the rotational velocity, which is consistent with the literature.

Since the thrust data compared well between the simulations and the Harris experiment, it showed that the aerodynamics model worked well. The lift, drag and pitching moment data were derived from their coefficient charts for speeds from Mach 0 to Mach 0.95. Adjustments to the lift, drag and pitching moment input would be minor to correlate better with the Harris experiment.

It remains to be seen if running the simulations longer, constructing a higher resolution of blade aerodynamic grid nodes, and increasing the time step resolution would improve the predictability of the simulation. Discrepancies between the flap amplitudes of the simulations and the Harris experiment will need to be clarified when these simulations are re-run for longer duration to ensure that the flap motion has settled. The assumption that the blade acts as rigid blade appears to work well, since blade deformations will be small, and are suitable for the rigid blade articulated hub model.

\subsection{Recommendations}

The SMARTROTOR program can continue to be amended and expanded upon. The SMARTROTOR program, written in Fortran 77 is a challenging program to amend. It is the intention of this author to provide some guidance to future users by providing a brief guide to 
how to operate the SMARTROTOR program in Appendix A of this Thesis. Comment lines by this author and previous authors embedded throughout the SMARTROTOR source code will guide one through the workings of this program.

One challenging area of the code that may require some corrections is the wake model. One should amend the aerodynamic section of the code so that if one is only concerned with the aerodynamic effects occurring within the zone of the rotor blades, and one can turn off the wake being generated downstream of the blade. This would reduce the computational time required to run these simulations as their wake aft of the rotor blades would not be infinitely increasing in complexity over time. It may appear that there are existing variables in the aerodynamic input finals that can be adjusted to accomplish this.

Once it is determined that the simulations can be run with the wake model for longer flight time, re-simulation of the Harris experiment may be in order. This will confirm or illustrate any other problems regarding whether the flap motions of simulations will settle in-phase with the Harris experiment. A comparison with other models and existing data would be useful to further illustrate the validation of the rigid blade model based on the equations of motion presented in Leishman.

With further study of both the rigid code based on the equations of motion presented by Leishman, and the hingeless Hodges equations, one may be able to couple both models together properly to have a hinged rotor blade model with blade deformation. Based on the methods or rearranging the SMARTROTOR code listed in this Thesis, there are opportunities for the addition of other structural blade model codes to couple with the GENUVP aerodynamics model. 


\section{References}

[1] J.G. Leishman, Principles of Helicopter Aerodynamics, Cambridge University Press, New York, NY, 2000.

[2] Bartha, M. and Madzer, J. 1913. "Schraubenflügelanordnung für Luftschraubenpaare," Patent No. 249,702 .

[3] J.R. Chiles, The God Machine, Bantam Dell, A Division of Random House, Inc., New York, New York, 2007.

[4] Domke, B. 2011, Aviation Images - Aircraft in Detail - Helicopter Rotorhead Gallery, http://www.b-domke.de/AviationImages/Rotorhead.html (current August 2011).

[5] Bauchau O.A., Bottasso C.L. and Nikishkov Y.G.: "Modeling Rotorcraft Dynamics with Finite Element Multibody Procedures." Mathematical and Computer Modeling, 33, pp 1113 $1137,2001$.

[6] Johnson, W. "Rotorcraft Aerodynamic Models for a Comprehensive Analysis." American Helicopter Society 54th Annual Forum, Washington, D.C., May 1998.

[7] D.A. Wachspress, T.R. Quackenbush, and A.H. Boschitsch, "Rotorcraft Interactional Aerodynamics Calculations with Fast Vortex / Fast Panel Methods”, American Helicopter Society 56th Annual Forum, Virginia Beach, VA, May 2-4, 2000.

[8] D. Opoku, "Aeroelastic and aeroacoustic modeling of rotorcraft," Master's thesis, Carleton University, 2002.

[9] F.D. Harris, “Articulated Rotor Blade Flapping Motion at Low Advance Ratios", Journal of the American Helicopter Society, 17(1), pp. 41-48, 1972. 
[10] T. Cheng, "Structural Dynamics Modeling of Helicopter Blades for Computational Aeroelasticity," Master's thesis, Massachusetts Institute of Technology, May 2002.

[11] S.G. Voutsinas, A GENeralized Unsteady Vortex Particle Method for Solving the Unsteady Flow around Multi-component Configurations, Fluids Section - Dept. of Mechanical Engineering, National Technical University of Athens, Greece, 1990.

[12] D.G. Triantor, Aerodynamic and Aeroacoustic Analysis of Helicopter Rotors, PhD dissertation, Fluids Section - Dept. of Mechanical Engineering, National Technical University of Athens, Greece, 2002.

[13] S.G. Voutsinas, "Vortex methods in aeronautics: how to make things work", International Journal of Computational Fluid Dynamics, Vol. 20 No. 1 pp. 3-18, January 2006.

[14] D.H. Hodges, “A Mixed Variational Formulation based on Exact Intrinsic Equations for Dynamics of Moving Beam”, International Journal of Solids and Structures, vol. 26, no. 11, pp. $1253-1273,1990$.

[15] P.P. Friedmann and F.X. Bagnoud, "Rotary Wing Aeroelasticity - A Historical Perspective and Some Current Trends”, Journal of Aircraft, vol 40, no. 6, pp. 1019-1046, 2003.

[16] X. Shang, Aeroelastic Stability of Composite Hingeless Rotors with Finite-State Unsteady Aerodynamics, PhD dissertation, School of Aerospace Engineering, Georgia Institute of Technology, Atlanta, Georgia, 1995.

[17] W.R. Splettstoesser et al. "The HELINOISE Aeroacoustic Rotor Test in the NDW - Test Documentation and Representative Results”, DLR-Mitt. 93-09, DLR, Braunschweig, Germany, 1993.

[18] M. Ghorashi, Dynamics of Elastic Nonlinear Rotating Composite Beams with Embedded Actuators, PhD dissertation, Carleton University, 2009. 
References

[19] Alan Hindmarsh, ODEPACK, a Systematized Collection of ODE Solvers, in Scientific

Computing, Elsevier, 1983. Program code available at http://people.sc.fsu.edu/ jburkardt/ f77_src/odepack/odepack.html (Current August 2011).

[20] Mark W. Spong et al., Robot Modeling and Control, John Wiley \& Sons, Inc., 2006.

[21] Dadone, L.U. "U.S. Army Helicopter Design Datcom Volume 1 Airfoils", U.S. Army Air Mobility Research and Development Laboratory, Aviations Systems Command, September 1976.

[22] Abbott, I.H. and Von Doenhoff, Theory of Wing Sections Including a Summary of Airfoil Data, Dover Publications, Inc. 1949.

[23] Gessow, A. and Myers, G.C., Jr. 1952, Aerodynamics of the Helicopter, Macmillon Co., Republished by Frederick Ungar Publishing, New York, NY, 1967. 


\section{Appendix A SMARTROTOR User's Guide and Input Files}

The Appendix summarizes how to use and operate SMARTROTOR. This is a preliminary guide to set-up and run the most basic helicopter simulations. SMARTROTOR has other capabilities regarding simulating helicopter noise, and activating the Active Twist Control. This guide should allow users to run hingeless deformed, hinged rigid, and deformed hinged simulations.

\section{A.1 SMARTROTOR Operators Guide}

The program SMARTROTOR consists of several files to run. The home folder for the SMARTROTOR code is located in a folder entitled "SMARTROTOR". This directory contains the following important files:

- the Fortran 77 sources files entitled with suffix ".f"

- the Fortran 77 object files entitled with suffix ".o"

- the executable program SMARTROTOR.exe

- the make file entitled "makefile", contains the list of source and objects files used for compliling.

- The Input/Output file Directories

- HARRIS_CH47 - contains the input and output files related to the Harris experiment simulations.

○ BO_105_FINAL.70 - contains the input and output files related to the Helioise experiment simulations. 


\section{To run the SMARTROTOR program:}

1. Open up a Terminal Server on a Linux Operating System. Alternatively if running from a remote Windows computer, logon via a SSH Secure Shell Account. Go to root directory.

2. Open SMARTROTOR directory via change directory command (but do NOT type quotes "and ") "cd SMARTROTOR".

3. Open Input/Output Directory (in this case for the Harris experiment), via change directory command "cd HARRIS_CH47".

4. Run SMARTROTOR via run command "./atfile".

5. SMARTROTOR will run until it completes the required number of timesteps or identifies an error. To stop program press these two keys together CTRL $+c$.

6. A number of output files are created and are stored in the HARRIS_CH47 directory.

\section{To compile the SMARTROTOR program:}

1. Open SMARTROTOR directory via change directory command "cd SMARTROTOR".

2. Open the source file requiring changes, via command "vi filename.f". Alternatively changes can be made via Notepad or Wordpad in Windows OS. The program "Force 2.0" is a good Fortran Compiler and Editor, which is available at http://force.lepsch.com/.

3. After completing changes to the code, close then opened file, press the two keys together CTRL + c, then ":", then "q".

4. Remove the source file's object file via remove command "rm filename.o". If one wants to remove all object files, type remove command " $r m$ *.o".

5. To compile SMARTROTOR, via make command "make". This runs the series of commands listed in the make file, which attributed the sources files to the object files, and creates the executable SMARTROTOR.exe. 


\section{Other useful commands:}

- To return down one folder level type "cd ..".

- To search for specific text in a source file such as the word DISC, type "grep "DISC" *.f" (Include quotes only around text string "DISC").

\section{A.2 atfile}

The "atfile" file is a list of commands that is called to run the executable SMARTROTOR.exe. It is best NOT to alter these:

cd BO105_static

.././static/x_HL_STATIC

cp xwholel.dat ..

$\mathrm{cd}$.

..SMARTROTOR <fare

\section{A.3 fare}

The "fare" file is called upon SMARTROTOR's first pass through the Aerodynamics section of the original GENUVP section of the code. It is called in subroutine TNWEAOA, located in source file rescpv-3_sp.coupled2.f. It contains a list of aerodynamic structural parameter input. This script specified the input relevant to the Harris simulations:

\section{CH47CHI.DAT}

4

$-1.35$

0.21

0 .

0

0

17

1. CH47CHL.DAT - refers to call the main aerodynamic input file.

2. 4 - the number of movement levels in the rotational system (do not change) 
3. -1.35 - rotor disc plane disc tilt relative to the incoming freestream (in Degrees, -ve tilt forward, +ve tilt aft). This must match Main Disc Tilt Angle in *.geo file.

4. 0.21 - Horizontal elastic axis from chord leading edge (fraction of chord length).

5. 0. - Vertical elastic axis, placement relative to airfoil midline (fraction of chord length).

6. 0 - Turn on Acoustic Pressure Data (1 - Yes, 0 - No).

7. 0-Input the offset between structural and aerodynamic meshes.

8. 17 - Specifies the number of spanwise aerodynamic nodes. This must match variable NCWB in *.geo file.

\section{A.4 CH47CHL.dat}

The main aerodynamic file is entitled CH47CHL.dat. Alternativly BO105HL.dat is the input file for the Helinoise simulations. This script specified the input relevant to the Harris simulations:

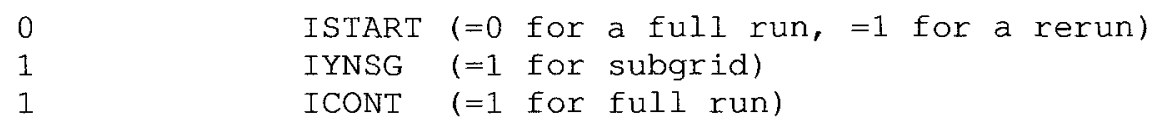

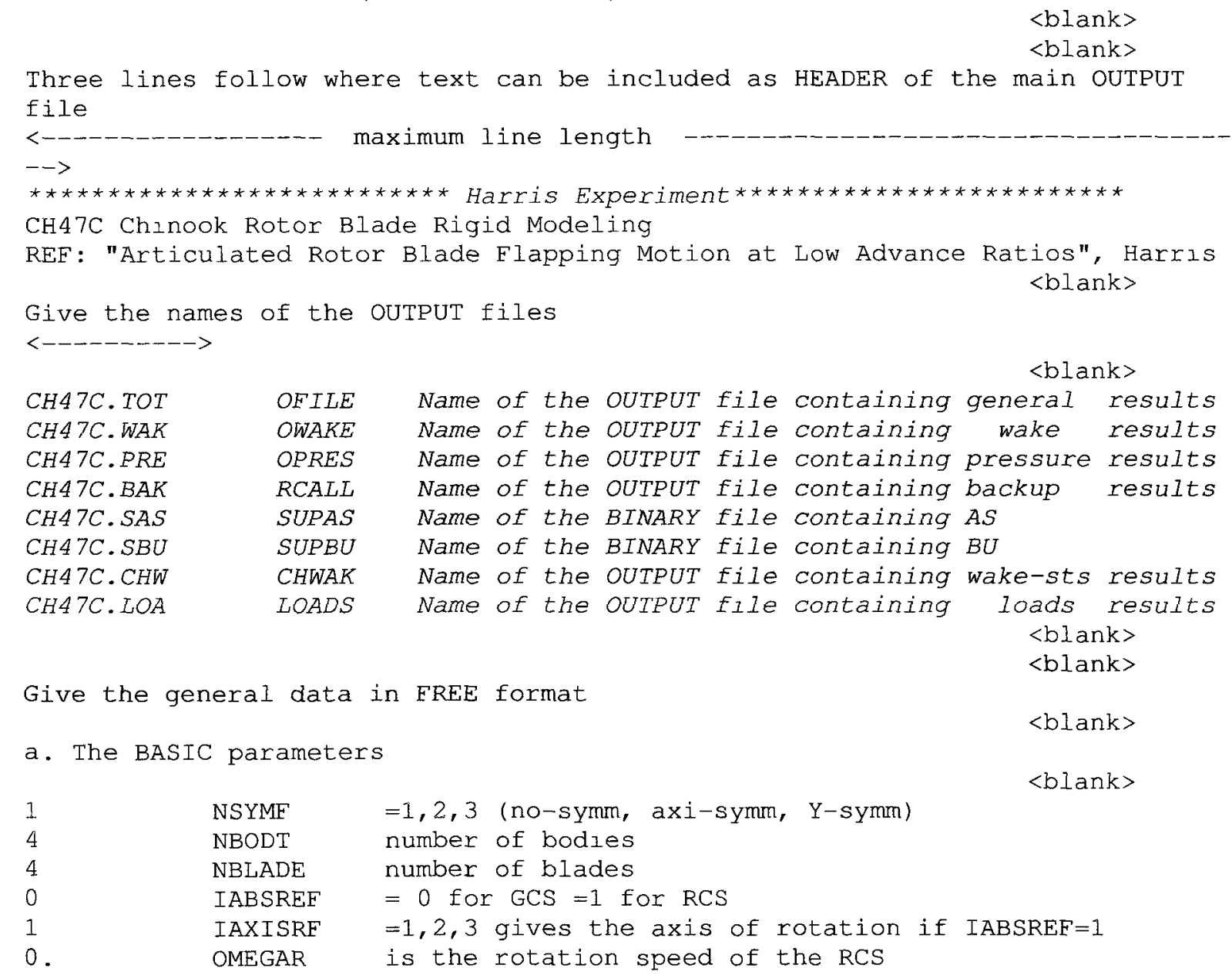

b. The TIME parameters

$\langle$ blank $>$ 


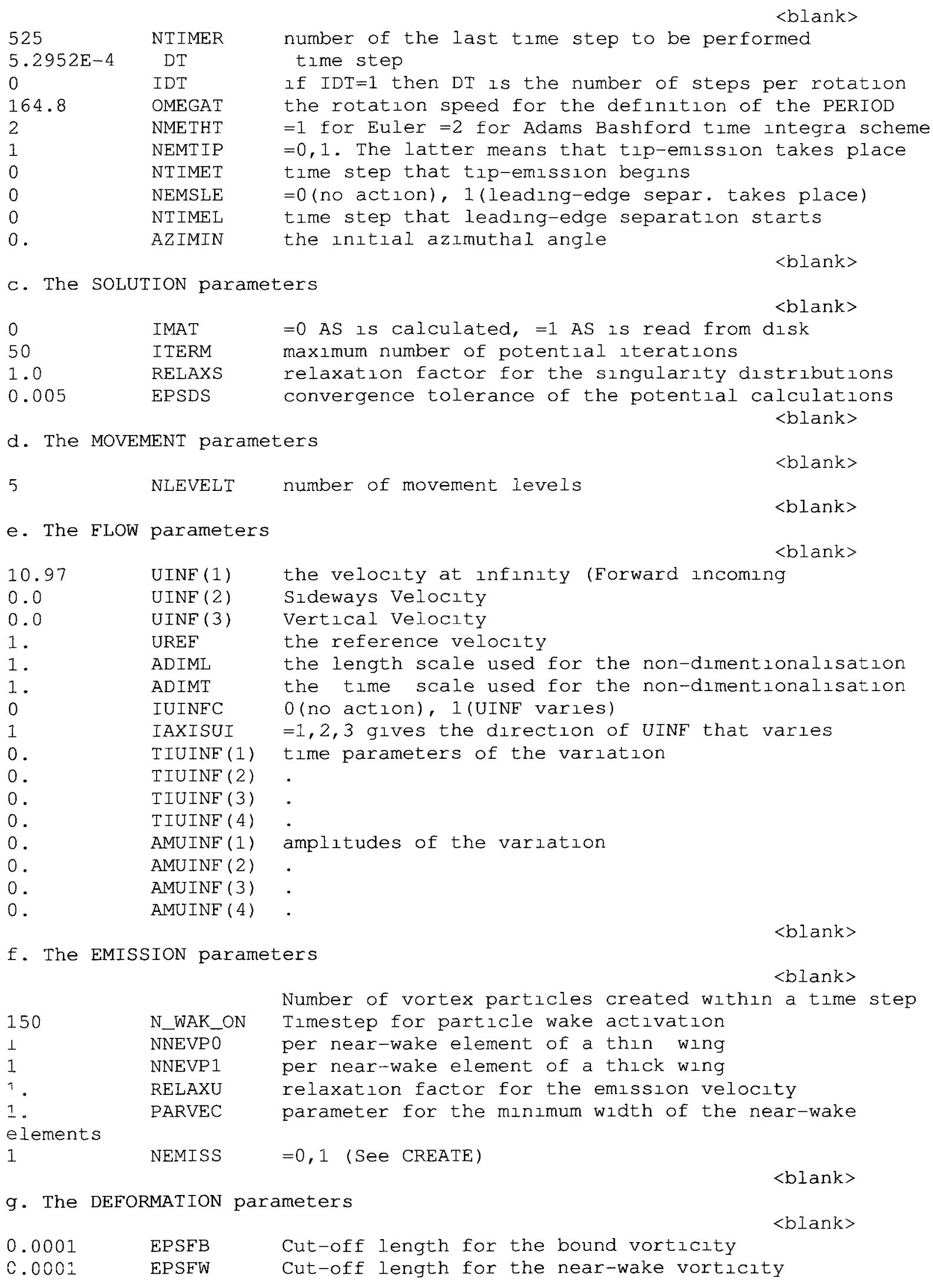




$\begin{array}{ll}0.005 & \text { EPSSRC } \\ 0.0001 & \text { EPSDIP } \\ 0.050 & \text { EPSVR } \\ 0.050 & \text { EPSO } \\ 0.0050 & \text { EPSINT } \\ 0 . & \text { COEF } \\ 0.001 & \text { RMETM } \\ 1 & \text { IDEFW } \\ 1000 . & \text { REFLEN } \\ 0 & \text { IDIVVRP } \\ 1000 . & \text { FLENSC } \\ 0 & \text { NREWAK } \\ 0 & \text { NMER } \\ 0 . & \text { XREWAK } \\ 0 . & \text { RADMER }\end{array}$

Cut-off length for source distributions

Cut-off length for dipole distributions

Cut-off length for the free vortex particles (final)

Cut-off length for the free vortex particles (init.)

cut-off length for VORTEX SOLID INTERACTION

Factor for the disipation of particles

Upper bound of the deformation rate

Parameter for the deformation induced by the near wake Length used in VELEF for suppresing far-particle calc. Parameter for the subdivision of particles Length scale for the subdivision of particles Parameter for merging of particles Parameter for merging of particles $X$ starting distance of merging Radius for merging

h. The FORCE parameters

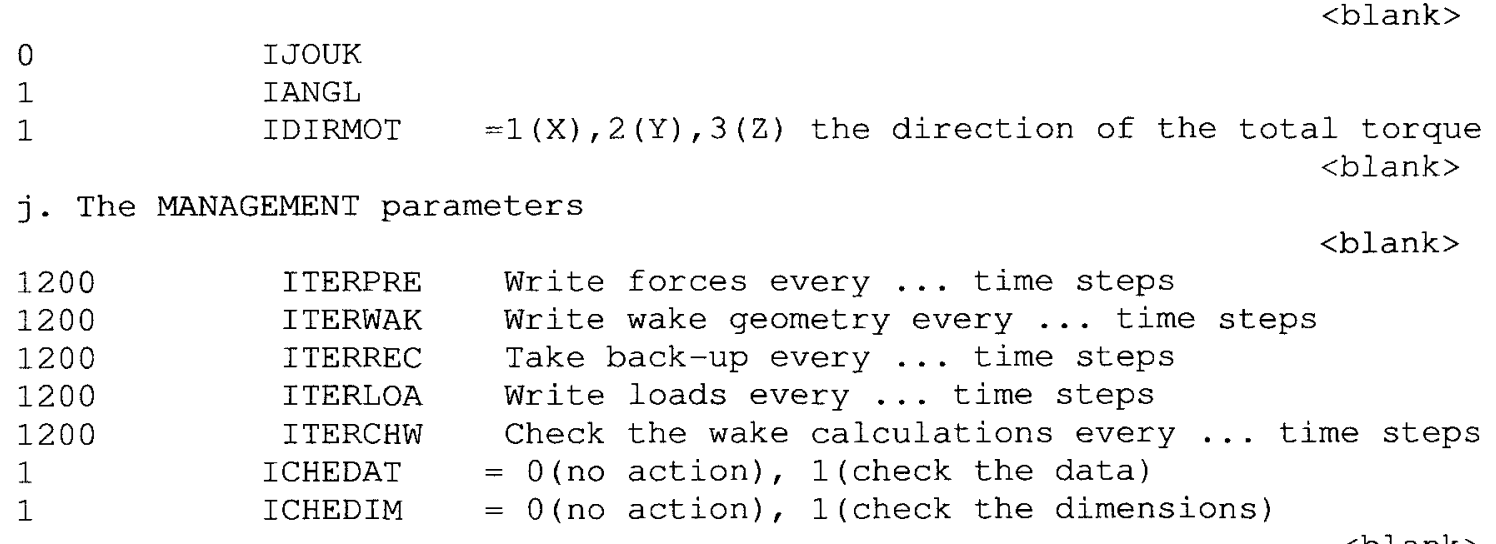

i. The FLUID parameters

$<$ blank $>$

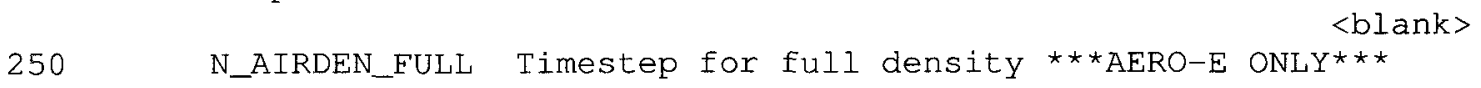
1.255 AIRDEN Fluid density

0.0000156 VISCO Kinematic viscosity

338.6 VSOUND Speed of sound

k. The APPLICATION parameters

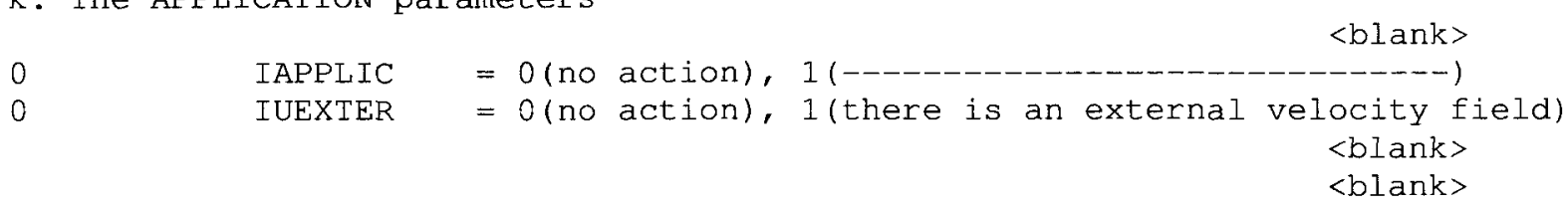

GIVE THE NAME OF THE DATA FILE FOR THE BODIES OF THE CONFIGURATION

$\begin{array}{lll}\text { CH47C.geo } & \text { FILEGEO } \\ & \text { FILEGO } & \begin{array}{c}\text { the data file for the geometry of the configuration } \\ \text { (See DGEOM-3. frm format file, Subr. INITGEO and } \\ \text { gnvp-3.txt) }\end{array} \\ 0 & \text { IYNELST } & \\ \text { elastin.dIr } & \text { FILELAST } \\ 0 & \text { NTIMELST } \\ 0 & \text { IYNSHIFT }\end{array}$




\section{A.5 CH47C.geo}

This is the *.geo which define the rotational parameters of the rotor blades. This file lists the parameters for each of the 4 blades.

The important parameters are:

NNBB $=9$, number of aerodynamic chordwise nodes

NCWB $=17$, number of aerodynamic spanwise nodes

TMOVEAB-4 = 164.8, rotational velocity (rad/s), located in (LOCAL ---> CYCLIC)

AMOVEAB-1 = 12.0, collective pitch (degrees), located in (LOCAL ---> CYCLIC)

AMOVEAB-1 = -1.35 , shaft tilt angle (degrees), located in (GLOBAL ---> MAIN DISC TILT ANGLE)

Global Shaft Rotation Input:

This is not as apparent, and must be listed like this:

$\begin{array}{llll}\text { NB }=1, \text { lev }=3 & \text { (GLOBAL } & -->\text { MAIN SHAFT ROTATION) } \\ \text { Rotation } & \text { IMOVEAB } & \text { type of ROTAIONAL movement } \\ 1 & \text { NAXISA } & =1,2,3 \text { axis of rotation } \\ 3 & \text { TMOVEAB } & -1 & 1 \text { st time step } \\ 0.00001 & \text { TMOVEAB } & -2 & 2 \text { nd time step } \\ 10.0 & \text { TMOVEAB } & -3 & 3 \text { rd time step } \\ 0 . & \text { TMOVEAB } & -4 & 4 \text { th time step } \\ 0 . & \text { AMOVEAB } & -1 & \text { ist value of amplitude } \\ 0 . & \text { AMOVEAB } & -2 & \text { 2nd value of amplitude } \\ 94424 . & \text { AMOVEAB } & -3 & 3 r d \text { value of amplitude } \\ 0 . & \text { AMOVEAB } & -4 & 4 t h \text { value of amplitude } \\ 0 . & \text { FILTMSA } & \text { file name for TIME SERIES [IMOVEB=6] }\end{array}$

TMOVEAD-1 specifies the time (seconds) at the first time step, and must be nonzero 0.00001 . TMOVEAD-2 specifies the last time (seconds) at the end of the simulation, and can be at a time much large than the actual simulation run, so 10 seconds is sufficient.

AMOVEAD-1 specifies the first azimuth position of the blade 1 , at time 0.00001 seconds. In this case it begins at $0^{\circ}$.

AMOVEAD-2 specifies the final azimuth position of the blade 1 , at time 10 seconds. In this case it begins at $0^{\circ}$. To calculate AMOVEAD-2 follow this equation:

$$
=(10 \mathrm{~s}-0.0001 \mathrm{~s})\left(164.8 \mathrm{rad} / \mathrm{s} \cdot \frac{180^{\circ}}{\pi}\right)=95,524^{\circ}
$$

For subsequent blades, increase AMOVEAD-1 and AMOVEAD-2, by blade separation angle increments of $90^{\circ}$. So at blade 2 :

90. AMOVEAB -1 lst value of amplitude

94514. AMOVEAB -2 2nd value of amplitude 


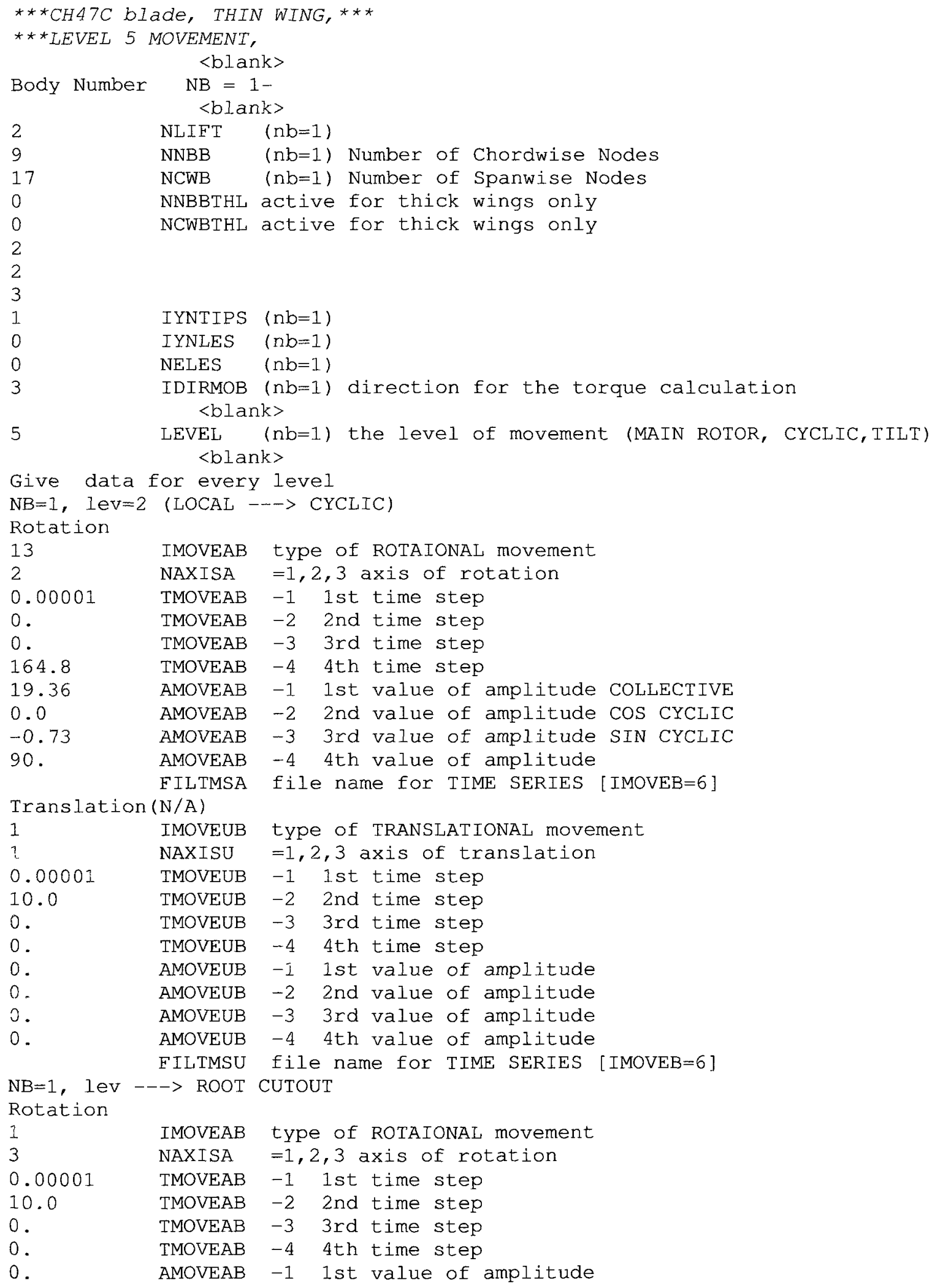




\begin{tabular}{|c|c|c|}
\hline 0 . & AMOVEAB & 2nd value of amplitude \\
\hline 0 . & AMOVEAB & 3rd value of amplitude \\
\hline \multirow[t]{2}{*}{0} & AMOVEAB & 4th value of amplitude \\
\hline & EILTMSA & file name for TIME SERIES [IMOVEB=6] \\
\hline \multicolumn{3}{|c|}{ Translation (N/A) } \\
\hline 1 & IMOVEUB & type of TRANSLATIONAL movement \\
\hline 2 & NAXISU & $=1,2,3$ axis of translation \\
\hline 0.00001 & TMOVEUB & 1st time step \\
\hline 10.0 & TMOVEUB & 2nd time step \\
\hline 0 . & TMOVEUB & 3rd time step \\
\hline 0 . & TMOVEUB & 4th time step \\
\hline 0 . & AMOVEUB & 1st value of amplitude \\
\hline 0. & AMOVEUB & 2nd value of amplitude \\
\hline 0 . & AMOVEUB & 3rd value of amplitude \\
\hline \multirow[t]{2}{*}{0} & AMOVEUB & -4 4th value of amplitude \\
\hline & EILTMSU & file name for TIME SERIES [IMOVEB=6] \\
\hline \multicolumn{3}{|l|}{$\begin{array}{l}\mathrm{NB}=1, \quad \text { lev }=3 \\
\text { Rotation }\end{array}$} \\
\hline 1 & IMOVEAB & type of ROTAIONAL movement \\
\hline 3 & NAXISA & $=1,2,3$ axis of rotation \\
\hline 0.00001 & TMOVEAB & -1 lst time step \\
\hline 10.0 & TMOVEAB & 2nd time step \\
\hline 0 & TMOVEAB & 3rd time step \\
\hline 0 . & TMOVEAB & 4th time step \\
\hline 0. & AMOVEAB & 1st value of amplitude \\
\hline 94424 . & AMOVEAB & 2nd value of amplitude \\
\hline 0. & AMOVEAB & 3rd value of amplitude \\
\hline \multirow[t]{2}{*}{0} & AMOVEAB & 4th value of amplitude \\
\hline & FILTMSA & file name for TIME SERIES [IMOVEB=6] \\
\hline \multicolumn{3}{|c|}{ Translation (N/A) } \\
\hline 1 & IMOVEUB & type of TRANSLATIONAL movement \\
\hline 1 & NAXISU & $=1,2,3$ axis of translation \\
\hline 0.00001 & TMOVEUB & -1 1st time step \\
\hline 10.0 & TMOVEUB & 2nd time step \\
\hline 0 . & TMOVEUB & 3rd time step \\
\hline 0 . & TMOVEUB & 4th time step \\
\hline 0 . & AMOVEUB & lst value of amplitude \\
\hline 0 . & AMOVEUB & 2nd value of amplitude \\
\hline 0. & AMOVEUB & 3rd value of amplitude \\
\hline \multirow[t]{2}{*}{0 . } & AMOVEUB & $-4 \quad 4 t h$ value of amplitude \\
\hline & EILTMSU & file name for TIME SERIES [IMOVEB=6] \\
\hline $\begin{array}{l}\mathrm{NB}=1, \text { lev }=4 \\
\text { Rotation }\end{array}$ & (GLOBAL & $-->$ MAIN DISC TILT ANGLE) \\
\hline I & IMOVEAB & type of ROTAIONAL movement \\
\hline 2 & NAXISA & $=1,2,3$ axis of rotation \\
\hline 0.00001 & TMOVEAB & -1 1st time step \\
\hline 10.0 & TMOVEAB & 2nd time step \\
\hline 0 . & TMOVEAB & 3rd time step \\
\hline 0. & TMOVEAB & 4th time step \\
\hline-1.35 & AMOVEAB & 1st value of amplitude \\
\hline-1.35 & AMOVEAB & 2nd value of amplitude \\
\hline 0 . & AMOVEAB & 3rd value of amplitude \\
\hline \multirow[t]{2}{*}{0} & AMOVEAB & 4th value of amplitude \\
\hline & EILTMSA & file name for TIME SERIES [IMOVEB=6] \\
\hline \multicolumn{3}{|c|}{ Translation (N/A) } \\
\hline 1 & IMOVEUB & type of TRANSLATIONAL movement \\
\hline 1 & NAXISU & $=1,2,3$ axis of translation \\
\hline
\end{tabular}




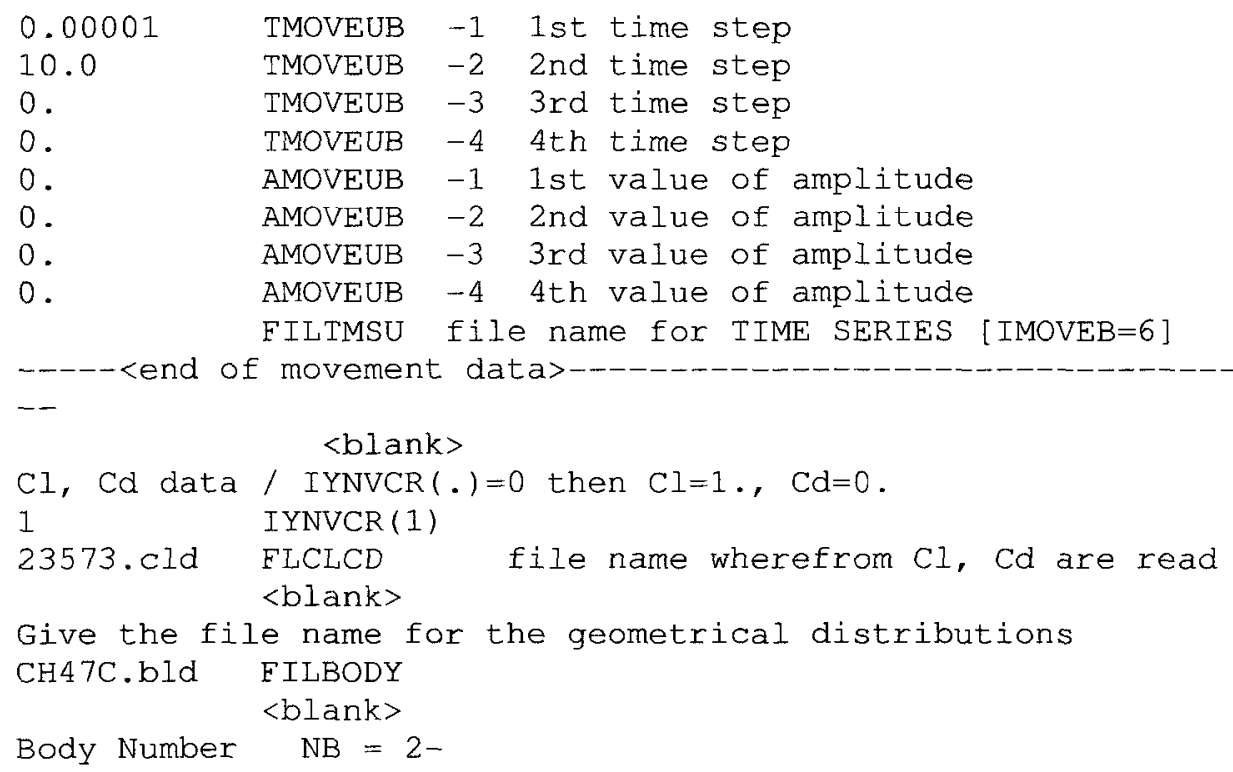

The file then repeats the content for each blade, whereby the only subsequent changes occur in Global Shaft Rotation Input Section, and is explained at the top of this section.

\section{A.6 CH47C.bld}

This is the *.bld which define the blade geometry specific only for the aerodynamic grid. The structural blade geometry is defined in file inputc.dat.

The variables of importance are for a simply constructed blade:

$\mathrm{RC}(1)=0.16$, root cut in meters.

$\mathrm{RC}(\mathrm{NCW})=0.8321$, blade radius in meters.

$\mathrm{FCCH}(1)=0.0582$, chord in meters

FCTW $(1)=0.03796$, imagined blade twist at the rotor centre in radians.

FCTW $(2)=-0.23735$, rate of blade twist across span, cut in radians/meter.

$\mathrm{FCXO}(1)=-0.25$, location of blade leading edge relative to the spanwise axis of blade, as chord fraction.

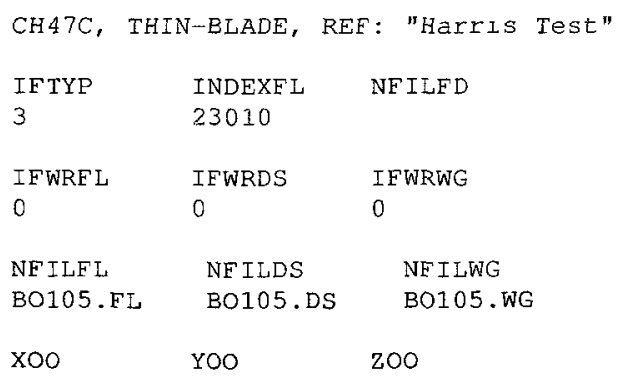




\begin{tabular}{|c|c|c|c|c|c|c|c|}
\hline 0.0 & 0.0 & 0.0 & & & & & \\
\hline $\mathrm{PITCH}$ & DELTA & WNGANG & & & & & \\
\hline 0.0 & 0.0 & 0.0 & & & & & \\
\hline IEXKS & NFILKS & AKSI (1) & AKSI (NNB) & & & & \\
\hline 1 & KS. nod & 0 & 1. & & & & \\
\hline IEXRC & NFILRC & $\mathrm{RC}(1)$ & $\mathrm{RC}$ (NCW) & & & & \\
\hline 1 & Bo. nod & 0.16 & 0.8321 & & & & \\
\hline IEXCH & $\mathrm{NF} I \mathrm{LCH}$ & $\mathrm{FCCH}(1)$ & $\mathrm{FCCH}(2)$ & $\mathrm{FCCH}(3)$ & $\mathrm{FCCH}(4)$ & $\mathrm{FCCH}(5)$ & $\mathrm{FCCH}(6)$ \\
\hline 4 & & 0.0582 & 0. & 0. & 0. & 0. & 0 . \\
\hline IEXTW & NEILTW & $\operatorname{FCTW}(1)$ & ECTW (2) & $\operatorname{ECTW}(3)$ & $\operatorname{FCTW}(4)$ & FCTW (5) & $\operatorname{ECTW}(6)$ \\
\hline 4 & & 0.03796 & -0.23735 & 0 & 0 & 0 & 0 . \\
\hline IEXXO & NF I LXO & $\mathrm{FCXO}(1)$ & FCXO (2) & FCXO (3) & $\mathrm{FCXO}(4)$ & FCXO(5) & FCXO $(6)$ \\
\hline 4 & & -0.25 & 0 & 0. & 0 & 0 & 0. \\
\hline IEXZO & NF ILZO & $\mathrm{FCzO}(1)$ & FCZO (2) & FCZO (3) & $\mathrm{FCZO}(4)$ & $\mathrm{FCZO}(5)$ & FCZO $(6)$ \\
\hline 4 & & 0 & 0. & 0. & 0. & 0 & 0 \\
\hline IEXRT & NF I LRT & FCRT (1) & FCRT (2) & FCRT (3) & $\operatorname{FCRT}(4)$ & FCRT (5) & $\operatorname{FCRT}(6)$ \\
\hline 4 & & 0 . & 0. & 0. & 0. & 0. & 0. \\
\hline
\end{tabular}

\section{A.7 23573.cld}

This file lists the coefficients of lift, drag and moments for the V23010-1.58 airfoil, adjusted to a nominal lift slope of $5.73 \mathrm{rad} / \mathrm{s}$, as shown in Chapter 4. It defines each coefficient through a pitch range of $-20^{\circ}$ to $20^{\circ}$, and from Mach 0.0 to 1.0 .

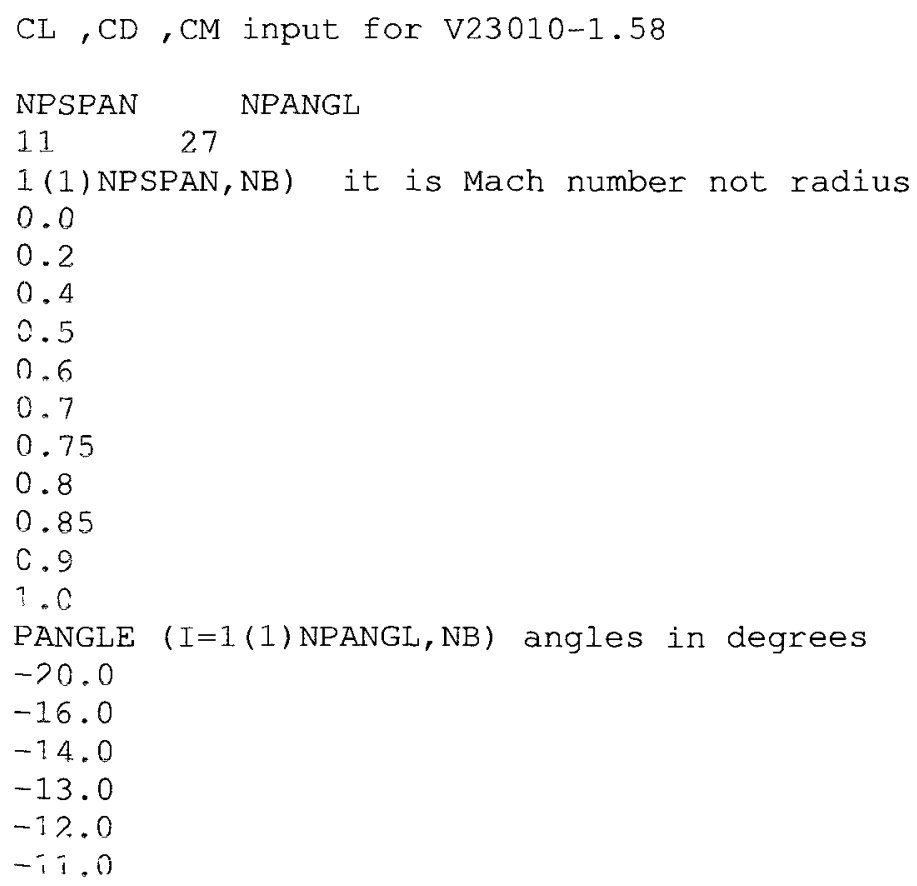




$$
\begin{aligned}
& -10.0 \\
& -9.0 \\
& -8.0 \\
& -7.0 \\
& -6.0 \\
& -4.0 \\
& -2.0 \\
& 0.0 \\
& 2.0 \\
& 4.0 \\
& 6.0 \\
& 7.0 \\
& 8.0 \\
& 9.0 \\
& 10.0 \\
& 11.0 \\
& 12.0 \\
& 13.0 \\
& 14.0 \\
& 16.0 \\
& 20.0
\end{aligned}
$$

\begin{tabular}{|c|c|c|c|c|c|c|c|c|}
\hline \multicolumn{3}{|c|}{ For Mach 0.0} & \multicolumn{3}{|c|}{ For Mach 0.2} & \multicolumn{3}{|c|}{ For Mach 0.4} \\
\hline-0.542 & 0.140 & 0.155 & -0.531 & 0.140 & 0.138 & -0.304 & 0.137 & 0.122 \\
\hline-0.936 & 0.055 & 0.130 & -0.915 & 0.055 & 0.114 & -0.697 & 0.054 & 0.098 \\
\hline-1.132 & 0.032 & 0.023 & -1.107 & 0.032 & 0.029 & -0.894 & 0.031 & 0.034 \\
\hline-1.230 & 0.024 & 0.023 & -1.203 & 0.024 & 0.021 & -0.992 & 0.023 & 0.019 \\
\hline-1.230 & 0.018 & 0.023 & -1.203 & 0.018 & 0.022 & -1.090 & 0.017 & 0.020 \\
\hline-1.132 & 0.013 & 0.023 & -1.107 & 0.013 & 0.022 & -1.108 & 0.012 & 0.021 \\
\hline-1.033 & 0.009 & 0.023 & -1.010 & 0.009 & 0.022 & -1.047 & 0.009 & 0.020 \\
\hline-0.934 & 0.006 & 0.021 & -0.914 & 0.006 & 0.020 & -0.947 & 0.006 & 0.019 \\
\hline-0.836 & 0.004 & 0.021 & -0.817 & 0.004 & 0.020 & -0.847 & 0.004 & 0.019 \\
\hline-0.737 & 0.003 & 0.019 & -0.721 & 0.003 & 0.018 & -0.747 & 0.003 & 0.017 \\
\hline-0.638 & 0.002 & 0.018 & -0.624 & 0.002 & 0.017 & -0.647 & 0.002 & 0.016 \\
\hline-0.441 & 0.001 & 0.011 & -0.431 & 0.001 & 0.012 & -0.447 & 0.001 & 0.013 \\
\hline-0.242 & 0.001 & -0.005 & -0.237 & 0.001 & -0.001 & -0.261 & 0.001 & 0.002 \\
\hline-0.046 & 0.001 & -0.007 & -0.045 & 0.001 & -0.008 & -0.046 & 0.001 & -0.008 \\
\hline 0.148 & 0.001 & -0.010 & 0.145 & 0.001 & -0.010 & 0.155 & 0.001 & -0.010 \\
\hline 0.343 & 0.001 & -0.011 & 0.335 & 0.001 & -0.012 & 0.343 & 0.001 & -0.013 \\
\hline 0.544 & 0.001 & -0.018 & 0.532 & 0.001 & -0.017 & 0.544 & 0.001 & -0.016 \\
\hline v. 646 & $\hat{U} \cdot \hat{U} L$ & $-\dot{u} \hat{u}$ & 0.032 & U. Uิ์ & $-\hat{u} . \hat{v}=0$ & 0.040 & $\hat{U} . \hat{U} \tilde{I}$ & $-6.3 \pm 7$ \\
\hline 0.754 & 0.001 & -0.021 & 0.737 & 0.001 & -0.020 & 0.754 & 0.001 & -0.019 \\
\hline 0.842 & 0.001 & -0.021 & 0.824 & 0.001 & -0.020 & 0.855 & $\hat{0} .001$ & -0.019 \\
\hline 0.946 & 0.001 & -0.023 & 0.925 & 0.001 & -0.022 & 0.946 & 0.001 & -0.020 \\
\hline 1.038 & 0.001 & -0.023 & 1.015 & 0.001 & -0.022 & 1.048 & 0.001 & -0.021 \\
\hline 1.128 & 0.002 & -0.023 & 1.104 & 0.002 & -0.022 & 1. 128 & 0.002 & -0.020 \\
\hline I. 218 & 0.003 & -0.023 & 1.192 & 0.003 & -0.021 & 1.189 & 0.003 & -0.019 \\
\hline 1.314 & 0.004 & -0.023 & 1.285 & 0.004 & -0.029 & 1.171 & 0.004 & -0.034 \\
\hline 1.215 & 0.009 & -0.130 & 1.189 & 0.009 & -0.114 & 0.975 & 0.009 & -0.098 \\
\hline 0.822 & 0.032 & -0.155 & 0.804 & 0.032 & -0.138 & 0.582 & 0.031 & -0.122 \\
\hline
\end{tabular}

The Mach data is listed in the table below: ( $1^{\text {st }}$ column is $C_{L}, 2^{\text {nd }}$ column is $C_{D}, 3^{\text {rd }}$ column is $C_{M}$ ) 


\begin{tabular}{|c|c|c|c|c|c|c|c|c|}
\hline For Mach & 0.5 & & For Mach & 0.6 & & For Mach & 0.7 & \\
\hline-0.135 & 0.162 & 0.100 & 0.000 & 0.187 & 0.094 & 0.000 & 0.254 & 0.094 \\
\hline-0.554 & 0.072 & 0.097 & -0.274 & 0.090 & 0.094 & -0.037 & 0.116 & 0.094 \\
\hline-0.764 & 0.044 & 0.083 & -0.502 & 0.060 & 0.090 & -0.268 & 0.074 & 0.094 \\
\hline-0.868 & 0.034 & 0.069 & -0.615 & 0.048 & 0.087 & -0.383 & 0.058 & 0.091 \\
\hline-0.973 & 0.026 & 0.050 & -0.729 & 0.038 & 0.076 & -0.498 & 0.045 & 0.082 \\
\hline-0.980 & 0.019 & 0.023 & -0.843 & 0.030 & 0.062 & -0.614 & 0.035 & 0.070 \\
\hline-0.970 & 0.014 & 0.005 & -0.832 & 0.023 & 0.044 & -0.729 & 0.027 & 0.056 \\
\hline-0.923 & 0.010 & 0.008 & -0.807 & 0.017 & 0.022 & -0.718 & 0.020 & 0.042 \\
\hline-0.884 & 0.007 & 0.010 & -0.781 & 0.013 & 0.007 & -0.692 & 0.015 & 0.023 \\
\hline-0.779 & 0.005 & 0.012 & -0.756 & 0.010 & -0.002 & -0.667 & 0.011 & 0.002 \\
\hline-0.675 & 0.003 & 0.013 & -0.714 & 0.007 & 0.003 & -0.642 & 0.009 & -0.014 \\
\hline-0.465 & 0.001 & 0.011 & -0.434 & 0.004 & -0.005 & -0.572 & 0.005 & -0.026 \\
\hline-0.253 & 0.001 & -0.006 & -0.248 & 0.002 & -0.008 & -0.302 & 0.002 & -0.014 \\
\hline-0.046 & 0.001 & -0.006 & -0.030 & 0.001 & -0.008 & -0.042 & 0.001 & -0.007 \\
\hline 0.167 & 0.001 & -0.009 & 0.205 & 0.001 & -0.010 & 0.222 & 0.001 & -0.005 \\
\hline 0.362 & 0.001 & -0.011 & 0.426 & 0.001 & -0.011 & 0.475 & 0.002 & -0.007 \\
\hline 0.582 & 0.001 & -0.013 & 0.653 & 0.002 & -0.008 & 0.650 & 0.003 & -0.039 \\
\hline 0.678 & 0.001 & -0.012 & 0.742 & 0.003 & -0 . & 0.678 & 0.005 & -0.052 \\
\hline 0.797 & 0.001 & -0.010 & 0.809 & 0.004 & -0 & 0.719 & 0.006 & -0.061 \\
\hline 0.898 & 0.001 & -0.008 & 0.850 & 0.006 & -0.036 & 0.744 & 0.009 & -0.071 \\
\hline 0.971 & 0.002 & -0.005 & 0.875 & 0.008 & -0.057 & 0.770 & 0.011 & -0.078 \\
\hline 1.010 & 0.003 & -0.023 & 0.901 & 0.011 & -0.076 & 0.796 & 0.015 & -0 \\
\hline 1.056 & 0.005 & -0.050 & 0.927 & 0.015 & -0.090 & 0.807 & 0. & -0.092 \\
\hline 1.067 & 0.007 & -0.069 & 0.938 & 0.020 & -0.101 & 0.691 & 0.027 & -0.097 \\
\hline 1.060 & 0.010 & -0.083 & 0.824 & 0.026 & -0.104 & 0.576 & 0.035 & -0.100 \\
\hline 0.850 & 0.019 & -0.097 & 0.596 & 0.043 & -0.107 & 0.345 & 0.058 & -0.100 \\
\hline 0.431 & 0.057 & -0.100 & 0.141 & 0.100 & -0.107 & 0.000 & 0.142 & -0.100 \\
\hline Mach & 0.75 & & Mach & .8 & & Mach & .85 & \\
\hline 0.000 & 0.295 & 0.094 & 0.000 & 0.336 & 0.094 & 0.000 & 0.418 & 0.094 \\
\hline 0.000 & 0.132 & 0.094 & 0.000 & 0.149 & 0.094 & 0.000 & 0.183 & 0.094 \\
\hline 0.000 & 0.084 & 0.094 & 0.000 & 0.094 & 0.094 & 0.000 & 0.115 & 0.094 \\
\hline-0.050 & 0.066 & 0.094 & 0.000 & 0.074 & 0.094 & 0.000 & 0.089 & 0.094 \\
\hline-0.128 & 0.051 & 0.093 & -0.021 & 0.057 & 0.094 & 0.000 & 0.069 & 0.094 \\
\hline-0.243 & 0.040 & 0.087 & -0.117 & 0.044 & 0 . & 0.000 & 0.053 & 0.094 \\
\hline-0.358 & 0.030 & 0.075 & -0.222 & 0.034 & 0.086 & -0.010 & 0.040 & 0.094 \\
\hline-0.473 & 0.023 & 0.058 & -0.327 & 0.026 & 0.076 & -0.093 & 0.031 & 0.094 \\
\hline-0.588 & 0.017 & 0.040 & -0.431 & 0.019 & 0.065 & -0.176 & 0.023 & 0.096 \\
\hline-0.635 & 0.013 & 0.020 & -0.536 & 0.015 & 0.0 & -0.259 & 0.018 & 0.098 \\
\hline-0.516 & 0.010 & 0.001 & -0.575 & 0.012 & 0.0 & -0.342 & 0.014 & 0.099 \\
\hline-0.598 & 0.006 & -0.013 & -0.554 & 0.007 & 0.025 & -0.425 & 0.005 & 0.091 \\
\hline-0.392 & 0.003 & -0.022 & -0.449 & 0.004 & 0.006 & -0.364 & 0.004 & 0.058 \\
\hline-0.072 & 0.001 & -0.010 & -0.079 & 0.002 & -0.015 & -0.095 & 0.002 & -0.007 \\
\hline 0.252 & 0.003 & -0.012 & 0.307 & 0.004 & -0.044 & 0.286 & 0.005 & -0.100 \\
\hline 0.512 & 0.003 & -0.043 & 0.456 & 0.005 & -0.012 & 0.350 & 0.006 & -0.109 \\
\hline 0.618 & 0.005 & -0.070 & 0.549 & 0.006 & -0.083 & 0.403 & 0.008 & -0.102 \\
\hline 0.641 & 0.006 & -0.076 & 0.578 & 0.007 & -0.089 & 0.434 & 0.010 & $-0.10 I$ \\
\hline 0.671 & 0.008 & -0.082 & 0.608 & 0.009 & -0.094 & 0.461 & 0.012 & -0.101 \\
\hline 0.689 & 0.010 & -0.087 & 0.629 & 0.012 & -0.097 & 0.378 & 0.014 & -0.101 \\
\hline 0.707 & 0.013 & -0.093 & 0.590 & 0.015 & -0.100 & 0.295 & 0.018 & -0.100 \\
\hline 0.661 & 0.017 & -0.096 & 0.485 & 0.019 & -0.100 & 0.212 & 0.023 & -0.100 \\
\hline 0.546 & 0.023 & -0.098 & 0.380 & 0.026 & -0.100 & 0.129 & 0.031 & -0.100 \\
\hline 0.431 & 0.030 & -0.100 & 0.276 & 0.034 & -0.100 & 0.046 & 0.040 & -0.100 \\
\hline 0.316 & 0.040 & -0.100 & 0.171 & 0.044 & -0.100 & 0.000 & 0.053 & -0.100 \\
\hline 0.088 & 0.066 & -0.100 & 0.000 & 0.074 & -0.100 & 0.000 & 0.089 & -0.100 \\
\hline 0.000 & 0.164 & -0.100 & 0.000 & 0.185 & -0.100 & 0.000 & 0.228 & -0.100 \\
\hline
\end{tabular}




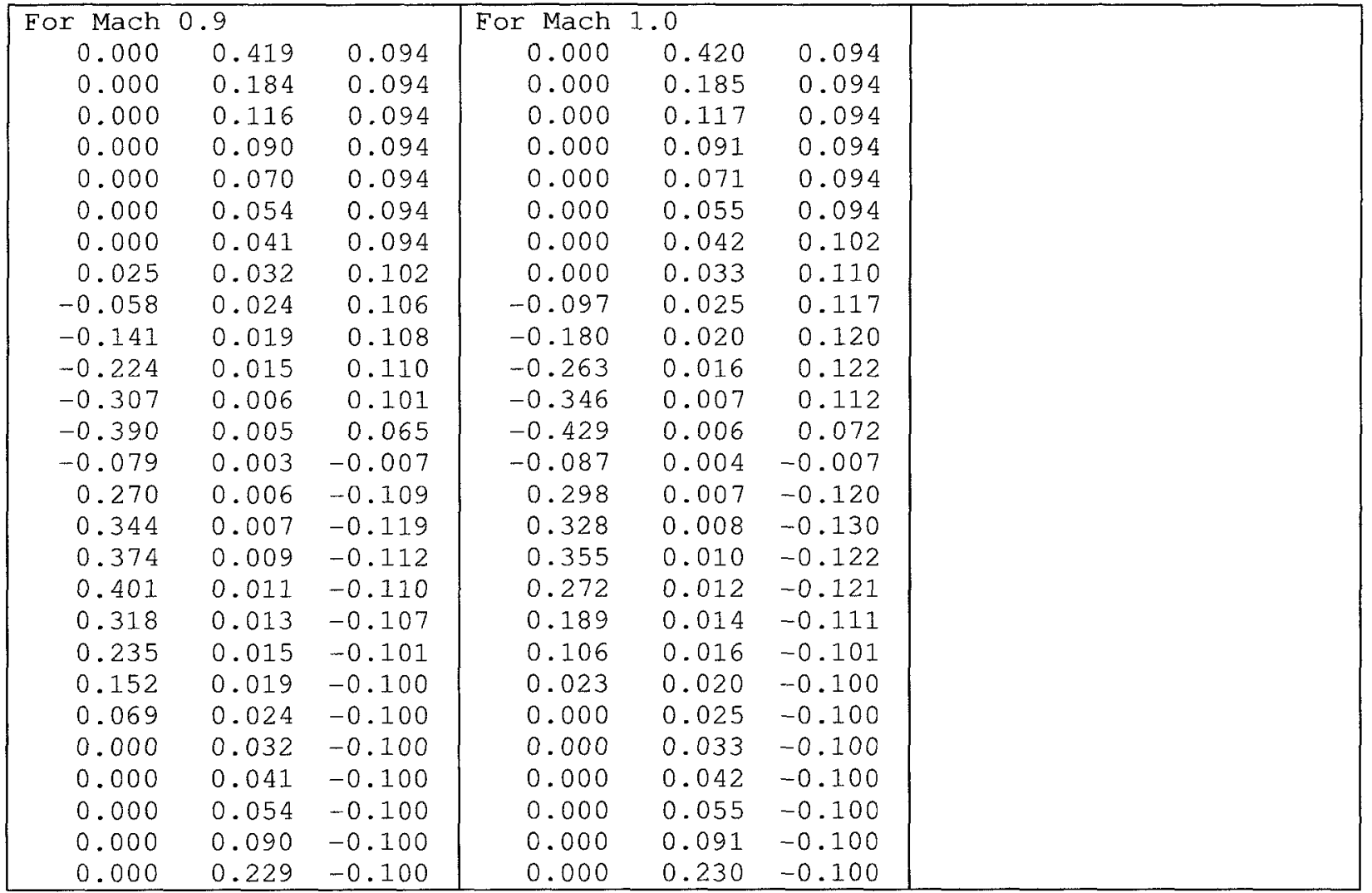

\section{A.6 inputc.dat}

This input file defines the structural component and articulation parameters.

The first two variables are important as:

$\mathrm{BC}$ is the variable that selects the hingeless mode $(\mathrm{BC}=0)$ or articulation mode $(\mathrm{BC}=1)$.

DEFORMONOFF selects the rigid model $(=0)$ or Cheng's articulation model $(=1)$

Make sure similar variables match in the preceding aerodynamic input files.

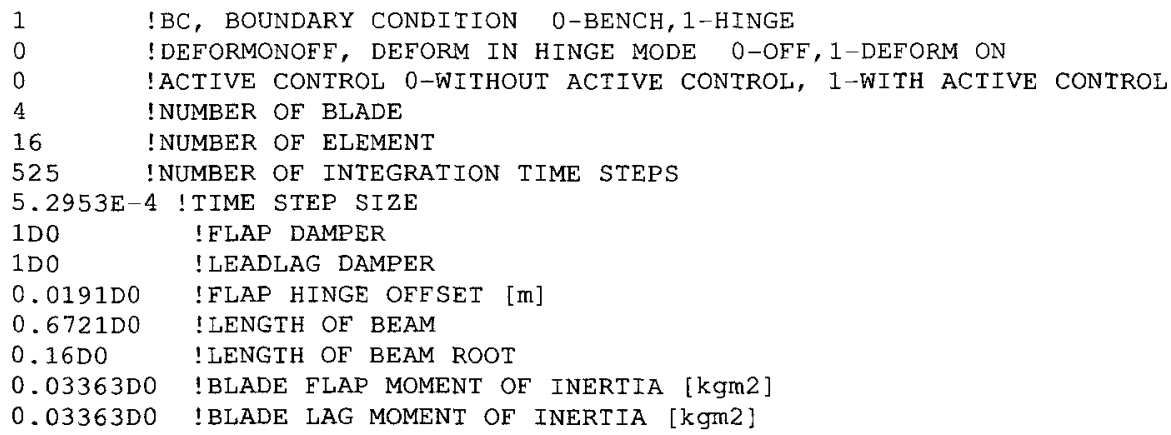




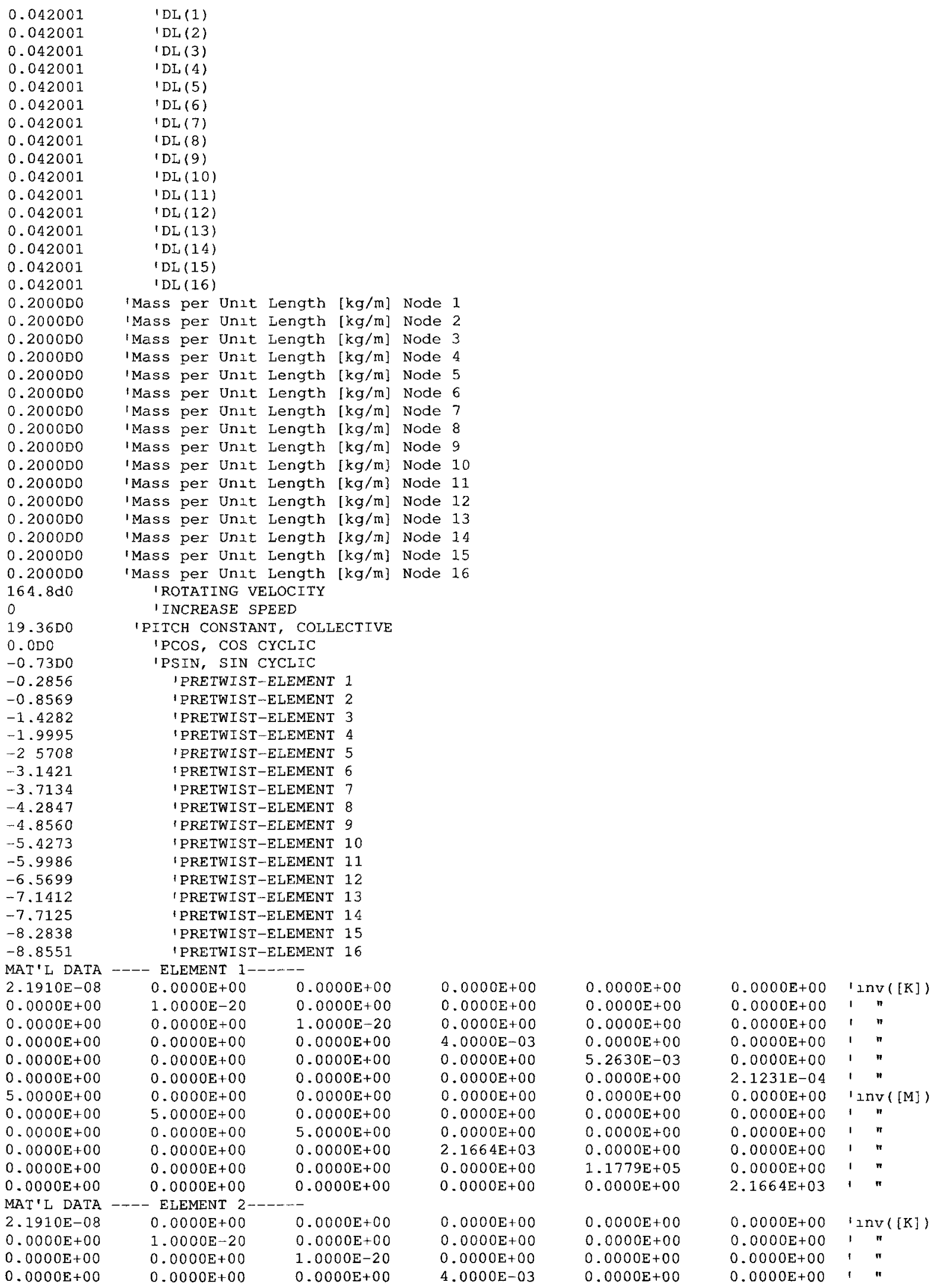


Appendix A SMARTROTOR User's Guide and Input Files

\begin{tabular}{|c|c|c|c|c|c|c|c|}
\hline $0.0000 \mathrm{E}+00$ & $0.0000 E+00$ & $0.0000 \mathrm{E}+00$ & $0.0000 \mathrm{E}+00$ & $5.2630 \mathrm{E}-03$ & $0.0000 \mathrm{E}+00$ & 1 & $n$ \\
\hline $0.0000 E+00$ & $0.0000 E+00$ & $0.0000 E+00$ & $0.0000 E+00$ & $0.0000 E+00$ & $2.1231 E-04$ & 1 & $n$ \\
\hline $5.0000 E+00$ & $0.0000 \mathrm{E}+00$ & $0.0000 \mathrm{E}+00$ & $0.0000 E+00$ & $0.0000 \mathrm{E}+00$ & $0.0000 \mathrm{E}+00$ & I & $\mathrm{VV}([\mathrm{M}])$ \\
\hline $0.0000 E+00$ & $5.0000 \mathrm{E}+00$ & $0.0000 \mathrm{E}+00$ & $0.0000 E+00$ & $0.0000 \mathrm{E}+00$ & $0.0000 \mathrm{E}+00$ & 1 & $n$ \\
\hline $0.0000 \mathrm{E}+00$ & $0.0000 \mathrm{E}+00$ & $5.0000 \mathrm{E}+00$ & $0.0000 \mathrm{E}+00$ & $0.0000 \mathrm{E}+00$ & $0.0000 \mathrm{E}+00$ & $i$ & $"$ \\
\hline $0.0000 \mathrm{E}+00$ & $0.0000 E+00$ & $0.0000 \mathrm{E}+00$ & $2.1664 E+03$ & $0.0000 \mathrm{E}+00$ & $0.0000 E+00$ & 1 & $n$ \\
\hline $0.0000 E+00$ & $0.0000 E+00$ & $0.0000 \mathrm{E}+00$ & $0.0000 E+00$ & $1.1779 E+05$ & $0.0000 E+00$ & 1 & $n$ \\
\hline $0.0000 E+00$ & $0.0000 E+00$ & $0.0000 \mathrm{E}+00$ & $0.0000 E+00$ & $0.0000 \mathrm{E}+00$ & $2.1664 \mathrm{E}+03$ & 1 & $"$ \\
\hline
\end{tabular}

The MAT'L DATA ---- ELEMENT \#------ repeats up to node 16. These are the inverted stiffness and mass matricies only used for the Opoku/Cheng's hingeless model, and not for the rigid model. 


\section{Appendix B SMARTROTOR Amended Source Code}

This Appendix summarizes the source code that has been changed from the previous version of SMARTROTOR. The full source code and files are not presented, due to the exorbitant length of the code. These sections provide the relevant code to the rigid blade model and modifications to allow for the Cheng articulation code to fully function.

\section{B.1 COMBINED_C.f}

B.1.1 This the main subroutine and it is stored in source file COMBINED_C.f.

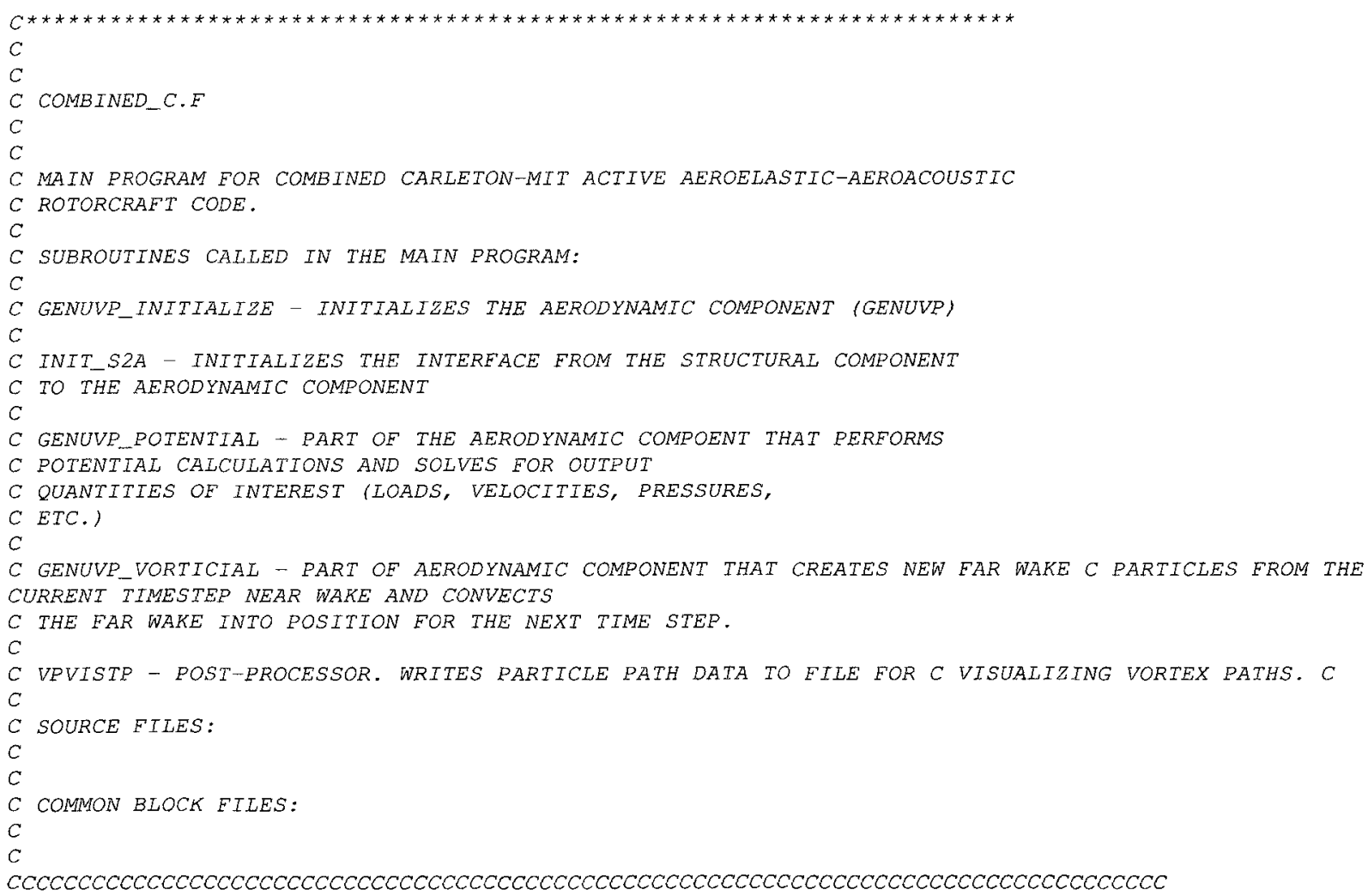

PROGRAM SMARTROTOR

C

INCLUDE 'Cgnvp-3.f' 


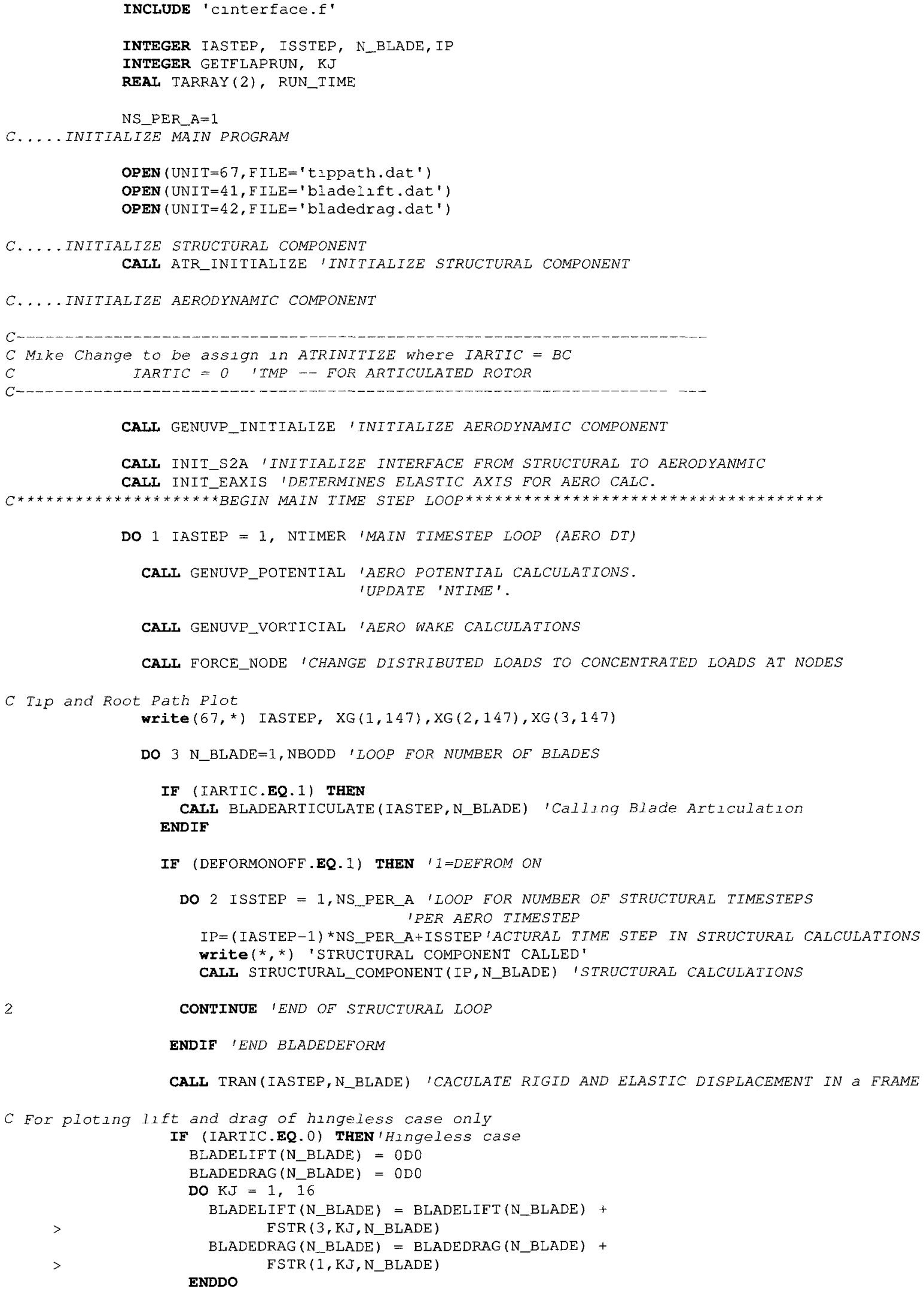

CALI. GENUVP_INITIALIZE 'INITIALIZE AERODYNAMIC COMPONENT

CALI INIT_S2A IINITIALIZE INTERFACE FROM STRUCTURAL TO AERODYANMIC 


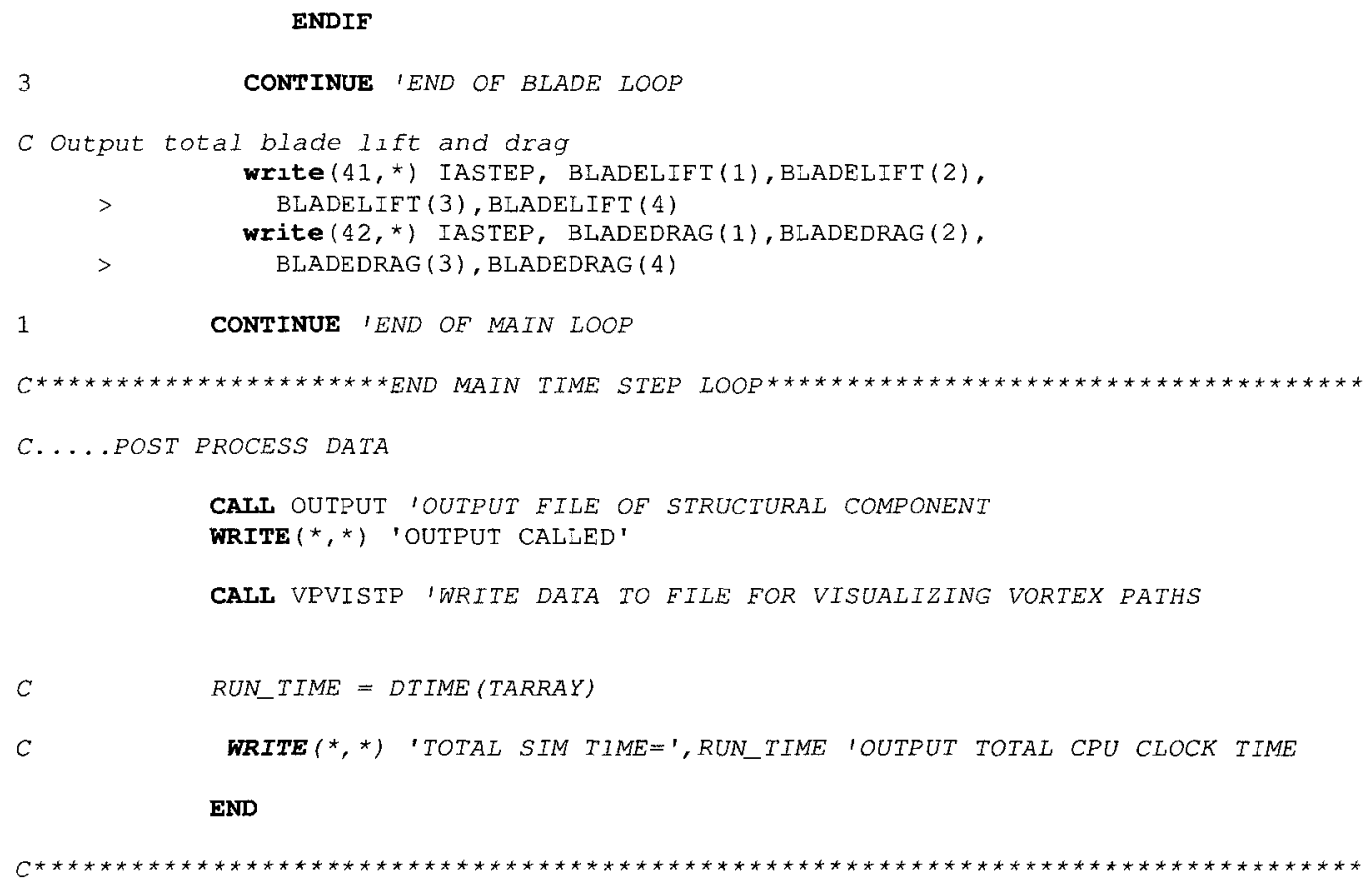

\section{B.2 gnvp-3.coupled.f}

\section{B.2.1 Subroutine GENUVP_POTENTIAL}

Only a portion of this file is show, as the changes only occurred in subroutine

GENUVP_POTENTIAL. This subroutine calls the subroutines that solve the aerodynamic changes around the blade. Subroutine ARTICULATE is turned off, as it was intended in for coupling Cheng's articulation model by Opoku, however this current version simplifies the blade articulation to occur in the TRAN subroutine located in source file couple.f.

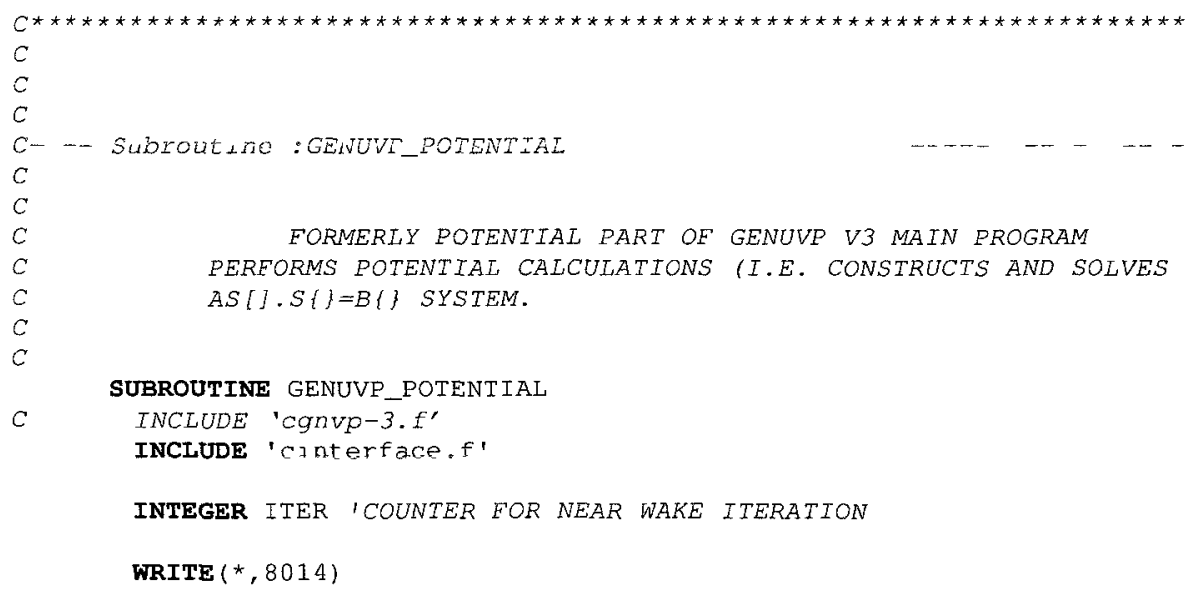




\section{Appendix B Amended Source Code}

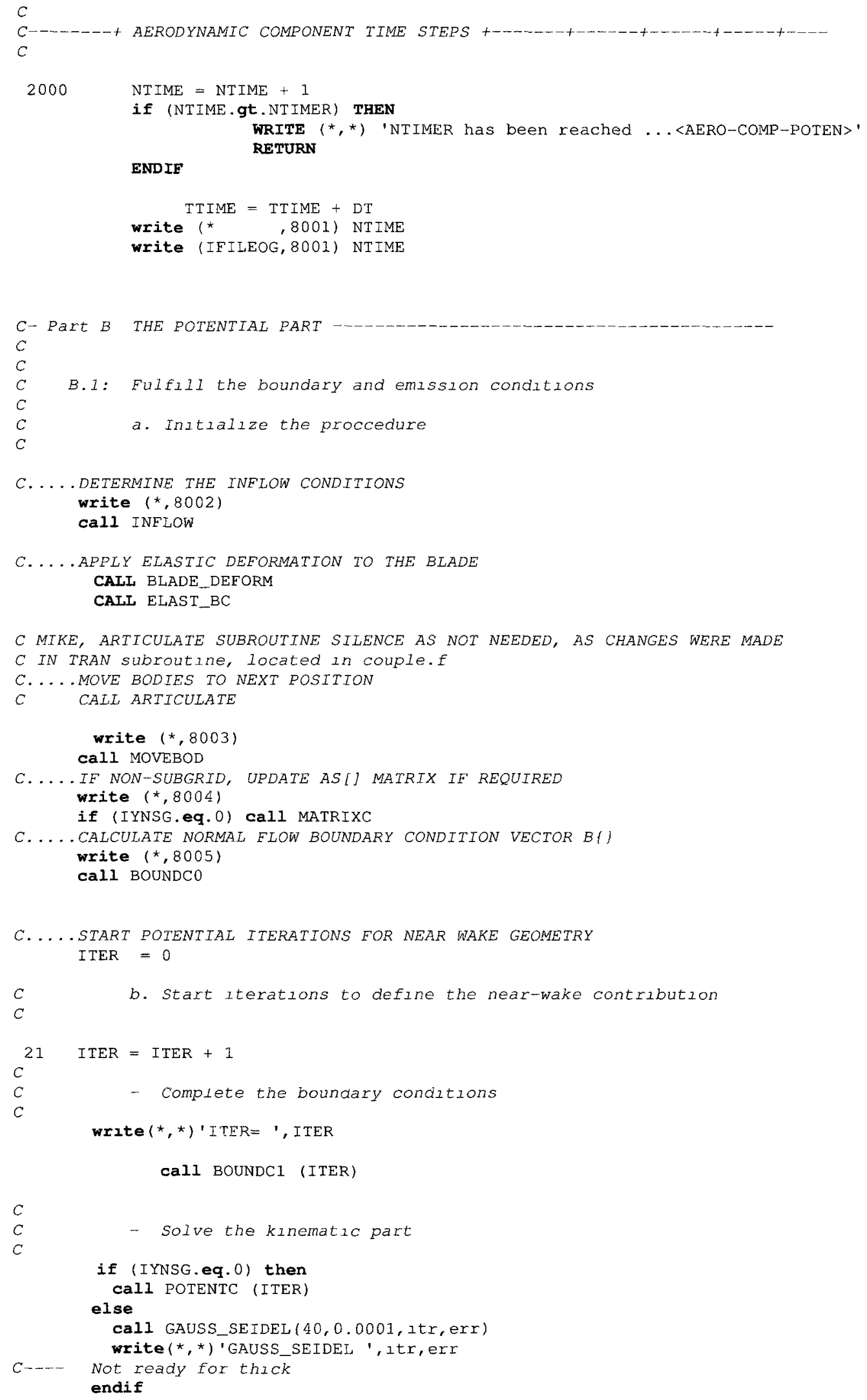




\section{Appendix B Amended Source Code}

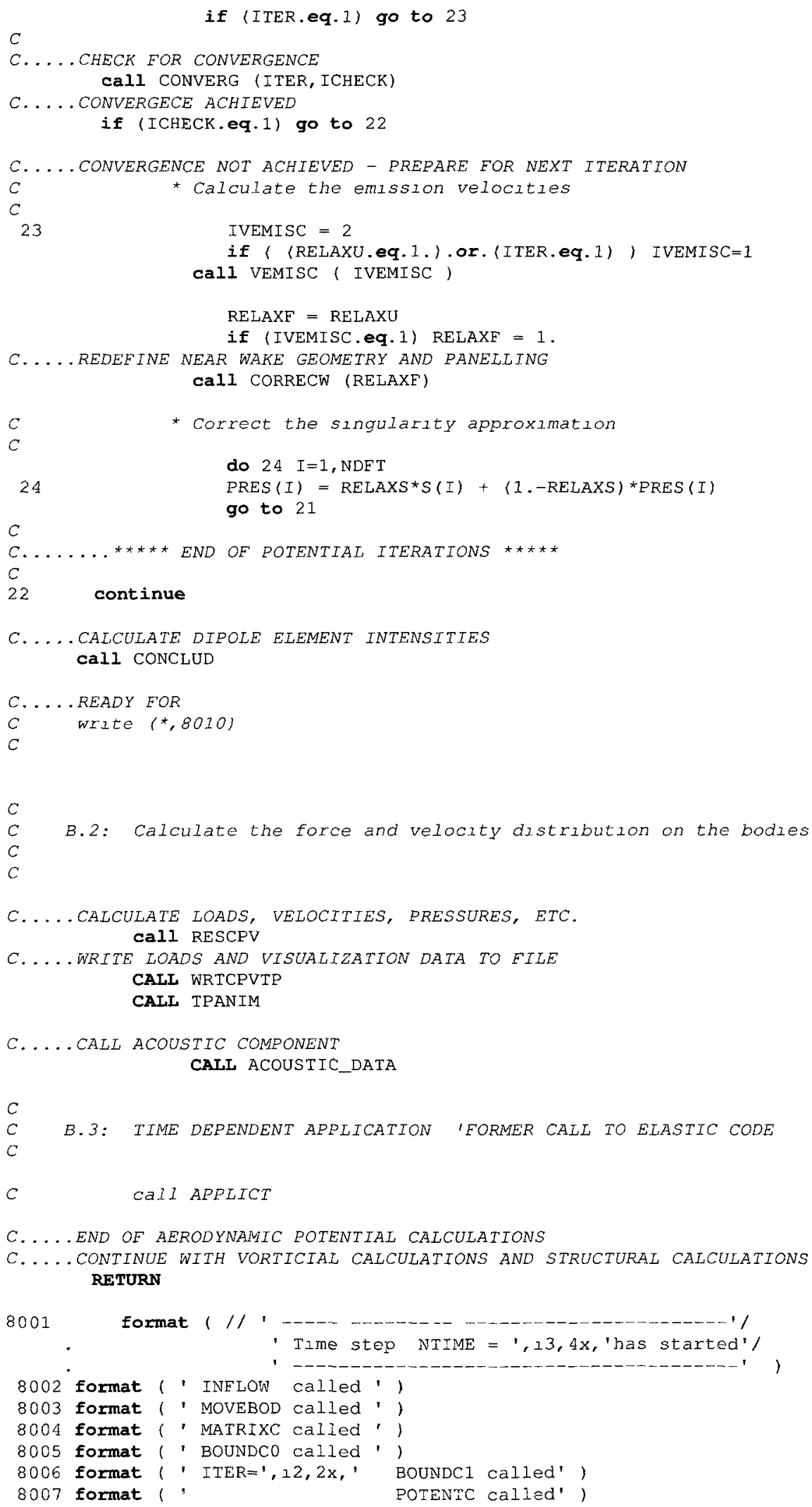




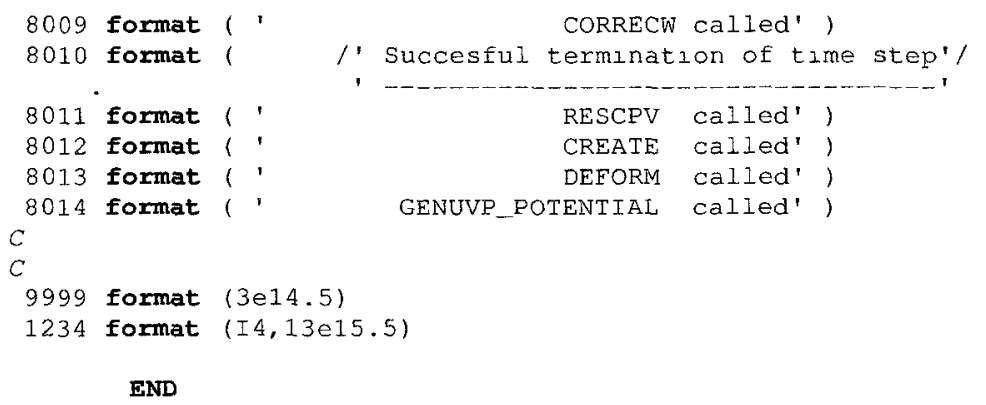

END

\section{B.3 blade_deform.f}

\section{B.3.1 Subroutine BLADE_DEFORM}

This subroutine was changed to call TWIST123 to allow for full articulated displacement of the aerodynamic grid nodes.

C PART 2/4: BLADE ELASTIC DEFORMATION

$C \longrightarrow \rightarrow$ APPLIES STRUCTURAL FEEDBACK TO DEFORM AERODYNAMTC BODIES

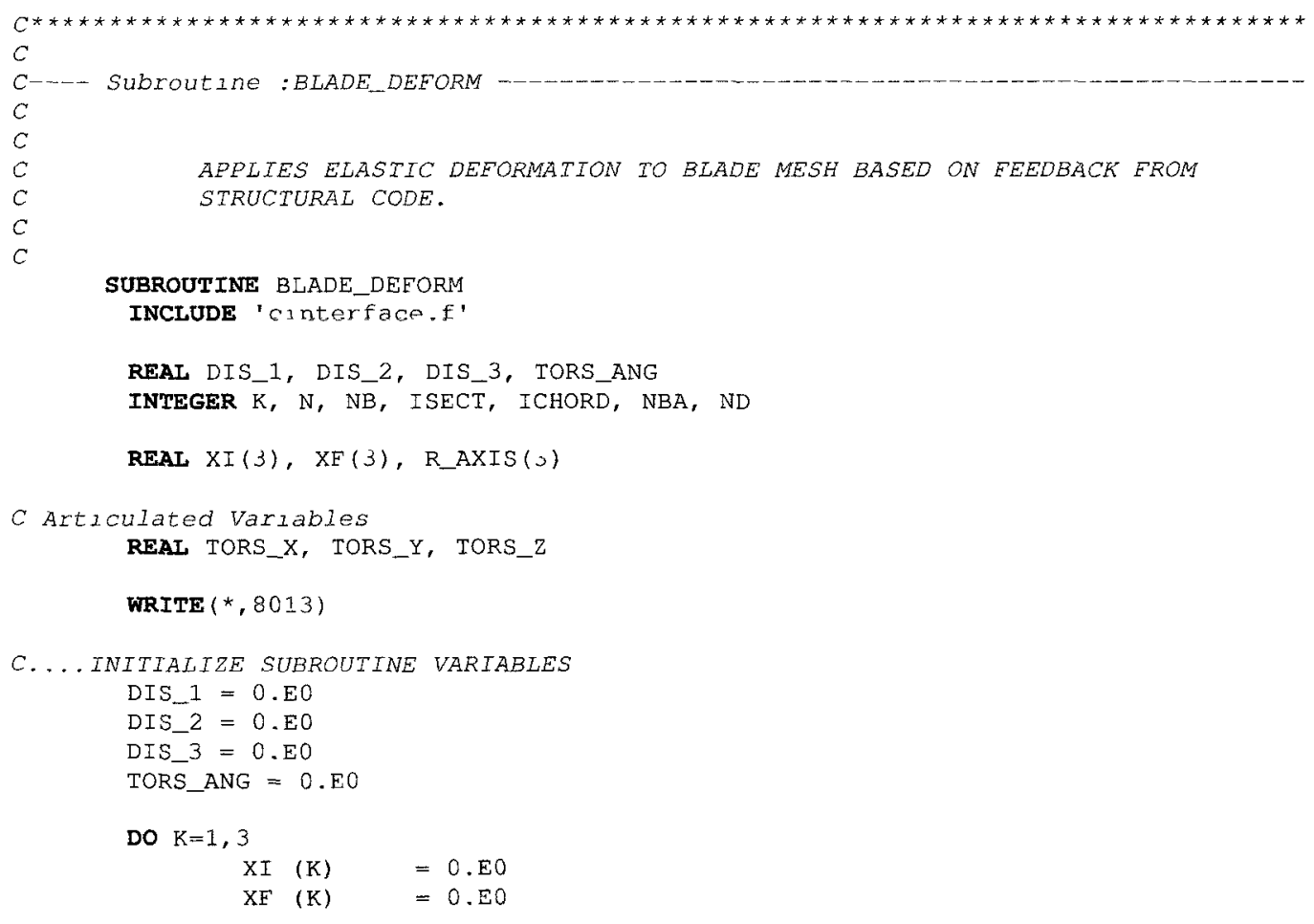


Appendix B Amended Source Code

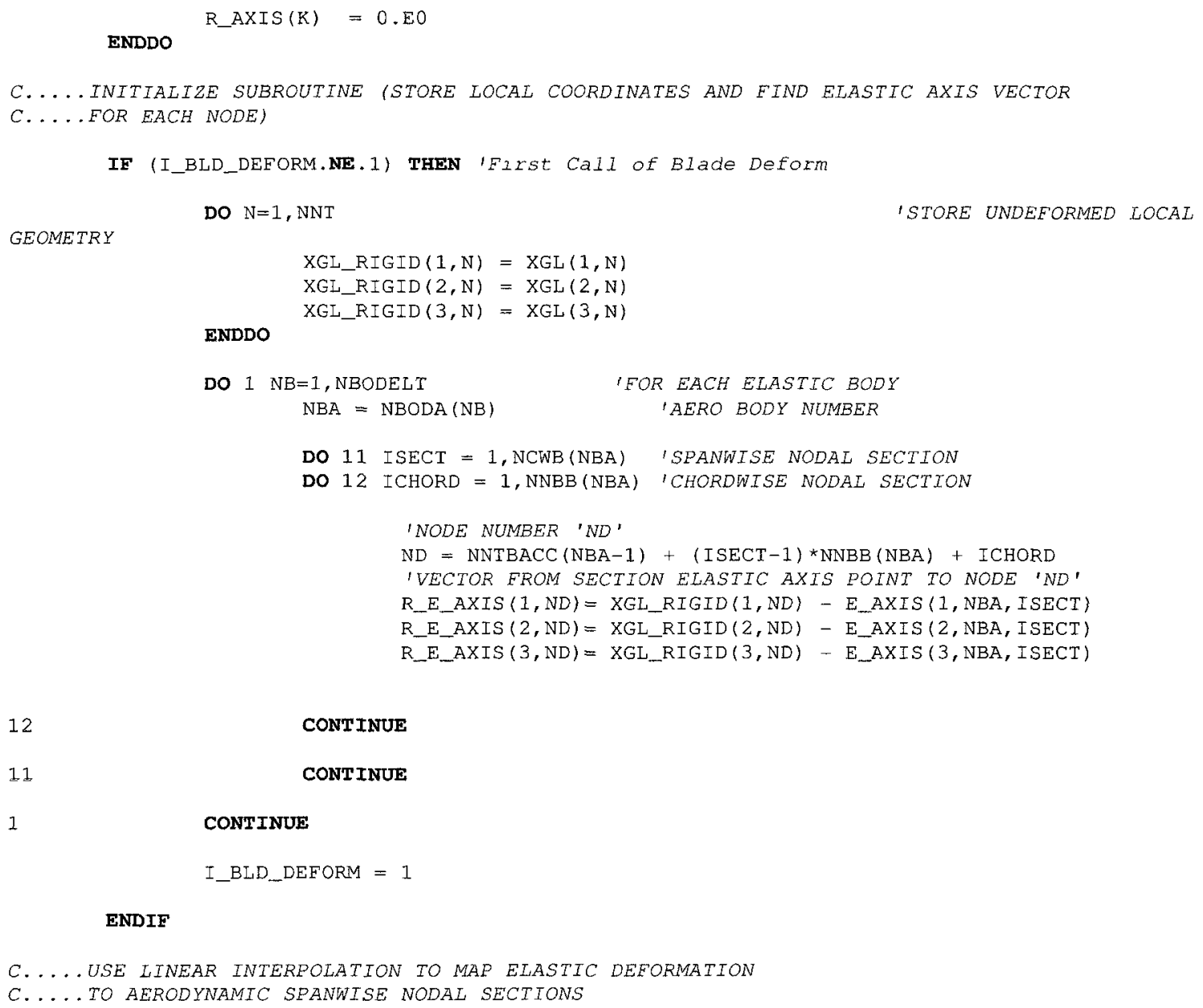

CALL MAP_DEFORM

C. . . APPLY ELASTIC DEFORMATION TO EACH ELASTIC BODY

DO $2 \mathrm{NB}=1$, NBODELT $\mathrm{NBA}=\mathrm{NBODA}(\mathrm{NB})$

'LOOP FOR EACH ELASTIC BODY IAERO BODY NUMBER

DO 21 ISECT $=1$, NCWB (NBA) ILOOP FOR EACH SPANWISE NODAL SECTION DO 22 ICHORD $=1$, NNBB(NBA) 'CHORDWISE NODAL SECTION

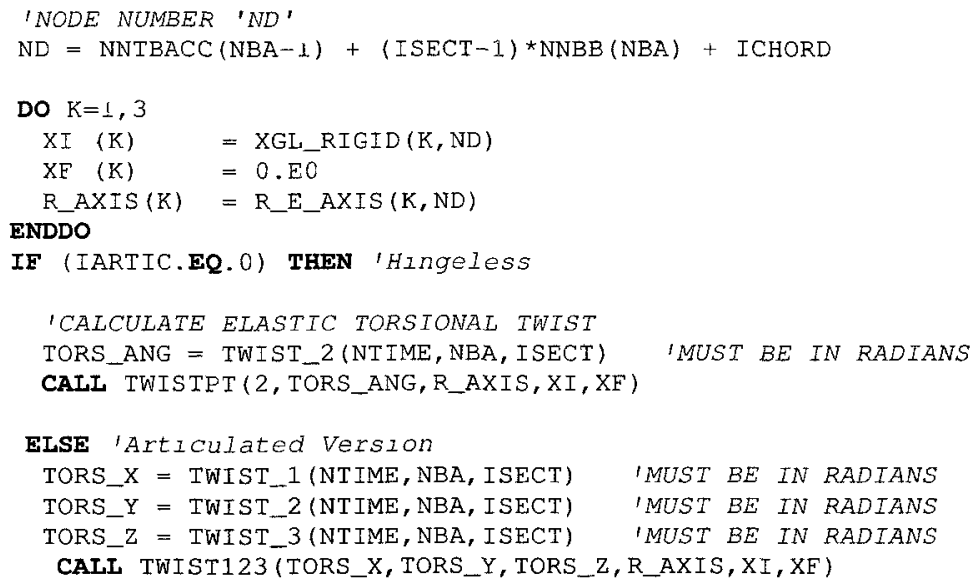




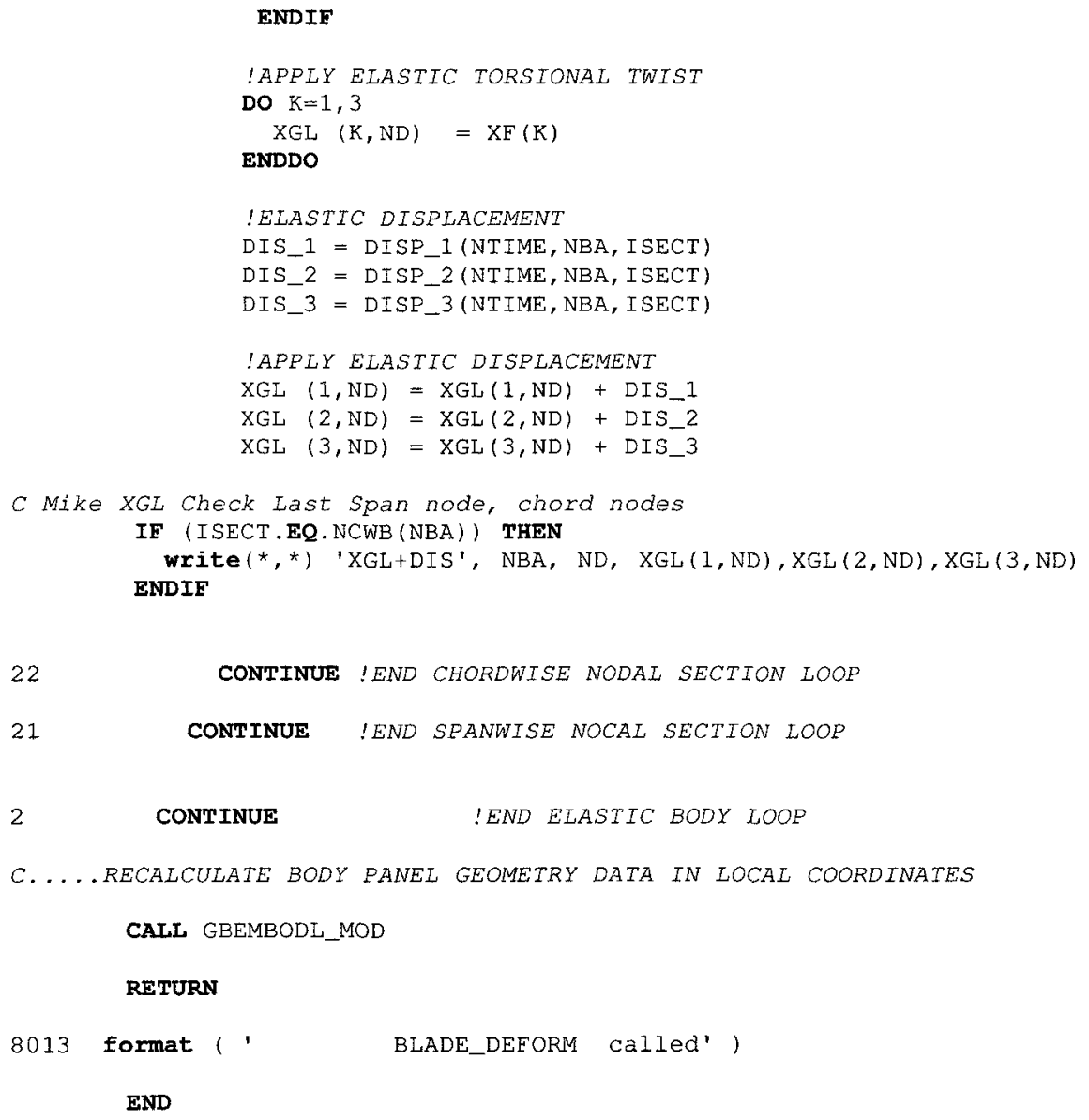

\section{B.3.2 Subroutine TWISTPT}

This is the unchanged subroutine that rotates the aerodynamic chordwise nodes only pitchwise in the hingeless mode.

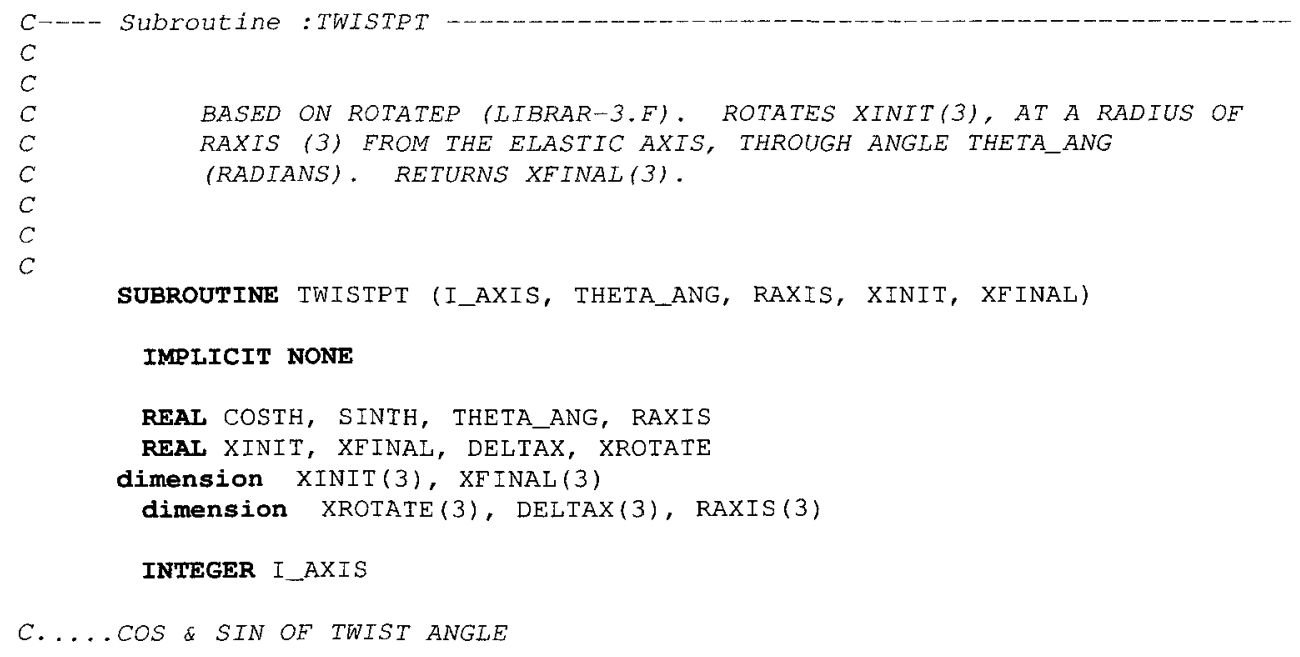




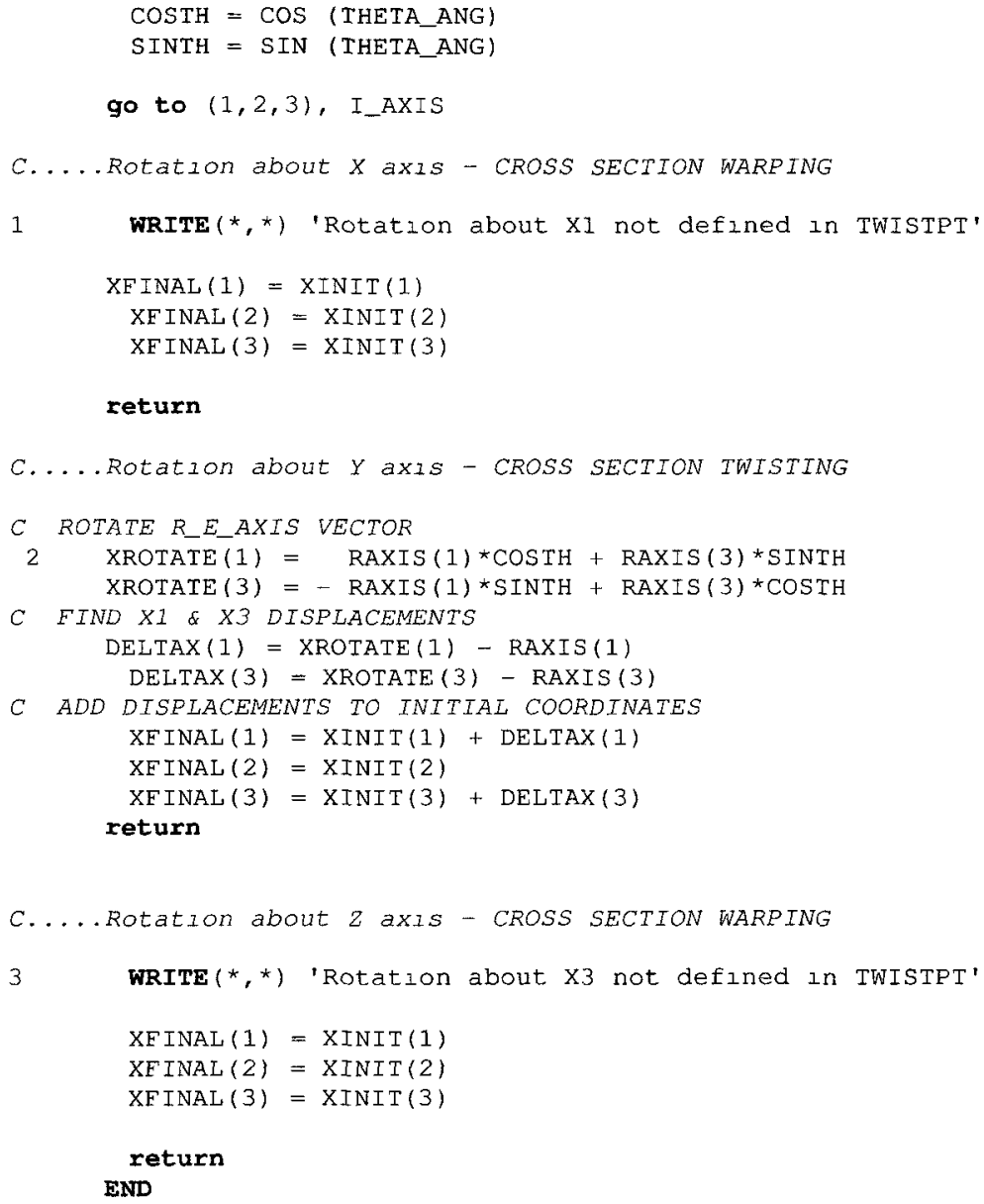

\section{B.3.3 Subroutine TWIST123}

This is the subroutine, based from TWISTPT that rotates and displaces the aerodynamic chordwise nodes from the hinge, in the articulation mode.

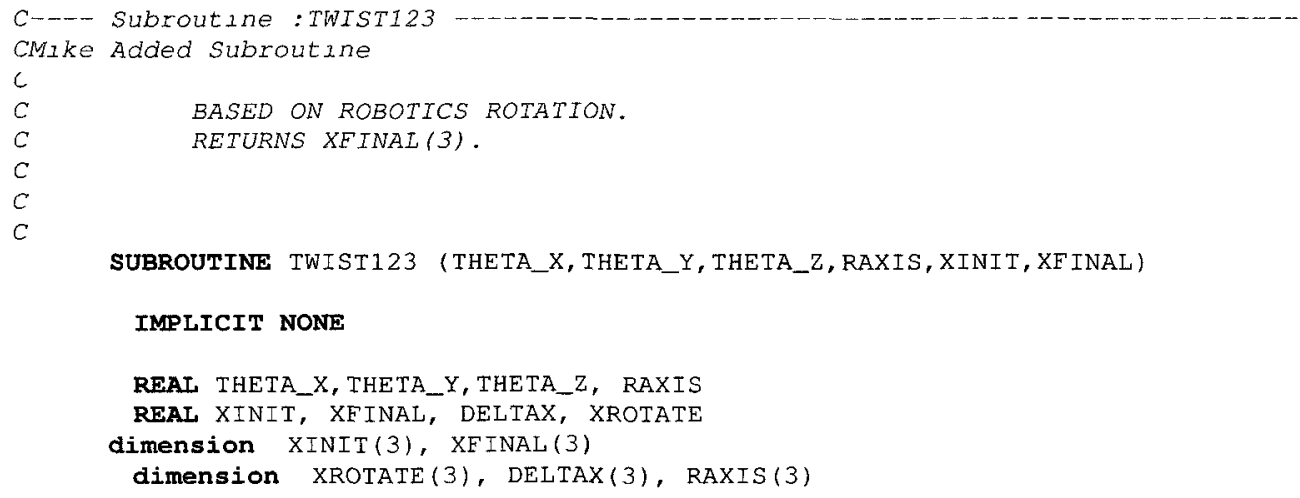


C ROTATE REEAXIS VECTOR

XROTATE $(1)=\operatorname{COS}(T H E T A \quad Y) * \operatorname{COS}(T H E T A Z Z) * \operatorname{RAXIS}(1)-$

$>\operatorname{COS}($ THETA_Y $) * \operatorname{SIN}\left(T H E T A \_Z\right) \star \operatorname{RAXIS}(2)+$

$>\quad$ SIN (THETA_Y) $*$ RAXIS (3)

XROTATE $(2)=\left(\operatorname{SIN}\left(T H E T A \_X\right) * \operatorname{SIN}\left(T H E T A \_Y\right) * \operatorname{COS}\left(T H E T A \_Z\right)+\right.$

$>$ COS (THETA_X $) * \operatorname{SIN}($ THETA_Z) $) * \operatorname{RAXIS}(1)+$

$>\left(-\operatorname{SIN}\left(T H E T A \_X\right) * \operatorname{SIN}\left(T H E T A \_Y\right) * \operatorname{SIN}\left(T H E T A \_Z\right)+\right.$

$\left.\operatorname{COS}\left(T H E T A \_X\right) * \operatorname{COS}\left(T H E T A \_Z\right)\right) * \operatorname{RAXIS}(2)$

$>\operatorname{SIN}($ THETA_X $) * \operatorname{COS}($ THETA_Y $) *$ RAXIS (3)

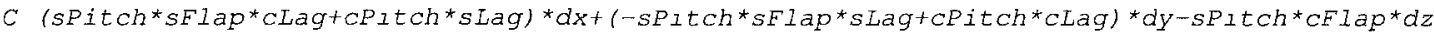

XROTATE $(3)=\left(-\operatorname{COS}(\right.$ THETA_X $) \star S I N\left(T H E T A \_Y\right) \star C O S\left(T H E T A \_Z\right)+$

$>\operatorname{SIN}($ THETA_X $) \star \operatorname{SIN}($ THETA_Z) $) \star \operatorname{RAXIS}(1)+$

$>\left(\right.$ COS $\left(T H E T A \_X\right) * \operatorname{SIN}\left(T H E T A \_Y\right) * S I N\left(T H E T A \_Z\right)+$

$>\operatorname{SIN}($ THETA_X $) * \operatorname{COS}($ THETA_Z) $) * \operatorname{RAXIS}(2)+$

$>\operatorname{COS}($ THETA_X $) * \operatorname{COS}($ THETA_Y $) *$ RAXIS $(3)$

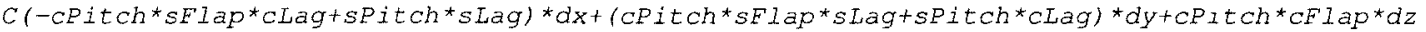

C FIND $X 1$ \& $X 3$ DISPLACEMENTS

$\operatorname{DELTAX}(1)=\operatorname{XROTATE}(1)-\operatorname{RAXIS}(1)$

$\operatorname{DELTAX}(2)=$ XROTATE $(2)-\operatorname{RAXIS}(2)$

DELTAX (3) = XROTATE (3) - RAXIS(3)

C ADD DISPLACEMENTS TO INITIAL COORDINATES

$\mathrm{XFINAL}(1)=\mathrm{XINIT}(1)+\operatorname{DELTAX}(1)$

$X F I N A L(2)=X I N I T(2)+\operatorname{DELTAX}(2)$

$\mathrm{XFINAL}(3)=\mathrm{XINIT}(3)+\operatorname{DELTAX}(3)$

return

END

\section{B.3.4 Subroutine MAP_DEFORM}

This subroutine was modified to allow the aerodynamic nodes to be extrapolated and interpolated to their new positions in the articulate mode.

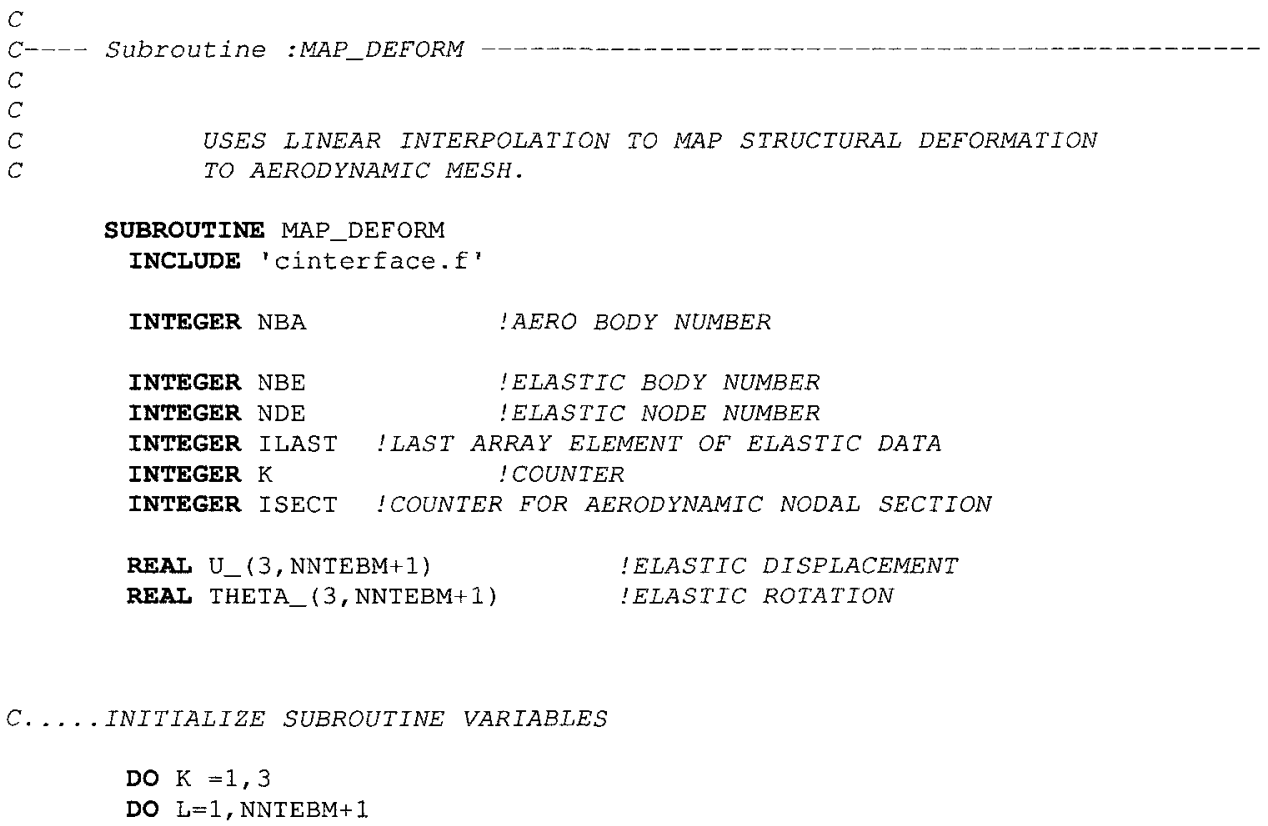




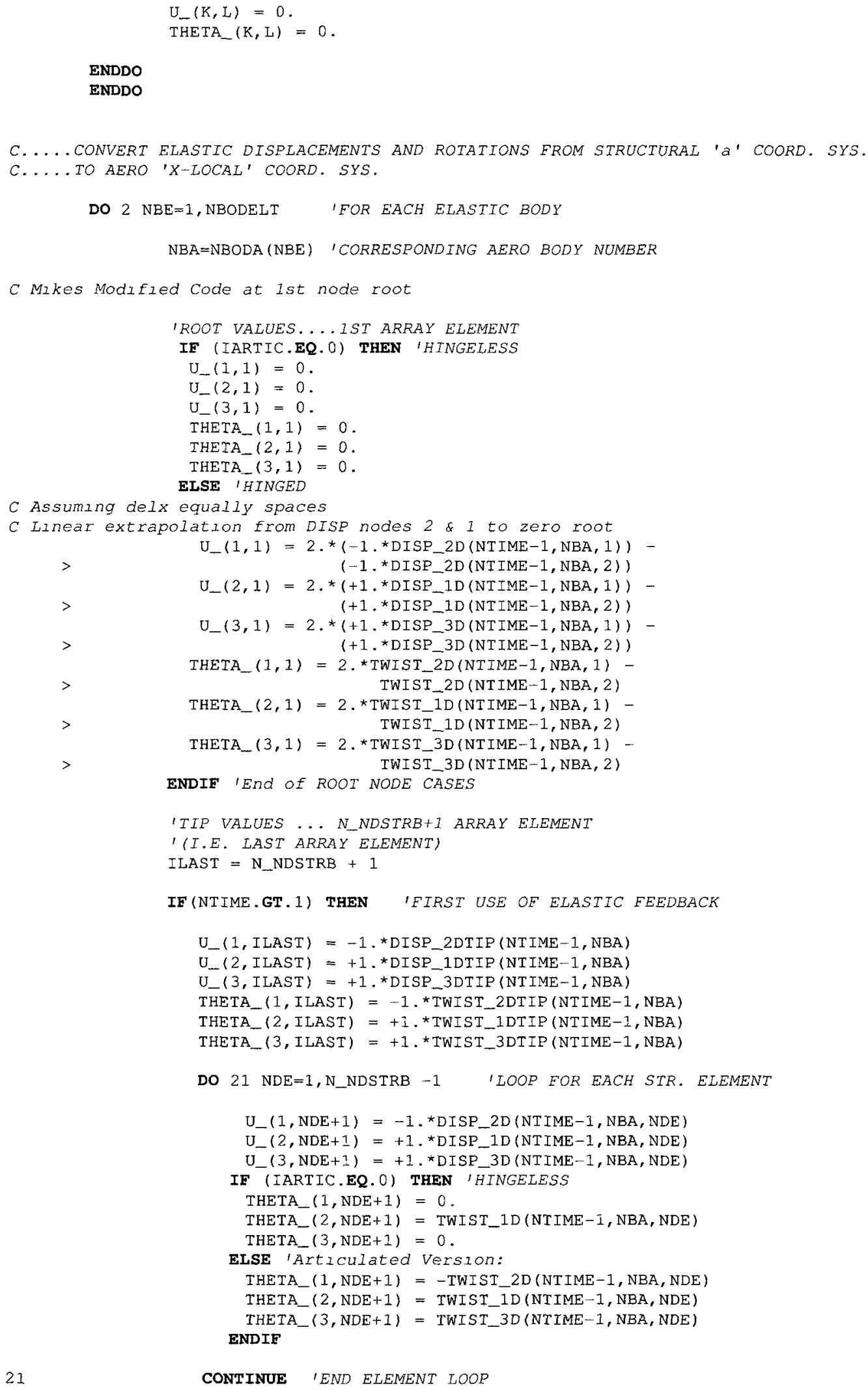




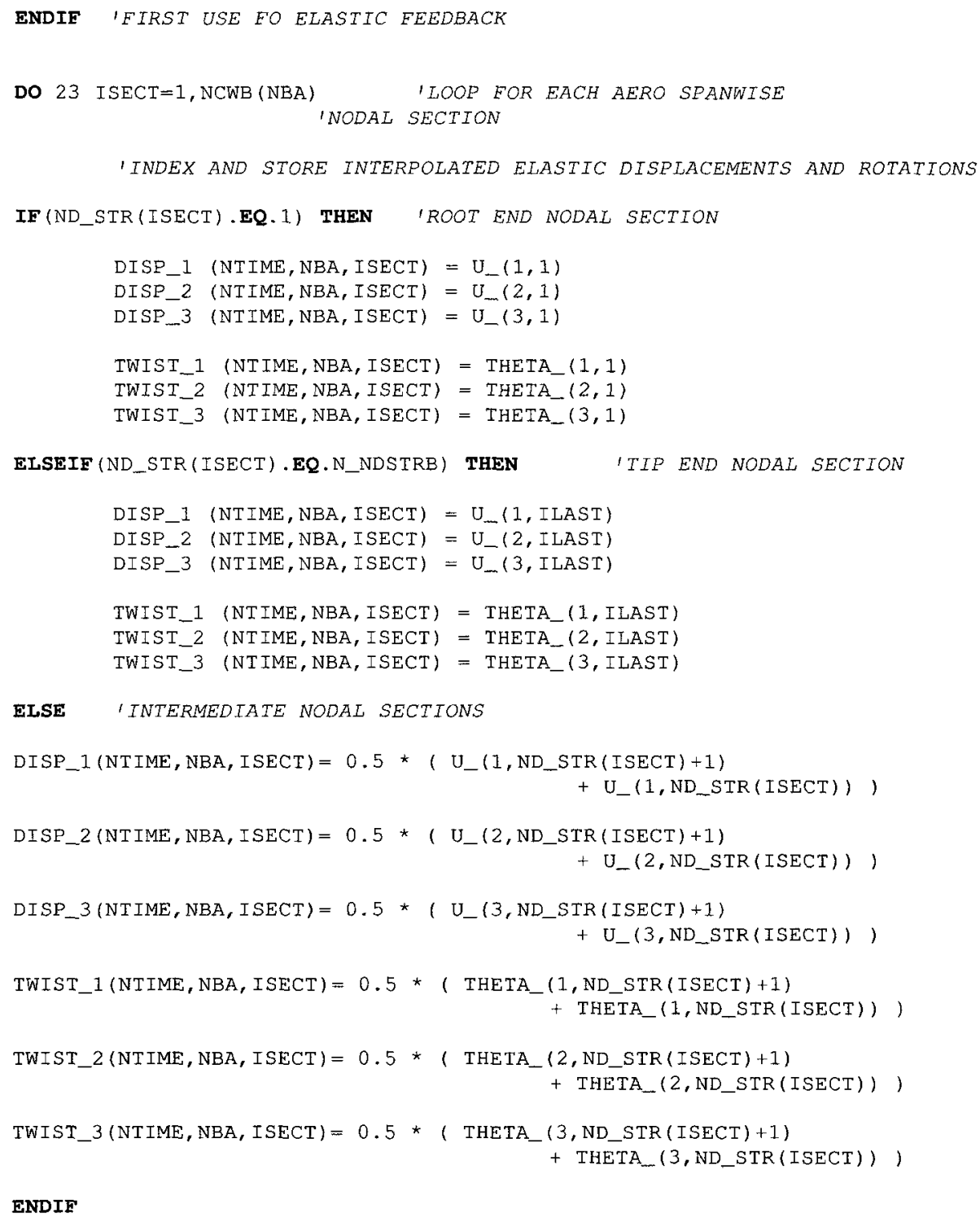

\section{B.4 bladeartic.f}

\section{B.4.1 Subroutine BLADEARTICULATE}

This subroutine is the structural model for the rigid model. 
SUBROUTINE BLADEARTICULATE (IASTEP, N _BLADE)

INCLUDE ' $C A T R C . f$ '

INCLUDE 'chinge. $f$ '

DOUBLE PRECISION YBLADESPAN, MASSMOMSUM, LIFTSUM, DRAGSUM

DOUBLE PRECISION GRAVITYACL

DOUBLE PRECISION G_FORCE lVariable Force Parameter

INTEGER IASTEP, I, J, N_BLADE

C Ordinary Differential Equation subroutine variables

EXTERNAL FEX

INTEGER IOPT, ISTATE, ITASK, ITOL, IWORK(20), LIW, LRW, $\mathrm{MF}$, NEQ

DOUBLE PRECISION ATOL (4), RTOL, RWORK(84), TIN, TOUT, Y(4)

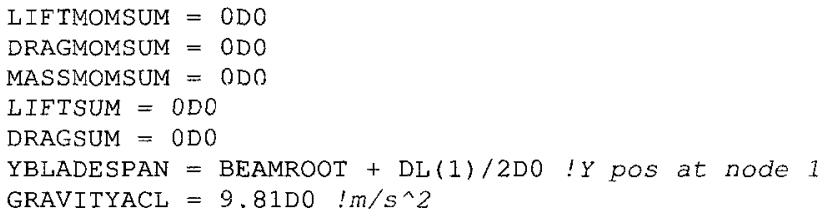




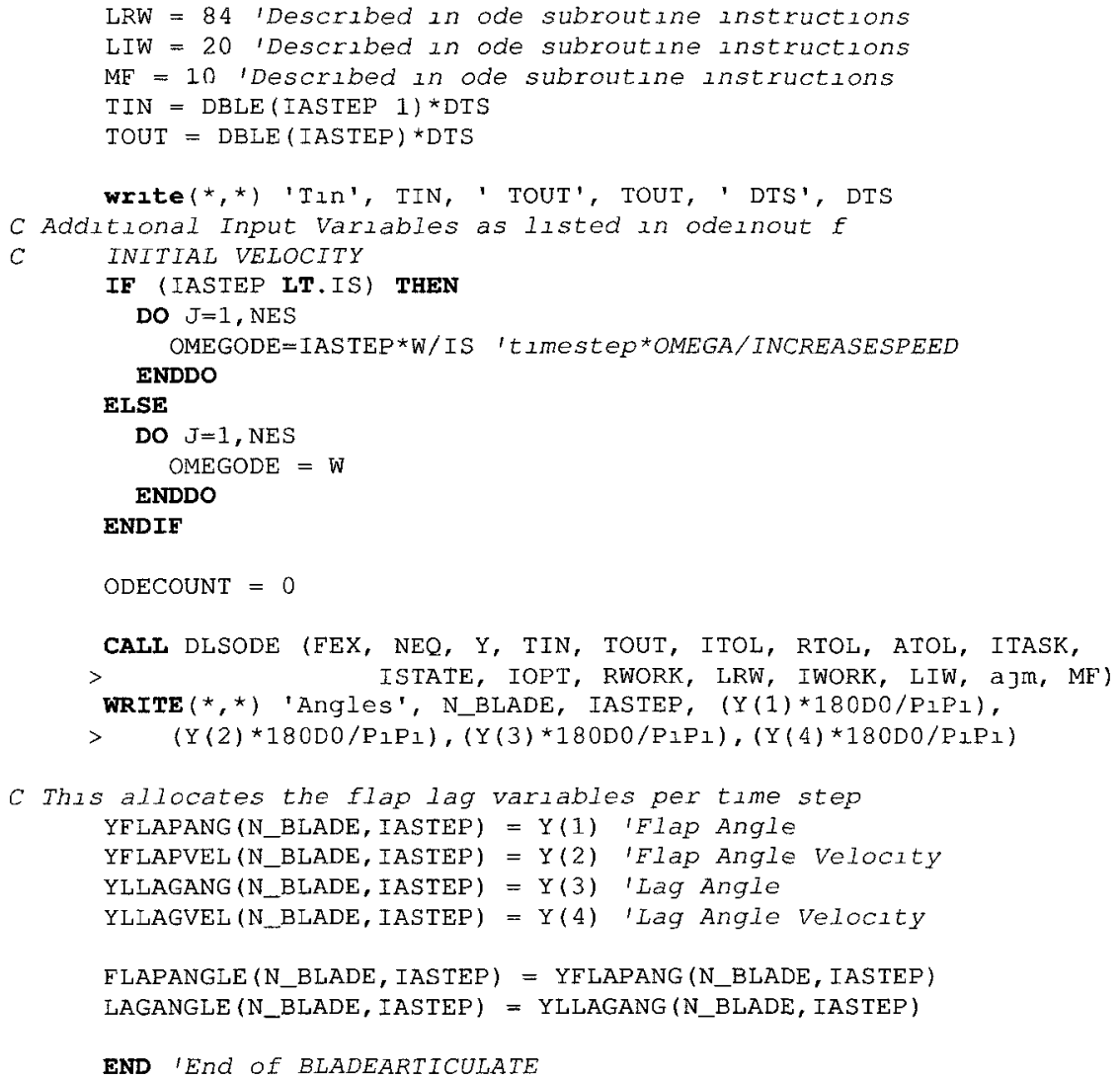

\section{B.5 odeblade.f}

\section{B.5.1 Subroutine FEX}

This subroutine contains the Leishman equations of motions that are solved using the ordinary differential equation solver ODEPACK.

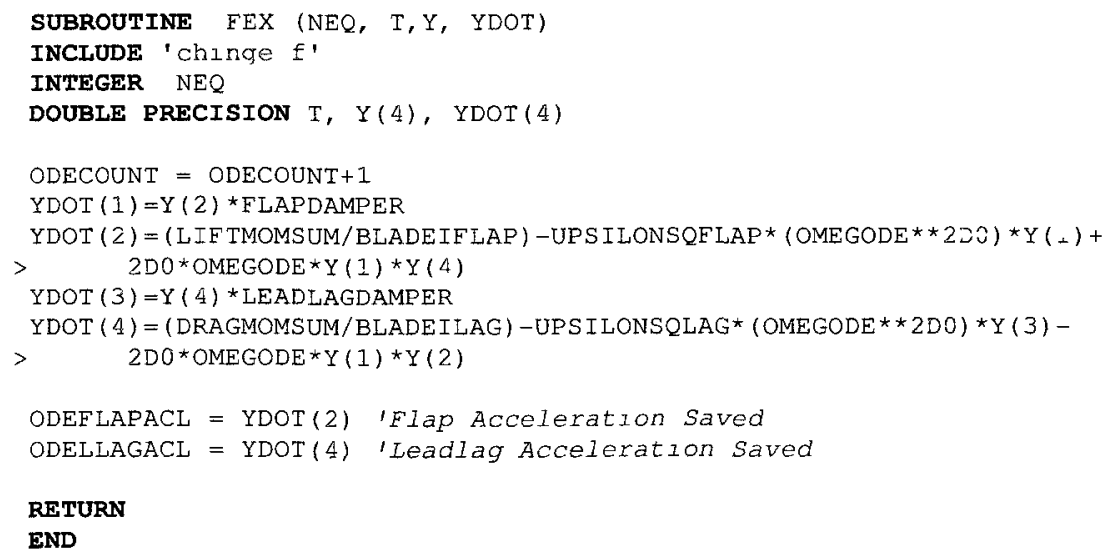


Subroutines DLSODE, DLSODES, DLSODA, DLSODAR, DLSODPK, DLSODKR, DLSODI, DLSOIBT, DLSODIS omitted for clarity, but located in odeblade.f.

Other ODEPAK Subroutines located in files odepack_sub1.f and odepack_sub2.f

Refer to: Alan Hindmarsh, ODEPACK, a Systematized Collection of ODE Solvers, in Scientific Computing, Elsevier, 1983.

Located at Website: http://people.sc.fsu.edu/ jburkardt/f77_src/odepack/odepack.html

\section{B.6 couple.f}

\section{B.6.1 Subroutine TRAN}

This subroutine contains prepares the displacements and orientations of the structural nodes that were solved in the STRUCTURAL_COMPONENT subroutine. This information is sent to subroutine BLADE_DEFORM, in source code file blade_deform.f, as listed in Appendix B.3.

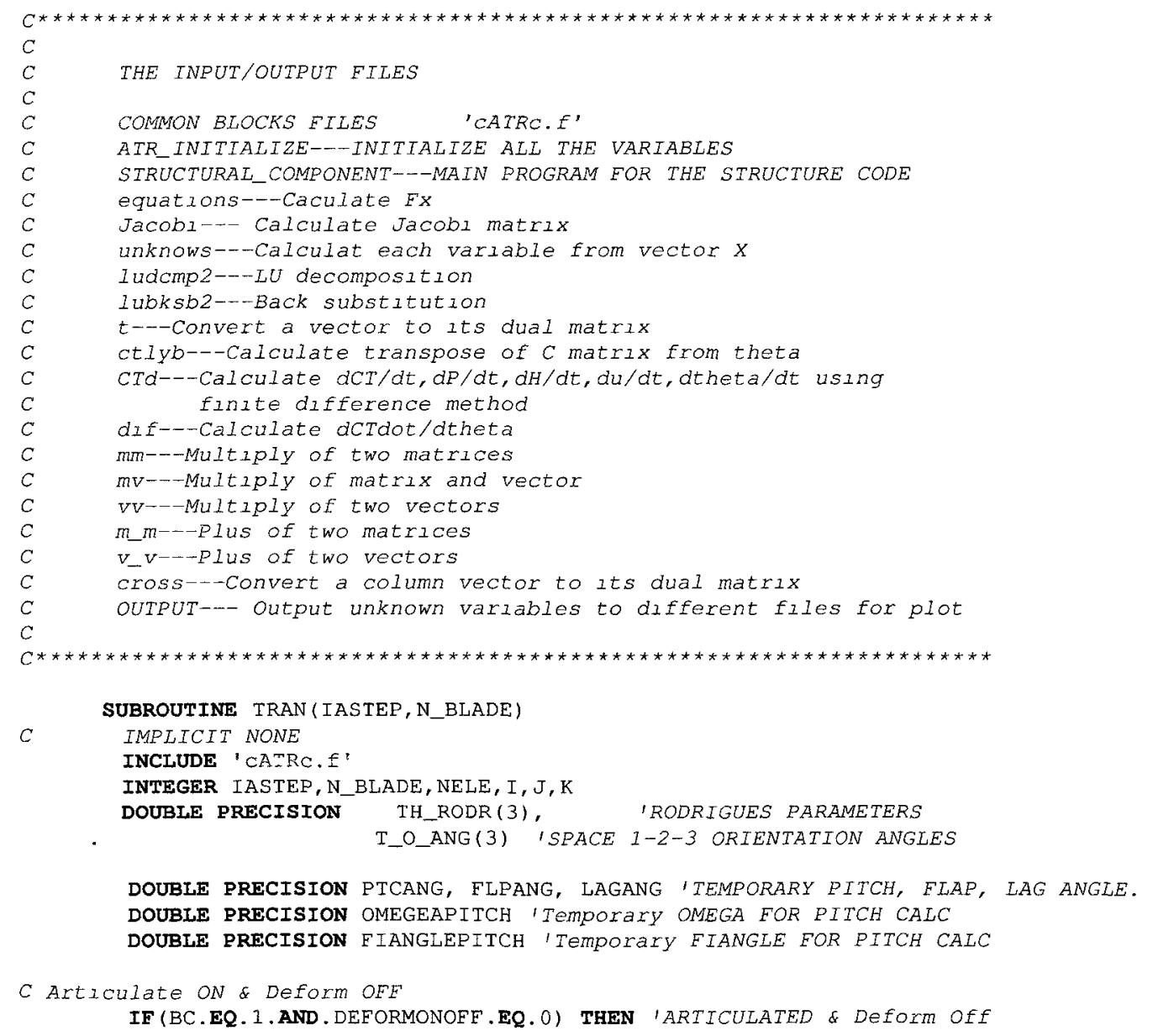




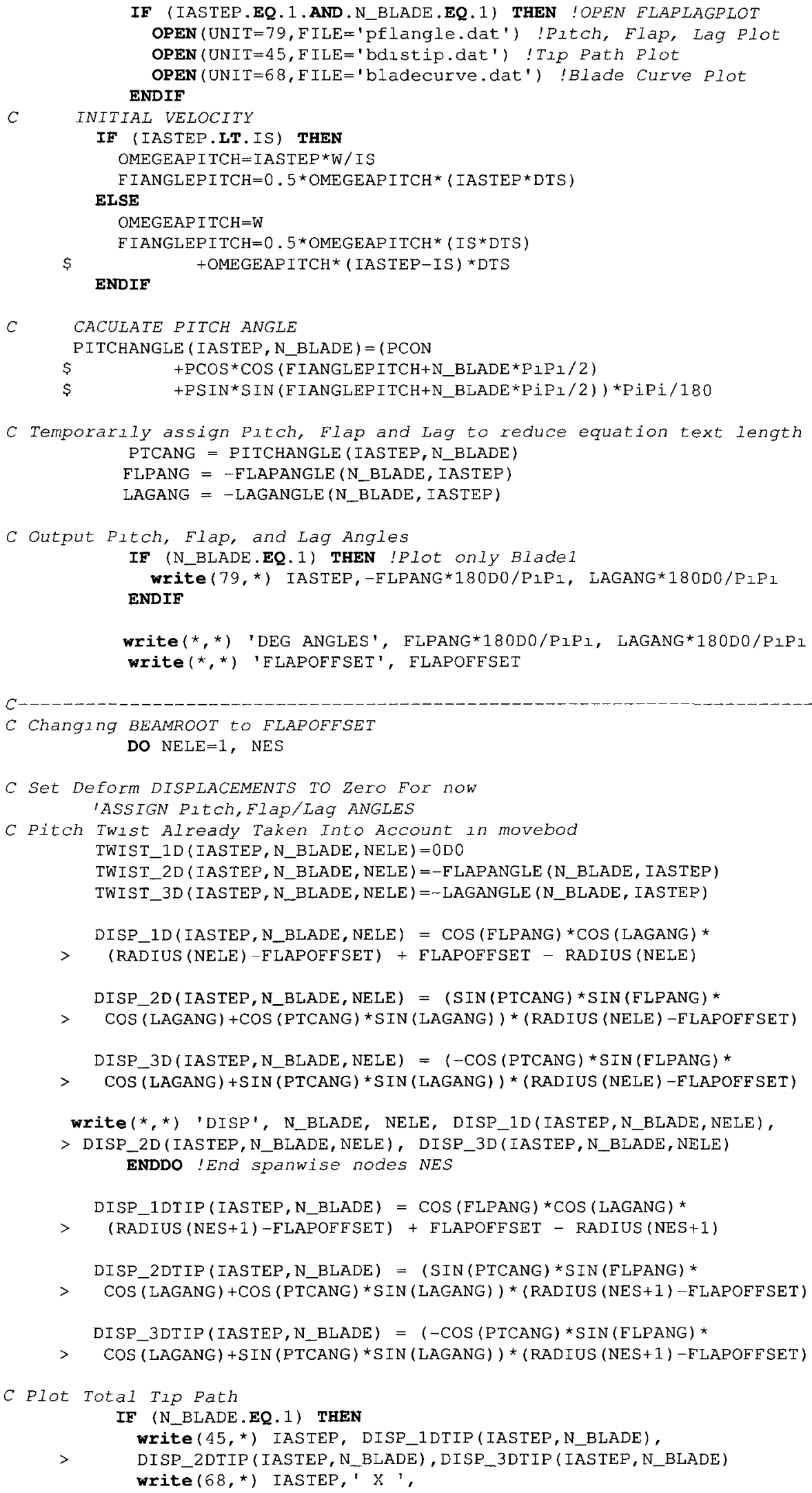




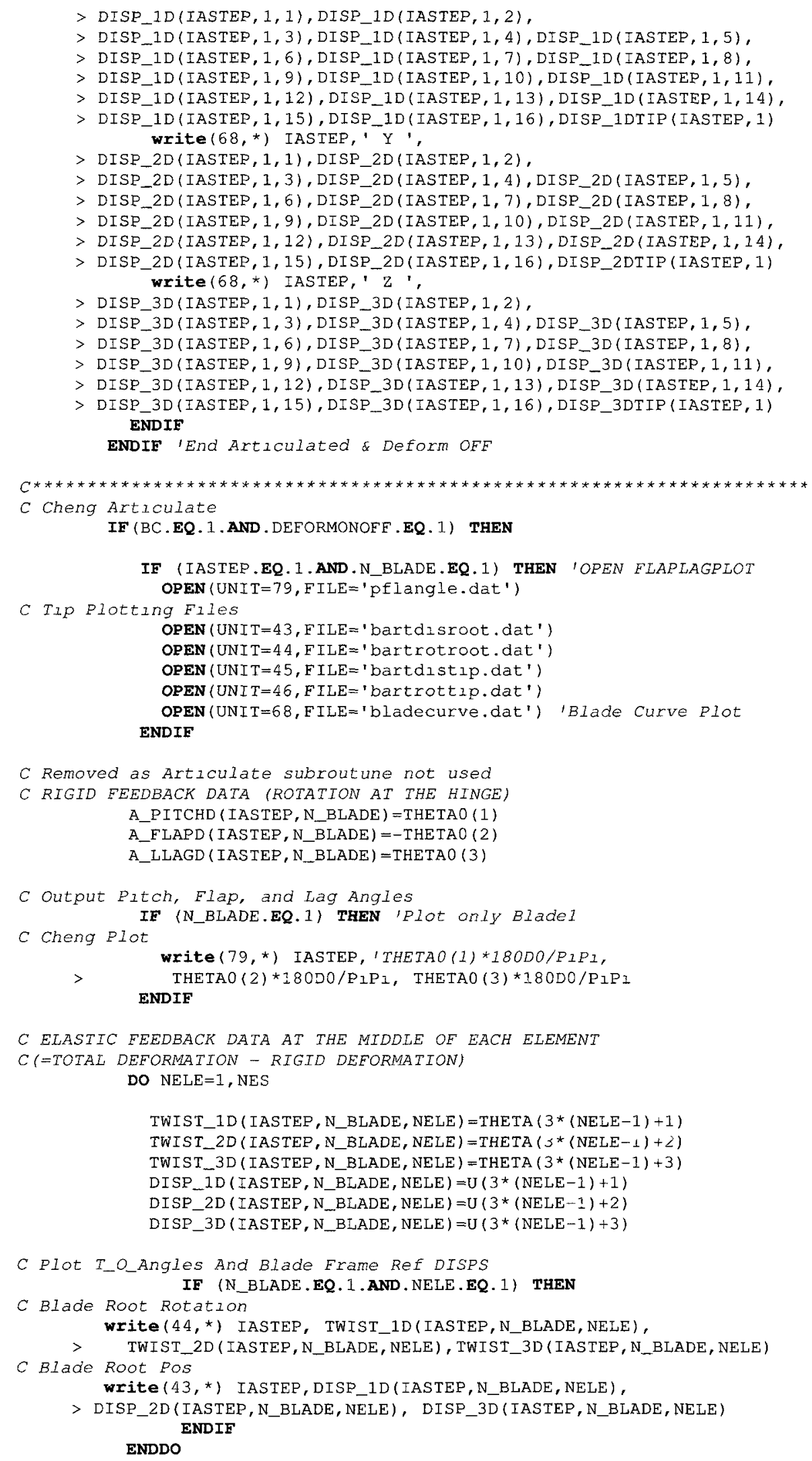


C DEFORMATION AT THE BLADE TIP POINT

$C$ Remove Cheng Twist and DISP equation as no longer using Articulate.f

C TWIST_IDTIP (IASTEP, N_BLADE) =THETANI (1) -THETAO (I)

C TWIST_2DTIP (IASTEP, N_BLADE) =THETAN1 (2) -THETAO(2)

C TWIST $3 D T I P$ (IASTEP, N_BLADE) =THETANI (3)-THETAO (3)

C DISP_IDTIP (IASTEP, N_BLADE) $=U N 1$ (I) -

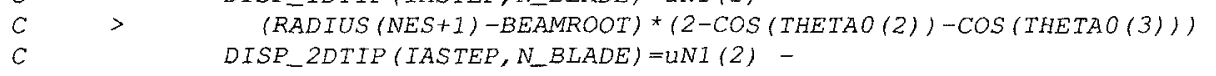

C > (RADIUS (NES+1)-BEAMROOT)*SIN (THETAO (3))

C DISP_3DTIP (IASTEP, N_BLADE) =UN1 (3) -

$C>\quad(R A D I U S(N E S+1)-B E A M R O O T){ }^{*} S I N(T H E T A O(2))$

TWISI_1DTIP (IASTEP, N_BLADE) =THETAN1 (1)

TWIST_2DTIP (IASTEP, N_BLADE) $=$ THETAN1 (2)

TWIST_3DTIP (IASTEP, N_BLADE) =THETAN1 (3)

DISP_IDTIP ( IASTEP, N_BLADE) $=$ UN 1 (1)

DISP_2DTIP (IASTEP, N_BLADE) $=\mathrm{UN1}(2)$

DISP_3DTIP (IASTEP, N_BLADE) $=$ UN1 (3)

IF (N_BLADE.EQ.1) THEN

C Blade Tip Rotation

46, *) IASTEP, TWIST_1DTIP(IASTEP, N_BLADE),

$\begin{aligned} C \text { Blade TIp POS } & \text { wrıte }(45, *) \text { IASTEP,DISP_1DTIP(IASTEP, N_BLADE) }\end{aligned}$

$>$ DISP_2DTIP(IASTEP, N_BLADE), DISP_3DTIP (IASTEP, N_BLADE)

$C$ plot $z$ Blade Curve

write $(68, *)$ IASTEP, ' $\mathrm{x}$ ',

$>$ DISP_ID(IASTEP, 1, 1),DISP_1D(IASTEP, 1, 2),

$>$ DISP_ID(IASTEP, 1, 3),DISP_1D(IASTEP, 1, 4), DISP_1D(IASTEP, 1, 5),

$>$ DISP_ID(IASTEP, 1, 6), DISP_ID(IASTEP, 1, 7), DISP_ID(IASTEP, 1, 8),

$>$ DISP_ID(IASTEP, 1, 9), DISP_1D(IASTEP, 1, 10), DISP_1D(IASTEP, 1, 11),

$>$ DISP_1D(IASTEP, 1, 12),DISP_1D(IASTEP, 1, 13), DISP_1D(IASTEP, 1, 14),

$>$ DISP_1D(IASTEP, 1, 15), DISP_1D(IASTEP, 1, 16), DISP_1DTIP (IASTEP, 1)

write $\left(68,{ }^{*}\right)$ IASTEP, ' Y ',

$>$ DISP_2D(IASTEP, 1, 1),DISP_2D(IASTEP, 1,2),

$>$ DISP_2D(IASTEP, 1, 3), DISP_2D(IASTEP, 1, 4), DISP_2D(IASTEP, 1, 5),

$>$ DISP_2D (IASTEP, 1, 6), DISP_2D(IASTEP, 1, 7), DISP_2D(IASTEP, 1, 8),

$>$ DISP_2D(IASTEP, 1, 9), DISP_2D(IASTEP, 1, 10), DISP_2D(IASTEP, 1, 11),

$>$ DISP_2D (IASTEP, 1, 12),DISP_2D(IASTEP, 1, 13),DISP_2D(IASTEP, 1, 14),

$>$ DISP_2D(IASTEP, 1, 15), DISP_2D(IASTEP, 1, 16),DISP_2DTIP(IASTEP, 1)

write $(68, *)$ IASTEP,' $Z$ ',

$>$ DISP_3D (IASTEP, 1, 1),DISP_3D(IASTEP, 1, 2),

$>$ DISP_3D(IASTEP, 1, 3),DISP_3D(IASTEP, 1, 4), DISP_3D(IASTEP, 1, 5),

$>$ DISP_3D(IASTEP, 1,6), DISP_3D(IASTEP, 1, 7), DISP_3D(IASTEP, 1, 8),

$>$ DISP_3D(IASTEP, 1,9), DISP_3D(IASTEP, 1, 10), DISP_3D(IASTEP, 1, 11),

$>$ DISP_3D(IASTEP, 1, 12), DISP_3D(IASTEP, 1, 13), DISP_3D(IASTEP, 1, 14),

$>$ DISP_3D(IASTEP, 1, 15), DISP_3D(IASTEP, 1, 16), DISP_3DTIP (IASTEP, 1)

ENDIF

ENDIF 'End Cheng Version

$C * * * \star * H I N G E L E S S$ CASE

IF (BC.EQ.0) THEN 'HINGELESS

IE (IASTEP.EQ.1.AND.N_BLADE.EQ.1) THEN 'OPEN FLAPLAGPLOT

C Tip and Root plotting Files

OPEN (UNIT=43, FILE= ' bartdisroot . dat')

OPEN (UNIT $=44$, FILE= ' bartrotroot . dat')

OPEN (UNIT $=45$, EILE $={ }^{\prime}$ bartdıstıp. dat' $)$

OPEN (UNIT $=46$, FILE= ' bart cott 1 p. dat')

OPEN (UNIT=68, FILE='bzcurve.dat') 'Blade Curve Plot

ENDIF

'RIGID FEEDBACK DATA

A_PITCHD (IASTEP, N_BLADE) $=$ PITCHANGLE (IASTEP, N_BLADE) 


\section{Appendix B Amended Source Code}

'ELASTIC FEEDBACK DATA

DO $\mathrm{NEIE}=1, \mathrm{NES}$

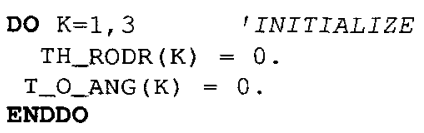

'ASSIGN ORIENTATION ANGLES AS ELASTIC ROTATION TWIST_1D (IASTEP, N_BLADE, NELE) =T_O_ANG (1) TWIST_2D (IASTEP, N_BLADE, NELE) $=$ T_O_ANG (2) TWIST_3D (IASTEP, N_BLADE, NELE) $=$ T_O_ANG (3)

IASSIGN ELASTIC DISPIACEMENT

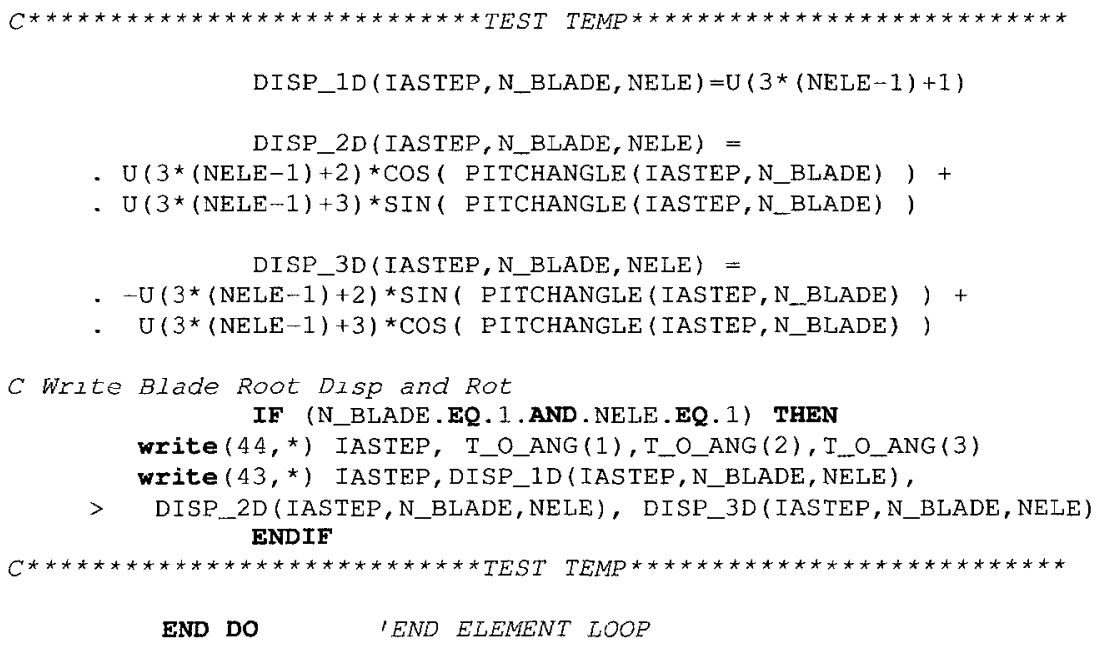




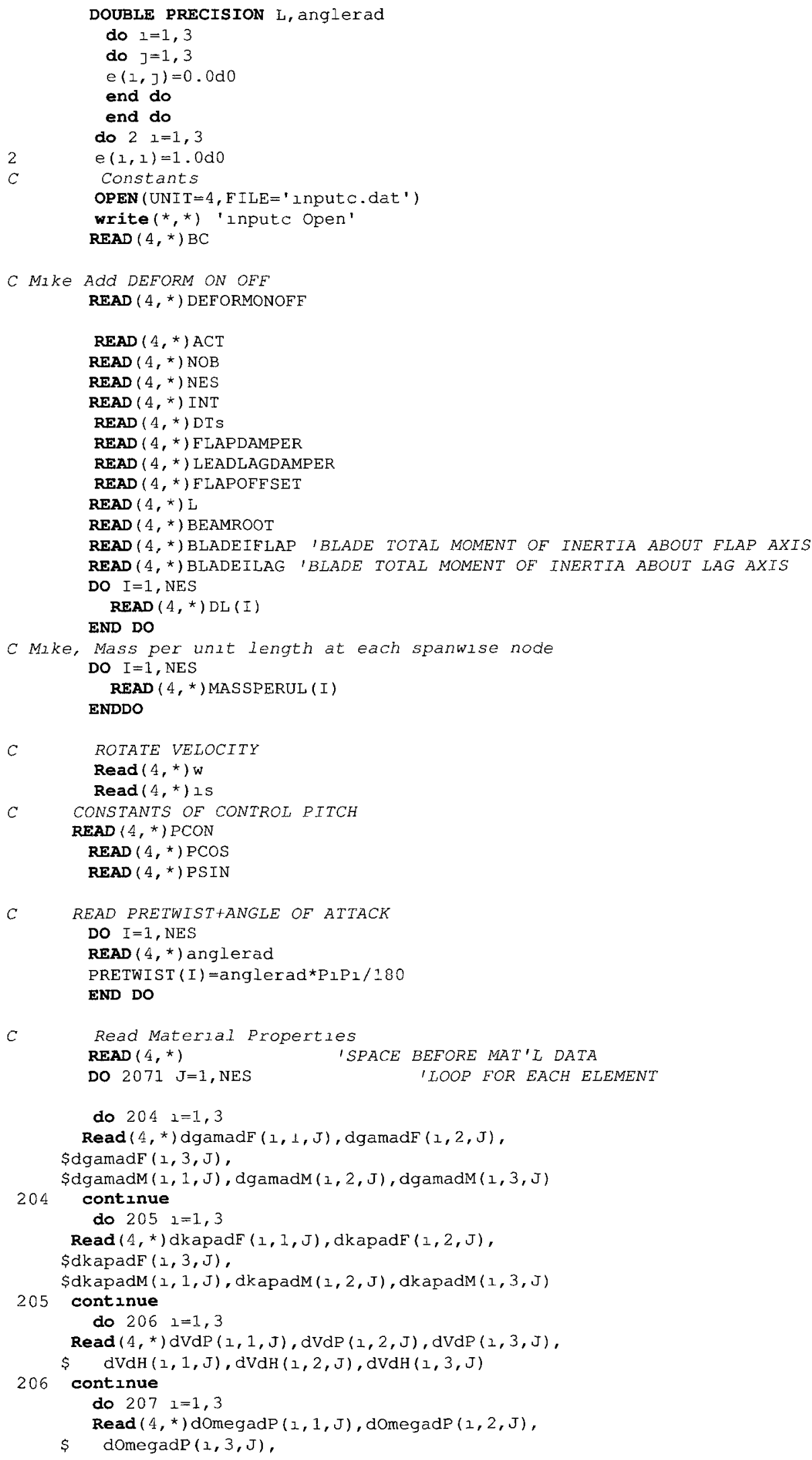




\section{Appendix B Amended Source Code}

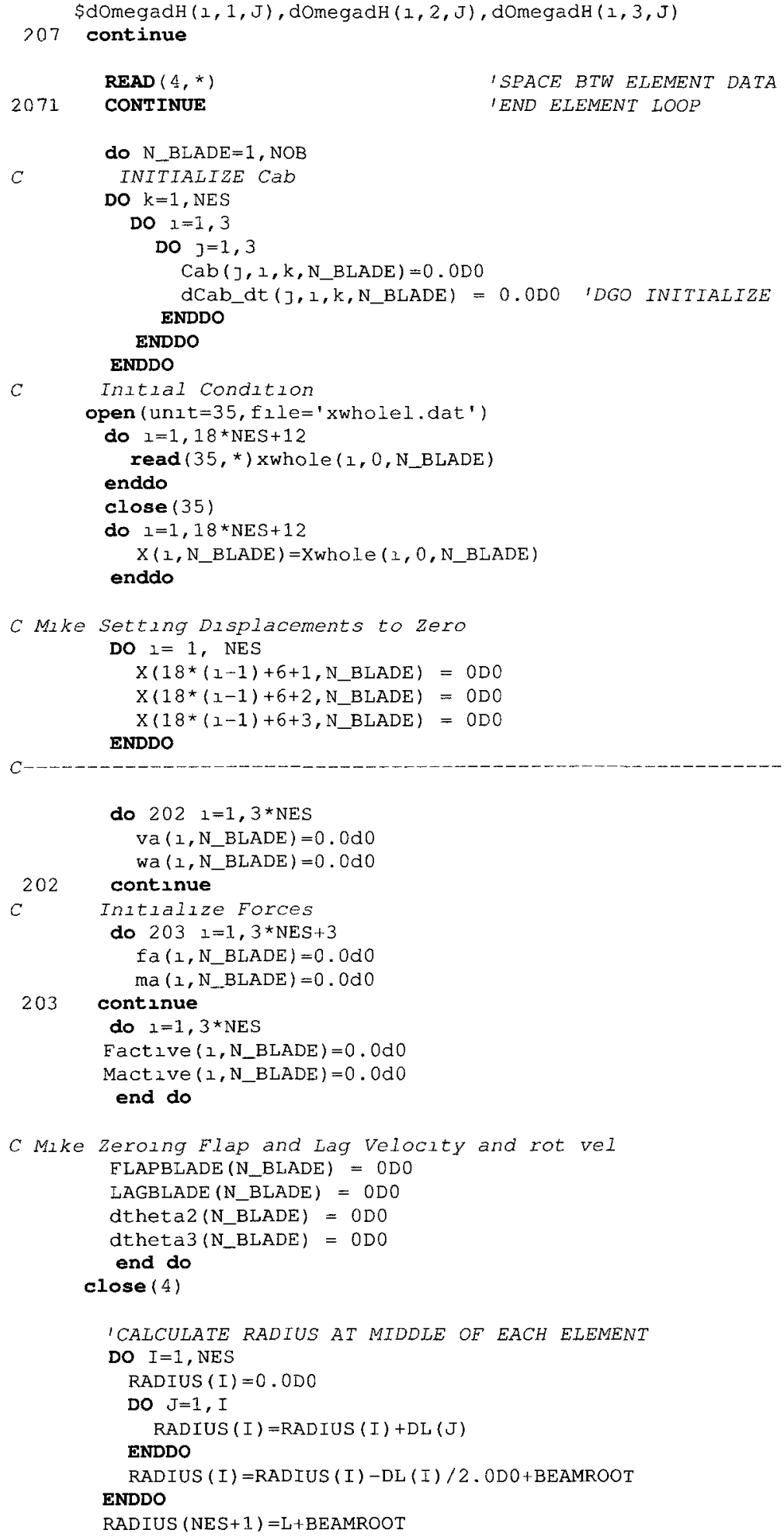


end

\section{B.7 chinge.f}

This file lists some of the added variables used to for the additional subroutines.

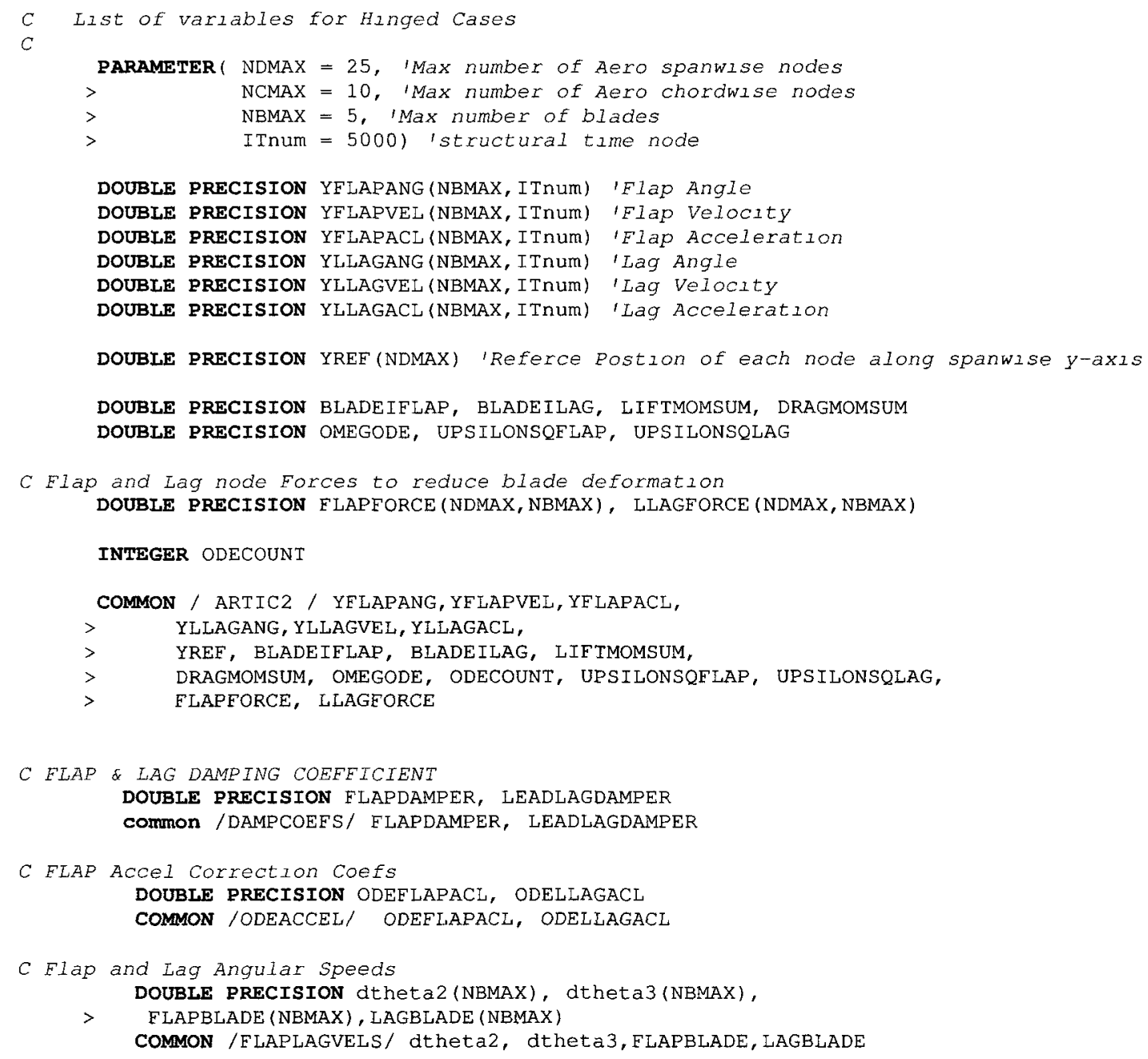

